UNIVERSIDAD NACIONAL DE LA PLATA

FACULTAD DE HUMANIDADES Y CIENCIAS DE LA EDUCACIÓN

SECRETARÍA DE POSGRADO

\title{
DE LA TRAGEDIA DE SÉNECA A LA ÉPICA DE LUCANO: ESTRATEGIAS DE REPRESENTACIÓN DE LOS PARADIGMAS FILOSÓFICOS Y LITERARIOS
}

Martín Miguel Vizzotti

Tesis para optar por el grado de Doctor en Letras

Dire ctor Dr. Pablo Martínez Astorino, UNLP

Codirector Dra. María Luisa la Fico Guzzo, UNS

La Plata, 22 de Octubre 2013 


\section{INTRODUCCIÓN: STATUS QUAESTIONIS, HIPÓTESIS Y \\ OBJETIVOS DEL TRABAJO.}

I. INTRODUCCIÓN 9

a) RECEPCIÓN CRÍTICA DE LA OBRA DE SÉNECA Y LUCANO 11

b) LA POSTURA HEGEMÓNICA DECIMONÓNICA Y BLACK ATHENA
DE MARTIN BERNAL

c) BLACK ATHENA 17

d) LA TRAGEDIA Y LA ÉPICA EN ROMA 21

e) CRONOLOGÍA RELATIVA DE LAS TRAGEDIAS DE SÉNECA 27

f) LUCANO, EL ELOGIO A NERÓN Y LOS FINALES POSIBLES DE PHARSALIA 29

g) HIPÓTESIS Y OBJETIVOS DEL TRABAJO 41

II. ESTRATEGIAS DE REPRESENTACIÓN EXPRESIONISTAS Y BARROCAS.

a) EL BARROCO Y SUS ALCANCES COMO HERRAMIENTA HERMENÉUTICA DE INTERPRETACIÓN

b) EXPRESIONISMO Y BARROCO 48

c) LA CAÍDA DEL CIELO EN THYESTES $\quad 50$

d) EXPRESIONISMO Y GROTESCO 60

e) ERICHTO, EL ABYECTO Y LA REPRESENTACIÓN GROTESCA 61

f) ERICHTO Y EL PROCESO DE DISOLUCIÓN DE LOS LÍMITES ESCATOLÓGICOS 64

g) RECAPITULACIÓN Y CONCLUSIONES PARCIALES 68

\section{PRIMERA PARTE: REPRESENTACIÓN DE LOS PARADIGMAS FILOSÓFICOS.}

III. SUBVERSIÓN DE LAS ESTRATEGIAS DE CONSTRUCCIÓN DEL YO ESTOICO.

a) SÉNECA Y FOUCAULT $\quad 72$

b) LAS TÉCNICAS DE SÍ

c) MÉTODOS Y ESTRATEGIAS ESTOICAS PARA FINES ANTI ESTOICOS $\quad 77$

d) CLITEMNESTRA: REINA DE LAS PASIONES 78

e) ATREO Y MEDEA: DUEÑOS DE SUS PASIONES 84

f) RECAPITULACIÓN Y CONCLUSIONES PARCIALES 101 
IV. EL ESPECTÁCULO DEL HORROR COMO SUBVERSOR DE LOS MECANISMOS DE REPRESENTACIÓN.

a) CONFIGURACIÓN ESPECTACULAR DE LA FIGURA DEL HÉROE ESTOICO EN SÉNECA.

b) EL SUICIDIO DE CATÓN: DIU MEDITATUM OPUS 105

c) DE PROVIDENTIA: EL SUICIDIO COMO SPECTACULUM 108

d) SUICIDIO Y TEATRALIDAD: EL TEXTO-ESPECTACULAR 111

e) RECAPITULACIÓN Y CONCLUSIONES PARCIALES 115

f) ATREO: LA CONSTRUCCIÓN ESTÉTICA DEL CRIMEN Y LA SUBVERSIÓN DE LA FIGURA DEL HÉROE ESTOICO 117

g) ATREO: SAEVUM SCELUS IUVAT ORDINARE 118

h) RECAPITULACIÓN Y CONCLUSIONES PARCIALES 123

V. EL CRIMEN COMO ESPECTÁCULO Y EL EXPRESIONISMO DEL HORROR.

a) EL ESPECTÁCULO DEL HEROÍSMO ESTOICO Y SU SUBVERSIÓN POR LA POÉTICA DEL HORROR 124

b) VULTEYO, ESCEVA Y TROYANAS: EL TEATRO DEL HORROR 126

c) RECAPITULACIÓN Y CONCLUSIONES PARCIALES 137

VI. DISOLUCIÓN UNIVERSAL Y SYMPÁTHEIA TÔN HOLÔN: VIRTUS, PIETAS Y CORPUS.

a) PNEUMMA, TÓNOS Y SYMPÁTHEIA TÔN HOLÔN 140

b) LA DISOLUCIÓN DEL CUERPO SOCIAL E INDIVIDUAL 142

c) LA BATALLA NAVAL FRENTE A MARSELLA 143

d) VULTEYO Y SUS HOMBRES

e) ESCEVA 155

f) LAS SERPIENTES Y LOS CUERPOS 161

g) RECAPITULACIÓN Y CONCLUSIONES PARCIALES 170

VII. LOS DIOSES Y EL APARATO DIVINO: EL SILENCIO DE DiOS.

a) INGMAR BERGMAN Y EL SILENCIO DE DIOS 172

b) LOS DIOSES-ECO EN SÉNECA 175

c) LOS DIOSES FURIOSOS E IRRACIONALES 182

d) RECAPITULACIÓN Y CONCLUSIONES PARCIALES 189

\section{SEGUNDA PARTE: REPRESENTACIÓN DE LOS}

\section{PARADIGMAS LITERARIOS.}

\section{REPRESENTACIÓN DE LA HISTORIA}

a) LA AUSENCIA DE LA REPRESENTACIÓN HISTÓRICA EN LA TRAGEDIA DE SÉNECA

b) ÉPICA E HISTORIA

191

192 
c) PHARSALIA Y La BATALla De FARSALIA 194

d) LA BATALLA SEGÚN CÉSAR 199

e) LA REPRESENTACIÓN DE LA BATALLA EN PHARSALIA VII. 203

f) RECAPITULACIÓN Y CONCLUSIONES PARCIALES 208

IX. UTILIZACIÓN, REFORMULACIÓN Y SUBVERSIÓN DEL MATERIAL POÉTICO AUGUSTEO

a) LA REFLEXIÓN HORACIANA SOBRE LA GUERRA CIVIL 210

b) TRAYECTORIA Y EVOLUCIÓN DE LA FIGURA DEL EXPIATOR EN LA OBRA DE HORACIO 212

c) LA REFORMULACIÓN LUCANIANA DE LA FIGURA DEL EXPIATOR 215

d) EL SUSTRATO POÉTICO HORACIANO EN LA CONFIGURACIÓN DEL CATO UTICENSIS LUCANIANO. 222

e) HORACIO Y LA CONFIGURACIÓN DE ATREO COMO FURIARUM SACERDOS 224

f) LA INVOCACIÓN DE LAS FURIAS 230

g) RECAPITULACIÓN Y CONCLUSIONES PARCIALES 236

X. PLURIMA MORTIS IMAGO: LA REPRESENTACIÓN DE LA MUERTE Y SU INSCRIPCIÓN EN LOS CUERPOS.

I. ENEIDA Y FARSALIA: FORMAS DE INSCRIPCIÓN DE LA MUERTE EN LOS CUERPOS. 238

II. LA REPRESENTACIÓN DE LA MUERTE EN ENEIDA 239

III. LA REPRESENTACIÓN DE LA MUERTE EN SÉNECA Y LUCANO 242

IV. KÉRE YTHÁNATOS 250

V. RECAPITULACIÓN Y CONCLUSIONES PARCIALES 253

\section{CONCLUSIONES FINALES}

$\begin{array}{ll}\text { CONCLUSIONES FINALES } & 254\end{array}$

EDICIONES Y COMENTARIOS $\quad 260$

BIBLIOGRAFÍA CITADA $\quad 262$ 


\section{REFERENCIAS}

Las citas latinas son tomadas de las siguientes ediciones:

\section{César:}

Peskett, A. (1957), Caesar. The Civil Wars. Loeb Classical Library, Cambridge, Harvard University Press.

\section{Cicerón:}

King, J. (1960), Cicero. Tusculan disputations. Loeb Classical Library, Cambridge, Harvard University Press.

Miller, W. (1956), Cicero. De officiis. Loeb Classical Library, Cambridge, Harvard University Press.

Rackham, H. (1956), Cicero. De natura deorum. Loeb Classical Library, Cambridge, Harvard University Press.

Walker Keyes, C. (1959), Cicero. De re publica. De Legibus. Loeb Classical Library, Cambridge, Harvard University Press.

\section{Horacio:}

Nisbet, R. \& Rudd, N. (2004), A Commentary on Horace: Odes. Book III, New York, Oxford University Press.

\section{Séneca:}

Basore, J. (1928), Seneca: Moral Essays. Vol. I. Loeb Classical Library, London \& New York, Putnam's Sons.

Basore, J. (1932), Seneca: Moral Essays. Vol. II. Loeb Classical Library, London \& New York, Putnam's Sons.

Basore, J. (1935), Seneca: Moral Essays. Vol. III. De Beneficiis. Loeb Classical Library, London \& New York, Putnam's Sons.

Gummere, R. (1917), Seneca IV. Epistles 1-65. Loeb Classical Library, Great Britain, St. Edmundsbury Press Ltd.

Gummere, R. (1920), Seneca IV. Epistles 66-92. Loeb Classical Library, Great Britain, St. Edmundsbury Press Ltd.

Gummere, R. (1925), Seneca IV. Epistles 96-124. Loeb Classical Library, Great Britain, St. Edmundsbury Press Ltd. 
Miller, F. (1917), Seneca's Tragedies. Vol. I. Loeb Classical Library, London \& New York, Putnam's Sons.

Miller, F. (1918), Seneca's Tragedies. Vol. II. Loeb Classical Library, London \& New York, Putnam's Sons.

Lucano:

Duff, J. (1928), Lucan. The Civil Wars. Books I-X. Loeb Classical Library, London \& New York, Putnam's Sons.

Virgilio:

Fairclough, H. (1964), Virgil. Vol.I. Eclogues. Georgics. Aeneid I-VI. Loeb Classical Library, Cambridge, Harvard University Press.

Fairclough, H. (1964), Virgil. Vol. II. Aeneid VII-XII. The Minor Poems. Loeb Classical Library, Cambridge, Harvard University Press.

Seguimos, principalmente, al OLD para las abreviaturas y referencias a autores latinos. Nos apartamos, sin embargo, del mismo en el uso de números romanos para indicar libros y parágrafos. De tal modo, la oda III, 30 de Horacio aparecerá en el trabajo no como HOR. Carm. 3.30, sino como HOR. Carm. III, 30. Hemos particularizado, además, los diálogos de Séneca, frente al genérico Dial. (Dialogi) del OLD, utilizando Ira (De ira), Tranq. (De tranquilitate animi), Const. (De Constantia sapientis) y Prov. (De providentia). 


\section{INTRODUCCIÓN: STATUS QUAESTIONIS, HIPÓTESIS Y}

OBJETIVOS DEL TRABAJO. 


\section{INTRODUCCIÓN}

El prestigio de Séneca y Lucano ha sufrido una suerte dispar a lo largo de los años. Séneca es reconocido y respetado, ante todo, como filósofo moral; los primeros escritores y pensadores cristianos lo sentían tan cercano que lo consideraron uno más de ellos, llamándolo "el venerable Séneca” o Seneca noster. ${ }^{1}$ San Jerónimo lo incluía en el número de los santos, Agustín se refiere a él con gran admiración ${ }^{2}$ e incluso su muerte era leída e interpretada como un episodio más del martirologio cristiano. ${ }^{3}$ La tradición le atribuyó también una apócrifa correspondencia con San Pablo. Su trabajo en prosa comprende doce libros de Diálogos, ciento veinticuatro cartas a Lucilio, siete libros de Cuestiones Naturales y una sátira, la Apocolocyntosis o Calabacificación, que incluye partes versificadas. La importancia y profundidad de sus trabajos filosóficos y el prestigio de su figura como sapiens de alma naturaliter christiana eclipsaron su faceta de poeta trágico. A diferencia del Séneca filósofo, siempre tenido en alta estima, Séneca tragicus sufrió una suerte adversa, incluso paradójica: sus tragedias siempre recibieron una muy buena acogida entre el público y los lectores ${ }^{4}$ e influyeron en todo el desarrollo posterior de la tragedia en Europa (Shakespeare, Racine y Lope de Vega, entre otros, abrevan de las obras de Séneca y estaban mucho más familiarizados con éste que con los predecesores griegos), sin embargo nunca tuvieron una buena acogida por parte de los círculos académicos o eruditos. ${ }^{5}$

Lucano, por su parte, puede considerarse el paradigma del dictum "ars longa, vita brevis". Sabemos, a partir de las tres biografías que tenemos, ${ }^{6}$ de al menos quince obras escritas por él: un Iliacon, poema épico que trataba sobre la muerte de Héctor y la posterior recuperación de su cadáver y un Catachtonion, que narraba el descenso a los infiernos de algún héroe. Su Laudes Neronis le valió la palma en las fiestas en honor del emperador en el 60 d.C.; fue autor también de unos Saturnalia, una colección de poemas de ocasión y de una colección de Epigrammata. Escribió una Adlocutio ad Pollam, dedicada a su esposa, unos libretos para pantomimas titulados Salticae fabulae,

\footnotetext{
${ }^{1}$ Long, A. (2003), 184-186; TERT. An. XX, 1.

${ }^{2}$ AUGUST, C. D. V, 8 \& VI, 10.

${ }^{3}$ TAC. Ann., XV, 60-63.

${ }^{4}$ Garcia Yebra, V. (1988), 15-17.

${ }^{5}$ Ahl, F. (1986), 16-18; Uscatescu, G. (1968), 167-169.

${ }^{6}$ Las principales fuentes sobre la vida y la obra de Lucano son las biografias de Suetonio y Vacca, así como los Annales de Tácito (XV, 49) y la Silva II, 7 de Estacio. Para un detallado análisis del contenido y la estructura de la Silva II, 7 véase Ahl, F. (1976), 333-345. Cf. también Ahl, F. (2010), 3-4.
} 
otra colección de poemas de ocasión, los Silvarum libri, una tragedia, Medea, y un Orpheus, poema que, por su título, se supone trataba sobre el otro mundo. Su producción epistolar estaba reunida en las Epistulae ex Campania y sus ejercicios declamatorios publicados comprendían la Oratio in Octavium Saggitam et pro eo. ${ }^{7}$ Sus dos últimas obras son, probablemente, las más controvertidas. La Pharsalia, único trabajo que ha llegado hasta nosotros, lamentablemente inconcluso, y el De incendio Urbis, que según Frederick Ahl es el carmen famosum que le valió el encono del emperador. ${ }^{8}$

La crítica lucaniana también ha sido absolutamente dispar a lo largo de los siglos y sus diferentes valoraciones de Pharsalia son un fiel reflejo de las variadas aproximaciones axiológicas de cada momento: ${ }^{9}$

"It was repeatedly claimed by scholars that his epic does not respond to our expectations of structural coherence, and that many episodes are painfully overwrought, overblown and even inadvertently comical; that his style, with a few exceptions, appears extremely artificial, and that his many pointed and convoluted sententiae often verge on obscurity and even nonsense. There have been long stretches of time when his accomplishment was appreciated by the great - from Dante to Marlowe to Corneille to Goethe to Shelley- and he was extolled as an exemplar of Latin letters, a young genius who tragically fell victim to a tyrant. Only in very recent years has Lucan started to enjoy a remarkable revival which may be explained as a belated recognition that his desperate vision of the world won over by evil is akin in many respects to the fashionable existential pessimism of the present day. Furthermore, much of what earlier was dismissed as Lucan's literary vice is indeed characteristic of modern aesthetics, including incoherence and self-indulgence as well as fascination with the horrible and the absurd." 10

Las radicales innovaciones respecto del género, la forma y el contenido que Lucano lleva a cabo en su épica (ausencia de aparato divino, representación poética del material histórico, estilo barroco y retorización, inter alia ${ }^{11}$ generaron, a lo largo de la historia, numerosas hipótesis e interpretaciones. ${ }^{12}$ Otra poderosa communis opinio, ahora discutida, ${ }^{13}$ dominó la producción académica de los últimos dos siglos: el poeta

\footnotetext{
${ }^{7}$ Narducci, E. (1979), 18-20; Bartsch, Sh. (2005), 492.

${ }^{8}$ Narducci, E. (2002), 8; Ahl, F. (1976), 346-353.

${ }^{9}$ Fantham, E. (1992), 3-5; D’angelo, E. (1999), 389 y ss.; Holgado Redondo, A. (1984), 36-50.

${ }^{10}$ Rudich, V. (1997), 107; cf. también Narducci, E. (1979), 149 y ss.

${ }^{11}$ Narducci, E. (1979), 11-15; Narducci, E. (2002), 6 \& 13-14; Bartsch, Sh. (1997), 4-8; Rolim de Moura, A. (2010), 71-72; Martindale, Ch. (1976), 45 y ss.

${ }^{12}$ El propio Quintiliano lo recomendaba a los oradores más que a los poetas (QUINT. Inst. X, 1, 90), véase Herrero Llorente, V-J, (1967), xv- xxv. Sin embargo Lucano siempre gozó de la admiración y el respeto de los poetas, cf. Johnson, W. (1987), xii; von Albrecht, M. (1997), 917; Bartsch, Sh. (2005), 494495.

${ }^{13}$ Ahl, F. (1976), 32; Lapidge, M. (1979), 344-346.
} 
no sólo estaba influido por la doctrina estoica sino que era, él mismo, un consagrado estoico que expone su doctrina a través de los discursos de Catón.

\section{RECEPCIÓN CRÍTICA DE LA OBRA DE SÉNECA Y DE LUCANO}

La controversia generada por el teatro de Séneca data de su propio tiempo. Empieza con su polémica literaria con Pomponio respecto de la lengua y el registro propio del género (Pomponio abogaba por un lenguaje arcaizante y elevado en contraposición a la postura más progresista e innovadora de Séneca en relación a la lengua $)^{14}$ y alcanza su punto más álgido en la antigüedad con Quintiliano, ${ }^{15}$ quien, básicamente, le critica sus 'desviaciones' lingüísticas y su alejamiento de los modelos "clásicos": Cicerón y César en prosa, Virgilio y Horacio en poesía. Como veremos más adelante, éste será un lugar común y un argumento recurrente en la crítica senequiana y lucaniana: tardíos, decadentes, desmesurados, excesivos, exagerados y sobrecargados, violentos y distorsionados, en definitiva, "no clásicos". ${ }^{16}$

Citamos una frase del completísimo trabajo de Charles Whitmore, The Supernatural in Tragedy, que resume diáfanamente la actitud y la perspectiva crítica que primó hasta casi mediados del siglo XX y que, en algunos casos, sigue hasta nuestros días: "In antiquity we shall also discuss Seneca, comparatively unimportant in himself, but very significant as an influence." ${ }^{\prime 17}$ La sentencia, casi un oxímoron, muestra claramente cómo trabaja este prejuicio, entendido en términos de Gianni Vattimo no como un error de lectura sino como condición hermenéutica objetiva y operativa. ${ }^{18} \mathrm{La}$ influencia de Séneca en la dramaturgia europea posterior es tal que muchos estudiosos han considerado su obra como la culminación del desarrollo del teatro antiguo y

\footnotetext{
14 Tarrant, R. (1995), 221-222.

15 Ahl, F. (1986), 15-16: “Quintilian's anxieties about Seneca's corrupting influence were echoed by many Latin Teachers who chose to instruct their students in the prose style of Caesar and Cicero and in the verse of Horace and Vergil. These teachers, too, found Seneca a corrupting influence who did not fit, [...] Seneca, like Apuleius and Statius, had to be rejected, however important he may have been in shaping Western literature, because he was 'late', decadent and 'not classical'." Cf. también Ahl, F. (2010), 2 y ss. \& 15.

${ }^{16}$ von Albrecht, M. (1997), 907.

${ }^{17}$ Whitmore, Ch. (1915), 12.

${ }^{18}$ Vattimo, G. (2002), 142; Habinek, Th. (1992), 240: "To describe the ideological underpinnings of the works of Winckelmann and Schiller, Niebuhr and Gildersleeve, Curtius and Commager, is to engage in neither praise nor blame but to make some attempt at understanding. The view of classical literature and culture that these men developed responded to pressures, anxieties, and needs of their respective eras."
} 
fundadora del moderno, volviéndose entonces, en palabras de Moses Hadas, un "embryonic Elizabethan". 19

Actualmente la importancia de la tragedia de Séneca en el Renacimiento y en la tragedia isabelina es indiscutible. ${ }^{20}$ De hecho, la gran mayoría de las manifestaciones artísticas europeas desde los siglos XIV y XV en adelante deben más a la cultura romana que a la griega:

"Early opera was of course neither Roman nor Greek, but Italian, French, German or English, each musical drama a product of its own age and venue. But it is also fair to say that the sensibilities of Europe in the period when opera was invented and thrived were essentially Roman imperial and almost never classical Greek in nature. Although appeal was made to Greek stories, forms and ideals, even by those who would violate them, this was not an age that admired Athenian democracy or copied classical Greek culture in any fundamental way. Rather, ever since the advent of Renaissance humanism, school education has centered around the study of Latin and the Roman classics. The philosophy of the seventhteen century was Roman Stoic. [...] Moreover, the Baroque age, as Robert Harbison has written, 'is set apart from what precedes it by an interest of movement above all, movement which is a frank exhibition of energy and escape from classical restraint'. This lack of restraint, I would argue, is also the spirit of the comedies of Plautus, the energy of Ovidian elegy and epic, and the excesses of Roman imperial architecture and its literary contemporary." 21

Los autores italianos del siglo XIV fueron los primeros en recurrir al amplio abanico de posibilidades expresivas abiertas por el estilo ampuloso y retóricamente cargado de Séneca, sus atmósferas opresivas y la violenta caracterización de sus personajes. $^{22}$ Éste es el Séneca que seduce también a los isabelinos, traductores y autores por igual. $^{23}$ Son precisamente las características que dispararon el desdén académico (sus “desviaciones" lingüísticas) aquellas que atraen a los autores de los siglos XV y XVI: la violencia verbal, el uso ampuloso de la retórica, sus "exageraciones", en definitiva, todo aquello que hacía a Séneca el "heavy Seneca" tan del gusto Isabelino (Hamlet II, ii, 399-401).

\footnotetext{
${ }^{19}$ Hadas, M. (1968), 5; Uscatescu, G. (1968), 188-202; Rosenmeyer, Th. (1989), 43.

${ }^{20}$ Rees, B. (1969), 119-120; Littlewood, C. (2004), 1; Armstrong, W. (1948), 20-23 \& 32-35; Costa, C. (1973), 10-13; Ettin, A. V.(1970), 333-334.

${ }^{21}$ Ketterer, R. (2003), 1-2.

${ }^{22}$ Rees, B. (1969), 122-123: "Seneca was acclaimed by Salutati and Petrarch, who wrote: apud poetas profecto vel primum vel primo proximum locum tenent. Scaliger approved of him as nullo Graecorum maiestate inferiorem."; Gioia, D. (1995), vii:"In 1543 Giambattista Giraldi Cinthio, the influential Italian play-wright, critic, and writer of novelle (from which Shakespeare borrowed the plots of Othello and Measure for Measure), judiciously summarized the Renaissance view of Seneca's dramas: 'In almost all his tragedies he surpassed (in as far as I can judge) all the Greeks who ever wrote - in wisdom, in gravity, in decorum, in majesty and in memorable aphorism'."

${ }^{23}$ Rees, B. (1969), 125-126 y 129-130; Gioia, D. (1995), xiii-xviii.
} 
Cada época posee una concepción particular y singular de lo que debe ser una tragedia, ${ }^{24}$ aunque los prestigiosos eruditos y académicos del siglo XIX persistan en juzgar las diversas manifestaciones trágicas a través de estándares áticos del siglo $\mathrm{V}$ a.C. y preceptivas poéticas del siglo IV a.C. ${ }^{25}$ Los autores trágicos de los siglos XV y XVI no encuentran en Séneca elementos o imágenes novedosas: la violencia, la venganza, los fantasmas, etc. ya estaban presentes en el drama vernáculo europeo. Séneca, más bien, les ofrece herramientas verbales, usos lingüísticos y estrategias expresivas específicas a través de las cuales articular estos elementos en modos acordes a su sensibilidad particular. ${ }^{26}$ Muchas de las críticas que el teatro isabelino recibió entre los siglos XVII y XIX, desde Dryden hasta Goethe, se deben precisamente a este gusto barroco y excesivo, que encontraban agramatical, oscuro, recargado y rebosante de expresiones figurativas. ${ }^{27}$ El estilo y la imaginería shakespeareana estaban incluidos, para la crítica alemana, entre las "faltas y defectos" del poeta inglés, ${ }^{28}$ no extraña que estas consideraciones parezcan referidas a la poesía de Séneca y Lucano. ${ }^{29}$

La obra de Séneca circulaba fluidamente por Europa ya desde el siglo XV, tanto en latín como en lenguas vernáculas, y sus tragedias eran representadas con gran éxito, al menos, desde 1471 en adelante. ${ }^{30}$ En Inglaterra, las primeras recuperaciones y amplificaciones de Séneca se dan en el marco de las traducciones "de autor" en la segunda mitad del siglo XVI. Jasper Heywood traduce Troas, Thyestes y Hercules furens entre 1559 y 1561; Thomas Newton, por su parte, edita Seneca. His Tenne

\footnotetext{
${ }^{24}$ Rees, B. (1969), 128: "they [The Elizabethans] saw in him [Seneca] what they wanted to see, and used his plays as models on which to mould their own view of tragedy".

${ }^{25}$ Ketterer, R. (2003), 3-5.

${ }^{26}$ Rosenmeyer, Th. (1989), 3: "Some sixty years ago Otto Regenbogen, in a remarkable essay published by the Warburg Institute, declared that Seneca was the first to write what is today understood by the term 'tragedy'. The Greek of the first century B.C. Wrote tragoîdiai that continue to serve as models of significance and power. But their plays do not invariably exhibit the peculiar combination of elements that since the earliest Renaissance, and in the wake of Seneca, has embodied the tragic vision: an unhappy and mournfully moving end supervening upon an abrupt fall; the centrality of the hero and his failure; the prominence of nefas, iniquity; grandiloquence, ghosts, and magic; an appeal to learning; a measure of didactism; and all the qualities summed up under the triad atrocitas, maiestas and gravitas: vehemence, grandeur and high seriousness."; Rees, B. (1969), 131-132.

${ }^{27}$ Clemen, W. (1951), 10-15.

${ }^{28}$ Clemen, W. (1951), 11-12: “In Dryden's view Shakespeare style is 'so pestered with figurative expressions, that it is affected as it is obscure', [...] his greatness and power, his portrayal of character, are admired, but certain anxiety prevails lest Shakespeare's style should become a model. For his style appeared to be too bombastic, too irregular and, often, too obscure.[...] Dr. Johnson, whose criticism of Shakespeare displays an astonishing acumen and understanding, also takes a somewhat negative attitude towards Shakespeare's style. 'The stile of Shakespeare was in itself ungrammatical, perplexed and obscure.'... 'In narration he affects disproportionate pomp of diction... He is not long soft and pathetic without some idle conceit' Thus we read in the preface of 1765."

${ }^{29}$ Para un completo panorama de las críticas de fines del XIX y principios del XX véase Luque Moreno, J. (1987), T. I, 18 y ss.

${ }^{30}$ Rees, B. (1969), 122-123.
} 
Tragedies en 1581. Denominamos a estas traducciones "de autor" ya que, si bien permanecen fieles al espíritu de las obras, los traductores se toman la libertad de agregar, amplificar y modificar pasajes, escenas y cantos, en algunos casos, como el de Neville, dejándose llevar demasiado lejos en su afán de emulación. ${ }^{31}$

La inclusión del fantasma de Aquiles en Troas es un claro ejemplo de cómo Heywood logra traducir con enorme efectividad y precisión una convención del teatro clásico, ${ }^{32}$ el discurso del nuntius, ${ }^{33}$ a una forma más cercana al gusto isabelino alterando levemente la estructura de la obra en cuestión, volviéndola más efectiva dramáticamente para una audiencia separada por casi quince siglos. ${ }^{34}$ Como contracara, a veces los traductores podían volverse "más senequianos que Séneca", siendo los 62 versos agregados por Heywood al lacónico y certero final de Thyestes una muestra cabal de esta actitud particular. ${ }^{35}$ La traducción de Oedipus del propio Neville y las de Medea y Hercules Oetaeus de Studley ofrecen los ejemplos más extremos de esta modalidad de apropiación y amplificación. ${ }^{36}$

Lucano sufrió una suerte similar ya que su obra fue interpretada, a lo largo de la historia, en base a ciertos supuestos apriorísticos que redundaron en una valoración negativa de su estilo y su obra en general. ${ }^{37} \mathrm{El}$ pre-supuesto de lectura más influyente y pervasivo surge de un curioso modo de abordar la escritura de Lucano. Se parte de una afirmación arbitraria y sin sustento firme: Lucano era un devoto estoico, por lo tanto su obra poética responde y se subyuga a los presupuestos éticos y morales de esta escuela. ${ }^{38}$ Sin embargo, ya desde el siglo I d.C. su obra fue apreciada tanto por los lectores como por los poetas a lo largo de toda la antigüedad. ${ }^{39}$

${ }^{31}$ Rees, B. (1969), 127-128.

${ }^{32}$ Whitmore, Ch. (1915), 207-208.

${ }^{33}$ Vázquez González, C. (1997), 231-235.

${ }^{34}$ Rees, B. (1969), 130.

${ }^{35}$ El final de Thyestes ofrece una economía dramática y una efectividad trágica impecables. Nótese el paralelismo semántico y la similitud lingüística de ambas elocuciones: "Thy.: Vindices aderunt dei/ his puniendum uota te tradunt mea. / Atr.: Te puniendum liberis trado tuis." (Thy. 1110-1112).

${ }^{36}$ Rees, B. (1969), 127-128.

${ }^{37}$ Heitland, W. (1971), lxxii-lxxix.

${ }^{38}$ Sklenáŕ, R. (1990), 281: "For many years, a powerful communis opinion dominated the scholarly literature on Lucan: that the poet is not merely influenced by Stoicism but is himself a committed Stoic, who expounds his doctrine both in his own voice and in the speeches of Cato. The Obvious difficulty with this argument is that Cato's stoic ideal defies reconciliation with some of the most powerful and characteristic utterances of Lucan's authorial voice. A more recent line of interpretation, typified by W. R. Johnson (1987), John Henderson (1988), and Jamie Masters (1992), has rejected the putatively stoic Lucan in favor of a dark, sinister, at times grimly parodic poet who both describes and exemplifies a view of the cosmos as chaotic, fragmentary, and ultimately meaningless. [...] Under this reading, which has gained currency mostly since the mid-80s, Lucan's Cato becomes a nasty caricature both of the Stoic sage and of the traditional Roman vir bonus. While this satirical interpretation of Lucan's Cato represents a significant improvement over the orthodoxy which it has displaced, it still does not adequately account 
Lo mismo le sucedió a Séneca con su tragedia, muchas veces menospreciada y considerada como simple propaganda o medio de difusión del estoicismo, cuando en realidad ésta es una profunda inquisición sobre los aspectos más controvertidos y paradójicos de su pensamiento. ${ }^{40}$ Los presupuestos señalados desestiman dos cuestiones fundamentales: en primer lugar, el estoicismo, particularmente el romano, nunca fue una escuela monolítica, sino que se caracterizó por un dinamismo, un eclecticismo y una personalidad admirables. ${ }^{41}$ En segundo lugar, en el caso de Lucano, es absolutamente cierto que éste se crió en un ambiente donde el marco de pensamiento era eminentemente estoico y que fue educado por célebres pensadores como su maestro Cornuto y el propio Séneca, ${ }^{42}$ pero de allí a convertirse en el severo y devoto estoico que los críticos crean a partir de la lectura de su obra, existe un largo trecho. De hecho, la pertenencia a la cohors amicorum de Nerón poco se condice con la práctica de la constantia, la apatheia $y$ la moderación propias del sapiens estoico. ${ }^{43}$ Séneca también sufrió este tipo de lecturas reduccionistas, particularmente durante la primera mitad del siglo XX, encabezadas por la profesora Berthe Marti, quien veía las tragedias de Séneca como meros instrumentos de exposición y difusión de las ideas estoicas. ${ }^{44}$ Otros autores han ido aún más lejos y han llegado a negar la autoría de Séneca aduciendo que el horror y la crueldad presentes en las tragedias no serían compatibles con la mesurada y meditada voz de sus trabajos en prosa. ${ }^{45}$

for the systematic opposition between Cato's Stoic ideal and the universe in which he attempts to practice it, or for both the painful futility of his attempt to make sense of a world where senselessness is sovereign." Cf. también Ahl, F. (1976), 7-8 \& 32-33.

${ }^{39}$ von Albrecht, M. (1997), 925 y ss.; MART. XIV, 194: Sunt quídam qui me dicant non ese poetam/ sed qui me vendit bibliopola putat"; Asso, P. (2010), 11-12.

${ }^{40}$ Galán, L. (2002), 69-70.

${ }^{41}$ Barrow, R. (1949), 151-162; Ferrater Mora, J. (1994), 1120-1123; Tatarkiewicz, W. (2000), 194-202; Brena, F. (1999), 277-283; Reydams-Schils, G. (2005), 1 y ss.; Long, A. (2003), 184 \& 203-205.

${ }^{42}$ von Albrecht, M. (1997), 913-914; Heitland, W. (1971), xlii-xliii.

${ }^{43}$ Ahl, F. (1976), 36-38.

${ }_{44}^{44}$ Marti, B. (1945), 216-223 \& Marti, B. (1947), 1-3; Gioia, D. (1995), vii-x.

${ }^{45}$ Fischer, E. (1945), 108-109. 


\section{LA POSTURA HEGEMÓNICA DECIMONÓNICA Y BLACK ATHENA DE MARTIN BERNAL}

La crítica más influyente, prestigiosa y voluminosa respecto de la Antigüedad Clásica surge durante el Romanticismo alemán en los siglos XVIII y XIX e instaura una clara jerarquización axiológica entre Grecia y Roma, en detrimento de esta última. ${ }^{46}$ Toda axiología despliega en su interior la ideología que la ha generado, así como también su proyecto hegemónico, ${ }^{47}$ por lo que la construcción de la "Antigüedad Grecolatina", configurada por el último romanticismo alemán, desde Winckelmann hasta Schiller, resulta ser un particular proceso de apropiación del mundo antiguo y la configuración de una imagen específica y acotada de éste como un todo binario, ${ }^{48}$ dicotómico, casi maniqueo, con una Grecia dominante y excelsa, fuente primordial y primer motor de Occidente, y una Roma decadente que representa el ocaso y la imitación tosca y burda de los logros culturales e intelectuales de la primera. ${ }^{49}$

Esta jerarquización no es casual ni inocente; responde, entre otros factores, a una operación ideológica precisa y particular: el distanciamiento con la Roma papal, asimilada a la Roma Aeterna de Virgilio. ${ }^{50}$ Consecuentemente todo lo romano tomará el carácter de imitación tardía o copia servil. ${ }^{51}$ Estamos frente a un proceso configurativo del pasado, a una organización axiológica particular y específica de significados, valores y prácticas incorporadas a una cultura significativa y a un orden social efectivo.

\section{Afirma Raymond Williams:}

"Sin embargo esta versión de la tradición [la tradición como supervivencia del pasado] es débil en el punto preciso en que es fuerte el sentido incorporado de la tradición: donde es visto, en realidad, como una fuerza activamente configurativa, ya que en la práctica la tradición es la expresión más evidente de las presiones y límites dominantes y hegemónicos. Siempre es algo más que un segmento histórico inerte, es en realidad el medio de incorporación práctico más poderoso. Lo que debemos comprender no es precisamente 'una tradición', sino una tradición selectiva: una versión intencionalmente

\footnotetext{
${ }^{46}$ Habinek, Th. (1992), 227-230; Ahl, F. (1986), 16.

${ }^{47}$ Calabrese, O. (1989), 11-12.

${ }^{48}$ Vattimo, G. (2002), 86-87: "Y así como el calificativo de clásica no la define tanto en su esencia [a la civilización griega] cuanto en su significado para nosotros, tampoco lo trágico será sólo un carácter de esa civilización, sino que calificará también fundamentalmente nuestro modo de relacionarnos con ella. Como la idea de lo clásico correspondía a un determinado modo de situarse respecto al pasado, epigonal y decadente, se trata de encontrar qué nuevo y diferente modo de plantear esta relación corresponde a la nueva concepción trágica de la antigüedad griega.” Cf. también 92 y ss.

${ }^{49}$ Habinek, Th. (1992), 227-231 \& 240-242.

${ }^{50}$ Habinek, Th. (1992), 238-239; Galán, L. (2005), 115-118; Johnson, W. (1967), 1-12; Vattimo, G. (2002), 85-86.

${ }^{51}$ Habinek, Th. (1992), 228: "Bernal's concern is with the exclusion of Semitic and African contributions to ancient Mediterranean civilization, but he could have written with equal zeal about the suppression of Rome."
} 
selectiva de un pasado configurativo y de un presente preconfigurado, que resulta entonces poderosamente operativo dentro del proceso de definición e identificación cultural y social. ${ }^{\circ 2}$

La polémica obra de Martin Bernal, Black Athena. The Afroasiatic Roots of Classical Civilization, muestra, entre otras cosas, cómo la invención de las nociones modernas de la antigüedad, de su historia y su cultura, realizada por los eruditos europeos, fue un cuidadoso y exhaustivo proceso de exclusión y supresión de todo elemento semítico, oriental y/o africano, más que uno de descubrimiento y articulación. ${ }^{53}$ El Romanticismo alemán se presenta como la continuación natural de la excelsa Grecia y construye una civilización absolutamente autógena, nacida de sí misma y sin influencia externa alguna, sin deudas culturales con ningún pueblo vecino o cercano, en particular y específicamente, si estos pueblos eran africanos o semitas. ${ }^{54} \mathrm{El}$ "modelo ario" de los siglos XIX y XX no sólo realiza una limpieza (étnica) de la antigua Grecia, sino que, por oposición, crea, dentro del sistema hegemónico de dominación, ${ }^{55}$ una imagen ficticia y literaria de Oriente en tanto 'Otro' frente al cual diferenciarse. ${ }^{56}$

\section{BLACK ATHENA}

La tesis del ambicioso proyecto de Martin Bernal, concebido como una extensa tetralogía, ha sido virulentamente atacada por su falta de rigurosidad metodológica, teórica y epistemológica, hecho que es reconocido incluso por sus defensores y adherentes. ${ }^{57}$ Muchos académicos de todas partes del mundo, entusiastas defensores de esta perspectiva de análisis, coinciden en que lo monumental del proyecto, que incluye numerosas y arduas disciplinas (lingüística, arqueología, historia y antropología, entre otras) y que implica complejos sistemas morales, políticos e ideológicos, excede las

\footnotetext{
${ }^{52}$ Williams, R. (1997), 137.

${ }^{53}$ Bernal, M. (1987), 17-38.

${ }^{54}$ Bernal, M. (1987), 29:“[18th Century’s] paradigm of 'races' that were intrinsically unequal in physical and mental endowment was applied to all human studies, but especially to history. It was considered undesirable, if not disastrous, for races to mix. To be creative, a civilization needed to be 'racially pure'. Thus it became increasingly intolerable that Greece -which was seen by the Romantics not merely as the epitome of Europe but also as its pure childhood- could be the result of the mixture of native Europeans and colonizing Africans and Semites.”. También Van Binsbergen, W. (2009), 3-7.

${ }_{55}$ Williams, R. (1997), 129-131; Said, E. (1993), 11-15.

56 Bernal, M. (1987), 33:"Michelet's views on the Phoenicians were spread even more widely in Flaubert's immensely popular historical novel Salammbô, published in 1861. Salammbô contained descriptions of Carthage at its most decadent which powerfully reinforced the already widespread antiSemitic and anti-Oriental prejudices.” Said, E. (1993), passim; Said, E. (2009), 19-23.

${ }^{57}$ Van Binsbergen, W. (2009), 1-2.
} 
posibilidades de una sola persona, que, además, se ha dedicado a responder meticulosamente cada una de las críticas que su trabajo ha generado. ${ }^{58}$

Sin embargo, la obra de Bernal, al igual que la de Nietzsche, ${ }^{59}$ tiene la particularidad de no ser importante y relevante por el carácter taxativo de sus conclusiones (algunas en verdad llevadas demasiado lejos, como por ejemplo la insistencia de Bernal al identificar, pars pro toto, a Egipto y a los pueblos subsaharianos, con África en su totalidad, ${ }^{60}$ o sus ataques a personajes como Kant, Goethe, Lessing y Herder $)^{61}$ sino de poner en primera plana la naturaleza hegemónica del sistema de saber europeo decimonónico. La virulencia y hostilidad de la reacción académica revela hasta qué punto sigue vigente y efectiva, en nuestros días, esta perspectiva ideológica. ${ }^{62}$

La cultura dominante en la Europa del siglo XIX y principios del siglo XX despliega un complejo efectivo de lecturas que instauran una tradición operativa para una organización social y cultural contemporánea, con intereses y objetivos específicos, cuyo resultado inmediato es una versión del pasado que ratifica el orden operativo de su época y se presenta en una relación de predispuesta continuidad. ${ }^{63}$ La filología clásica adquiere, en tanto institución y formación, ${ }^{64}$ una importancia nueva y efectiva que se convertiría en el instrumento por excelencia de validación axiológica de las obras literarias de la antigüedad Clásica. La tarea de estas formaciones, en palabras de Raymond Williams:

“Consistía en una discriminación de las obras auténticamente 'grandes' o 'principales', con la consecuente categorización de obras 'menores' y una exclusión efectiva de las obras 'malas' o 'insignificantes', a la vez que una comunicación y una realización práctica de los 'principales' valores. Lo que se había reclamado para el 'arte' y la

\footnotetext{
${ }^{58}$ Van Binsbergen, W. (2009), 10-20.

${ }^{59}$ Magnus, B. \& Higgins, K. (1996), 3-6; Porter, J. (2006), 553-556.

${ }^{60}$ Van Binsbergen, W. (2009), 5-6 y 21 y ss.

${ }^{61}$ Van Binsbergen, W. (2009), 16: "Here [i.e. the history of the $18^{\text {th }}$ and $19^{\text {th }}$ centuries] the specialist have little difficulty showing that some of Bernal's allegedly racist villains (Kant, Goethe, Lessing, Herder) were in fact -at least at the height of their career - heroes of intercultural learning and modernity's theoreticians of tolerance, recognized as such in the whole world."

${ }^{62}$ Said, E. (2009), 25-26: "No hay que creer que el orientalismo es una estructura de mentiras o de mitos que se desvanecería si dijéramos la verdad sobre ella. Yo mismo creo que el orientalismo es mucho más valioso como signo del poder europeo-atlántico sobre Oriente que como discurso verídico sobre oriente (que es lo que en su forma académica o erudita pretende ser). Sin embargo, lo que tenemos que respetar o intentar comprender es la solidez del entramado del discurso orientalista, sus estrechos lazos con las instituciones socioeconómicas y políticas existentes y su extraordinaria durabilidad. [...] El orientalismo, pues, no es una fantasía que creó Europa acerca de Oriente, sino un cuerpo de teoría y práctica en el que, durante muchas generaciones, se ha realizado una inversión considerable."

${ }^{63}$ Williams, R. (1997), 134-138; Said, E. (2009), 34 y ss.

${ }^{64}$ Las formaciones son aquellos movimientos y tendencias efectivos que, en los ámbitos intelectuales, artísticos y académicos, poseen una influencia significativa y decisiva en el desarrollo activo de una cultura específica. Cf. William, R. (1997), 139.
} 
'imaginación creativa' en los asertos románticos fundamentales se reclamaba ahora para la 'crítica' considerada como una 'disciplina' y una actividad 'humana' fundamental. Este desarrollo dependía, en primer lugar, de una elaboración del concepto de 'tradición'.,"65

En su afán por construir una continuidad político-literaria entre esta peculiar “Grecia Clásica” y la Alemania del siglo XIX, presentándose como los herederos naturales de los logros poéticos y filosóficos de ésta, la Filología Clásica, genera la más voluminosa, erudita e influyente producción crítica e instaura su factura teórica como un saber positivista y una categoría histórica particular y especializante. ${ }^{66}$ Sin embargo, las tradiciones selectivas son vulnerables precisamente porque sus operaciones ideológicas están ligadas a los límites y presiones de su propia época y a su entorno políticoideológico, por lo que gran parte de las prácticas excluidas o desestimadas son recuperables y aprovechables. ${ }^{67}$

La tajante sentencia de Ulrico von Wilamowitz-Moellendorff, "Diese Medea hat offenbar die Medea des Euripides gelesen"68 es particularmente reveladora tanto de la agudeza y la perspicacia de las lecturas de la "Filología Clásica" en tanto formación particular y efectiva, así como también del posicionamiento ideológico-literario de ésta, detectando el profundo juego de alusiones metatextuales que caracteriza la tragedia de Séneca y, al mismo tiempo, juzgándolo como otro de los típicos excesos y las faltas propias de su poética. En esta configuración específica del pasado, Séneca tragicus fue particularmente vulnerable, pues se encuentra en un territorio especialmente desprotegido dentro de la historia de la literatura latina; desestimado por los latinistas eruditos como decadente y artificial, se lo considera un escritor típico del "Siglo de Plata" de la literatura latina. ${ }^{69}$ Esta consideración encierra en su misma definición un subjetivema denigratorio: si el "Siglo de Oro", con César, Cicerón, Virgilio y Horacio, es el cenit de la cultura latina, teleológica y necesariamente, lo que sigue sólo puede ser un atardecer y un decaer. ${ }^{70}$ Como si esto no fuese suficiente, Séneca escribe tragedias, ${ }^{71}$

\footnotetext{
${ }^{65}$ Williams, R. (1997), 66.

${ }^{66}$ Williams, R. (1997), 68-69.

${ }^{67}$ Williams, R. (1997), 139; Said, E. (1993), 14-15.

${ }^{68}$ von Wilamowitz-Moellendorff, U. (1906), 162.

${ }^{69}$ Narducci, E. (1979), 9-10; Ahl, F. (1986), 16; Meltzer, G. (1988), 311-312.

${ }^{70}$ Galinsky, K. (2009), 11: "En lugar de ofrecer una perspectiva crítica, la mayor parte de los estudiosos de los siglos XIX y XX simplemente vistió los viejos juicios de valor con el atuendo de la terminología estética y teórica. El oro se volvió plata, el ascenso a las alturas devino decadencia, lo clásico se volvió anticlásico, epigonal y manierista. La empresa consistió en documentar este cambio y la decadencia poniendo el énfasis en las supuestas faltas y excesos de estos poetas, siendo la 'retórica' el principal chivo expiatorio."
} 
género griego por antonomasia, no sólo por la excelencia literaria lograda por sus representantes, sino también por las vicisitudes históricas e incluso, por llamarlas de alguna manera, arqueológicas, ya que entre nuestro autor y Esquilo, Sófocles y Eurípides existe, para nosotros, un vacío de quinientos años de evolución literaria. ${ }^{72}$

\footnotetext{
${ }^{71}$ Rosenmeyer, Th. (1989), 3: "Some Sixty years ago Otto Regenbogen, in a remarkable essay Publisher by the Warburg Institute, declared that Seneca was the first to write what is today understood by the term 'tragedy'. The Greek of the first century B.C. wrote tragôidiai that continue to serve as models of significance and power. But their plays do not invariably exhibit the peculiar combination of elements that since the earliest Renaissance, and in the wake of Seneca, has embodied the tragic vision: an unhappy and mournfully moving end supervening upon an abrupt fall; the centrality of the hero and his failure; the prominence of nefas, iniquity; grandiloquence, ghosts, and magic; an appeal to learning; a measure of didactism; and all the qualities summed up under the triad atrocitas, maiestas and gravitas: vehemence, grandeur and high seriousness."

72 Costa, C. (1973), 2-7; Littlewood, C. (2004), 1: "Although the influence of Senecan tragedy on Renaissance drama assures it a place in the history of Western theatre its own roots and its own tradition are less sure. Fragmentary plays, some material evidence, and the discussion of ancient critics are all that span the centuries from Sophocles to Seneca."
} 
LA TRAGEDIA Y LA ÉPICA EN ROMA

La tragedia y la épica latinas fueron una continuación voluntaria y consciente de las obras griegas. Sin embargo nunca fueron una imitación servil ni meras traducciones, pues desde sus más tempranas manifestaciones exhibieron rasgos personales y profundas y radicales innovaciones:

"Thus, imitation allowed an author to emphasize precisely his own contribution by measuring it expressly against the achievement of a predecessor. The more significant the model, the greater the emulator's gain in artistic capability. Therefore, a literature conscious of its history is not necessarily a mere dialogue with the past conducted by epigones. Again and again, even at a distance of centuries, it may become a 'summit meeting', as has been with the case of Dante, Virgil and Homer."

Resulta absurdo negar a los poetas latinos la capacidad de creación poética pues éstos siguen el proceder normal de los poetas de la antigüedad, combinando tradición, originalidad e innovación en el tratamiento de los mitos. En el caso particular de la tragedia, esta problemática se torna particularmente espinosa, pues sobre ella pesó siempre la sombra del prestigio y la excelencia de los autores áticos. Sin embargo, así como a nadie se le ocurre pensar que las tres tragedias Filoctetes, de Esquilo, Sófocles y Eurípides hayan sido obras idénticas o copias serviles de la más antigua, no resulta, entonces, lícito asumir que las tragedias latinas hayan sido sólo traducciones o copias de modelos griegos prestigiosos. ${ }^{74}$ Un claro ejemplo de innovación trágica romana, por ejemplo, es el coro de soldados introducido por Ennio en su Iphigenia, que no tiene antecedentes en los modelos griegos. ${ }^{75}$

\footnotetext{
${ }^{73}$ von Albrecht, M. (1997), 13. Cf. también p. 58: “[...] unlike most of the Mediterranean peoples, the Romans remained loyal to their native language, and responded to Greek literature by creating a literature of their own. In the Hellenistic period, Latin assimilated Greek literary forms, and, in the first instance, those that were contemporary. The encounter with the Greek culture did not take place in a vacuum. It was tied to those particular cities and areas where Rome came sequentially into closer connections. Greek authors were not read at random; preference was given to those who, through their subject, their origin or their biography, had ties with Italy. Ennius, for example, turned his attention to Sicilian authors like Epicharmus and Archestratus of Gela. Even later the Romans liked to refer to Pythagoras as an 'Italian' philosopher or to Theocritus' 'Sicilian Muses'. [...] The Romans owed their triumphant course not to their alleged conservatism, but to their ability to relearn, and to find new answers to new challenges."

${ }^{74}$ Littlewood, C. (2004), 5:“Attempts have been made for example to reconstruct Euripides' lost Kalyptómenos from Seneca's Phaedra by comparing it with the surviving Hippolytus play: deviations mark the influence of the lost play. Such 'terrorisme philhellène' as Dupont termed it has been derided more widely but a presumption of Greek influence continues to appear in more measured form."

${ }^{75}$ von Albrecht, M. (1997), 102; Codoñer, C. (1997), 50 y ss.
} 
Desde sus comienzos, la tragedia romana mostró una predilección por la obra de Eurípides, ${ }^{76}$ como así también una marcada tendencia a la hora de seleccionar la materia dramática de sus obras, destacándose un interés por la saga troyana y por los temas más truculentos. El interés por los temas relacionados con Eneas y los troyanos se ha explicado siempre por la resonancia emotiva y las implicancias políticas e históricas que los acontecimientos de la guerra de Troya y la llegada de Eneas al Lacio generaban en el auditorio. ${ }^{77}$ Existió también una marcada preferencia por la utilización de los mitos más sangrientos y truculentos ofrecidos por la tradición. Livio Andrónico escribe un Aias mastigophorus e inaugura la puesta en escena de masacres y venganzas horrorosas con su Tereus. ${ }^{78}$

Otra característica de la tragedia latina es la tendencia a repetir temas ya utilizados por otros dramaturgos contemporáneos o muy cercanos en el tiempo: ${ }^{79}$ el Tereus de Livio Andrónico fue retomado casi inmediatamente por Accio y poco más tarde por Fausto, un autor del que no tenemos mayores datos. Las cruentas disputas de los Pelópidas, por su parte, aparecen plasmadas en las tragedias Atreus de Accio, Pomponio Secundo, Emilio Escauro y Rubreno Lapa, y en los Thyestes de Ennio, Vario, ${ }^{80}$ Graco, Séneca, Curiacio Materno y Baso; abarcando diez dramas de igual número de autores, repartidos a lo largo de la República y el Imperio. ${ }^{81}$

Es propio de la cultura romana, tal como puede verse por los temas seleccionados, un profundo interés por la naturaleza y el ejercicio del regnum (un claro ejemplo de esto es el tratamiento absolutamente alejado del de Sófocles del Oedipus

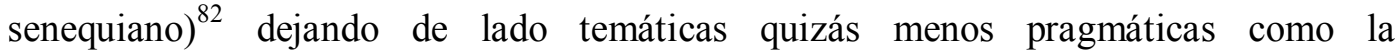
incompatibilidad y la dicotomía existentes entre las esferas divina y humana, ${ }^{83}$ a tal punto que no sabemos de ninguna tragedia romana sobre Antígona. Existieron, sin embargo, varias tragedias latinas consagradas y elogiadas por los autores más importantes de la Antigüedad, ${ }^{84}$ pero al no conservarse estos antecesores trágicos romanos la tragedia de Séneca se vio irremediablemente estudiada en conexión, o quizás mejor, en sujeción, a la tragedia ática, a los "originales" griegos del siglo V a.

\footnotetext{
${ }^{76}$ von Albrecht, M. (1997), 93; Fitch, J. (1987), 115-117.

${ }^{77}$ Goldberg, S. (2005), 432-433.

${ }^{78}$ von Albrecht, M. (1997), 112 y ss.

${ }^{79}$ Fantham, E. (1982), 24-28.

${ }^{80}$ Jocelyn, H. (1980), 392 y ss.

${ }^{81}$ Tarrant, R. (1985), 41-43; Codoñer, C. (1997), 51-53; von Albrecht, M. (1997), 95-97.

${ }^{82}$ Galán, L. (1997).

${ }^{83}$ von Albrecht, M. (1997), 24.

${ }^{84}$ von Albrecht, M. (1997), 13-16; Codoñer, C. (1997), 48-58.
} 
C. ${ }^{85}$ Sin embargo, los estudios sobre la literatura latina en general, ${ }^{86}$ y sobre Séneca en particular, dieron un giro importante en las últimas décadas; afirma Tarrant:

"Current analyses of Senecan tragedy consequently tend to treat Seneca either on his own terms as a dramatist, which has the beneficial side effect of freeing him from unfair comparison with the Greek, or to situate him in a Roman literary context." 87

Volviendo sobre el problema del género, la tragedia ya estaba establecida en Roma desde hacía varios siglos y contaba con importantes autores y obras: Pacuvio, Nevio, Accio, Vario, incluso Ovidio, ya habían incursionado en el género y creado los “clásicos romanos", 88 por lo que la competencia y la discusión literaria con los modelos griegos, del tipo que era indispensable en los dos últimos siglos antes de Cristo, ya no representaba una necesidad en el siglo I d. C. Los trágicos griegos, por supuesto, están presentes en la obra de Séneca pero, aun cuando el material trabajado sea específicamente griego, su tratamiento se revela íntimamente tamizado por las fuentes romanas. Séneca se acerca a los temas trágicos principalmente a través de los poetas augusteos: ${ }^{89}$

"If I had to say what Senecan tragedy is I would say that it is Neronian Literature and hope thereby to emphasize its place in the Roman world and in the corpus of Latin literature. The isolationist Stoic cast of the moralizing is characteristically Neronian, so too the close and frequently destructive engagement with the literary and political

\footnotetext{
${ }^{85}$ Tarrant, R. (1995), 216: "With no Roman predecessors or successors available for comparison, Seneca as a dramatist was inevitable studied for a long time in conjunction with the fifth-century Athenian tragedy, the only other corpus of serious drama to survive from antiquity. As a result his plays were often regarded as adaptations of fifth-century 'originals' considerably freer in their treatment then the comedies of Plautus and Terence, but standing in analogous relation to their Greek models". Transcribimos también la nota 6 referida a este pasaje: "This view was firmly enough established to subsist even in absence of evidence: as E. Phillips Barker wrote in OCD, à propos the connection between Seneca's Agamemnon and the Aeschylian play of the same name, 'a debt to Aeschylus is rather to be assumed than easily traced' (827 f.: retained in OCD 977). The Agamemnon is admittedly an extreme case, and I would not wish to deny that Seneca was familiar with such classic texts as Sophocles's Oedipus Tyrannus, as Töchterle (Heildelberg 1994 9-18) rightly insists, my point is that treating any Senecan tragedy as primarily an adaptation of a fifth-century Greek 'model' will have a limiting and distorting effect of its interpretation.” Cf. también Uscatescu, G. (1968), 185-186.

${ }^{86}$ Habinek, Th. (1992), 227-228: "[...] the construction of classical studies that arose during and immediately following the Romantic period involved the creation of a hierarchy between Greece and Rome that the privileged the former and denigrated the latter, and that worked, in particular, to aestheticize the study of Latin Literature, removing it from the connection with Roman culture that might have made clear its relevance and intrinsic interest to contemporary society. Rome was suspect to the romantics for a variety of reasons, and if Latin literature was to be preserved as an area of study, it had to be removed as far as possible from the culture that enabled its production"

${ }^{87}$ Tarrant, R. (1995), 217.

${ }^{88}$ von Albrecht, M. (1997), 143 y ss.

${ }^{89}$ Tarrant, R. (1995 \& 2002); Littlewood, C. (2004), 6: "In some cases we can see Seneca apparently reading Euripides through Latin Poetry. Angry Juno at the opening of Hercules Furens owes something to Ovid, but also to Juno's summoning of Allecto in Aeneid 7. This in turn is modelled on Hera's summoning of Lyssa in Euripides' Heracles Furens. That Seneca should adapt the Virgilian characters for a Hercules tragedy suggest a recognition of Euripides in the background [...] He revisits Greek tragedy not directly but as it is mediated by Virgil."
} 
rhetoric of Augustus's Golden Age. Lucan, Ovid, Vergil and even Horace have been more important figures to me than any tragedian. It has long since been unacceptable to characterize Seneca simply as an imitator of Euripides and is no need to fight a battle already won. No one would now deny the centrality of the Aeneid in an interpretation of his work." ${ }^{90}$

En general, las percepciones respecto de la obra de Séneca, más allá de reconocer cierta originalidad en el tratamiento de los temas trágicos, no escapan al influjo del prestigio y el volumen teórico desplegado por la Filología Clásica decimonónica. ${ }^{91}$ Los comentarios suelen recuperar opiniones y consideraciones que se remontan a prestigiosas publicaciones del siglo XIX y la primera mitad del $\mathrm{XX},{ }^{92}$ y se hace hincapié en la falta de organización dramática, la poca o inexistente relación entre las partes y la ausencia del más elemental agente de unidad estructural. ${ }^{93}$

Respecto de la tragedia de Séneca y su influencia, citamos a continuación dos fragmentos de un completísimo trabajo de Charles Whitmore, editado en 1915, que, creemos, muestra a la perfección cómo operan estos prejuicios en la percepción de la obra trágica de Séneca:

"His Pompous rhetorical plays have little intrinsic merit; but because of their great influence in the Renaissance, when Seneca was regarded as one of the chief tragic masters, if not indeed superior to his Greek predecessors, it becomes important to see just what modifications of Greek usage he introduced." 94

$[\ldots]$

"Having thus disposed of the external stylistic features of Seneca, we are prepared to turn to his chief contribution to our subject, the Senecan ghost. Three ghosts actually appear on the stage in his plays, and three others are described in detail; so that we do not lack material for discussion. Of the first group, two appear in the prologues of the plays in question; and the simplest type if that of the ghost of Thyestes in the Agamemnon. [...] He goes on to speak of his own crime, and to predict the impending murder of Agamemnon, after which he withdraws, in order to permit the sun, which is unwilling to shine on such a criminal, to rise. His role is thus seen to be exclusively

\footnotetext{
${ }^{90}$ Littlewood, C. (2004), 1-2.

${ }^{91}$ Habinek, Th. (1992), 227.

${ }^{92}$ Luque Moreno, J.(1987), T. I, 3 y ss.; también T. I, 183: "Esta obra [Troyanas] ha sido considerada también como una de las típicas de Séneca, sobre todo en lo que respecta a la falta de interés por una estructura dramática global y unitaria, por un desarrollo armónico de los personajes y por un diálogo que lleve a estos últimos a la acción trágica", y T. I, 283: "Medea es, en efecto, uno de los personajes más conseguidos de Séneca. No quiere decir que se trace aquí el desarrollo interno de este personaje a lo largo de la obra, ni que esta obra sea una excepción en la general falta de interés de Séneca por la estructura dramática."

${ }^{93}$ Park Poe, J. (1969), 355: "These days not much attention is paid to the plays of Seneca. Of a recently published collection of essays on Roman drama not one in devoted to Senecan tragedy as such. The reason for this is clear to anyone familiar with Seneca's plays and with the kind of drama criticism done by the Classicists: by comparison with the Greek tragedies Senecan tragedy is deficient in both plot and characterization. This means, to those whose critical thinking has been informed by Aristotle's Poetics, that it also is deficient in meaning." Luque Moreno, J. (1987), T. II, 89.

${ }^{94}$ Whitmore, Ch. (1915), 97.
} 
expository. In the prologue of Thyestes we have a more elaborate form. Here the ghost is that of Tantalus, and he is accompanied by a Fury who brings him to the light, [...] The Fury proceeds to give a catalogue of the future crimes of Tantalus' descendants, which so appalls him that he starts back for Hades, preferring the tortures there; but the Fury intercepts him, and bids him bring woe on the house of Pelops. He is reluctant, but at last obeys. The Fury declares that the house feels him near and shudders at the contact. The whole earth is blighted by his presence; Alpheus is dried up, the snows melt on Cithaeron, and even the sun is on the point of halting! Such frantic hyperbole is of course utterly futile as regards giving any sense of supernatural power of the ghost. $\mathrm{He}$ is confined to the prologue, not the slightest reference being made to his baleful power in the subsequent course of the drama. [...] These three cases [los de los fantasmas de Tiestes, Tántalo y Agripina], then, comprise a purely expository ghost, a ghost supposed to be capable of exercising baleful power, but described in such absurdly exaggerated terms as to lose all impressiveness, and a ghost appearing in the midst of the action, but without any other effect on it than a subsequent appearance in a dream." 95

Por supuesto no es nuestra intención desautorizar estas opiniones sino discutir y discrepar con ellas ${ }^{96}$ para así marcar ciertos lugares del texto donde creemos detectar una Wille zum Griechischen Einheit que opera por debajo de las afirmaciones resaltadas. ${ }^{97}$

Poco nos queda de los comienzos de la épica latina: sólo unos 50 versos de la Odusia de Livio Andrónico, apenas 70 del Bellum Poenicum de Nevio ${ }^{98}$ y unos 600 fragmentos de los Annales de Ennio. Muy poco para hacernos una idea cabal de las obras, pero suficiente para vislumbrar ciertas características tendencias y gustos

\footnotetext{
${ }^{95}$ Whitmore, Ch. (1915), 101-103.

${ }^{96}$ Para una visión completamente diferente de estos pasajes y del rol de los fantasmas en general dentro de la obra de Séneca, cf. Rosenmeyer, Th. (1989), 83-84: "There is some truth in the proposition that Senecan drama is religious drama, in the sense that the presence of the gods is not only taken for granted but exploited for powerful end. For 'gods' we may also write 'demons'. With the exception of the fragmentary Phoenissae, all of Seneca's plays, including the spurious Octavia, have within them demons or, as we would call them, ghosts. In three of them, Troades, Medea and Oedipus, messengers report the appearance of ghosts; in three, Agamemnon, Thyestes and Octavia, a ghost or ghosts actually appear on the scene; and in one, Hercules Oetaeus, the voice of the hero at the end is that of a hero turned demon. It is true that many of these ghosts are revenant humans. [...] More properly, their horrific presence hints at the fundamental instability to which the world of Senecan drama is heir. Juno runs in her own person through all the changes of temper and of will that are subsequently exhibited in the violent turns of the hero's career. The ghost of Tantalus, in the prologue of Thyestes, embodies several contrary conceptions at war with one another. On the one hand, he is needed in the palace to initiate and preside over the crime (62ff.); on the other, he must not tarry (105-6) because otherwise the whole world will be dissecated with the thirst of which he is the mythological guarantor; and finally (95) he expresses a desire to stay and prevent the crime, a desire he is incapable of translating into action because he will not enter the palace", y 172 "Thus Octavia goes back to the techniques of Agamemnon, the prologue of which, spoken by Thyestes, 'explains' the crimes of the characters who are about to appear by an enumeration of the vices of their progenitors. The richer the inventory, the more forcible the impression that the personae of the present drama cannot help their viciousness." Cf. también Tarrant, R. (1985), 116.

${ }^{97}$ Vattimo, G. (2002), 84-85: "Filología significa para Nietzsche, ante todo, planteamiento del problema de nuestra relación con el pasado. Ahora bien, este problema está de algún modo en el fondo de todo desarrollo del pensamiento moderno, que no por casualidad culmina (y llega también a una inflexión decisiva) en las grandes doctrinas historicistas de los siglos XIX y XX."

${ }^{98}$ von Albrecht, M. (1997), 119 y ss.
} 
literarios y estéticos. La épica latina comienza con la Odusia de Livio Andrónico, en la cual ya pueden detectarse ciertos aspectos esenciales de la sensibilidad latina, pues no estamos ante una simple traducción. ${ }^{99}$ Las habituales críticas de "[...] comentaristas y editores del poema, sobre su exactitud o inexactitud, acierto o desacierto, elegancia o torpeza, etc., parten de ese incorrecto planteamiento del poema como mera traducción." ${ }^{\prime 100}$ Los romanos actualizan e interpretan de manera muy personal e innovadora los modos, métodos y estrategias de expresión helénicos y el material poético griego y automáticamente ponen sub veste Latina todas sus creaciones desde sus más tempranas manifestaciones. ${ }^{101}$

Nevio produce la primera épica histórica en su Bellum Poenicum, donde aúna la historia y el origen mítico de Roma. Este poema épico, escrito en saturnios, aun en su fragmentario estado de conservación, despliega claramente la actitud romana de la aemulatio, logrando apropiarse y reformular los logros artísticos griegos, agregando una profunda romanización tanto de contenido como de forma. ${ }^{102}$ Ennio, ${ }^{103}$ al igual que los autores anteriores (otra característica eminentemente romana) incursiona en variados géneros literarios (tragedia, comedia, sátira, etc.), pero su obra más importante son los dieciocho libros de los Annales. Este poeta es el primero en adoptar el hexámetro como medio de expresión y en enfrentar la dificultad de armonizar el ritmo natural del latín con la rigidez de este metro. Ovidio, resumiendo con gran precisión la imagen que de él tenían los poetas augusteos, lo llama Ennius ingenio maximus, arte rudis (Trist. II, 424) ${ }^{104}$ Lucrecio fue el primero en lograr una combinación radical de filosofía y épica y muestra también esta capacidad romana de reformular y renovar la tradición cultural. ${ }^{105}$ El propio Cicerón, a pesar del contenido epicúreo del De rerum natura, no dudaba en destacar el ingenium y el ars que caracterizan al poema. ${ }^{106}$

Poca justicia puede hacérsele a Virgilio en un espacio tan acotado, por lo que recurriremos a las certeras palabras de Jorge Luis Borges en su prólogo a Eneida:

"Una parábola de Leibniz nos propone dos bibliotecas: una de cien libros distintos, de distinto valor, otra de cien libros iguales todos perfectos. Es significativo que la última conste de cien Eneidas. Voltaire escribe que, si Virgilio es obra de Homero, éste fue de todas sus obras, la que le salió mejor. Diecisiete siglos duró en Europa la primacía de

\footnotetext{
${ }^{99}$ Goldberg, S. (2005), 430-431.

${ }^{100}$ Codoñer, C. (1997), 15.

101 von Albrecht, M. (1997), 79 y ss.

${ }^{102}$ Codoñer, C. (1997), 17-18.

103 von Albrecht, M. (1997), 130 y ss.

${ }^{104}$ Codoñer, C. (1997), 21-22.

105 Barrow, R. (1949), 147-150; Long, A. (2003), 194-196.

${ }^{106}$ Codoñer, C. (1997), 92.
} 
Virgilio; el movimiento romántico lo negó y casi lo borró. Ahora lo perjudica nuestra costumbre de leer los libros en función de la historia, no de la estética. La Eneida es el ejemplo más alto de lo que se ha dado en llamar, no sin algún desdén, la épica artificial, es decir la emprendida por un hombre, deliberadamente, no la que erigen, sin saberlo, las generaciones humanas. Virgilio se propuso una obra maestra; curiosamente la logró." 107

La obra de Virgilio está ligada inexorablemente a la época de Augusto, particularmente a las primeras décadas de su proyecto de pacificación y restauración de estado romano, i.e. la pax Augusta, del mismo modo que la obra de Séneca y Lucano, especialmente, reflejan los últimos años de la estirpe julio-claudiana.

En las últimas décadas, afortunadamente, surgieron numerosos estudios que retomaban la figura de Lucano y se acercaban al texto dejando de lado los criterios clásicos en busca de los criterios intrínsecos de esta obra contraclásica, violenta, desmesurada y, según muchos autores, nihilista. ${ }^{108}$ La radicalidad de las innovaciones lucanianas (su violenta y fracturada sintaxis, su original uso del material poético, la subversión y la confutación de los paradigmas constitutivos de su poética) ha generado acercamientos hermenéuticos muy originales. ${ }^{109}$ Los trabajos de Shadi Bartsch (1997), W. R. Johnson (1987) y Jamie Masters (1992), por nombrar algunos de los más influyentes, aplican al texto perspectivas deconstruccionistas con gran éxito y profundidad. ${ }^{110}$

\section{CRONOLOGÍA RELATIVA DE LAS TRAGEDIAS DE SÉNECA}

Las tragedias de Séneca presentan, además de las dificultades para su datación habituales en los autores antiguos, un particular celo en evitar referencias a cuestiones políticas o contemporáneas del autor. ${ }^{111} \mathrm{La}$ única evidencia clara sobre una fecha precisa de composición es un terminus ante quem sito en el año 54 d.C. para Hercules furens, gracias a la parodia que el propio autor hace de sus versos en la Apocolocyntosis. ${ }^{112}$ Los variados intentos de datar las obras a partir de supuestas

\footnotetext{
${ }^{107}$ Borges, J. (1996), 521.

108 Johnson, W. (1987); Sklenáŕ, R. (1999).

${ }^{109}$ La Fico Guzzo, M. (2012).

${ }^{110}$ Johnson, W. (1987); Bartsch, Sh. (1997), 6-8; Bartsch, Sh. (2005), 396; Narducci, E. (1999), 45 y ss.; Narducci, E. (2002), 22-23; La Fico Guzzo, M. (2012); Hunink, V. (1992), xxi.

${ }^{111}$ Ahl, F. (1986), 13-14; Töchterle, K. (1994), 44-48; Papadopoulou, Th. (2004), 278.

112 Existe actualmente un consenso generalizado entre los críticos sobre la pertenencia de esta obra al corpus senequiano, cf. Lund, A. (1994), 11 y ss.; Fitch, J. (1981), 289; Tarrant, R. (1995), 219-220; Nisbet, R. (2008), 348-349; Fantham, E. (1982), 10-14; Athanassakis, A. (1974), 11.
} 
alusiones a eventos históricos no han llegado a buen puerto y han sido, en general, desestimadas. ${ }^{113}$ Nisbet, sin embargo, propone un minucioso y casi microscópico análisis de las tragedias donde encuentra veladas referencias históricas, acepta el terminus ante quem del año 54 para Hercules Furens e incluso Troades y propone el período comprendido entre los años 49-54 como la fecha más probable de composición de la mayor parte de las tragedias. Sugiere, además, una fecha de composición tardía para Thyestes. $^{114}$

Careciendo de seguridades extratextuales, los estudiosos se han volcado a la búsqueda de evidencias intratextuales con variados resultados. ${ }^{115} \mathrm{John}$ Fitch, en su estudio "Sense-Pauses and Relative Dating in Seneca, Sophocles and Shakespeare", logra un claro avance en esta cuestión al proponer una datación relativa de las tragedias basada en específicos aspectos de estilo: el porcentaje de cambios de interlocutor que ocurren a mitad del verso, la incidencia de las unidades y las pausas de sentido revelan, según Fitch, el grado de fluidez y de confianza literaria con que el poeta maneja y despliega su estilo particular; ${ }^{116}$ analiza luego, para confirmar sus hipótesis, el tratamiento senequiano de la $o$ al final de palabra, cuya tendencia a acortarse se intensificó a mediados del siglo I d.C. Sus conclusiones tienen la ventaja de ofrecer una organización razonable de la obra trágica de Séneca agrupándola en tres períodos: ${ }^{117}$

- Tragedias tempranas: Oedipus, Phaedra y Agamemnon.

- Tragedias medias: Troades, Medea y Hercules furens.

- Tragedias tardías: Thyestes y Phoenissae.

\footnotetext{
113 Tarrant, R. (1976), 6.

${ }^{114}$ Nisbet, R. (2008), 370-371. Cabe destacar que el trabajo de Nisbet despliega una admirable erudición y un conocimiento histórico envidiable, pero ciertas conclusiones se basan en algunos a priori discutibles, como el suponer la agenda de Séneca en los últimos años de la década del 50: "It also makes sense if the plays were written when Seneca was Nero's tutor, and interested in the role of poetry in moral education; after 54 he might be too busy and too distinguished (for drama was a frivolity compared with philosophy)" (351), o cuestiones relativas a la sensibilidad particular de la época: "We should look not only for allusions to recent happenings but for remarks that would be implausibly tactless after a particular date." (350). Cf. también Narducci, E. (2002), 66-67.

${ }^{115}$ Fantham, E. (1982), 13-14.

${ }^{116}$ Fitch, J. (1981), 290- 292: “[...] the characteristic of the verse that they [i.e. the speaker changes within the lines] measure is presumably determined to a large extent by the poet's instinct [...] Seneca's use of antilabe at $A g$. 791-99 was the result of a conscious decision, but no one would suppose that he consciously decided to write a play with one third of all sense-pauses within the line; clearly he wrote in that way because it felt right and sounded right to him when composing, and it is not difficult to accept that that largely instinctive feeling would evolve over a period of time”. Cf. también Fantham, E. (1982), 14 .

${ }^{117}$ Fitch, J. (1981), 302- 303; Frank, M. (1995), 42-44; Nisbet, R. (2008), 356-357; Volk, K. (2006), 199 200.
} 
Distinta es la postura de K. Münscher, quien nos ofrece un riguroso análisis métrico y sugiere, al contrario, que es precisamente el incremento de la complejidad estructural el indicador a utilizar para la organización temporal de las tragedias, culminando con los complejos polimétricos de Agamemnon y Oedipus. ${ }^{118}$ Sin embargo, es un prejuicio biológico-positivista propio de la tradición decimonónica suponer que toda evolución ocurre necesariamente desde lo simple a lo complejo como si de organismos unicelulares se tratase. Esta concepción spenceriana revela también otro prejuicio operativo: ${ }^{119}$ que la complejidad esta únicamente ligada a la estructura y no a la red de interrelaciones inherentes al entramado textual. No por carecer de hipermetría el tercer estásimo de Thyestes es menos complejo que los furiosamente cambiantes coros de las tragedias tempranas, tal como veremos más adelante. La polimetría no es garantía de complejidad, sin embargo, como puede apreciarse en el himno a Baco de Oedipus. Si un formato estructural complejo está en consonancia con su contenido semántico y simbólico, el pasaje adquiere relevancia e importancia integrándose al desarrollo global de la obra.

\section{LUCANO, EL ELOGIO A NERÓN Y LOS FINALES POSIBLES DE PHARSALIA}

Raro es el lector que no se pregunta cómo hubiera concluido Lucano su poema, afirma Frederick Ahl en su trabajo Lucan. An introduction. Esta cuestión no es menor ya que numerosas interpretaciones de los diez libros que han llegado hasta nosotros han estado basadas primordialmente en la proyección, eminentemente ideológica, vislumbrada como cierre de este poema. ${ }^{120}$ Hay quienes sugieren que Pharsalia concluye donde concluye, es decir, con el abrupto final de las tropas cesarianas a punto de enfrentarse con su contraparte egipcia. ${ }^{121}$ Según Jamie Masters, en Poetry and Civil War in Lucan's Bellum Civile, no existen evidencias firmes, externas o internas, de que

\footnotetext{
${ }^{118}$ Fitch, J. (1981), 305. Cf. también Nisbet, R. (2008), 369: "Münscher used the metrical simplicity of the choruses of Thyestes as an argument for a very early; but though one may concede that the most complicated metrical systems were not the first to be attempted, that does not mean that all the plays can be neatly arranged in a sequence of increasing complexity."

${ }^{119}$ Ruse, M. (1980), 26: "Spencer saw everything -inorganic, organic, and human-, as subject to one and same law of evolutionary progress: a change from what he called the 'homogeneous' to the 'heterogeneous'. [...] This law of progress, which Spencer certainly seemed to think of as a necessary and in some sense end-directed (i.e. teleological), he saw as applying to every aspect of the human dimension."

${ }^{120}$ Ahl, F. (1976), 306 y ss.

${ }^{121}$ Masters, J. (1992), 216: "The best evidence for the intended ending of a poem is the place where it does, in fact, end"
} 
la obra esté inconclusa. Respecto de las evidencias externas, i.e. los testimonios de Tácito, Suetonio y Vacca, el trabajo concluye:

"So far, then, the combined witness of Tacitus and Suetonius, if no other evidence existed, would give us no reason to believe that the Bellum Civile was not completed some time before Lucan's suicide." ${ }^{122}$

\section{$[\ldots]$}

"From our examination of Suetonius and Vacca, we have managed to work with two hypothesis, depending on whether we believe Vacca to be a reliable source. The first hypothesis based only in Suetonius, is that the Bellum Civile might have been complete (or complete enough to read in public) before Nero's ban. The second hypothesis, based on Vacca in conjunction with Suetonius, is that part of the poem (perhaps three books) was published before the ban, and that the remainder, which (perhaps) had not received the poet's ultima manus, was published after his death. It does not matter yet which of these hypothesis is more likely. What is important is that in the sources presented so far, there is not a scrap of evidence to support a hypothesis that the poem failed to reach its planned conclusion." 123

Esta interpretación, absolutamente válida y minuciosamente argumentada, no resulta, sin embargo, concluyente, pues, tal como parece suceder en cualquier interpretación de la obra de Lucano, todo termina siendo una cuestión de énfasis e ideología. El propio Masters reconoce que los testimonios del Genethliacon Lucani (Silv. 2.7), de Estacio, deben ser tomados con la necesaria cautela que requiere el análisis de cualquier panegírico, pues "we are, let it be said, dealing with a poem, not a document." ${ }^{24}$ Sin embargo, cuando tratamos con documentos historiográficos antiguos, debemos considerar lo laxo y creativo que resultaba ser este género en la Antigüedad y resulta fundamental tener en cuenta que los propios biógrafos poseían agendas e intereses personales y políticos que se ven reflejados en sus textos. ${ }^{125}$ Además, como suele suceder cuando las hipótesis se basan en los testimonios de la Antigüedad, el punto de consenso entre los investigadores suele concluir con la certeza de que, en rigor, poco

\footnotetext{
${ }^{122}$ Masters, J. (1992), 218.

${ }^{123}$ Masters, J. (1992), 222-223.

${ }^{124}$ Masters, J. (1992), 223.

125 Taylor, M. (2010), 205-206: "Sir Ronald Syme observed that Tacitus was not just the exponent of a process of historical change but 'also an item in it, a personal document'. Likewise Seneca, whose dramatic and philosophical writings defined the literature of the Julio-Claudian age, was himself implicated in the world they so richly represented. [...] But for the purpose of this paper I propose to examine how this symbiosis of auctor and actor functions in the opposite direction: that is, to consider how Seneca's identity as a writer -'the embodiment of an epoch'. As Syme described it- has generic and thematic implications within the historical world constructed by Tacitus. There is by now a prevailing consensus that this world is replete with references to the language and subject matter of tragedy, references which encourages the reader to understand the Julio Claudian dynasty as an entity belonging more to a genre than to history, and which emphasize the performative nature of Imperial political life. Syme himself recognized that the elaboration of Seneca as a character in the Annals offers a clear signpost to this particular element of Tacitus's historiographical agenda."
} 
puede probarse fehacientemente utilizándolos. Los biógrafos antiguos no consideraban descabellado intercalar anécdotas, eventos o situaciones ficticias si esto ayudaba a la representación del sujeto de acuerdo a la concepción que de éste deseaban transmitir: ${ }^{126}$

"Dihle has shown how greatly the classical biographies has been defined by Aristotle's view about relationship between someone's Práxis ('deeds') and his êthos ('character'). In this interpretation the human qualities do not just show up in the deeds; they are the result of the deeds: 'Nicht an die Handlungen wird sie zugroundeliegende Eigenschaft erkannt (...), sondern durch das Handeln im Sinne einer bestimmten Eigenart wird diese überhaupt erst konstituiert' (Dihle, A. (1954), 61) [...] This technique of the 'Charakterisierung durch Fakten' is also very notable in the Roman biographies of emperors.", 127

Respecto de las evidencias internas que podrían presagiar el final vislumbrado por el poeta, es importante señalar que nuevamente prima la ideología por sobre la casuística en la interpretación de las mismas. ${ }^{128}$ El poema consta de diez libros, de los cuales los dos últimos presentan características particulares que los diferencian del resto. El libro IX, que narra las acciones de Catón en Libia y contiene el famoso pasaje del combate con las serpientes, resulta excesivamente extenso: unos 308 versos más largo que el promedio de los ocho libros anteriores, ${ }^{129}$ mientras que el libro diez, donde se cuentan las acciones de César en Troya y Alejandría, termina abruptamente en el verso 546. ${ }^{130}$ Más allá de cualquier entelequia respecto del estilo de escritura de Lucano, su velocidad y/o su metodología de corrección, ${ }^{131}$ es innegable que los dos últimos libros presentan una forma diferente a la de los libros anteriores.

Los profesores Haffter y Schremp sostienen que el poema termina casi exactamente en el mismo punto en que César cierra su comentario sobre la Guerra Civil y que, además, es poco probable que el poema continúe luego de la muerte de Pompeyo Magno. La última hipótesis es refutada por el propio poema, que de hecho sí continúa luego de la muerte del general. Esta interpretación tiene la virtud de destacar el uso que hace Lucano de los escritos cesarianos, pero no considera relevante la precisa operación discursiva que implica la finalización de Bello Civili en ese punto en particular:

\footnotetext{
${ }^{126}$ Rose, K. (1966), 379: “The ancient evidence for Lucan's life, and for dating of his various writings, have been examined many times by scholars; but the usual judgment has been that the evidence is not only excessively scanty but also unreliable."; Mellor, R. (1999) sobre Tácito cf. 76, 88-92 \&105-109; sobre Suetonio cf. $149 \& 152-156$.

${ }^{127}$ Burgersdijk, D. \& van Vaarden, J. (2010), 86-87.

${ }^{128}$ Ahl, F. (1976), 306.

${ }^{129}$ El promedio de versos de los primeros ocho libros es de poco más de 800 versos. (800.75 para ser exactos). Cada libro presenta la siguiente cantidad de versos: Libro I, 695, L.II, 736, L. III, 762, L. IV, 824, L. V, 815, L. VI, 830, L. VII, 872, L. VIII, 872, L. IX, 1108, L. X, 546.

${ }^{130}$ Spencer, D. (2005), 66.

${ }^{131}$ Rose, K. (1966), 381-384.
} 
precisamente el fin de la Guerra Civil, lo cual le permite al general representar los conflictos posteriores (Munda y Tapso) como conflictos con fuerzas extranjeras y, por lo tanto, legítimos y dignos de triumpha. ${ }^{132}$

En cuanto a la evidencia interna, Masters destaca algunos elementos verdaderamente relevantes para la interpretación moderna de este poema en verdad vanguardista. En primer lugar y con gran precisión, cuestiona la relevancia y la pertinencia de los ideales aristotélicos y de las supuestas prescripciones del género épico para la interpretación y evaluación de Pharsalia. ${ }^{133}$ En segundo lugar destaca como característica pervasiva y constante a lo largo del poema la imposibilidad de cierre o fin definitivo y la inaprehensibilidad constante del signo poético gracias a las operaciones del lenguaje sobre éste:

"For the civil war can have no ending. Everything about the war and the poem is boundless, illimitable, infinite. Caesar's ambition, nil actum credens cum quid superesset agendum; Pompey's tomb, which spatially confines him to a few feet of earth, but by a trick of rhetoric expands over the whole world; the enormity of nefas in which the whole universe participates the grotesque repetitiveness of the series of civil wars that go on and on over the same ground ad nauseam. To treat all of this in its entirety - in any case an impossible task- to gather everything into the form of completeness, would be to contain and limit what must, in Lucan's terms, be uncontainable." 134

El poema no podría resolverse porque la resolución en sí misma implicaría una contradictio terminis con el desarrollo propuesto en el plano diegético: la lucha, aunque perdida, se revela eterna - sed par quod semper habemus/ libertas et Caesar, erit (LUC. VIII, 695-696). ${ }^{135}$ El propio poeta se niega, durante la batalla de Farsalia, a narrar el horror (LUC. VII, 552-554) pero, pese a sus palabras, sigue adelante y describe con lujo de detalles los horrores subsiguientes (LUC. VII, 555 y ss.). Lucano comparte con Séneca y exacerba esa fascinación casi esquizofrénica de narrar minuciosa y puntillosamente aquello que se execra. ${ }^{136}$ Esta fascinación no responde a un deseo morboso por estos temas, más bien implica todo lo contrario: es una profunda y valiente

132 Ahl, F. (1976), 307-308; Raaflaub, K. (2009), 175-176 \& 189-190; Masters, J. (1992), 244-247. Masters, sin embargo, adhiere, como hemos comentado, a la hipótesis de que el poema termina en el verso 546 del libro X, pero por distintos motivos (Vid. Infra.).

${ }^{133}$ Masters, J. (1992), 248-249: "So what is at issue here is not the question of whether or not the text literally 'breaks off', which it clearly does not, but whether the poem is felt to have an ending that is, in a broader sense, smooth, rounded, satisfying; whether, to use Rutz's terms, the poem fits into the Aristotelian mold of the hóle kai teleía prâxis. But this, exactly this, should sound the warning note. Is the Aristotelian ideal relevant here at all?" \& 250: "Genre is nothing more or less than imitatio on a grand scale; and this has some profound implications. For built into the practice of imitatio is the requirement of deviation, subversion, change. In other words, genre is not prescriptive; it is a challenge."

${ }^{134}$ Masters, J. (1992), 251.

${ }^{135}$ Ahl, F. (1976), 314-315.

${ }^{136}$ Frank, M. (1995), 30. 
inquisición sobre los aspectos más paradójicos, espinosos y quizás absurdos del estoicismo y de la angustiante situación existencial del individuo arrojado a un mundo absurdo e inadecuado. ${ }^{137}$

Existe, sin embargo, una realidad que debemos tener en cuenta todos aquellos que pergeñamos hipótesis y finales para las grandes obras inconclusas de la historia de la literatura: los académicos sólo podemos trabajar con aquello que los caprichos de la historia nos ofrecen. Si una obra como la Eneida nos hubiera llegado con un grado menor de compleción y nos faltasen los libros XI y XII, o incluso sólo el XII, no nos parece arriesgado afirmar que ningún erudito a lo largo de la toda la historia de la crítica hubiese propuesto como cierre a Eneas furioso enterrando su espada en un Turno indefenso y el alma de éste deslizándose indignada hacia las sombras. La visión posmoderna de infinitud o endlessness muestra hasta qué punto Lucano es permeable a este tipo de lecturas e interpretaciones contemporáneas, pero más allá de los caprichos de la historia el poema habría de terminar en algún punto. Cómo hubiera tratado Lucano este final, no lo sabremos jamás, pero las especulaciones sobre qué punto de la historia hubiese elegido sí resultan, al menos, válidas desde nuestra perspectiva académica. Los momentos históricos que más consenso cosechan en la crítica son la batalla de Actium, el asesinato de César y el suicidio de Catón. Actium es la hipótesis que mayores problemas presenta: en primer lugar el arco temporal que implica resulta excesivo y, además, si bien esta batalla representó el fin de la sucesión de guerras civiles que azotaban a Roma, al mismo tiempo significa la instauración y la llegada de la pax Augusta. Sin embargo, esta paz, tal como lo profetiza Nigídio Fígulo en el libro primero de Pharsalia, trae consigo un amo: ${ }^{138}$

cum domino pax ista uenit. duc, Roma, malorum continuam seriem clademque in tempora multa extrahe ciuili tantum iam libera bello.

(LUC. I, 670-672)

Con un amo llega esta paz. ¡Prolonga, Roma, esta serie incesante de males y extiende por mucho tiempo la destrucción (serás) libre en tanto dure ya la guerra civil!

El asesinato de César o el suicidio de Catón son dos puntos de la historia que resultan, al menos desde nuestra perspectiva, plausibles. ${ }^{139}$ El asesinato de César, sin

\footnotetext{
${ }^{137}$ Rosenmeyer, Th. (1989), 79; Sklenáŕ, R. (1990), 281-283 \& 285 y ss. Masters, J. (1992), 247 y ss.

${ }^{138}$ Ahl, F. (1976), 308-315; Narducci, E. (1979), 42-43.

${ }^{139}$ Leigh, M. (2009), 242.
} 
embargo, parece un final demasiado optimista ya que crearía la ilusión de que es posible vencer el avance histórico encarnado en la figura de César:

"If the epic were to end, as the Aeneid does, with the striking of the fatal blow [to Caesar], some part of the historical irony would be shorn away. It might then seem to be a vindication of libertas, if only for a delusive instant. But such an ending would create the illusion that Caesarianism too had been struck down, which is neither historically correct nor consistent with Lucan's emphasis on the continuing struggle between Caesar and libertas."

El suicidio de Catón, por su parte, resulta ser, tal como veremos más adelante, un acto fundacional para la sociedad romana, instaurándose como el modelo por excelencia para la voluntaria mors $^{141}$ y se destaca del resto de las posibilidades conjeturadas por la profunda identificación que se instaura a lo largo de todo el poema entre la figura del senador republicano y el ideal de la libertas. Resulta plausible, entonces, una épica de doce libros cuya culminación sería el suicidio de Catón. ${ }^{142}$

Creemos que el elogio de Nerón es otro pasaje que, probablemente por ser el único locus del poema donde se menciona explícitamente al emperador, ha llamado poderosamente la atención de los críticos y exégetas del poema y ha generado, además, las más variadas y numerosas interpretaciones. Estas abarcan todo el espectro actitudinal posible, desde la más sincera y honesta admiración al emperador hasta diversas interpretaciones marcadamente irónicas y paródicas, pasando por posturas que abogan por considerarlo incluso un pasaje convencional y artificioso. ${ }^{143}$ Respecto de los problemas de detectar, o interpretar, una ironía, dice Linda Hutcheon:

"The major players in the ironic game are indeed the interpreter and the ironist. The interpreter may -or may not- be the intended addressee of the ironist's utterance, but $\mathrm{s} /$ he (by definition) is the one who attributes irony and then interprets it: in other words, the one who decides whether the utterance is ironic (or not), and then what particular ironic meaning it might have. This process occurs regardless of the intentions of the ironist (and makes me wonder who really should be designated the 'ironist'). This is why irony is 'risky business' (Fish 1983:176): there are no guarantee that the interpreter will 'get' the irony in the same way as it was intended. In fact, 'get' may be an inaccurate and even inappropriate verb: 'make' would be much more precise."144

\footnotetext{
${ }^{140}$ Ahl, F. (1976), 318-319.

${ }^{141}$ Griffin, M. (1986b), 195: "It was the way in which the younger Cato chose to stage his end and the way in which others celebrated it thereafter that explain why political opponents of the Emperors, who were ordered to kill themselves or even were actually executed, came to be thought of, and probably thought of themselves, as following the great Stoic Cato in his death." También 198: "[...] philosophy, again via Cato, helped to provide the etiquette and style for suicide."

${ }_{142}$ Ahl, F. (1976), 320-326.

143 Ahl, F. (1976), 47-49 \& 333 y ss.; Brena, F. (1988), 134-137; Gresseth, G. (1957), 26; Holmes, N. (1999), 75-76 \& 80-81; Hunink, V. (1992), xiii (nota 1), Heitland, W. (1971), xxxvii-xlii; Bartsch, Sh. (2005), 501-502.

${ }^{144}$ Hutcheon, L. (1994), 11.
} 
Dada la clara posición anticesariana que despliega el poeta a lo largo de la épica, no es descabellado considerar una actitud hostil por parte de éste hacia el emperador; sin embargo existen indicios fehacientes sobre una etapa temprana de composición en la cual la relación entre Lucano y Nerón no se había deteriorado aún y que permitiría suponer una actitud de sincera admiración en esta parte de la obra. ${ }^{145}$

El elogio a Nerón es quizás el primer momento en el cual Lucano somete al lector a una novedosa operación de lectura que será una de las constantes innovaciones del poema. La ironía convive con el posible elogio y el lector se ve forzado a tomar una decisión efectiva y operativa respecto de los significantes que el texto le ofrece: ${ }^{146}$

Esta decisión es violenta en tanto anula la opción descartada: así como Borges proponía el derrotero del autor a través de un jardín de senderos que se bifurcan, Lucano, como gran innovador y precursor que es de muchos conceptos literarios y filosóficos del siglo $\mathrm{XX},{ }^{147}$ pone al lector ante esta disyuntiva semiótica e ideológica obligándolo, ${ }^{148}$ en cierta manera, a "abrirse camino con la ruina" ${ }^{149}$ La coexistencia de significados polémicos para un solo significante fuerza a este lector devenido cesariano a privilegiar sólo uno de los significados posibles. Incluso, aun si el lector intenta llevar a cabo una operación de lectura forzada que mantenga la existencia simultánea de ambos significados, esto representa, de cualquier manera, una decisión ideológica efectiva.

Tan poderosamente operativo es este procedimiento poético que el lector no sólo se ve enfrentado a diversas opciones a nivel sígnico, sino que también debe privilegiar, de acuerdo a su ideología particular, cómo funcionan ciertos elementos específicos y significativos a nivel sintáctico:

his Caesar Perusina fames Mutinaeque labores accedant fatis et quas premit aspera classes Leucas et ardenti seruilia bella sub Aetna, multum Roma tamen debet ciuilibus armis quod tibi res acta est.

(LUC. I, 41-45)

\footnotetext{
${ }^{145}$ Ahl, F. (1976), 40-44; Masters, J. (1992), 216 y ss.

${ }^{146}$ Vieira, B. (2011), 37-39.

${ }^{147}$ Nos referimos, por supuesto, a Lucano como precursor siguiendo la idea que J. L. Borges propone en su cuento “Kafka y sus precursores”. Respecto a este tema, cf. Sklenár, R. (2003), 1: "His [Lucan's] rehabilitation in the classical cannon, moreover, results in part from the ability of the reader whose own tradition includes Kafka and Beckett to appreciate the nihilism of Lucan's art"; Rudich, V. (1997), 107.

${ }^{148}$ Es una constante en la obra de Lucano las intrusiones del narrador en el devenir diegético del poema, forzando a la audiencia y/o al lector a participar y ser "cómplice" de las acciones criminales descriptas, cf. Asso, P. (2009), 161-163 \&172-173.

${ }_{149}$ Lucano, Pharsalia, I, 150. Sobre la asimilación de la figura de César, de Atreo y la del poeta, cf. Leigh, M. (2009), 243, 247-248 \& 250.
} 
A estas fatalidades se añadan [,] César, el hambre de Perusa

los desastres de Mútina y las flotas que oprimen la áspera

Leucas y las guerras serviles bajo el Etna ardiente,

sin embargo, mucho debe Roma a las armas civiles,

pues por ti se llevaron a cabo.

¿Cómo debe leerse el signo Caesar? ¿Es, como afirman algunos críticos, inequívoca e inexorablemente vocativo? ${ }^{150}$ ¿O podemos interpretar sin menoscabar el rigor sintáctico el signo Caesar como nominativo y agregar así a César como el primer eslabón en la turbulenta serie de catástrofes que azotaron Roma? Estamos ante una encrucijada semiótica cuya respuesta está íntimamente ligada a una posición y a una decisión ideológica, tal como dijimos anteriormente. El elogio al emperador es el primer momento de la obra donde el lector es forzado a compartir y ejercer la violencia simbólica y semiótica omnipresente en el entramado textual. ${ }^{151}$

En los versos siguientes continúa este procedimiento discursivo aunque de un modo menos violento, aludiendo y trastrocando el elogio virgiliano de Geórgicas I, 2439. ${ }^{152}$ La ambivalencia sígnica oscila entre la posibilidad de interpretación encomiosa o irónica, haciendo, o no, veladas referencias a los defectos físicos de Nerón y relacionando éstas con la posición que el emperador tomará en el alto éter (LUC. I, 45 y ss.). ${ }^{153}$ Sin embargo el mayor obstáculo para la interpretación de este pasaje es considerarlo de manera estanca respecto del desarrollo general del poema, pues la operación discursiva efectuada por Lucano sobre el signo poético y sobre la relación significante/ significado apenas ha comenzado a alterar la relación interna entre estos. A lo largo de nuestro trabajo demostraremos cómo y dónde ocurre esto. Ciertos signos, que en el contexto de los primeros versos del poema parecerían aceptar una interpretación convencional de los significantes y sus respectivos significados, ven sus relaciones internas alteradas radicalmente por las operaciones poéticas que subvierten los paradigmas poéticos y filosóficos que, en principio, son los elementos constitutivos e inherentes a su naturaleza. ${ }^{154}$

\footnotetext{
${ }^{150}$ Getty, R. (1979), 33; Holmes, N. (1999), 78.

151 Littlewood, C. (2004), 26-27: “This moral confusion of crime and virtue, promised in the epic's second line (iusque datum sceleri canimus, and legality conferred to crime we sing) is part of a wider phenomenon of rhetorical damage. Chaotic language mimics the chaos of civil war and thus taints its user"

${ }^{152}$ Holmes, N. (1999), 78 -79, defiende un uso no subversor del modelo virgiliano.

153 Particularmente LUC. I, 52-57, Getty, R. (1979), 35-36; Narducci, E. (1979), 21-23; Narducci, E. (2002), 22-23.

${ }^{154}$ Bartsch, Sh.(1997), 25; Sklenáŕ, R. (2003), passim.
} 
Los estoicos desarrollaron una doctrina de los signos que anticipó muchos aspectos de la teoría saussureana. Las operaciones lucanianas sobre el signo someten a las partes de éste a tensiones múltiples que deben ser resueltas por una operación de lectura ideológica y efectiva en la cual, como en los procesos de anamorfosis, la posición elegida por el lector define las relaciones sígnicas que, por ende, son relevantes en el nivel hermenéutico de interpretación. A medida que avanza el poema comienza a revelarse cierta naturaleza inestable del signo, producto de las operaciones discursivas que el poema ejerce sobre éste. Esta es otra de las profundas operaciones discursivas que Lucano lleva a cabo sobre los paradigmas constitutivos de su poética, en este caso subvirtiendo la doctrina estoica de los signos:

"The Stoics distinguished four elements of the signs: the sêmaion, or signifier; the sêmainomenon, or signified; the tynkhanon, or external object/referent; and the lekton, or 'thing said', 'statement'. The Stoic theory of the sign thus anticipates that of Saussure in many respects, with one crucial difference: for the Stoics, arbitrariness in the signification manifest itself only so far as the connection between the first and third elements cannot be understood except by a speaker of the language to which sêmaion (as spoken word) belongs, and, obviously, the lekton depends on the connection. What is important is that the connection is always there, even if unperceived. Of course, Stoicism, in his extreme rationalism, cannot admit the doctrine of the floating signifier: in a rational universe, the various elements of the sign must add up; if a sign is incomprehensible to me, it is because my understanding is inadequate, not because the sign's element are out of joint. To which Lucan opposes a complete arbitrariness of the signifier, a linguistics in which the same chaos that governs the universe also governs the relation between sêmaion and semainomenon." 155

La mayoría de los significantes que operan en el elogio aceptan, a esta altura de la obra, tanto acepciones positivas como negativas o irónicas. Sin embargo el desarrollo posterior del poema y el proceso de anamorfosis sígnica que se lleva a cabo en el entramado textual alterarán radicalmente la relación entre el significante y el significado y la función hermenéutica de estos. Los significantes mercede (I, 38), numen (I, 50 \& 63) o $\operatorname{pax}(\mathrm{I}, 61)$ se verán alterados por completo. ${ }^{156}$ Veamos, por ejemplo, los siguientes versos:

sed (quis erit nobis lucri pudor?) inde petuntur huc Libycae mortes et fecimus aspida mercem".

(LUC. IX, 706-707)

pero, (¿cuándo tendremos vergüenza del lucro?) hacia aquí solicitan, desde allí, las muertes de Libia y hemos transformado a las áspides en mercancías.

\footnotetext{
${ }^{155}$ Sklenár̆, R. (2003), 10.

${ }^{156}$ Leigh, M. (2009), 249-250.
} 
La disolución de los valores y los paradigmas romanos ha convertido a las cosas más ponzoñosas y nocivas en una mercem, la pax missa per orbem (LUC. I, 61) pierde todo matiz positivo, como señalamos anteriormente, en el momento en que Fígulo hace su profecía (LUC. I, 670-672). Los signos que al comienzo de la obra se encontraban en un estado de equilibrio comienzan a verse empujados hacia un estado de inestabilidad y entropía superiores a medida que la relación significante/significado se disuelve y se vuelve difusa dentro de esta batalla semántica que Lucano establece al nivel del signo y que implica, necesariamente, al lector.

Pero quizás la clave más importante para la interpretación de este pasaje se encuentre en los versos finales del elogio: ${ }^{157}$

sed mihi iam numen; nec, si te pectore uates accipio, Cirrhaea uelim secreta mouentem sollicitare deum Bacchumque auertere Nysa: tu satis ad uires Romana in carmina dandas.

(LUC. I, 63-66)

Pero para mí ya eres una divinidad, y no querría, si te recibo como vate en mi pecho, perturbar al dios que mueve los misterios de Cirra ni alejar a Baco de Nysa: tú bastas para darme las fuerzas necesarias para un canto Romano.

Nerón, ante quien todo numen cederá su lugar y ante cuyo derecho la Naturaleza ofrecerá la posibilidad de elegir qué clase de deus querrá ser (I, 50-52), es elogiado con gran refinamiento y precisión: para el poeta el emperador ya es un dios que supera incluso a Apolo y a Baco, deidades con las que Nerón gustaba ser asociado ${ }^{158}$ e incluso aparece un sutil homenaje etimológico en el uso de vires, ya que según nos dice Suetonio, Nero, significaba, en lengua sabina, fortis ac strenuus. ${ }^{159}$ ¿Cómo conciliar este elegante pasaje con las afirmaciones que el poeta hará en los libros posteriores?:

sunt nobis nulla profecto

numina: cum caeco rapiantur saecula casu, mentimur regnare Iouem.

(LUC. VII, 445-447)

$[\ldots]$ sunt curata deo

mortalia nulli

(LUC. VII, 454-55)

En verdad no existe para nosotros divinidad alguna: puesto que las generaciones son arrastradas por el ciego azar, nos mentimos diciendo que Júpiter gobierna el universo.

$[\ldots]$

Ningún dios tiene

\footnotetext{
${ }^{157}$ Narducci, E. (1979), 25.

${ }^{158}$ Narducci, E. (2002), 26-28; Champlim, E. (2003), 275-276 \& 282; von Albrecht, M. (1997), 907.

${ }^{159}$ Suetonio, Tiberius, I, 1.
} 
preocupaciones mortales.

Muchos exégetas, situados firmemente en el a priori de considerar a Lucano como un severo estoico, han intentado armonizar estos dicta iconoclásticos con el pensamiento estoico. ${ }^{160}$ Por supuesto que estaríamos volviéndonos contra nuestra propuesta de lectura si impusiéramos lecturas unívocas e inequívocas al inestable y evasivo entramado poético de Lucano, ${ }^{161}$ pero es claro que, según estos versos, no hay dioses o, en el mejor de los casos, si estos existen son, como mínimo, indiferentes a los asuntos humanos. ${ }^{162}$ Por lo tanto, a medida que avanzamos en el texto y las relaciones entre los significantes y los varios significados que orbitan en torno a ellos se ven alterados y problematizados, el encomio opera coherentemente en relación con la propuesta estética de ambigüedad y existencia simultánea de significados polémicos cuya interpretación obliga al receptor a elegir uno de ellos en detrimento del otro, destruyendo inexorablemente la posibilidad de interpretación contraria y forzando una operación de lectura que implica en su proceso la ideología del receptor. La guerra intestina que azota Roma se proyecta no sólo a nivel cósmico ${ }^{163}$ sino también a nivel semiótico, operando en el corazón mismo del signo y generando la convivencia violenta de varios significados para un mismo significante.

Esta espinosa cuestión puede resolverse, entonces, si cambiamos la perspectiva de abordaje al texto ${ }^{164}$ y nos desentendemos de cuestiones e hipótesis subjetivas e incomprobables tales como el grado de sinceridad o el estado anímico de un poeta muerto hace casi dos mil años. ${ }^{165}$ Desde nuestra perspectiva hermenéutica no resulta relevante, entonces, la cuestión actitudinal del autor al momento de composición o

\footnotetext{
${ }^{160}$ Feeney, D. (1991), 284: “Lucan maintains Stoicism's beliefs in providential government of the natural world; the absence of divine regulation of human affairs is an exposed exception to a comprehensive system."

${ }^{161}$ Littlewood, C. (2004), 28: "It would be a mistake to insist on a single interpretation in the epic's moral rhetoric."

${ }^{162}$ Feeney, D. (1991), 282: "the gods exist, but have no care for human affairs, and events in the world are therefore random chance". Cf. también Sklenář, R. (2003), 8-9.

${ }^{163}$ Lapidge, M. (1979), 360 y ss.

${ }^{164}$ Brena, F. (1988), 136: "L'analisi di questi versi, superate le ipoteche del biografismo, dovrebbe in primo luogo individuare i tratti pertinenti con il percorso concettuale sviluppato nel resto dell'opera"

165 Este tipo de afirmaciones e interpretaciones presentan un problema hermenéutico clave: nunca abandonan, en realidad, el ámbito de una Glaube y la creencia personal por más que los argumentos suelen ser en verdad eruditos y extensivos (Holmes, N. (1999)). Sabemos, a partir de los testimonios de las vitae, que existió un alejamiento entre el poeta y el emperador y que Lucano se unió a la conjura de los Pisones, acto que finalmente le costó la vida (Gresseth, G. (1957)), pero está fuera de nuestras posibilidades cognitivas afirmar qué sintió o pensó Lucano en tanto individuo particular en determinados momentos específicos de su vida. Sin embargo, sí podemos analizar el texto que nos dejó y nos es lícito plantear hipótesis sobre éste, cf. Masters, J. (1992), 217-219 \& Ahl, F. (1976), 36-38.
} 
exposición del elogio, sino el modo de operar de este pasaje dentro de una obra que se vuelve constantemente sobre sí misma para resignificarse y retroalimentarse de sus propios procedimientos literarios. 
HIPÓTESIS Y OBJETIVOS DEL TRABAJO

En nuestro trabajo intentamos, entonces, comprender y detectar los rasgos estéticos y las características estructurales que operan dentro de los entramados textuales donde son construidos y que, al mismo tiempo, ayudan a construir. Afirma Hans- Georg Gadamer en "El Texto Eminente y su verdad":

\begin{abstract}
"Pero el texto con configuración literaria es un texto en un sentido todavía más elevado, y a esto corresponde que la interpretación de configuraciones poéticas sea 'interpretación' en un sentido eminente. Mi tesis es que la interpretación está esencialmente e inseparablemente unida al texto poético precisamente porque el texto poético nunca puede ser agotado transformándolo en conceptos. Nadie puede leer una poesía sin que en su comprensión penetre siempre algo más, y esto implica interpretar. Leer es interpretar, y la interpretación no es otra cosa que la ejecución articulada de la lectura. Por consiguiente el 'texto' no es aquí un dato fijo al que, al final, tengan que retrotraerse el lector y el intérprete. El texto eminente es una configuración consistente, autónoma, que requiere ser continua y constantemente releída, aunque siempre haya sido antes comprendido." 166
\end{abstract}

Un texto como tal ofrece siempre infinitas posibilidades de lectura; una lectura se concreta en la medida en que se eligen presupuestos, es decir, una perspectiva definida y clara que ofrezca una descripción coherente con aquello de que se habla. ${ }^{167}$ Es importante tener en cuenta que no existe la objetividad inmediata de los hechos, sino que se debe aspirar a la coherencia de la perspectiva propuesta para interrogar y dialogar con las obras. ${ }^{168}$

El lector atento notará que el análisis de ciertos pasajes específicos será recurrente en nuestra argumentación. Esto se debe a una meditada elección hermenéutica efectiva: la complejidad y el espesor semántico de estos pasajes permite que sean abordados desde diferentes perspectivas de análisis. Los pasajes fueron seleccionados precisamente porque hemos detectado que los procesos de anamorfosis sígnica resultan particularmente operativos en ellos y su densidad hermenéutica revela la polivalencia de los significantes que los constituyen. Las operaciones de representación y subversión simultánea de diversos paradigmas rectores del entramado poético tanto en la tragedia de Séneca como en la épica de Lucano ofrecen numerosas y

\footnotetext{
${ }^{166}$ Gadamer, H-G. (1998), 100-101.

${ }^{167}$ Cf. Vattimo, G. (2002), 90.

${ }^{168}$ Calabrese, O. (1989), 22-24.
} 
variadas posibilidades de abordaje, dependiendo del énfasis hermenéutico con el que nos acerquemos a ellos.

La tragedia senequiana despliega originales e innovadoras estrategias de representación y subversión de los paradigmas estéticos, filosóficos y literarios que problematizan los métodos y las estrategias de subjetivación del sujeto y construcción del yo utilizados por el sapiens y recomendados al proficiens, tales como las técnicas de sí y la concepción espectacular de las acciones. ${ }^{169}$ A través de diferentes estrategias y métodos de representación expresionistas y barrocos las tragedias despliegan espectáculos horrorosos y grotescos que perturban y confutan la sólida y optimista cosmovisión estoica y desestabilizan los presupuestos de esta doctrina en tanto Weltanschauung. Lucano, por su parte, toma estas estrategias y procedimientos de representación presentes en el entramado trágico y, apropiándoselos, los exacerba y radicaliza, tanto en lo literario como en lo filosófico. Lucano crea una verdadera machina discors discursiva, ${ }^{170}$ un verdadero Einstürzende Neubauten literario, ${ }^{171}$ una novedosa construcción literaria que a medida que es construida y desplegada va confutando los propios elementos y paradigmas rectores que la constituyen en tanto constructo poético.

Lucano, en cierta manera, deconstruye el género épico y la tradición que lo sostiene ${ }^{172}$ y subvierte en ese proceso los valores fundantes de Roma y del vir Romanus, principalmente la virtus y la pietas. A través de diversas estrategias discursivas y de distintos procedimientos poéticos, presentes en la obra trágica de Séneca y exacerbados por Lucano, se difumina la estructura interna del signo y las relaciones significante/significado se vuelven difusas y polémicas, pues el significado primigenio se ve metamorfoseado en varios nuevos significados que no pueden convivir en el mismo ámbito sígnico y cuya inestabilidad semiótica debe ser resuelta por la intervención necesaria del lector.

\footnotetext{
${ }^{169}$ Las técnicas de sí pueden definirse, según Foucault, como “[...] prácticas meditadas y voluntarias mediante las cuales los hombres no sólo se fijan reglas de conducta, sino que procuran transformarse a sí mismos, modificarse en su ser singular y hacer de su vida una obra." Cf. Foucault, M. (1983), 237; Foucault, M. (1994), 545. Trataremos en profundidad este tema en la sección 'SÉNECA y FouCAULT' y 'LAS TÉCNICAS DE Sí', pertenecientes a la primera parte de nuestro trabajo, REPRESENTACIÓN DE LOS PARADIGMAS FILOSÓFICOS.

${ }^{170}$ Johnson, W. (1987), 14 y ss.

${ }^{171}$ Bartsch, Sh. (2005), 495; Johnson, W. (1987), x: “The Pharsalia is, in Santayana's words, omnimodal: it has no privileged center except for the energetic, bitter, and witty skepticism that devotes itself to demolishing the structures it erects as fast as it erects them."

${ }^{172}$ La Fico Guzzo, Ma. L. (2012), passim.
} 
En la introducción de nuestro trabajo hemos realizado un recorrido por el status quaestionis de los estudios sobre Séneca y Lucano, señalando nuestra posición hermenéutica e indicando la línea interpretativa de los autores que seguimos y en los que nos apoyamos. En el segundo apartado de la Introducción, explicitamos ciertas herramientas de interpretación que son funcionales y operativas a lo largo el trabajo.

La primera parte de nuestra exposición consta de cinco apartados en los cuales analizamos cómo los paradigmas filosóficos -principalmente el estoico-, que constituyen el sustrato y que otorgan cohesión al entramado textual, se ven subvertidos y desestabilizados a través de las innovadoras operaciones poéticas de nuestros autores. A lo largo de nuestra exposición destacamos cómo estos procedimientos, presentes y operativos en la tragedia de Séneca, son retomados y exacerbados por Lucano en su épica, produciéndose entonces una relación de formación (Séneca) y consolidación (Lucano) poética. Los apartados que cierran esta primera parte ofician de transición entre el análisis de la representación de los paradigmas literarios y de los filosóficos, pues presentan una yuxtaposición efectiva de estos paradigmas. En ellos analizamos conceptos tales como la sympátheia tôn holôn, la virtus y la representación y naturaleza de los dioses, aspectos que se apoyan simultáneamente en ambos paradigmas. El proceso de anamorfosis y disolución sígnica de conceptos como la virtus y la pietas repercuten, a través de la sympátheia tôn holôn, en la integridad física del cuerpo social e individual. Por otro lado, las estrategias de representación del aparato divino y de las diversas naturalezas de los dioses, tanto en la tragedia de Séneca como en la épica de Lucano, involucran cuestiones que pertenecen simultáneamente a ambos paradigmas, por lo que decidimos ubicar estos apartados cerrando la primera parte y oficiando de transición hacia la segunda.

La segunda parte trata sobre las estrategias de representación de los distintos paradigmas literarios subvertidos por nuestros autores. La primera sección se enfoca en la estrecha y compleja relación entre la épica y la historia. Nos concentramos en el particular uso que Lucano hace de sus fuentes, que actúan como paradigmas histórico/ literarios y que son reformuladas y subvertidas a lo largo de todo el poema. Pharsalia despliega una representación poética de la historia donde las alteraciones, desviaciones y transformaciones de los hechos históricos operan en función de una voluntad estética y simbólica. Las dos secciones que siguen tratan sobre la utilización, recuperación y subversión del material poético augusteo, principalmente Horacio y Virgilio, que Séneca y Lucano llevan a cabo en su obra poética, siguiendo nuestro planteo de la 
profunda relación de formación y consolidación poética entre la tragedia de Séneca y

\section{Pharsalia.}




\section{ESTRATEGIAS DE REPRESENTACIÓN EXPRESIONISTAS Y BARROCAS.}

\section{EL BARROCO Y SUS ALCANCES COMO HERRAMIENTA HERMENÉUTICA DE INTERPRETACIÓN}

August von Schlegel repudiaba las violentas écfrasis de la tragedia de Séneca, identificándolas con claras muestras del mal gusto y con desprecio por las formas armónicas propio de una época decadente y marchita. Unas décadas más tarde, los académicos europeos atribuyeron estas "faltas" al regodeo de los romanos del siglo I d. C. en la indulgencia retórica propia de este "siglo de plata" de la literatura latina. ${ }^{173}$ Sin embargo, como ya hemos visto, el carácter denigratorio de estas aseveraciones surge no de errores de lectura o de interpretación, sino de presupuestos hermenéuticos efectivos y activos que imponen estándares clásicos a obras con características de composición más cercanas a las formas barrocas. De hecho, los términos "Barroco" y "manierista" han ganado, en las últimas décadas, popularidad entre los críticos dedicados a la literatura latina, ya que permiten evadir y evitar adjetivos axiológicamente cargados como, por ejemplo, el ya mencionado "siglo de plata" o era "post-clásica" de las letras latinas. ${ }^{174}$

La palabra "Barroco" resulta, per se, un significante difuso y aglutinador, incluye estilos arquitectónicos, musicales, literarios e incluso un período histórico particular. Como adjetivo suele ser asociado a lo estrambótico, a lo excéntrico, a lo imperfecto o a lo que carece de forma. ${ }^{175} \mathrm{El}$ propio Wölfflin tiene dificultades en escapar a la idea de historicidad y periodicidad de los distintos estilos y de un carácter evolutivo de los mismos, aunque no llega tan lejos como Focillon, quien plantea un proceso teleológico casi biologicista de las formas. Eugenio D’Ors, con su perspectiva metahistórica, transforma (al igual que Severo Sarduy) las categorías de análisis histórico en categorías del espíritu, denominadas "eones" y de este modo extiende la noción de este movimiento concreto a cualquier tiempo y lugar. ${ }^{176}$ También Gilles Deleuze comparte esta opinión, considerando el Barroco no como una esencia, sino

\footnotetext{
${ }^{173}$ Segal, Ch. (1984), 311.

${ }^{174}$ Galisnky, K. (2010), 11; Segal (1984), 112-114; Vessey, D. (1970), 234; Morford, M.(1968), 85-88; Tucker, R. (1969), 295: "Surely baroque is an apt adjective for the rhetorical, highly colored, pointed poetry of the Bellum Civile, rich with sententiae, dramatic, often macabre and vividly horrific ad nauseam. The 'New Style' of Lucan's epic is patently different from the style in the Augustan era."

175 Tatarkiewicz, W. (2004), 413-416; Sarduy, S. (1974), 15-16; Warnke, F. (1970), 145- 147; Wölfflin, H. (1968), 13-14.

${ }^{176}$ Calabrese, O. (1989), 33-36.
} 
como una función operatoria, como un rasgo distintivo: ${ }^{177}$ adjetivos como desmesurado, excesivo, exagerado y sobrecargado, violento en sus contenidos, distorsionado, transitivo, frenético, cambiante, opresivo, amplificado, discontinuo y organizado por bloques molares son comúnmente aplicados a las manifestaciones barrocas, frente a los de lógico, mesurado, claro, sereno, real y/o reposado que caracterizan la cultura clásica. ${ }^{178}$ Vemos también que la gran mayoría, por no decir su totalidad, son aplicados para describir las características propias de los proyectos creadores de Séneca y Lucano. ${ }^{179}$

Existe, entonces, una importante cantidad de coincidencias entre las estéticas de Séneca y Lucano y las características del eón Barroco. ${ }^{180}$ Los adjetivos enumerados en los párrafos anteriores pierden entonces su matiz negativo y se convierten en principios estilísticos, estéticos y compositivos que otorgan coherencia y personalidad a la obra poética de Séneca y Lucano. La crítica derogativa de la Filología Clásica decimonónica es producto de una ideología específica que, en medio de un proceso de configuración de un pasado efectivo, instaura lo que Raymond Williams llama una tradición selectiva. Esta operación responde a una ratificación cultural e histórica particular que ensalza los estándares estéticos de la Grecia Clásica. ${ }^{181}$ La poesía de Séneca y Lucano queda absolutamente indefensa, ya que al ser leída desde una perspectiva “clásica" resulta desmesurada, exacerbada y/o distorsionada. Del mismo modo, si se lo juzga desde los estándares renacentistas, un cuadro como La crucifixión de Tintoretto resultará anisotrópico, desproporcionado y de heterogénea disposición espacial, pues la cabeza de Jesucristo chocaría contra el marco superior de no estar caída en agonía. Lo mismo ocurre en el caso de El Greco y sus proporciones imposibles: los cuerpos estirados llegan a medir una docena de cabezas o un brazo puede ser más corto que el otro si con

\footnotetext{
${ }^{177}$ Deleuze, G. (2005), 11.

${ }^{178}$ Maraval, J. A. (1990), 421-422. Deleuze, G. (2005), 13-14.

179 Tatarkiewicz, W. (2004), 414: "Las formas clásicas son económicas, y las barrocas generosas; por un lado hay mesura y formas estáticas, y por otro un fortissimo y formas dinámicas."

${ }^{180}$ Galisnky, K. (2010), 12-15; Codoñer, C. (1997), 435; Segal, Ch. (1984), 313: "Roman 'Baroque' does not, of course, have behind it the cultural forces of the reformation and counter- reformation that stimulated such artistic developments in the $16^{\text {th }}$ century. One may, however speculate on analogous influences: the concentration of enormous power in the hands of the few, the irrational terror of living under capricious or even insane emperors, the expansion of the empire to hitherto unknown limits, and so on. With suitable adjustment, then, some of Wölfflin categories are useful for Senecan drama. Among these are the preference for a complex, multifarious whole over simplicity and directness, the loss of clear linear perspective, the tendency to crowd the ensemble with a plethora of details, the mood of pathos, violence and grandiosity. What Bardon, apropos of Ovid, says of the baroque may also be aplied to Seneca: 'une plénitude de vie qui ne s'accomode pas des ordonnances classiques, et les remplace par une sorte de dynamisme tourmenté et ecplosif.'."

${ }^{181}$ Habinek, Th. (1992), 227 y ss.; Galán, L. (2005), 114-115.; Williams, R. (1997), 137 y ss.
} 
esto se acentúa la expresividad dramática. En favor de esta última se sacrifica la verosimilitud y la lógica. ${ }^{182}$

Toda cultura de una época se expresa, en mayor o menor medida, en sus manifestaciones artísticas, por lo tanto es posible detectar las semejanzas existentes en los fenómenos artísticos de una época particular como también advertir las diferencias que hay entre los fenómenos de épocas diferentes; es decir, podemos encontrar la forma de las manifestaciones artísticas, ese coherente principio de organización inherente a su sistema interno de relaciones. ${ }^{183} \mathrm{Si}$ atribuimos al término "Barroco" el valor de una categoría morfológica, y al término "Clásico" el de otra categoría antagónica, éstas ya no actuarían, tal como postulaba Severo Sarduy, ${ }^{184}$ como categorías del espíritu sino como modos de expresión de un contenido particular y específico. En este sentido podemos considerar cualquier fenómeno de acuerdo a la forma que prevalece en sus manifestaciones. Tal como lo expresa Omar Calabrese:

"Clásico y Barroco se admitirán como constantes formales y se admitirá igualmente su preeminencia en un período más que en otro. El principio de reversibilidad, en cambio, se rechazará. En realidad, la historia no demuestra absolutamente -si no es a costa de forzar las cosas- la alternancia de las dos constantes (como precisamente deseaban Wölfflin y Focillon). Tampoco permite establecer -si no es, en este caso, a costa de inmotivadas fantasías- que el clásico es un momento de perfección de un sistema cultural y el barroco su correlativo momento degenerado (como quería Focillon)." 185

Un texto puede ser, por un lado, analizado alegóricamente respecto de aquello que quiere significar y, por otro, se puede acceder a él a partir de sus propias reglas de formación, de la lógica (o las lógicas) de enunciación, de las leyes que rigen su funcionamiento autónomo en busca de los planteos, exigencias y presupuestos teóricos de la poética particular que los despliega. ${ }^{186}$ Las grandes obras llevan implícito, en mayor o menor grado, con mayor o menor transparencia, el modo en que requieren ser abordadas, así como también es necesario que cada interpretación ofrezca, como mínimo, una descripción coherente de su objeto de estudio y una explicitación de las formas de descripción utilizadas. ${ }^{187}$

\footnotetext{
${ }^{182}$ Valverde, J. (1985), 25-27.

${ }^{183}$ Calabrese, O. (1989), 12-13.

${ }^{184}$ Calabrese, O. (1989), 31-32: “Sarduy define 'Barroco' no sólo en tanto un período específico de la historia de la cultura, sino una actitud general y una cualidad formal de los objetos que la expresan. En este sentido puede haber algo barroco en cualquier época de la civilización. 'Barroco' llega a ser casi una categoría del espíritu, contrapuesta a la de 'clásico'."

${ }^{185}$ Calabrese, O. (1989), 33.

${ }^{186}$ Albano, S. (2004), 19.

${ }^{187}$ Calabrese, O. (1989), 27-33.
} 


\section{EXPRESIONISMO Y BARROCO}

El Expresionismo, al igual que el Barroco, genera numerosas dificultades cuando se lo considera como un mero movimiento cronológico determinado o un conjunto acotado de obras pertenecientes a una generación de escritores en general muy diferenciados entre ellos. ${ }^{188}$ Resulta más bien una actitud, una forma de ver las cosas que va más allá del marco y las teorías y los programas y que atraviesa numerosas manifestaciones artísticas, muy especialmente las alemanas. El expresionismo, como movimiento que hunde profundamente sus raíces en el Sturm und Drang dieciochesco, es la eclosión simultánea de un impulso artístico particular en un momento determinado de la historia del espíritu humano. ${ }^{189}$ Tal como hemos destacado en la primera parte de este trabajo, es posible formular y aplicar conceptos relacionados a ciertos períodos históricos a manifestaciones artísticas pertenecientes a otros momentos de la historia, pues un período no es, en definitiva, un tipo de patrón determinado o una serie de normas ideales sino una secuencia temporal dominada por una serie de normas específicas.

La perspectiva hermenéutica metahistórica, promovida por estudiosos como Eugenio D’Ors, Severo Sarduy o Gilles Deleuze, que considera al Barroco como una categoría de análisis más que como un indicador cronológico, puede ser aplicada también al concepto Expresionismo y podemos entonces considerar a éste como una función operatoria y como un rasgo distintivo de ciertas manifestaciones artísticas a lo largo de la historia. ${ }^{190}$ Los productos literarios y artísticos de determinado lapso temporal están dominados por normativas específicas, de las cuales sólo una parte o selección de ellas estarán presentes en determinada obra. ${ }^{191}$ Existen ciertas manifestaciones artísticas en cuyas representaciones prevalecen la asimetría, la deliberada y programática violación de las reglas del decoro y la visión subjetiva y distorsionada de la realidad, que pueden ser consideradas como barrocas y/o expresionistas, y otras, que pueden considerarse "clásicas" donde prima una consistencia estilística que aspira a la simetría, al decoro, a la racionalidad y a una mímesis pretendidamente fiel y objetiva. ${ }^{192}$

\footnotetext{
${ }^{188}$ Weisstein, U. (1967), 46-47.

${ }^{189}$ de Brugger, I. (1967), 7-15.

${ }^{190}$ Deleuze, G. (2005), 11.

${ }^{191}$ Warnke, F. (1970), 145-146; Calabrese, O. (1989), 12-13.

192 Warnke, F. (1970), 150; Calabrese, O. (1989), 32-33: "Por ejemplo: si consiguiéramos demostrar que existen formas subyacentes a los fenómenos culturales y que consisten en un propio proceder estructural;
} 
En este aspecto, resulta casi fundacional el artículo de Charles Segal "Senecan Baroque: The Death of Hippolytus in Seneca, Ovid and Euripides", donde se analiza los diferentes modos de representar la muerte del joven cazador y la descripción del monstruoso toro marino que surge del océano. ${ }^{193}$ Afirma Segal en este trabajo:

"The term baroque is appropriate, if anywhere in this passage, to Seneca's version of the sea-monster. The creature is a fusion of contrasting forms, colours, and masses. Its emergence from the sea is framed between two similes of awful marine monsters (1029f., 1047f.). It heaves itself forth from its liquid womb (cf. 1019f.) in a metamorphic fluidity of earth and water. [...] Like its Senecan counterpart, Ovid's creature snorts through flaring nostril [Met. 15.512f. \& Pha. 1024f.] the two passages also show a different way of composing the two taurine bodies. Ovid presents the unity of the whole creature emerging from the water into the air; Seneca stresses the separately articulated masses of the flesh, the massive 'heavy neck' and the bulging 'hard muscles', in a manner that recalls the Sperlonga sculptures or the Laocoon." 194

La remembranza del episodio de la muerte de Laocoonte no es casual. La cola serpentina del monstruo (Phaed. 1036 y ss.) retoma la descripción virgiliana de las serpientes en Eneida II, 206-208, mientras que la carga del monstruo trae a la memoria otro pasaje virgiliano, esta vez, la batalla de los toros en Geo. III, 232-234. Sin embargo, Séneca, a diferencia de Virgilio, despersonaliza al animal convirtiéndolo en una horrorosa otredad asesina donde la yuxtaposición de moles y animos (hic se illa moles acuit atque iras parat / ut cepit animos, Phaed. (1059-1060)) produce un barroco juego de fluida alternancia entre lo animado y lo inanimado, lo real y lo fantasmagórico y lo estático y lo dinámico. ${ }^{195}$

Si bien las características de composición barrocas y expresionistas son pervasivas en la tragedia de Séneca y en la épica de Lucano, existen ciertos pasajes que resultan paradigmáticos de estas formas de expresión, por lo que nos dedicaremos en

y si consiguiéramos también demostrar que tales formas coexisten conflictivamente con otras de diferente naturaleza y estabilidad interna, entonces podríamos decir que atribuimos al 'barroco' el valor de cierta morfología y, por ejemplo, al 'clásico' el de una morfología en competición con aquel. 'Barroco' y 'Clásico' no serían ya categorías del espíritu, sino categorías de la forma (de la expresión del contenido). En este sentido cualquier fenómeno sería clásico o barroco e idéntico destino le correspondería a cada edad o episteme, que vean la emergencia del uno o del otro. Esto no excluirá el hecho de que las manifestaciones, en cada determinado momento histórico, mantengan sus especificidades y deferencias por cuanto son casos singulares."

${ }^{193}$ Segal, Ch. (1984), 314 y ss.

${ }^{194}$ Segal, Ch. (1984), 319-320.

195 Segal, Ch. (1984), 320- 321; Wölfflin, H. (1968), 47-49 y 31: "En uno todo es línea [i.e. bocetos renacentistas], todo está delimitado y los contornos son precisos, la expresión principal reside en el contorno; en el otro [i.e. estilo pintoresco], hay sólo masa anchas y difuminadas, el contorno se expresa fugazmente en trazos vacilantes y repetidos, o bien falta completamente. No sólo el detalle, sino la composición en su conjunto, se divide en masas de claroscuro; grupos enteros se mantienen juntos y opuestos a otros por una tonalidad luminosa. El antiguo estilo pensaba linealmente, su propósito era encontrar la fluidez y la armonía de las líneas, el estilo pintoresco no piensa más que en masas: sombras y luz son sus elementos." 
esta parte a hacer un detallado análisis de estos con el fin de ilustrar el despliegue de formas, procedimientos, organizaciones y expresiones pertenecientes a los movimientos analizados. Comenzaremos por ver el tercer estásimo de Thyestes, conocido también como "el apocalipsis de Séneca".

\section{LA CAÍDA DEL CIELO EN THYESTES.}

Este famoso estásimo es particularmente apto para ser analizado a la luz de los procedimientos ya señalados. En él aparecen condensadas y explicitadas ciertas formas de expresión y representación que, si bien se reconocían como "características" de nuestro autor, eran consideradas grotescas, excesivas o desmesuradas. ${ }^{196}$ El canto se estructura en masas molares que acumulan la materia poética en grupos masivos, ${ }^{197}$ cuya ordenación va en detrimento de una ordenada secuenciación temporal de los eventos, la cual se hace presente en el texto a través de una retórica densa e íntimamente ligada al desarrollo dramático de la obra que genera las turbulencias discursivas que, en el plano diegético, resulta en la caída de los astros y del Zodíaco, ${ }^{198}$ y que produce una separación inexorable entre los ámbitos humanos y celestiales a través del hundimiento hacia abajo y el empuje hacia lo alto producido por el vaciamiento del cielo. El canto posee, además, una trabazón interna muy compacta.

Dice Heinrich Wölfflin al respecto de este tipo de composiciones:

"La composición pintoresca, que se dice libre, rehúsa, por principio, repartir sus figuras según un esquema arquitectónico; desconoce una ley figural y en cambio no conoce más que un juego de luz y de sombra, que se sustrae a toda regla. [...] El 'desorden pintoresco' requiere que la representación de los distintos objetos en sí mismos no sea totalmente clara, sino que quede en parte velada. El motivo del cubrimiento es uno de los más importantes de este estilo. Es consciente del hecho de que todo aquello que se deja aprehender completamente en una primera mirada, resulta monótono en un cuadro; por ello, algunas partes del cuadro permanecen veladas; los objetos se sobreponen, no se muestran más que en parte, estimulando la imaginación al más alto grado para adivinar lo que está oculto."199

\footnotetext{
${ }^{196}$ Segal, Ch. (1984), 311-312.

${ }^{197}$ Rosenmeyer, Th. (1989), 178-179.

${ }^{198}$ Rosenmeyer, Th. (1989), 188-189; Deleuze, G. (2005), 13; Segal, Ch. (1986), 26: "Seneca inherits the surface coherence of his plots from Greek tragedy, but his rhetorical language parts company with the Greek tragedians' verbal mimesis of character. He reveals the personal interrelations and the psychological conflicts among the characters not so much in scenes of direct confrontation as in the heavily encrusted, self-consciously verbal dramatizing of rhetoric."

${ }^{199}$ Wölfflin, H. (1968), 34.
} 
Entre otras cosas, Wölfflin señala como rasgos típicos del Barroco el tratamiento del material a través de masas, agrupaciones o agregados, la constitución de una forma turbulenta que surge de turbulencias previas y la tendencia de la materia a desbordar el espacio, a conciliarse con lo fluido y a agruparse en masas molares. El mundo barroco se organiza también según dos vectores: el hundimiento hacia abajo y el empuje hacia lo alto. ${ }^{200}$ Este estilo busca, en sus más altas expresiones, las profundidades insondables, lo indefinido y lo que se pierde en el infinito. En su búsqueda no de figuras y formas definidas tiende a un efecto de masa dentro de un espacio no delimitado donde la imposibilidad de aprehender las individualidades genera un efecto de conjunto cuyo resultado es una riqueza inagotable de los motivos. ${ }^{201}$

Antes de analizar la estructura interna del canto veamos cómo funciona éste dentro del conjunto de la obra y qué relaciones traba con el prólogo y el episodio que lo preceden. Es importante recordar que este estásimo sigue a la detallada y extensa descripción del ritual asesino de Atreo, donde la naturaleza retrocede horrorizada al igual que las aguas huyen espantadas por la presencia del fantasma de Tántalo sobre la tierra (vv. 106-119). El desarrollo de este motivo del prólogo refleja, a través de una imaginería de disolución cósmica y ruina, la magnitud de la ira real. Del mismo modo que en Agamemnon la terrible tormenta se revela como la contrapartida de la guerra y, más significativamente, cómo la expresión natural, vía sympátheia tôn holôn, de la agitación interior de Clitemnestra, en este caso particular, la ruina del cielo, la nox alia profetizada por la Furia en el prólogo, es el reflejo cósmico y universal de lo ocurrido en los penetralia del palacio. ${ }^{202}$ El estásimo intensifica, a modo de una caja de resonancia, los motivos puestos en escena en el comienzo de la tragedia, al mismo tiempo que reduplica a escala cósmica la subversión de las leyes naturales. ${ }^{203}$ En una clara ironía trágica, el coro expresa su deseo de huir ante el sufrimiento y el horror que ocurre ante sus ojos, deseando abandonar la escena que, precisamente por las convenciones propias del género, no puede dejar vacía. ${ }^{204}$

\footnotetext{
200 Deleuze, G. (2005), 28; Rosenmeyer, Th. (1989), 164: "Some catalogues are severely limited dimensionally in their field of speculation. The drama of the collapse of the zodiac (Thy. 884ff) lists, in unrelenting sequence, the various disorderly motions of fully fifteen constellations and their major stars. More typically, verticality and horizontality are, in obedience to krasis, combined into compound structures. Astronomy and mythology, history and meteorology, anatomy and apocalypse support one another."

${ }^{201}$ Wölfflin, H. (1968), 34-35.

${ }^{202}$ Narducci, E. (1979), 55-56; Volk, K. (2006), 189-191.

${ }^{203}$ Rosenmeyer, Th. (1989), 140 y ss.; Lapidge, M. (1979), 344-346 \& 359-361.

${ }^{204}$ Rosenmeyer, Th. (1989), 165.
} 
Pasemos ahora a la organización interna del estásimo y su particularmente propicio campo para la aplicación de una perspectiva de análisis barroca. En el comienzo del canto el coro lanza preguntas a dioses y deidades que jamás responderán pues la distancia que separa al individuo de los supuestos receptores de sus súplicas resulta infranqueable. Es más, la distancia que separa hombres y dioses está a punto de volverse aún mayor, ya que el empuje hacia lo alto la volverá casi infinita cuando el cielo se vea vaciado de estrellas, constelaciones y dioses. La primera turbulencia emocional se refleja en las vanas preguntas lanzadas a los dioses que huyen (vv. 789793). La soledad y la desprotección del individuo se reflejan discursivamente en los anafóricos quo... que abren las interrogaciones retóricas; el sentimiento de abandono es reforzado por el campo semántico al que pertenecen los verbos utilizados: quo... fugit; quo... vertis... perdis. El verso 793 resume el sentimiento de la plegaria: ${ }^{205}$

cur, Phoebe, tuos rapis aspectus?

(Thy. 793)

¿Por qué, Febo, nos arrebatas tu rostro?

Es recurrente en la obra trágica de Séneca la presencia de individuos desamparados y abandonados en un mundo inconmensurable e inabarcable, ${ }^{206}$ a menudo despojado de dioses debido a las acciones de los propios protagonistas. Su máxima expresión en la obra de Séneca se encuentra, quizás, en las últimas palabras pronunciadas por Jasón en Medea, que, si bien están dirigidas a la maga enloquecida, describen a la perfección el estado espiritual del personaje: ${ }^{207}$

Per alta vade spatia sublimi aethere;

Testare nullos esse, qua veheris, deos.

(Med. 1026-1027)

Ve por los altos espacios del sublime cielo;

puedes atestiguar que, por donde pasas, no existen los dioses.

El enorme universo, carente de la reconfortante presencia de númenes y dioses, ya porque nunca estuvieron, ya porque la acción trágica los ha ahuyentado, se vuelve una profundidad insondable para los individuos arrojados en él.

\footnotetext{
${ }^{205}$ Volk, K. (2006), 185-186.

${ }^{206}$ Rosenmeyer, Th. (1989), 160 y ss.

${ }^{207}$ Costa, C. (1973), 159-160: "nullos esse deos is not a characteristic complaint in Greek tragedy, even in Euripides: rather the sufferer asks 'How can the gods allow these things to happen? [...] On this ending T. S. Elliot remarked: 'In the verbal coup de théatre no one has ever excelled him. The final cry of Jason to Medea departing in her car is unique; I can think of no other play which reserves such a shock for the last Word...' ('Seneca in Elizabethan Translation'in Selected Essays, 1948, 73.)"'
} 
El coro describe los efectos que una nox alia produce en la naturaleza (vv. 794801), la cual ha sido subvertida. ${ }^{208}$ La inadecuación natural de esta noche prematura se refleja en ocho versos pareados, introducidos por nondum (vv. 794,796 y 788) ${ }^{209}$ en los cuales se muestra a los dioses anunciadores del atardecer y el crepúsculo quedar estupefactos e indecisos del mismo modo que el humilde campesino se asombra junto a sus bueyes descansados.

La agitación y el asombro inmediatamente se convierten en miedo y pavor. Aun sabiendo qué causó este cataclismo, pues ya escuchó el relato del mensajero, el coro busca, en un ejercicio de patética retórica, otras causas para el mismo. Incluso un nuevo alzamiento de los gigantes parece preferible al monstruoso crimen de Atreo: ${ }^{210}$

Quid te aetherio pepulit cursu? quae causa tuos limite certo deiecit equos? numquid aperto carcere Ditis uicti temptant bella Gigantes? numquid Tityos pectore fesso renouat ueteres saucius iras? num reiecto latus explicuit monte Typhoeus? numquid struitur uia Phlegraeos alta per hostes et Thessalicum Thressa premitur Pelion Ossa?

(Thy. 802-812)

¿Qué te ha apartado de tu curso celeste?

¿Qué causa ha desviado tus caballos de su recorrido constante? ¿Acaso, abierta la cárcel de Dite, los gigantes vencidos intentan otra guerra? ¿Acaso Titio herido renueva las antiguas iras en su cansado pecho? ¿O Tyfeo ha liberado sus flancos, sacudiéndose de encima su montaña? $¿ \mathrm{O}$ se construye acaso un alto camino a través del enemigo Flegra y en Tesalia el Pelión es aplastado por la Osa tracia?

La futilidad y patetismo de estas preguntas refuerzan la impresión de que la tragedia no es sólo cósmica, sino también personal. Las dos primeras preguntas muestran la fuerza y el pathos que la retórica puede adquirir en un contexto trágico, siendo un claro ejemplo del uso dramático que Séneca hace de ésta. ${ }^{211}$ Sigue luego, en esta Schreirhetoric, el catálogo de gigantes, que no sólo expande y desarrolla la mención de Titio del verso 9,

\footnotetext{
${ }^{208}$ Rosenmeyer, Th. (1989), 140-141.

${ }^{209}$ SEN. Thy. 794-801, "nondum serae nuntius horae/ nocturna uocat lumina Vesper;/ nondum Hesperiae flexura rotae/ iubet emeritos soluere currus;/ nondum in noctem uergente die/ tertia misit bucina signum. / stupet ad subitae tempora cenae/ nondum fessis bubus arator."

${ }^{210}$ Davis, P. (1989), 432-434; Tarrant, R. (1985), 206-207.

${ }^{211}$ Rosenmeyer, Th. (1989), 187-190.
} 
sino que también preanuncia la entrada triunfal de un desmesurado Atreo, convertido en un gigante que toca el polo con su cabeza soberbia. La primera turbulencia la aporta el genérico gigantes, que se dispersa en nuevas turbulencias encarnadas en la mención particular de los distintos gigantes y sus respectivas liberaciones. ${ }^{212}$ Los elementos barrocos conservan su carácter masivo y están poco diferenciados ya que no alcanzan por sí solos una existencia simple o definida; al contrario, los elementos de una representación barroca no aparecen desunidos o libres, más bien suelen repetirse y formar parte de un conjunto molar mayor. ${ }^{213}$

A esta segunda agrupación molar de preguntas retóricas, sigue una segunda descripción de los efectos sobre los ciclos naturales. Los primeros versos resumen la situación: ${ }^{214}$

Solitae mundi periere uices?

nihil occasus, nihil ortus erit?

¿Se han acabado los habituales ciclos del mundo?

¿No habrá ocaso, no habrá amanecer?

La caída del cielo ha desplazado los ciclos naturales del mundo y ya no habrá ocaso ni amanecer, tampoco los soles podrán morir y renacer, marcando así el fin del tiempo natural:

ipse insueto nouus hospitio

Sol Auroram uidet occiduus

tenebrasque iubet surgere nondum

nocte parata: non succedunt

astra nec ullo micat igne polus,

non Luna graues digerit umbras.

(Thy. 822-826)

El Sol, desacostumbrado a este inusual alojamiento,

ve a la Aurora al ponerse

y ordena que surjan las tinieblas,

mientras aún no está preparada la Noche: no se alzan las estrellas

ni brilla en el cielo astro alguno con su fuego,

ni la Luna disipa las pesadas sombras.

\footnotetext{
212 Wölfflin, H. (1968), 39-40: "[El Barroco] No evoca la plenitud del ser, sino el devenir, el acontecimiento; no la satisfacción, sino la insatisfacción y la inestabilidad. Uno no se siente liberado, sino arrastrado al interior de la tensión de un estado apasionado. Este efecto, tal como hemos pretendido caracterizarlo en su generalidad, se basa en el tratamiento de la forma, que se debe describir desde dos puntos de vista principales: efecto de masa y movimiento. Lo que puede llamarse, con palabras de Vasari, la 'maniera grande'."; Deleuze, G. (2005), 13.

${ }^{213}$ Wölfflin, H. (1968), 53-54.

${ }^{214}$ Tarrant, R. (1985), 207-208.
} 
Termina aquí esta primera sección del canto, cuya estructura interna está organizada en cuatro secciones:

- Primera parte: consta de una agrupación de desesperadas preguntas lanzadas a los cielos (vv. 789-793).

- Segunda parte: donde se describen los primeros efectos que la nox alia causa en la creación entera (vv. 794-801).

- Tercera parte: se desarrolla un segundo grupo de patéticas preguntas retóricas y la turbulenta presencia de los Gigantes es deseada cómo causante de tal agitación de la Naturaleza (vv. 802-812).

- Cuarta parte: en la que se produce una reduplicación de los efectos de la cena repentina (813-826).

A continuación tenemos un verso de vital importancia en la organización interna del canto en particular y de la obra en general:

Sed quidquid id est, utinam nox sit!

(Thy. 827)

¡Pero que sea cualquier cosa, con tal que sea una noche!

Este grito desesperado no sólo confirma la presencia de la noche extraña, sino que resume y aglutina todos los elementos precedentes, desde las preguntas retóricas que buscaban en vano causas diferentes al cataclismo desestabilizador del orden, hasta la soledad del individuo ante el abandono, alejamiento, o ausencia de los dioses (vv. 789793) y los efectos de la nox alia en la creación (vv. 794-802 y 813-826). ${ }^{215}$ Por otro lado es una genuina expresión de temor, que da paso al desarrollo de la misma:

trepidant, trepidant pectora magno

percussa metu.

(Thy. 828-829)

Tiembla, tiembla mi pecho golpeado por un enorme miedo.

Si antes el coro temía y, al mismo tiempo, anhelaba una nueva llegada de los belicosos gigantes, ahora va más atrás en la línea temporal mitológica y se remonta al turbulento y deforme Chaos quien retornará el mundo a su condición indiferenciada de los primeros tiempos.

No es sólo la apariencia accidentada de la forma lo que califica al Caos sino también su aspecto turbulento: la turbulencia resulta un modo caótico de representación dentro de cierto umbral de complejidad de un fenómeno comunicativo o cultural en el cual influye no sólo sobre el objeto representado sino también su proceso de producción

${ }^{215}$ Tarrant, R. (1985), 209; Narducci, E. (2004), 18-19. 
y recepción. ${ }^{216}$ La primera turbulencia origina otras nuevas, aunque sería mejor, quizás, decir que dentro de esta gran turbulencia primigenia existen, a modo de una construcción fractal, turbulencias menores que la constituyen y reflejan: ${ }^{217}$

ne fatali cuncta ruina

quassata labent iterumque deos

hominesque premat deforme chaos,

iterum terras et mare cingens

et uaga picti sidera mundi

natura tegat. Non aeternae

facis exortu dux astrorum

saecula ducens dabit aestatis

brumaeque notas, non Phoebeis

obuia flammis demet nocti

Luna timores uincetque sui

fratris habenas curuo breuius

limite currens.

(Thy. 830-842)

Que no caiga todo

derrumbado en fatal ruina

y a los hombres y a los dioses los oprima el deforme Caos,

y de nuevo, ciñendo la tierra, el mar

y las estrellas errantes del adornado cielo,

los cubra la Naturaleza. El señor de los astros, que llevando su antorcha

guía a los siglos, no regalará el verano

ni las conocidas brumas, ni la Luna, que sale al encuentro

de las llamas de Febo, privará a la noche de sus temores,

ni vencerá las riendas de su hermano

recorriendo en menos tiempo su curvo camino.

La turbulencia disparadora, el deforme chaos, genera y contiene las diferentes turbulencias particulares: la tierra, el mar y las estrellas errantes se verán conturbadas en una sola masa amorfa, el dux astrorum no gobernará más las estaciones ni marcará los ritmos naturales ni la luna, siempre compañera y protectora, ahuyentará los terrores nocturnos, en una nueva duplicación retórica -cf. el verso 826 "non luna graves digerit umbras"- que reafirma la sensación de inestabilidad y ruptura del desarrollo lineal y de la simetría lógica, logrando de este modo una atmósfera de barroca efectividad donde

\footnotetext{
${ }^{216}$ Calabrese, O. (1989), 140.

${ }^{217}$ Deleuze, G. (2005), 28; Calabrese, O. (1989), 135-140; Sarduy, S. (1974), 44: "El barroco será extravagancia y artificio, perversión de un orden natural y equilibrado: moral. A la dicotomía aristotélica natural/ violento, que se aplica al movimiento, la rutina represiva que comienza con la intercepción moralizante del texto galileano, irá substituyendo progresivamente la oposición natural/ artificial. Partiendo desde lo alto - del ángulo superior derecho, por ejemplo, en El santo Entierro, del Caravaggio-, un movimiento brusco desequilibra y fuerza a los personajes hacia el ángulo inferior izquierdo - Bouleau señala las connotaciones de la palabra sinistra-: el peso los degrada, la gravedad los arrastra, río abajo."
} 
reina un sentimiento de extremosidad, suspensión y terribilidad. ${ }^{218}$ Dice respecto a esto Heinrich Wölfflin:

"En el Renacimiento cada elemento era limpio y único, el barroco multiplica los elementos. La primera razón de esta multiplicación es la existencia de proporciones dimensionales anómalas: la sensibilidad exige formas más robustas. [...] Este hábito que se adquiere de la multiplicidad se acompaña además con una multiplicidad de los motivos iniciales y terminales. Las formas ya no son delimitadas hacia arriba y hacia debajo de manera exacta, se tiene la impresión de un comienzo vacilante y de una imposibilidad de concluir." ${ }^{219}$

Esta sección (vv. 828-842) finaliza con una frase que resume el contenido de la misma y a su vez da paso al desarrollo de la que le sigue, en este caso, la caída del zodíaco:

$$
\begin{gathered}
\text { Ibit in unum } \\
\text { congesta sinum turba deorum. } \\
\text { Caerá en un mismo abismo } \\
\text { la turba congestionada de los dioses. }
\end{gathered}
$$

La turba deorum caerá in unum sinum, hundiéndose en las turbulentas aguas y dejando el cielo vacío, el hundimiento hacia abajo da lugar al empuje hacia lo alto, siendo evidentes en el texto estas características típicas del barroco. El derrumbe del cielo se da de modo turbulento y tumultuoso, que responde también a una organización fractal donde cada turbulencia está compuesta de otras similares al mismo tiempo que ella misma forma parte de otra mayor. Este efecto conjunto de masa y movimiento es una de las características propias del estilo barroco, donde la fuerza no se comunica a elementos aislados sino que el cuerpo en su totalidad es arrastrado por el impulso poderoso del movimiento. ${ }^{220}$

No es casual que las primeras constelaciones en caer sean Aries y Tauro, que designan principios activos propicios para arrojarse in praeceps y originar las turbulencias iniciales al lanzarse y buscar con sus cuernos las profundidades:

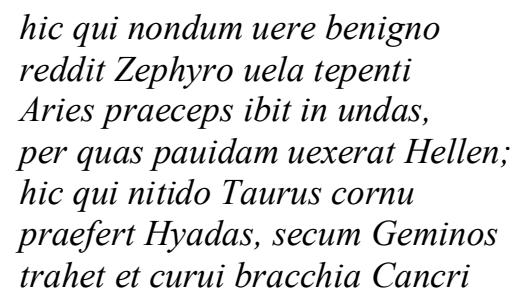

Aquí quien, sin ser favorable aún la primavera, entrega sus velas al Céfiro,

\footnotetext{
${ }^{218}$ Maravall, J. (1990), 431-433; Tarrant, R. (1985), 209-211.

${ }^{219}$ Wölfflin, H. (1968), 57-58.

${ }^{220}$ Wölfflin, H. (1968), 63; Deleuze, G. (2005), 28-29.
} 
Aries, irá de cabeza hacia las olas, por las que había transportado a la pálida Helle; aquí Tauro, que lleva en sus brillantes cuernos a las Hyadas, arrastrará consigo a los gemelos y a los brazos del curvo cangrejo.

Aries se arroja de cabeza, generando la primera turbulencia que invita a Tauro a seguirlo, dando lugar a su vez a la segunda turbulencia, que contiene las siguientes: el enorme toro, con sus brillantes cuernos portadores de las Hyadas, arrastrará consigo (secum... trahet) a los gemelos y al cangrejo, el cual aparece con una particularmente interesante imagen compuesta por la sinécdoque bracchia Cancri, como si el cangrejo se aferrara al toro por voluntad propia para ser llevado in undas por el poderoso animal. El movimiento es pesado y masivo y su materia está subrayada y destacada en el entramado textual: ésta desborda los marcos que la contienen y precipita a su vez las masas adyacentes creando este efecto de masa molar característico del Barroco. ${ }^{221}$

Los principios activos ya generaron el turbulento espiral de destrucción, por lo tanto el resto puede seguirlos:

Leo flammiferis aestibus ardens iterum e caelo cadet Herculeus, cadet in terras Virgo relictas iustaeque cadent pondera Librae secumque trahent Scorpion acrem.

(Thy. 855-859)

El León de Hércules, ardiendo en el flamígero verano, caerá nuevamente del cielo, caerá Virgo a las tierras que abandonó y caerán los pesos de la justa Libra, y consigo arrastrarán al punzante escorpión.

Tres veces se repite el mismo verbo (cadere) resaltando el aspecto pasivo de la caída de estas constelaciones que, a diferencia de Aries y Tauro, quienes se arrojaban motu propio al vacío, son arrastradas por esta fuerza sobrenatural. Hay aquí otra duplicación de imágenes que presentan sólo algunas leves diferencias de matiz: el cangrejo que se aferraba al enorme toro es aquí el Scorpion acrem que es arrastrado por los pesos de Libra. Finalmente Quirón se lleva consigo a Piscis y a Acuario:

et qui neruo tenet Haemonio pinnata senex spicula Chiron, rupto perdet spicula neruo; pigram referens hiemem gelidus

${ }^{221}$ Wölfflin, H. (1968), 37-38 \& 59. 
cadet Aegoceros frangetque tuam, quisquis es, urnam; tecum excedent

También el viejo Quirón, quien sostiene en su arco hemonio las flechas adornadas con plumas, perderá sus flechas, roto su arco; el frío Capricornio, que trae nuevamente al lento invierno, caerá y romperá tu urna, quienquiera que tú seas; contigo caerán las últimas estrellas del cielo, los peces.

Capricornio cae y rompe la urna de un indefinido Acuario (quisquis es), y con él se irán las últimas estrellas del cielo, que termina de vaciarse cuando los monstruos que nunca tocan las aguas (vv. 869-874) se hundan para siempre.

Vaciado el cielo, el coro lamenta el raro privilegio de ver esta ultima aetas: ${ }^{222}$

digni, premeret quos euerso

Nos e tanto uisi populo

cardine mundus? in nos aetas ultima uenit?

uitae est auidus quisquis non uult

mundo secum pereunte mori.

¿Nosotros, entre tantos pueblos, hemos sido considerados dignos para que el mundo, arrancado de su eje, nos aplaste? ¿Llega contra nosotros la última era?

Ávido de vivir está quien no quiere morir cuando el mundo perece con él.

La descripción toda es acontecimiento e inestabilidad que arrastra por su propia masa los elementos aglutinados en el discurso: el cielo ha sido vaciado y sus componentes naturales ya no funcionan como signos, ni zodiacales ni semánticos, pues la perversión del orden natural ha generado un movimiento de hundimiento hacia abajo cuyo resultado es un empuje infinito hacia lo alto. ${ }^{223}$

\footnotetext{
${ }^{222}$ Davis, P. (1989), 434-435.

${ }^{223}$ Sarduy, S. (1974), 22 \& 44; Wölfflin, H. (1968), 39-40; Deleuze, G. (2005), 28;
} 
El grotesco desafía también todo tipo de intento de clasificación absoluto o estanco y resulta mejor entendido, al igual que el Barroco y el Expresionismo, como una categoría de análisis metahistórica que se manifiesta en ciertas épocas y obras con mayor prevalencia que en otras. Varios estilos recurren al grotesco a lo largo de la historia del arte, entre ellos, y no casualmente, los estilos barroco, manierista, expresionistas e incluso también el dadaísmo y el surrealismo. ${ }^{224}$ El grotesco es, en cierta manera, un ornamento que añade significación:

"Ornament might be purely visual, but as Ruskin pointed out, the grotesque expresses meaning through the purely visual. Also, the grotesque truly is the image at play, and its humour and irreverence offer a welcome antidote to all forms of conventional thinking. Another characteristic of the grotesque is that it is not content to be solely the object of the aesthetic gaze. Instead, it is engaged in the world, always pushing against boundaries and raising questions. It acknowledges the individuality and particularity of viewer's responses and sometimes even speaks for those whose experiences fall outside the norm. Finally, and perhaps more importantly, there is a fundamental humility to the grotesque, rooted as it is in the living (and dying) body, an embrace of the relativity and changefulness of life as we live it.",225

La periodista y crítica alemana Margarete Susman afirmaba ya en 1918 que el expresionismo había superado los límite estéticos impuestos por el concepto de lo "bello" y que el mundo en su totalidad, incluido lo bello, lo feo y aun el hombre mismo eran, para el artista expresionista, sólo un signo de una realidad más vasta. ${ }^{226} \mathrm{El}$ movimiento expresionista intentó, en cierta manera, dar forma artística a la experiencia irracional del individuo enfrentado al fracaso de las formas de representación prevalentes en las últimas décadas de siglo XIX. ${ }^{227}$

Una rápida mirada al cuadro de Edvard Munch, El Grito (1893), nos muestra precisamente no un momento sino un proceso particular: debajo del turbulento flujo de líneas rojas y naranjas que representan un cielo más subjetivo que natural, que también encontramos en su cuadro Ansiedad (1894), se puede ver un mar, casi muerto en su calma, surcado por un oscuro barco solitario. Sobre este fondo aparece el grito: no

\footnotetext{
${ }^{224}$ Connelly, F. (2012), 4.

${ }^{225}$ Connelly, F. (2012), ix.

${ }^{226}$ de Brugger, I. (1967), 23.

${ }^{227}$ Howie, G. (2002), 187; Kokoschka, O. (1953), 320; de Brugger, I. (1967), 16: "Los expresionistas descubren nuevamente el valor de las visiones y se dejan llevar por ellas (su 'concepto clave' según Sokel), porque están convencidos de la existencia y el poder de lo irracional. Consecuentemente, emprenden la 'demolición de la realidad'."
} 
vemos una cara gritando sino que ésta surge del propio grito, como una reverberación desesperada del mismo. Este tipo de manifestaciones artísticas prefieren formas de representación lábiles y fluidas usualmente en forma de acciones: el grotesco es más afín a las formas verbales que a las sustantivas. Las figuras grotescas, aberrantes (desviadas), combinatorias y metamórficas, rompen los límites establecidos de aquello que se considera 'normal', propio' o 'decoroso' generando sentido a través de las apertura de nuevos espacios que llevan hacia terrenos extraños y perturbadores. ${ }^{228}$

\section{ERICHTO, EL ABYECTO Y LA REPRESENTACIÓN GROTESCA}

La palabra grottesche tuvo su origen en el Renacimiento, durante la excavación de la Domus Aurea neroniana, a fines del 1400, y se usó para describir la arquitectura, la decoración y las pinturas que adornaban las paredes del palacio de Nerón. Las extravagantes combinaciones pictóricas y arquitectónicas del palacio, ${ }^{229}$ con su plétora de plantas, figuras y criaturas míticas encontradas en los niveles inferiores de la excavación, en el grotto, dieron origen a esta denominación y muy pronto encontraron eco en los artistas del Renacimiento como Rafael y Giovanni Da Udine. ${ }^{230}$

En esta parte de nuestro trabajo analizaremos la construcción de la figura de Erichto desde la perspectiva expresionista y grotesca y mostraremos cómo la figura de la bruja se configura no a través de imágenes descriptivas sino por medio de acciones que traspasan y violan los límites y las convenciones normativas y se regodea en los abyectos grotescos de las normas sociales. Según Julia Kristeva, el abyecto puede definirse de la siguiente manera:

"The abject has only one quality of the object- that of being opposed to the $I$. If the object, however, through its opposition, settles within the fragile texture of a desire for meaning, which, as a matter of fact, makes me ceaselessly and infinitely homologous to it, what is abject, on the contrary, the jettisoned object, is radically excluded and draws me toward the place where meaning collapses." 231

El abyecto, usualmente asociado con lo demoníaco y lo monstruoso, se hunde en un universo liminal que amenaza nuestras construcciones subjetivas de identidad pero produce a su vez una intensa fascinación en el observador. Lo abyecto y lo horroroso

\footnotetext{
${ }^{228}$ Connelly, F. (2012), 1-2.

${ }^{229}$ von Albrecht, M. (1997), 900-902.

${ }^{230}$ Connelly, F. (2012), 3.

${ }^{231}$ Kristeva, J. (1982), 1-2.
} 
generan rechazo y fascinación de manera simultánea: Lucano comparte con Séneca, y exacerba, esa fascinación casi esquizofrénica de narrar minuciosa y puntillosamente actos execrables y horrorosos que suelen estar rodeados de un aura demoníaca de maldad y crueldad. El poeta dice retirarse ante el horror de la batalla de Farsalia, pero los versos que siguen son un verdadero regodeo estético en las figuras de la muerte y la disolución de los cuerpos (LUC. VII, 555 y ss.). El crimen de Atreo atraviesa todo límite y se deleita en la acción de desecrar y profanar los cadáveres de sus sobrinos, cuyas muertes son descriptas a través de lo que Deleuze y Guattari denominaron descripciones maquínicas. $^{232}$ Los cuerpos explotan y se independizan en sus constituyentes anatómicos particulares, órganos, músculos y fibras:

erepta uiuis exta pectoribus tremunt spirantque uenae corque adhuc pauidum salit. at ille fibras tractat ac fata inspicit et adhuc calentes uiscerum uenas notat. postquam hostiae placuere, securus uacat iam fratris epulis. Ipse diuisum secat in membra corpus, amputat trunco tenus umeros patentis et lacertorum moras, denudat artus durus atque ossa amputat; tantum ora seruat et datas fidei manus. (Thy. 757-764) $[\ldots]$

Stridet in ueribus iecur; nec facile dicas corpora an flammae magis gemuere. Piceos ignis in fumos abit; et ipse fumus, tristis ac nebula grauis, non rectus exit, seque in excelsum leuat ipsos penates nube deformi obsidet.

Las entrañas arrancadas de los pechos aún vivos tiemblan y las venas aún se agitan y el corazón aterrado aún late. Pero él manipula las fibras e inspecciona los hados y analiza las venas aún calientes de las vísceras. Luego de que las ofrendas lo complacieron, tranquilo, tiene tiempo ya para la cena de su hermano. Él mismo corta los cuerpos separados en sus miembros, amputa los brazos abiertos desde el tronco y las articulaciones de los antebrazos, desuella firme las piernas y amputa los huesos; tan sólo guarda los rostros y las manos para dar fe. $[\ldots]$

\footnotetext{
${ }^{232}$ Una descripción maquínica es aquella en donde el objeto descripto estalla en objetos parciales, moleculares y que poseen una existencia casi autónoma, separados del cuerpo inicial, Cf. Deleuze, G. \& Guattari, F. (2005), 75. "[Proust, M. Sodoma y Gomorra] Así ocurre en un pasaje ejemplar, el primer beso a Albertine. El rostro de Albertine primero es una nebulosa, apenas extraída del colectivo de las muchachas. Luego aparece la persona de Albertine, a través de una serie de planos que son como sus distintas personalidades, el rostro de Albertine saltando de un plano al otro, a medida que los labios del narrador se acercan a la mejilla. Por último, en la proximidad total, todo se deshace como una visión sobre la arena, el rostro de Albertine estalla en objetos parciales, moleculares, mientras que los del rostro del narrador reúnen el cuerpo sin órganos, ojos cerrados, nariz encogida, boca llena."
} 
Resuena el hígado en la parrilla;

y no podrías decir si gimieron más los cuerpos

o las llamas. El fuego escapa en un humo negro como la pez;

y el propio humo, triste y denso como la niebla,

no surge recto ni se eleva hacia lo alto-

asedia a los propios penates en una nube deforme.

El acto de cocción termina por confutar toda norma social. ${ }^{233}$ El abyecto es desplegado por completo en la representación y es resocializado al ser ofrecido como un banquete formal y familiar, que, sin embargo, resulta en la desintegración y confutación de todo lazo familiar y social: el padre canibalizará los abyectos de sus hijos ofrecidos como una cena fraterna por el propio hermano de la víctima.

El abyecto es, entonces, una condición, un proceso o un estado que colapsa los definidos límites existentes entre sujeto y objeto. ${ }^{234} \mathrm{El}$ abyecto está conformado por un complejo orgánico compuesto por todas aquellas excrecencias del cuerpo, en parte vivo en parte muerto y habita la frontera que separa la condición animada de la inanimada y que, finalmente, se manifiesta en el cadáver en proceso de descomposición que desestabiliza los sentidos de identidad, orden y normas:

"These body fluids, this defilement, this shit that are what life withstands, hardly and with difficulty, on the part of death. There, I am at the border of my condition as living being. My body extricates itself, as being alive, from that border. Such wastes drop so I might live, until, from loss to loss, nothing remains in me and my entire body falls beyond the limit- cadere, cadaver. If dung signifies the other side of the border, the place where I am not and which permits me to be, the corpse, the most sickening of wastes, is a border that has encroached upon everything. It is no longer I who expel, 'I' is expelled. [...] The corpse, seen without God and outside of science, is the utmost of abjection. It is death infecting life. Abject." ${ }^{235}$

La figura de Erichto encarna, en cierta manera, esta intromisión de lo muerto en el ámbito de lo vivo y viceversa, pues ella habita precisamente el territorio donde el límite entre lo corporal y lo cadavérico, entre este y el otro mundo y entre lo puro y lo impuro, se vuelve difuso y perturbador.

\footnotetext{
${ }^{233}$ Hook, B. (2005), 22-24, 28-30 \& 35.

${ }^{234}$ Connelly, F. (2012), 115-116.

${ }^{235}$ Kristeva, J. (1982), 3.
} 
ERICHTO Y EL PROCESO DE DISOLUCIÓN DE LOS LÍMITES ESCATOLÓGICOS

La descripción de la bruja Erichto en Pharsalia VI carece, curiosamente, de detalles respecto de la constitución física de la bruja. Sólo un par de líneas, muy convencionales, hacen referencia a su aspecto:

tenet ora profanae

foeda situ macies, caeloque ignota sereno

terribilis Stygio facies pallore grauatur

inpexis onerata comis

(LUC. VI, 515-518)

Posee el rostro de la sacrílega

un aspecto horrible de suciedad, desconocedor del cielo abierto.

su aspecto terrible es agravado por una palidez estigia

cubierta por despeinados cabellos.

El resto del retrato está compuesto, básicamente, por la descripción de las acciones de la bruja. La representación de Erichto resulta de la descripción del proceso de transgresión y profanación impune de todo rito piadoso que guarda ese impuro límite entre el cadáver y el resto de los vivos. ${ }^{236}$ Erichto es definida, desde un principio, como transgresión incluso de los tenebrosos ritos de las demás brujas de Tesalia:

hos scelerum ritus, haec dirae crimina gentis

effera damnarat nimiae pietatis Erictho

inque nouos ritus pollutam duxerat artem.

(LUC.VI, 507-509)

A estos ritos de las brujas criminales, a estos crímenes de un pueblo aterrador la fiera Erichto los había despreciado por ser en exceso piadosos y había dirigido su corrupto arte hacia ritos novedosos.

La bruja es representada a través de los distintos niveles de transgresión absoluta que perpetra. Erichto habita incólume en las fronteras del abyecto, reposa su cabeza no en ámbitos sociales y definidos tales como hogares y techos o al abrigo social de una urbe sino en tumbas violentamente vaciadas y participa, desafiando a los dioses, en conversaciones prohibidas a los vivos (LUC. VI, 510-528). Sus acciones pervierten y trastruecan los delicados límites entre la vida y la muerte confundiendo y conturbando las claras fronteras entre los cuerpos vivos y los cadáveres y prevaleciendo sobre los propios dioses, supuestos garantes del orden universal, e incluso sobre la muerte misma:

${ }^{236}$ Connelly, F. (2012), 13: "A grotesque history focuses on the 'impure' boundaries: where intermixing and negotiating contest the normative center and pull it into flux." 
omne nefas superi prima iam uoce precantis

concedunt carmenque timent audire secundum.

uiuentis animas et adhuc sua membra regentis

infodit busto, fatis debentibus annos

mors inuita subit; peruersa funera pompa

rettulit a tumulis, fugere cadauera letum.

(LUC. VI, 527-532)

Toda impiedad, ante la primera palabra de su plegaria,

conceden los dioses y temen escuchar un segundo encantamiento.

Almas vivas y que aún controlan sus miembros

las entierra en su tumba, la muerte, contra su voluntad,

arrebata años a hados que aún los merecían; la pompa fúnebre

se retiró de los túmulos y los cadáveres huyeron de la muerte.

Erichto se mueve cómodamente en ese espacio grotesco e indefinido que desde sus más tempranas manifestaciones la humanidad ha tratado de significar a través de los distintos ritos funerarios: el cuerpo muerto. Éste, visto por fuera de las normas sociales, religiosas, incluso científicas, se convierte entonces en lo abyecto por excelencia. ${ }^{237} \mathrm{El}$ cadáver putrefacto es el campo donde la bruja cosecha sus tesoros:

ast, ubi seruantur saxis, quibus intimus umor ducitur, et tracta durescunt tabe medullae corpora, tunc omnis auide desaeuit in artus inmergitque manus oculis gaudetque gelatos effodisse orbes et siccae pallida rodit excrementa manus. laqueum nodosque nocentis ore suo rupit, pendentia corpora carpsit abrasitque cruces percussaque uiscera nimbis uolsit et incoctas admisso sole medullas. insertum manibus chalybem nigramque per artus stintis tabi saniem uirusque coactum sustulit et neruo morsus retinente pependit.

(LUC. VI, 538-549)

$[\ldots]$

saepe etiam caris cognato in funere dira Thessalis incubuit membris atque oscula figens truncauitque caput conpressaque dentibus ora laxauit siccoque haerentem gutture linguam praemordens gelidis infudit murmura labris arcanumque nefas Stygias mandauit ad umbras.

(LUC. VI, 564-569)

Pero, cuando se guardan en lápidas, en las que corre la secreción interna, y se endurecen los cuerpos que producen el destilado de las médulas, entonces se ensaña cruelmente con todos los miembros y hunde sus manos en las órbitas y se complace en extraher los helados ojos y roe las pálidas excrecencias de las manos secas. Rompió el lazo y los nudos asesinos con su boca, y cosechó los cuerpos colgantes

\footnotetext{
${ }^{237}$ Kristeva, J. (1982), 4 y ss.
} 
y los raspó de las cruces y arrancó las vísceras golpeadas por las lluvias

y las médulas desacostumbradas a admitir el sol.

Robó los clavos insertos en las manos y la negra excrecencia

de la putrefacción que corre por los brazos y los coágulos agrupados

y mordiendo cuelga mientras aguantan los nervios.

$[\ldots]$

Es más, a menudo en el funeral de un pariente la terrible

tesalia se inclinó sobre los miembros queridos y fingiendo besarlo

mutiló su cabeza y, oprimiendo la boca con sus dientes,

y mordiendo la lengua adherida al seco paladar

vertió murmullos en los labios secos y envió

arcanas impiedades a las sombras Estigias.

Erichto, al igual que lo hace el poeta, manipula y utiliza lo abyecto para su obra. El foco obsesivo en la boca como instrumento de apropiación del abyecto no sólo agrega horror a la descripción de los actos de la bruja sino que, en cierta manera, refleja exacerbado la imagen del padre devorando los restos de sus hijos del final de Thyestes. El horror no nace sólo de las imágenes escatológicas presentes en estos pasajes, sino de este proceso de desestabilización de los órdenes establecidos, ${ }^{238}$ de este ataque radical contra todo lo normativo y convencional y contra todo intento de significar un evento trascendente como es la muerte, que es, en definitiva, Erichto. Afirma Julia Kristeva:

"It is thus not lack of cleanliness or health that causes abjection but what disturbs identity, system, order. What does not respect borders, positions, rules. The in-between, the ambiguous, the composite. [...] Any crime, because it draws attention to the fragility of the law, is abject, but premeditated crime, cunning murder, hypocritical revenge are even more because they heighten the display of such fragility. He who denies morality is not abject; there can be grandeur in amorality and even in crime that flaunts its disrespect for the law-rebellious, liberating, suicidal crime. Abjection, on the other hand, is immoral, sinister, scheming, and shady: a terror that dissembles, a hatred that smiles, a passion that uses the body for barter instead of inflaming it",239

Erichto es una figura femenina que aglutina diversas características propias de las representaciones grotescas y abyectas tanto en su obsesión por los cuerpos muertos y sus abyecciones sino también, principalmente, por la constante ruptura de todo límite y convención humanas. El cuerpo monstruoso es un constructo eminentemente cultural,

\footnotetext{
${ }^{238}$ Connelly, F. (2012), 2: "First, the grotesque is best understood by what it does, not by what it is. It is an action, not a thing -more like a verb than a noun. Readers familiar with theories of the carnavalesque body 'in act of becoming', or the abject as a collapse of boundaries, will recognize the similarities, and indeed this study discusses them as subsets of the grotesque."

${ }^{239}$ Kristeva, J. (1982), 4.
} 
una proyección. ${ }^{240}$ Monstrum es, etimológicamente, "aquello que revela", "aquello que avisa" ${ }^{241}$ Esta monstruosidad, que es Erichto, resulta aterradora y fascinante al mismo tiempo pues se transforma en un principio enigmático y aterrador que se mueve precisamente en espacio indefinido entre la vida y la muerte.

${ }^{240}$ Connelly, F. (2012), 115-116 \& 2: "Second, what the grotesque does best is to play or, rather, put things into play. As visual forms, grotesques are images in flux: they can be aberrant, combinatory, and metamorphic. This visual flux in necessary but not sufficient in itself to define the grotesque because, at its core, the grotesque is culturally generated. Grotesque come into being by rupturing cultural boundaries, compromising and contradicting what is 'known' or what is 'proper' or 'normal'. As will become apparent, the grotesque is closely bound to the body and, consequently, to the feminine as it is constructed by western culture. [...] If the boundaries of the normative and conventional are drawn around the cultural attributes of the masculine, it is not difficult to see that grotesque creatures threatening these boundaries, any aberrations from this norms, typically bear the attributes of the feminine. Because the grotesque is a cultural phenomenon, it fuses ethical with aesthetic questions. And most important, the grotesque is best understood as something that creates meaning by prying open a gap, pulling us into unfamiliar, contested terrain."

${ }^{241}$ Calabrese, O. (1989), 106-107; Connelly, F. (2012), 116 y ss. 


\title{
RECAPITULACIÓN Y CONCLUSIONES PARCIALES
}

Existe en la literatura augustea un texto programático que, en cierta medida, define los límites y los alcances del decus apropiado para las representaciones artísticas de la época: el Ars Poetica de Horacio. En este trabajo Horacio expresa un manifiesto rechazo a toda manifestación y a toda representación grotesca o barroca aunque, por supuesto, no con estos términos precisos:

\author{
Humano capiti ceruicem pictor equinam \\ iungere si uelit et uarias inducere plumas \\ undique collatis membris, ut turpiter atrum \\ desinat in piscem mulier formosa superne, \\ spectatum admissi, risum teneatis, amici? \\ Credite, Pisones, isti tabulae fore librum \\ persimilem, cuius, uelut aegri somnia, uanae \\ fingentur species, ut nec pes nec caput uni \\ reddatur formae. 'Pictoribus atque poetis \\ quidlibet audendi semper fuit aequa potestas.' \\ Scimus, et hanc ueniam petimusque damusque uicissim, \\ sed non ut placidis coeant immitia, non ut \\ serpentes auibus geminentur, tigribus agni. \\ $[\ldots]$ \\ Denique sit quod uis, simplex dumtaxat et unum. \\ (Ars. 23)
}

Si un pintor quisiera unir a una cabeza humana un cuello de caballo e introducir coloridas plumas a los miembros asignados, de modo que torpemente una mujer hermosa por arriba terminaría en un horrible pez, ¿contendríais la risa ante esto, amigos presentes? Creedme, Pisones, que será idéntico a este cuadro el libro cuya forma invente estas figuras vanas como lo sueños de un enfermo, de modo que no posea forma única ni de pies a cabeza: 'A los pintores y a los poetas siempre se les permitió atreverse a lo que quisiesen' Lo sabemos, y esta libertad exigimos y ofrecemos por igual, pero no para que se mezclen lo plácido con lo agitado, ni se acoplen las serpientes a los pájaros ni los corderos a los tigres.

\section{$[\ldots]$}

En fin, sea lo que emprendes, al menos simple y unitario.

Horacio advierte sobre los excesos en las formas y el andamiaje lógico de la representación y los peligros que conlleva la confutación de los límites y las fronteras 
entre el material poético y las formas de expresión. ${ }^{242}$ Por lo tanto, las representaciones grotescas y barrocas que encontramos a lo largo de todas la obra de Séneca y de Lucano no son sólo una respuesta a episodios particulares y relevantes del canon literario establecido sino que también manifiestan una postura subversiva y desafiante ante un paradigma de representación particular que se instaura como un monumento arqueológico del pasado. Los proyectos creadores de nuestros autores se revelan como sistemas anti-clásicos que generan rupturas radicales en los diversos órdenes de la representación a través de la desestabilización turbulenta de los paradigmas utilizados. El "monstruo" horaciano es, en realidad, la representación de un proceso de disolución de los límites establecidos entre las distintas naturalezas de las cosas que lo componen. $^{243}$ Se plantea un ideal de representación aristotélico que impone ideológicamente un límite a la forma de lo representado:

"El arte entonces, según la concepción aristotélica, debe ser imitación de lo real y figurar las cosas como son o podrían ser. Debe representar lo verosímil (to eíkos). En el cuadro que Horacio escarnece, por el contrario, las species son inconsistentes y confusas (vanae v. 7): fantasías privadas de contacto con la realidad, como las imágenes concebidas en el sueño del enfermo que delira - prefiguración del poeta insanus-, y combinadas de tal modo que ni la cabeza ni los pies podrían atribuirse a una única forma (uni... formae, vv. 8-9). En los términos uni ... formae vuelve a asomar, de modo contundente, el concepto aristotélico de la unidad de la obra de arte y podemos entonces dejar establecía junto a la equivalencia species- eídos señalada por Bink, la equivalencia forma- eídos; equivalencia que, por otra parte, es tradicional." 244

"Pero entiendo que es esencial atender a la forma característica de una y otro, no para oponer el ánfora al cántaro [vv. 21-22], sino para asumir como incompatible que de una forma simétrica surja una forma asimétrica, es decir, que se desvirtúe la forma pensada originalmente." 245

El axioma simplex et unum es, entonces, la coraza que los modos de representación augusteos imponen a la forma de lo representado. Simplex (sine plico) significa sin pliegues ni dobleces, sin composición, mientras que unum expresa la unidad sintética: el término simplex equivale al griego haploús, mientras que unum equivale a hén y es común encontrarlo en Aristóteles trabajando en conjunto con el término hólon (todo, completo) -tó hén kai tó hólon, la unidad y la totalidad (1451 a). ${ }^{246}$

Lo grotesco irrumpe en las formas barrocas y expresionistas que hemos analizado para revelar la inadecuación de los ideales representados y expresar la

\footnotetext{
${ }^{242}$ Connelly, F. (2012), 26-28.

${ }^{243}$ Caballero, M. (2007), 73-74.

${ }^{244}$ Calabrese, O. (1989), 197-199; Kilpatrick, R. (1990), 37-38; Caballero, M. (2007), 74-75.

${ }^{245}$ Caballero, M. (2007), 77.

${ }^{246}$ Caballero, M. (2007), 77-78.
} 
naturaleza deforme de estos: el horror que permea la representación actúa como catalizador de las operaciones poéticas que generan la disolución de la forma de lo representado y de los signos que conforman la representación, generando la polivalencia del significante y la subversión de los significados. ${ }^{247}$ La representación grotesca se caracteriza por poner en juego los límites entre el sujeto y el objeto y en forzar al receptor a tomar decisiones estéticas e ideológicas específicas:

"Ruskin grasped the essential elements. The first was that the grotesque confounds language and logical sequence as it fuses together disparate realities. The second element was that the grotesque opens up a liminal space, full of ambiguities and contradiction that requires us to 'overlap the gaps' in order to make meaning of it. Of enormous importance is Ruskin's insight that the grotesque places the viewer in an inbetween, unresolved space, compelling each individual to take these disparate elements and make meaning of it." 248

Los pliegues y repliegues de los significantes senequianos $\mathrm{y}$, sobre todo, de los lucanianos difuminan la relación significante/significado: las conexiones múltiples y variadas deben ser resueltas por el lector/ espectador a través de una violenta operación ideológica para imponer sentido a costa de la ruina de los demás significados posibles.

247 Asso, P. (2009), 169: "We should however regard the Stoic imagery of cosmic dissolution as enhancing Lucan's rhetorical poetics rather than as a statement of Stoic orthodoxy."

${ }^{248}$ Connelly, F. (2012), 152. 


\section{PRIMERA PARTE: RePRESENTACIÓN DE LOS}

PARADIGMAS FILOSÓFICOS. 


\title{
III. SUBVERSIÓN DE LAS ESTRATEGIAS DE CONSTRUCCIÓN DEL YO ESTOICO.
}

\begin{abstract}
"From the idea that the self is not given to us, I think that there is only practical consequence, we have to create ourselves as a work of art.",249
\end{abstract}

SÉNECA Y FOUCAULT

Los personajes senequianos presentan, a lo largo de la obra, una profunda y lúcida conciencia de sí. Esta característica hace que la tragedia de Séneca se concentre en los métodos y los procesos a través de los cuales sus dramatis personae construyen, adoptan y reafirman sus identidades existenciales. La búsqueda y construcción de la identidad del héroe es puesta en escena de manera casi obsesiva a través de la mención del propio nombre y de ciertas técnicas discursivas que Foucault ha identificado como las "técnicas de sí". ${ }^{250}$ Debemos sin embargo, antes de seguir adelante, hacer una breve reseña sobre la relación de Michel Foucault con nuestro autor y con la filosofía antigua en general pues, en los últimos trabajos y cursos dictados por Michel Foucault antes de su muerte en 1984, el pensador se vuelca de lleno al análisis del pensamiento grecoromano, con el cual siempre tuvo una particular relación de proximidad y extrañamiento. $^{251}$

La aparición impresa del curso de L'Herméneutique du Sujet, dictado a principios de 1982 permitió descubrir una innovadora y particular relectura de los pensadores clásicos grecolatinos como Platón, Epicteto, Musonio Rufo, Séneca y Marco Aurelio entre otros. ${ }^{252}$ El trabajo despliega un verdadero uso de estas doctrinas filosóficas: Foucault se detiene más en las estrategias utilizadas por estos autores en sus obras que en refutar o defender las distintas tesis propuestas por los filósofos. ${ }^{253}$ Nos

\footnotetext{
${ }^{249}$ Foucault, M. (1983), 237.

${ }^{250}$ Fitch, J. \& McElduff, S. (2008), 157-158 \& 163 y ss. Cf. también Rosenmeyer, Th. (1989), xvi.

${ }^{251}$ O’Leary, T. (2002), 21-22; Gros, F. (2003), 5.

${ }^{252}$ Foucault, M. (2001b), "Cours du 20 janvier 1982- Première heure", 79-103; "Cours du 27 janvier 1982- Deuxième heure", 144-162; "Cours du 3 février 1982- Deuxième heure", 180-196; "Cours du 17 février 1982- Première heure", 237-259; "Cours du 17 février 1982- Deuxième heure", 260-276; "Cours du 24 février 1982- Première heure", 277-300; "Cours du 10 mars 1982", 355-394; "Cours du 17 mars 1982- Deuxième heure", 419-434.

${ }^{253}$ El propio Foucault reconoció siempre no ser un especialista en la filosofía antigua. De hecho, se sabe que gran parte de sus interpretaciones surgen de fuentes indirectas y remiten a comentarios de grandes historiadores franceses, por supuesto, como Festugière y Hadot, por eso hablamos siempre de "usos" y no
} 
interesa, por supuesto, la en principio curiosa relación de Foucault con el estoicismo y los conceptos operativos que él llama "las prácticas de sí". 254 Foucault distingue un cambio notorio entre los modelos de sujeto que se construyen durante la "época clásica" (siglos V y IV a.C.), particularmente en las obras de Platón y Aristóteles, ${ }^{255}$ centrado éste en el dominio de sí (maîtrise de soi), donde este dominio de sí es el paso necesario para el gobierno, o dominio, del otro y los modelos romano y helenístico propuestos por autores como Séneca, Marco Aurelio y Epícteto, particularmente, en los cuales Foucault encuentra otro tipo de sujeto: uno carente del enfoque teleológico apuntado a la polis pero enfocado sobre sí mismo, dedicado a un cuidado de sí (souci de soi) que se concentra y se vuelve casi atléticamente sobre su propia subjetividad. ${ }^{256}$ En sus últimos trabajos Foucault analiza la evolución de las técnicas de sí y de los modos de conducirse y constituirse como sujetos de los antiguos griegos y romanos, así como también las prácticas de los primeros cristianos. ${ }^{257}$

Por supuesto que estas afirmaciones han encontrado tanto detractores como defensores. $^{258}$ Quienes defienden al pensador francés, aun reconociendo ciertas falencias metodológicas, consideran más importante su actitud de:

“[...] prestar atención a las estrategias más que a las tesis tiene como resultado una concepción original de las diferencias entre las escuelas filosóficas helenísticas. De hecho, Foucault no toma en cuenta jamás los debates teóricos entre las escuelas y parece concebir sus diferencias como divergencias tácticas en el seno de un mismo modelo estratégico del cuidado de sí. [...] Foucault se contenta con recopilar y yuxtaponer las distintas prácticas de sí que encuentra en los textos pues, según su enfoque, su divergencia no implica incompatibilidad lógica alguna sino que se inscribe en una misma doctrina estratégica." ${ }^{259}$

Otros estudiosos no coinciden con esta perspectiva de análisis y encuentran ciertas falencias puntuales en los análisis y en la fundamentación de los conceptos que dan forma a los diversos cuidados de sí. Brad Inwood, especialmente, afirma en varios artículos que la tesis de Foucault no termina de demostrar la existencia de un "yo" ontológicamente determinable: ${ }^{260}$

de "lecturas" o "interpretaciones". Bénatouill, Th. (2003) 13-14, 20-28, 40 \& Gros, F. (2003), 5-9; Luxon, N. (2008), 396-397.

${ }^{254}$ Long, A. (2003), 204-205.

${ }^{255}$ Foucault, M. (2001b), "Cours du 6 janvier 1982", "Course du 13 janvier 1982" \& "Cours du 20 janvier 1982- Première heure", 3-103; Foucault, M. (1988), 20-27; Ingwood, B. (2005), 326-332.

${ }^{256}$ Gros, F. (2003), 8-9; Luxon, N. (2008), 384 y ss. Long, A. (2003), 192 \& 204.

${ }^{257}$ Gabilondo, A. (1999), 27.

${ }^{258}$ Longford, G. (2001), 570-574.

${ }^{259}$ Bénatouill, Th. (2003), 23.

${ }^{260}$ Cf. particularmente "The will in Seneca" y "Seneca and Self-assertion" en Inwood, B. (2005). 
"Let me conclude. I've tried to sort out what it might and might not mean to talk about a new distinctive sense of the self in Seneca's philosophical works. I've pushed for a strong negative answer on the question of whether there are any new ontological commitments in the philosophy of the mind. [...] Similarly, I don't think that there are interesting new conceptual breakthroughs in the area of moral education or moral improvement. This was a common theme from the fourth century BC onwards and I don't think we have adequate grounds for following Foucault in detecting dramatically new techniques of self-shaping in Seneca-I certainly think we need to be very cautious about regarding them as quasi- institutionalized practices new to the environment of the early empire."261

Sin embargo, aun si la originalidad de los conceptos y su formulación ontológica puede estar en discusión, sí es cierto que existe, tanto en la obra de Séneca como en la de los otros autores estudiados por Foucault, un vocabulario determinado aplicado a una actitud particular frente a la existencia que el pensador francés denomina cuidado de sí y que se lleva a cabo a través de ciertas técnicas y estrategias específicas. ${ }^{262}$ Pretendemos aplicar las herramientas hermenéuticas proporcionadas por Foucault en la obra poética de Séneca, dejando de lado la cuestión filosófica de la novedad ontológica de los conceptos (ajena, en todo caso, a nuestro enfoque particular). ${ }^{263}$

\section{LAS TÉCNICAS DE SÍ}

Las técnicas de sí pueden definirse, según Foucault, como "prácticas meditadas y voluntarias mediante las cuales los hombres no sólo se fijan reglas de conducta, sino que procuran transformarse a sí mismos, modificarse en su ser singular y hacer de su vida una obra."264 Foucault detecta diferentes procedimientos y estrategias de autocontrol, auto-contemplación y auto-afirmación de la propia subjetividad del sujeto dentro de la práctica del estoicismo de diversos autores (Séneca y Marco Aurelio particularmente) en el iterativo y efectivo proceso de volver la mirada sobre sí mismo del yo estoico. ${ }^{265}$ Estas pueden agruparse en las siguientes preceptivas: sibi vindicare, se facere, ad studia revocare, sibi applicare, suum fieri, in se recedere y secum morari. ${ }^{266}$

\footnotetext{
${ }^{261}$ Inwood, B. (2005), 351-352.

${ }^{262}$ Reydams-Schils, G. (2005), 3-5.

${ }^{263}$ Foucault, M. (1974), 523-524.

${ }^{264}$ Foucault, M. (1983), 237; Foucault, M. (1994), 545.

${ }^{265}$ Reydams-Schils, G. (2005), 3-4, 9-10 \& 23-26.

${ }^{266}$ Foucault, M. (1997), 44-45; Reydams-Schils, G. (2005), 36-37. Cf. también Séneca, Sibi vindicare: Ep. I, 1: "Ita fac, mi Lucili: vindica te tibi, et tempus quod adhuc aut auferebatur aut subripiebatur aut excidebat collige et serva"; Se facere: Vit. XXIV, 4: Non est ergo quod perperam exaudiatis quae honeste fortiter animose a studiosis sapientiae dicuntur. Et hoc primum adtendite: aliud est studiosus sapientiae, aliud iam adeptus sapientiam. Ille tibi dicet: 'optime loquor, sed adhuc inter mala uolutor plurima. Non
} 
Estas estrategias y metodologías existenciales se basan en el constante monitoreo por parte del individuo de sus procesos subjetivos $\mathrm{y}$ en una atenta vigilancia de las vicisitudes de su alma con el objetivo de detectar, prevenir y rectificar, a través de la askêsis y la auto-admonición, ${ }^{267}$ cualquier fluctuatio animi que pretenda desviar al proficiens de su búsqueda de la virtud. ${ }^{268}$ La tragedia de Séneca no es, como se ha sugerido, un complemento a sus escritos filosóficos, ${ }^{269}$ ni tampoco es plausible, tal como lo han propuesto algunos críticos, negar la autoría de Séneca aduciendo que la crueldad y el gore presentes en el marco de la representación no coincidiría con la voz

est quod me ad formulam meam exigas: cum maxime facio me et formo et ad exemplar ingens attollo; si processero quantumcumque proposui, exige ut dictis facta respondeant. "; Ad studia revocare: Tranq. III, 6 : "Si te ad studia reuocaueris, omne uitae fastidium effugeris, nec noctem fieri optabis taedio lucis, nec tibi grauis eris nec aliis superuacuus; multos in amicitiam attrahes affluetque ad te optimus quisque. Numquam enim, quamuis obscura, uirtus latet, sed mittit sui signa: quisquis dignus fuerit uestigiis illam colliget."; Sibi applicare: De tranq animi, XIV, 2: "Vtique animus ab omnibus externis in se reuocandus est: sibi confidat, se gaudeat, sua suspiciat, recedat quantum potest ab alienis, et se sibi applicet; damna non sentiat, etiam aduersa benigne interpretetur."; Suum fieri: Ep. LXXV, 16-18: "'Ego vero' inquis 'spero me posse et amplioris ordinis fieri.' Optaverim hoc nobis magis quam promiserim: praeoccupati sumus, ad virtutem contendimus inter vitia districti. Pudet dicere: honesta colimus quantum vacat. At quam grande praemium expectat, si occupationes nostras et mala tenacissima abrumpimus! Non cupiditas nos, non timor pellet; inagitati terroribus, incorrupti voluptatibus, nec mortem horrebimus nec deos; sciemus mortem malum non esse, deos malo non esse. Tam inbecillum est quod nocet quam cui nocetur: optima vi noxia carent. Expectant nos, $<$ si $>$ ex hac aliquando faece in illud evadimus sublime et excelsum, tranquillitas animi et expulsis erroribus absoluta libertas. Quaeris quae sit ista? Non homines timere, non deos; nec turpia velle nec nimia; in se ipsum habere maximam potestatem: inaestimabile bonum est suum fieri. Vale."; In se recedere: Tranq. III, 2 : "Sed, quia in hac, inquit, tam insana hominum ambitione, tot calumniatoribus in deterius recta torquentibus, parum tuta simplicitas est et plus futurum semper est quod obstet quam quod succedat, a foro quidem et publico recedendum est. Sed habet ubi se etiam in priuato laxe explicet magnus animus, nec, ut leonum animaliumque impetus caueis coercetur, sic hominum, quorum maximae in seducto actiones sunt.", Ep. XXII, 8 : "Ne illud quidem quod existimas facturum eum faciet, ut ambitiosis rebus implicitus semper aestus earum ferat; sed cum viderit gravia in quibus volutatur, incerta, ancipitia, referet pedem, non vertet terga, sed sensim recedet in tutum.", Ep. XXV, 6-7: "incipiam tibi permittere quod idem suadet Epicurus: 'tunc praecipue in te ipse secede cum esse cogeris in turba'. Dissimilem te fieri multis oportet, dum tibi tutum [non] sit ad te recedere.", Secum morari: Ep. II, 1: "Ex iis quae mihi scribis et ex iis quae audio bonam spem de te concipio: non discurris nec locorum mutationibus inquietaris. Aegri animi ista iactatio est: primum argumentum compositae mentis existimo posse consistere et secum morari."

${ }^{267}$ Reydams-Schils, G. (2005), 15-18; Foucault, M. (1988), 35: "In the philosophical tradition dominated by Stoicism, askêsis means not renunciation but the progressive consideration of the self, or mastery over oneself, obtained not through the renunciation of reality but through the acquisition and assimilation of truth. [...] It is a set of practices by which one can acquire, assimilate, and transform truth into a permanent principle of action. Aletheia becomes ethos. It is a process of becoming more subjective." Cf. también Foucault, M. (2001b), "Cours du 24 février 1982- Deuxième heure”, 301-314.

${ }^{268}$ Foucault, M. (1988), 28-29 \& 33-34; Star, Ch. (2006), 225-226 \& 207-208: "The characters in Seneca's tragedies talk to themselves. This habit is not unique to Seneca; self-apostrophe can be tracked back to Homeric epic. Yet Senecan characters address themselves, their animus, or their passions with a frequency that has often attracted the comments of scholars. [...] I argue that the rhetorical language these characters [Clitemnestra, Medea \& Atreus] direct at themselves has explicit connections to Seneca's philosophy. As they plot and carry out their revenge, the language of self-address becomes the mean by which Seneca's characters fashion themselves, battle against psychological fluctuation and strive to achieve consistency of mind and action." Respecto del despliegue sistemático y obsesivo de los diversos procedimientos literarios y dramáticos en la tragedia de Séneca, cf. Rosenmeyer, Th. (1989), xii.

${ }^{269}$ Marti, B. (1945), passim. 
calma y mesurada de sus trabajos en prosa. ${ }^{270} \mathrm{Al}$ contrario, creemos que la tragedia de Séneca es parte integral y orgánica de su pensamiento, la otra cara del optimismo estoico desplegado en su obra en prosa. ${ }^{271}$

Séneca fue un filósofo que supo apreciar y dialogar con otras escuelas filosóficas con gran altura, inteligencia y profundidad y de ningún modo fue un defensor fanático o ciego de su propia doctrina: ${ }^{272}$ sus tragedias son, finalmente, una valiente exploración de los rincones más oscuros e inestables del pensamiento estoico, ${ }^{273}$ donde la representación paradójica de las problemáticas estoicas eclipsa por completo la exposición doctrinaria que le suelen achacar ciertos autores. ${ }^{274}$ Los personajes recurren a estas técnicas de subjetivación recomendadas por Séneca al proficiens para que éste pueda afirmarse a sí mismo, mantener su curso en la búsqueda de la virtus y lograr desarrollar todo su potencial, ${ }^{275}$ para construirse y afirmarse existencialmente en tanto criminales y para combatir cualquier fluctuatio animi que los haga dudar de su propósito, mostrando de esta manera una constantia propia del sabio. ${ }^{276}$ En las tragedias las pasiones representadas no arrebatan a los personajes contra su voluntad, más bien

\footnotetext{
${ }^{270}$ Fischer, E. (1945), 108-109.

${ }^{271}$ Fitch, J. (1987), 40-41.

${ }^{272}$ SEN. Ep. I, 5: "Hoc ipse quoque facio; ex pluribus quae legi aliquid apprehendo. Hodiernum hoc est quod apud Epicurum nanctus sum - soleo enim et in aliena castra transire, non tamquam transfuga, sed tamquam explorator-"; Sharples, R. (1996), 1-4; Frank, M. (1995), 27: "John Herington has suggested that Seneca's mode of composition in his prose works and his tragedies "was ... that of free modelling in his own manner around some relatively simple armature provided by tradition; that he worked currente calamo with no other man's book open before him continually, but with a thousand literary memories swarming in his brain."; Rosenmeyer, Th. (1989), 5: "He is, to be sure, an eclectic philosopher. Like bees, he says (Ep. 84.5), we must gather our readings from various sources and use our intelligence to make them into one authentic essence."

${ }^{273}$ Rosenmeyer, Th. (1989), 43: "In his role as a moral guide and imperial voice, Seneca naturally preferred to express himself in the flexible, but unequivocal cadences of philosophical tract. But no great leap of imagination is required to see him turning to verse and fully dramatized arguments where he wished, not to teach, but to submit the more controversial, less settled movements of his thinking to the test of confrontation with the realities of a familiar world. In the process, one imagines, he was also intrigued by the possibilities of creating something new, an art that might show him to have written finis to a moribund tradition, and to have put in its place a worthy and enriching successor."; Frank, M. (1995), 29-32.

${ }^{274}$ Marti, B. (1945), 216-223. Cf., contra, Rosenmeyer, Th. (1989), 79: "The Stoic paradoxes win out over the Stoic sermonizing"

275 Graver, M. (2007), 53.

${ }^{276}$ Star, Ch. (2006), 210: "This criminal application of Stoicism also reveals a horrifying danger that lies at the core of Seneca's theory of self-command. As the Stoics argue, the passions are intimately related to reason and intention, spring from voluntas and judgment, and can thus be quelled by the application of reason. In his tragedies, Seneca isolates and reveals the rational and intentional element inherent in the passions; he shows that it is possible to create a consistently vicious character by manipulating and 'misapplying' Stoic ideas. Self-control and consistency lie at the core of the performance of criminal acts. The control that the characters are able to exert over their passions brings out some of the darker, and unspoken, implications of the famous Stoic paradox of the relationship of the passions to reason and judgment. [...] The oppositions of constantia and inconsistency, vice and virtue do not lie as comfortably distant as we would like to believe."
} 
todo lo contrario, los personajes, lejos de describir pasivamente el efecto de la pasión en sus mentes o ánimos, constantemente monitorean y alimentan los monstruosos impulsos que se agitan en lo más profundo de sus almas. El horror nace no del crimen mismo, sino de la razón desequilibrada que lo impulsa, lo pergeña y lo lleva a cabo con una conciencia estética verdaderamente racional.

\section{MÉTODOS Y ESTRATEGIAS ESTOICAS PARA FINES ANTIESTOICOS}

Los personajes senequianos despliegan un uso particular de una virtud específica, la constantia, aplicada al seguimiento, monitoreo y control de su ímpetu irracional. Este control tiene como objetivo primordial no detectar y sofocar el furor sino todo lo contrario: el objetivo es protegerlo de cualquier fluctuatio animi o displicentia sui $^{277}$ que pueda debilitarlo o apagarlo. Esto se logra a través de constantes órdenes y exhortaciones dirigidas a sí mismos, a su animus o a sus pasiones: el lenguaje del yo es, para Séneca, eminentemente imperativo. La representación de personajes esforzados y constantes en el crimen, que despliegan además una constantia casi ideal en el desarrollo de sus pasiones, resulta en una radical subversión del paradigma filosófico sobre el que se construye el universo trágico senequiano, en el cual la virtud puede estar ligada inexorablemente al vicio. El constante uso de métodos y conceptos estoicos para alcanzar ideales anti-estoicos es lo que da profundidad, densidad dramática y espesor semántico a los personajes senequianos. ${ }^{278}$ Las pasiones, paradigma de la inconsistencia, se construyen, se alimentan a través de precisas técnicas de autocontrol y auto-evaluación. ${ }^{279} \mathrm{El}$ hecho de que los personajes recurran al arsenal de estrategias y técnicas propuestas por el filósofo en sus obras en prosa revela indudablemente que se está indagando en los aspectos más profundos y paradójicos del modelo. ${ }^{280}$ Nos concentraremos en las tragedias de venganza (Ag., Med. y Thy.) pues

\footnotetext{
277 SEN. Tranq. II, 10.

${ }^{278}$ Star, Ch. (2006), 220: "Seneca's characters are not simply antitypes; rather, they present a complicated and multilayered portrayal of the passions. Thus, while they appear to perform a transvaluation of Stoic values, and embrace nefas, vice, and the passions, this 'transvaluation' is in fact set in Stoic terms. The means by which Clytemnestra, Atreus, and Medea achieve their goals are paradoxically based upon Stoic ideals of consistency and self-command. The implications of this fact are two-fold. On the one hand, Seneca's characters remain parasitical upon Stoicism. Despite their declarations of 'going beyond' all previous crimes, they cannot break free of the moral structures they wish to destroy. At the same time, however, the tragedies reveal that Stoic control and constantia contain the seeds of their opposite, the ideal of criminal self- control and consistency of vice“"

${ }^{279}$ O'Leary, T. (2002), 33-34.

${ }^{280}$ Star, Ch. (2006), 208-210; Rosenmeyer, Th. (1989), 43.
} 
son las que despliegan con mayor frecuencia y profundidad estos procedimientos filosóficos/literarios.

\section{CLITEMNESTRA: REINA DE LAS PASIONES}

Clitemnestra hace su aparición en escena en el preciso momento en que su determinación y resolución flaquean. Sus primeras palabras dan cuenta de esta fluctuatio animi que ella detecta operando en su subjetividad:

Quid, segnis anime, tuta consilia expetis? quid fluctuaris? clausa iam melior uia est. licuit pudicos coniugis quondam toros et sceptra casta uidua tutari fide; periere mores ius decus pietas fides et qui redire cum perit nescit pudor; da frena et omnem prona nequitiam incita: per scelera semper sceleribus tutum est iter.

¿Por qué, ánimo perezoso, esperas proyectos seguros? ¿Por qué fluctúas? ya se ha cerrado el camino mejor. Pudiste antaño cuidar los púdicos lechos conyugales y los cetros viudos con casta lealtad; ha muerto toda costumbre, todo derecho, decoro, piedad, lealtad y todo pudor, que no sabe regresar una vez que se ha perdido; afloja las riendas y excita, lanzándote adelante, toda indolencia: el camino para los crímenes siempre es seguro a través de los crímenes.

La reina repliega su mirada sobre sí misma, hacia su propia interioridad subjetiva y allí donde encuentra una falla o una debilidad, aplica su ratio para enmendar y corregir la falla, es decir, aplica su voluntad sobre sí misma y se construye de acuerdo a esto. ${ }^{281}$ Sin embargo, la aplicación de estas metodologías eminentemente estoicas se da con fines decididamente anti-estoicos:

quocumque me ira, quo dolor, quo spes feret, hoc ire pergam; fluctibus dedimus ratem.

ubi animus errat, optimum est casum sequi.

A donde la ira, a donde el dolor, a donde la esperanza me lleve, hacia allí me esforzaré en ir; a las olas entregamos la nave. Cuando el ánimo se pierde, lo mejor es seguir el azar.

${ }^{281}$ Tarrant, R. (1976), 194. 
Los personajes se afirman existencialmente a través de estos procedimientos, que suelen aparecer en el entramado textual junto a otro recurso que caracteriza la profunda conciencia criminal de los personajes: la libido superandi o necesidad de superar a sus predecesores míticos. Los personajes están al tanto, en mayor o menor medida, de la necesidad de superar famosos crímenes previos, ya sean estos en el plano familiar o histórico-mítico, manifestando a nivel diegético lo que Harold Bloom llamó la angustia de las influencias con tanta profundidad que, como en el caso de Medea y Atreo, los personajes parecen poseer una conciencia meta-teatral y meta-literaria. Clitemnestra es consciente de la historia de crímenes ejemplares que la preceden: ${ }^{282}$

Tecum ipsa nunc euolue femineos dolos, quod ulla coniunx perfida atque impos sui amore caeco, quod nouercales manus ausae, quod ardens impia uirgo face Phasiaca fugiens regna Thessalica trabe: ferrum, uenena-uel Mycenaeas domos coniuncta socio profuge furtiua rate. Quid timida loqueris furta et exilium et fugas? soror ista fecit: te decet maius nefas.

(Ag. 116-124)

Repasa ahora los engaños femeninos, aquello a lo que toda esposa pérfida se atrevió fuera de sí por su ciego amor, a lo que se atrevieron las manos de una madrastra o una doncella enamorada por una antorcha impía al huir de los reinos de Tesalia en la nave de fasos: hierro, veneno- o abandona los palacios de Micenas junto a su cómplice en un navío furtivo.

¿Por qué hablas tímida de cosas furtivas y del exilio y de fugas?

Esto lo hizo tu hermana: a ti te corresponde una impiedad mayor.

La adecuación de los personajes a los modelos mítico-familiares se lleva a cabo, nuevamente, a través de la propia auto-configuración del protagonista, ${ }^{283}$ a través de su propia historia y, en general, en relación directa con diversos exempla criminales, los que deben ser superados para poder así afirmarse existencialmente, motivados por un sentido de timé y kléos desbocado y criminal, tal como el desplegado por Vulteyo en el libro cuatro de Pharsalia. ${ }^{284}$ En este caso las menciones a Fedra, Helena y Medea son claras y operativas. Los personajes senequianos son profundamente conscientes de su propia reputación, casi al punto de crear una ruptura en el verosímil dramático. ${ }^{285}$

\footnotetext{
${ }^{282}$ Tola, E. (2009), 85-86.

${ }^{283}$ Dupont, F. (1995), 123 y ss.

${ }^{284}$ Sklenáŕ, R. (2003), 23-33.

${ }^{285}$ Star, Ch. (2006), 223.
} 
Las palabras que el fantasma de Tiestes dirige a su hijo muestran características similares: $:^{286}$

\author{
causa natalis tui, \\ Aegisthe, uenit. quid pudor uultus grauat? \\ quid dextra dubio trepida consilio labat? \\ quid ipse temet consulis torques rogas, \\ an deceat hoc te? respice ad matrem: decet.
}

Llega, Egisto, la causa

de tu nacimiento. ¿Por qué la vergüenza abruma tu rostro?

¿Por qué bajas tus manos temblorosas por el peligroso proyecto?

¿Por qué te consultas, te atormentas y te ruegas a tí mismo?

¿Acaso no te corresponde esto?: Mira a tu madre: te corresponde.

(Ag. 48-52)

Los exempla míticos y familiares operan, dentro de la tragedia, como el reverso de los distintos modelos de virtud que abundan en la obra filosófica de Séneca. ${ }^{287}$ Los personajes configuran las imágenes que, según ellos, corresponden (decet) a su posición y condición existencial: los Escipiones, Mucios, Fabricios, Rutilios, Régulos, Sócrates y Catones $^{288}$ son reemplazados entonces por Medeas, Fedras, Tereos, Tántalos y Tiestes. La propia reina se inscribe en esa tradición de modo tal que no duda en aplicar su razón desbocada al control y domesticación de las tibias virtudes que sobreviven en su alma: ${ }^{289}$

Maiora cruciant quam ut moras possim pati;

flammae medullas et cor exurunt meum;

mixtus dolori subdidit stimulos timor;

inuidia pulsat pectus, hinc animum iugo

premit cupido turpis et uinci uetat;

et inter istas mentis obsessae faces

fessus quidem et deiectus et pessumdatus

pudor rebellat. fluctibus uariis agor,

ut, cum hinc profundum uentus, hinc aestus rapit,

incerta dubitat unda cui cedat malo.

proinde omisi regimen e manibus meis:

quocumque me ira, quo dolor, quo spes feret,

hoc ire pergam; fluctibus dedimus ratem.

(Ag. 131-143)

Cosas mayores me atormentan como para que pueda soportar demoras,

${ }^{286}$ Tola, E. (2009), 88-89.

${ }^{287}$ Fitch, J. (1987), 42-44.

${ }^{288}$ SEN. Prov. II, 4-14; Const. I, 3 - II, 3; Tranq. XVI- XVII; Vit. XVII \& XXI; Ira. 2, XXXII; Ep. VII, 6; IX, 8 \& 17-19; XII, 14; XIV, 12; XXIV, 1-14; XXVI; 6; LI, 10-12; LVII, 11; LVII, 5-16; LXIV; 10; LXX, 17-22; LXXI, 8-28; LXXIX; 14; LXXXII, 11-13; LXXXVI; XCIV, 27; XCVIII, 67-72; CXVII, 816; CXVIII, 11-18; CIV; 21 \& 29-33; CXVIII, 4;CXX, 6-19; CXXII, 3. Cf. también Gowing, A. (2005), $80-82$.

${ }^{289}$ Para los estoicos, la razón humana y la divina están necesariamente relacionadas, cf. Setaioli, A. (2007), 356. 
las llamas consumen mis huesos y mi corazón.

El temor, mezclado al dolor, apaga mi impulso,

la envidia golpea mi pecho; de un lado una vergonzosa pasión

oprime mi ánimo con su yugo y no permite ser vencida,

en medio de esas antorchas que invaden mi mente,

en verdad agotado y abatido y agobiado

se rebela el pudor. Soy llevada por olas contrarias,

como cuando al mar profundo hacia allí los vientos, hacia allá la marea

lo arrastran, e indecisa la ola duda a qué mal ceder.

Por lo tanto he soltado el timón de mis manos:

A donde la ira, a donde el dolor, a donde la esperanza me lleve, hacia allí me esforzaré en ir; a las olas entregamos la nave.

La inversión de la imagen del timonel como garante de la nave (ya sea esta una metáfora del estado o del alma) es precisa y operativa. La resolución criminal de la reina se ve amenazada por el pudor, que presenta una tímida resistencia a las pasiones. Éstas agitan y gobiernan el alma de Clitemnestra quien, en medio de la tormenta, toma la decisión racional de entregar la nave a los vientos y a las olas. ${ }^{290}$

La ratio es entregada a la furiosa tempestad espiritual que azota el alma de Clitemnestra a través de una decisión racional y meditada, lograda luego de superar la fluctuatio animi generada, paradójicamente, por el último resabio de virtud que sobrevivía en su alma y que amenazaba con desviarla de su objetivo criminal. La reina ha seguido las prácticas y los procedimientos estoicos de auto-control y autoadmonición, es decir, las técnicas de sí, apropiadas para detectar, identificar y someter cualquier resistencia a su propósito. Además, a su constantia se suma ahora su propia conciencia de formar parte de una tradición criminal, tal como vimos en los versos 116124. Como ya hemos destacado, renombrados críticos han acusado a los personajes senequianos de poseer una conciencia extra-diegética en lo que respecta a la tradición clásica y de expresarse entonces con conocimientos meta-teatrales y meta-literarios. En cuanto a esta operación de lectura, creemos que en ella actúan dos factores de gran importancia para comprender este procedimiento dramático: lo que dice el personaje en sí y la respuesta que estas palabras disparan en nuestro saber enciclopédico como receptores de la obra, es decir, la proyección sobre los significantes escénicos de los conocimientos literarios, míticos y dramáticos. ${ }^{291}$ Este procedimiento puede

\footnotetext{
${ }^{290}$ Tola, E. (2009), 89; Star, Ch. (2006), 224-225; Littlewood, C. (2004), 63-65; La cercanía semiótica y simbólica entre ratio y ratis ya había sido destacada por Cicerón en Tusc. I, 30, 73: tamquam in rate mari inmenso nostra vehitur ratio.

${ }^{291}$ Rosenmeyer, Th. (1989), 170.
} 
interpretarse como una falla, tal como lo demuestra la famosa exclamación de Ulrico von Wilamowitz y tal como lo consideran algunos estudiosos aún en nuestros días: ${ }^{292}$

"[...] the vengeance of Medea and Atreus has the authority of an established myth. The dramatic illusion is shaken, the world broken, at line 171 because Medea implies a knowledge of the course of the tragedy. The Nurse speaks of Medea as a person, Medea of herself as a myth already written." 293

Por otro lado, estos pasajes también pueden ser interpretados como un particular e innovador procedimiento que pone en juego de manera extremadamente sutil una relación directa de identificación entre el receptor y el protagonista, generando una proyección de nuestro saber enciclopédico al plano de la acción dramática. Medea no ha leído a Eurípides, tampoco Clitemnestra o Atreo, pero von Wilamowitz, Séneca y nosotros sí lo hemos hecho y nuestros saberes se disparan de manera casi inconsciente al leer estos pasajes. Habla de la maestría y pericia con que este recurso poético está utilizado en la obra el hecho de que pueda pasar desapercibido aun para críticos de la talla de von Wilamowitz.

Cuando Atreo dice:

Hoc, anime, occupa dignum est Thyeste facinus et dignum Atreo, quod uterque faciat. Vidit infandas domus Odrysia mensas - fateor, immane est scelus, sed occupatum; maius hoc aliquid dolor inueniat.

Aprópiate, ánimo, de esto, digno es este crimen de Tiestes y digno de Atreo, cualquiera de los dos que lo cometa. Ya contempló estas mesas infames el palacio Odrysio- lo reconozco, enorme es el crimen, pero ya fue realizado; que mi dolor encuentre algo aún mayor.

El rey se refiere a la venganza de Procne y Filomela sobre Tereo ocurrida en Tracia, un evento, si se quiere, "diegéticamente contemporáneo" a la acción dramática. Pero la importancia de estos versos no está en el aspecto "cronológico-mítico" sino en la respuesta involuntaria e inconsciente que producen sobre los saberes enciclopédicos del receptor disparando asociaciones sintagmáticas inmediatas. ${ }^{294} \mathrm{El}$ protagonista menciona un crimen famoso ocurrido en el plano mítico, pero el receptor, familiarizado con Ovidio, no puede evitar que Metamorfosis 6, 424-674 opere en su decodificación del

\footnotetext{
${ }^{292}$ von Wilamowitz-Moellendorff, U. (1906), 162.

${ }^{293}$ Littlewood, C. (2004), 46.

${ }^{294}$ Littlewood, C. (2004), 105.
} 
pasaje. Opera también, para nosotros, cierto cuerpo de información histórica que para el público romano era, en realidad, obras teatrales presentes y tangibles: nos referimos a la gran producción trágica del siglo II y I a.C., que sólo conocemos de manera extremadamente fragmentaria. Cuando Atreo dice "Ya conoció la casa Odrysia/ estas mesas infandas. Lo reconozco, enorme es el crimen/ pero ya fue actuado. Que mi dolor encuentre/ algo aún más grande.”, resuenan inexorable e inevitablemente en el receptor, particularmente en el romano, los Tereus de Accio y Livio Andrónico y las numerosas producciones teatrales que trataban sobre la serie de crímenes fraternos que caracteriza a los Pelópidas, tal como las representaron el ya nombrado Accio, Pomponio Secundo, Emilio Escauro, Ennio, Vario y Graco. ${ }^{295}$ Como vemos, ambos proyectos, el del tragediógrafo y el del protagonista son ambiciosos y yuxtapuestos: mientras Atreo intenta superar los crímenes de sus predecesores míticos, Séneca explicita su proyecto creador y su intención de sobrepasar los méritos de los tragediógrafos anteriores. El complejísimo espesor semántico y dramático de estos pasajes es claro y operativo en varios niveles de lectura. En unos pocos versos aparecen varios procedimientos simultáneos, tanto a nivel escénico como a nivel del receptor de la acción dramática: la auto-admonición abre el discurso del rey, quien de inmediato demuestra una profunda conciencia y seguridad en su propósito criminal, pero además los significantes operan también en el nivel extra-diegético disparando en el receptor conexiones históricoliterarias y meta-dramáticas. No es casual la aparición en el pasaje de los nombres en el verso 271 (dignum est Thyeste facinus et dignum Atreo), referencia extratextual a los títulos elegidos por los predecesores trágicos de Séneca que trataron este tema, las varias tragedias tituladas Thyestes y Atreus, y la mención sinecdóquica de los Tereus de Livio Andrónico y Accio. ${ }^{296}$

La cuarta pared no se rompe desde la representación hacia el receptor sino viceversa: la ruptura y la intrusión se producen desde el receptor hacia el espacio de la representación. En cierta manera, este procedimiento enfoca la atención del receptor en los procedimientos meta-teatrales de composición y concepción del material trágico.

\footnotetext{
295 von Albrecht, M. (1997), 95-97; Tarrant, R. (1985), 129-130; Codoñer, C. (1997), 51-53; Trinacty, Ch. (2007), 67: "Clearly Seneca felt that the tragic tales of characters such as Medea, Atreus and Phaedra were not exhausted and that his account, in part because of their intertextual play with previous material, could offer a fresh view of the story."

${ }^{296}$ SEN. Ep. LXXIX, 6: "Multum interest utrum ad consumptam materiam an ad subactam accedas: crescit in dies, et inventuris inventa non obstant. Praeterea condicio optima est ultimi: parata verba invenit, quae aliter instructa novam faciem habent. Nec illis manus inicit tamquam alienis; sunt enim publica."
} 
Las famosas frases de Medea son un claro ejemplo de estas estrategias de representación:

Nutrix Medea++Medea Fiam.

[...]

Medea nunc sum

(Med. 171)

(Med. 910)

Nod.: Medea.... Med.: seré/ me volveré.

$[\ldots]$

Med.: Ahora soy Medea.

En el texto se despliegan los conceptos de timé y kléos tanto a nivel diégetico como meta-teatral. ${ }^{297}$ En el plano estricto de la representación, estos conceptos logran que el verosímil dramático y la cuarta pared permanezcan intactos y al mismo tiempo se vislumbra cómo esta operación subvierte el paradigma épico de la figura del héroe que Lucano llevará a extremos casi absurdos. ${ }^{298}$ Por su parte, en el plano meta-dramático Séneca explicita los alcances teóricos, las ambiciones literarias de su proyecto creador y su postura frente a los tragediógrafos y poetas romanos que lo precedieron: "Lo reconozco - parece decir el autor detrás de las palabras del protagonista- estos crímenes ya han sido representados, pero mi objetivo es hacer algo mayor, superarlos en todo aspecto." 299

ATREO Y MEDEA: DUEÑOS DE SUS PASIONES.

Los personajes de Medea y Atreo muestran estas características de modos mucho más complejos y profundos que el personaje de Clitemnestra. ${ }^{300}$ En ellos se ponen en juego complejos procedimientos literarios y estrategias poéticas que los equiparan con la figura del artista creador. La constante afirmación existencial de Medea adquiere ribetes estéticos tanto en lo que concierne a su propia imagen en tanto

\footnotetext{
${ }^{297}$ King, C. (1987), 32: "The second of the two specific components that make heroic life meaningful is kléos, which reports the deeds than won timé to all men even to after generations (Il.7.87-91, 22.304-305) and is the compensation if in risking one's life for timé one actually loses that life. Timé is the more important component while one is alive, kléos is, of course, the more important component after death." ${ }^{298}$ Sklenáŕ, R. (2003), 28-30.

${ }^{299}$ Trinacty, Ch. (2007), 74: "Seneca is a self-conscious writer whose tragedies revel in self-conscious characters. His Medea recognizes that she must act like 'herself' in pursuing her revenge against Jason. She constructs the Plot accordingly, and Seneca stresses that his Medea outstrips previous representations [...] The language he employs to describe Medea's possible revenge can also be interpreted as a critique of his own version of the story."

${ }^{300}$ Littlewood, C. (2004), 105-106.
} 
individuo como a su venganza, la cual concibe y ejecuta artísticamente. La fortaleza y seguridad que demuestra Medea es aún más admirable si consideramos su delicada situación personal y social. ${ }^{301}$ Medea es una mujer abandonada y exiliada que ha dejado atrás su reino y su familia para ayudar a un ingrato y pusilánime Jasón (Med. 116 y ss.), quien seguramente no hubiera logrado cumplir su misión sin su ayuda:

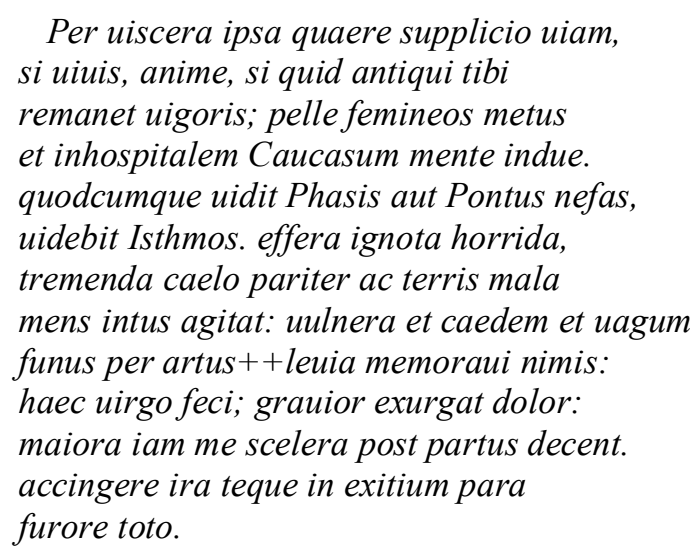

Busca por estas mismas vísceras el camino del suplicio, si vives, ánimo, si algo queda en ti del antiguo vigor, expulsa el temor femenino e impón el inhóspito cáucaso en tu mente. Toda impiedad que vio Fasis o el ponto, la verá el Istmo. [Cosas] feroces, desconocidas, horrorosas, males que harán temblar por igual el cielo y la tierra se agitan en el interior de mi mente: heridas y masacres y muertes vagan por mis miembros - muy livianas son las cosas que recuerdo: estas las hice como doncella; surja más grave mi dolor: crímenes mayores me corresponden ya después de los partos. Cíñete de ira y prepárate para la destrucción con tu furor entero.

\section{$[\ldots]$}

La casa que nació de un crimen, sea abandonada con otro.
(Med 55.)

(Med. 40-52) 
personaje: la afirmación de la subjetividad se da a través de las muertes y asesinatos pasados $\mathrm{y}$, ante la nueva situación existencial, el sujeto se afirma sobre el constructo inmediato (haec virgo feci), que debe ser superado. ${ }^{302}$ Medea habla de su venganza, aún no vislumbrada, ${ }^{303}$ en términos de gestación, concepción, parto y maternidad, lo cual, como ya dijimos, dispara en el receptor conexiones sintagmáticas inherentes a su propia capacidad enciclopédica $y$, en cierta manera, ponen en escena, a través de este procedimiento proléptico, el asesinato de los hijos de Jasón y Medea.

Luego de la entrada del coro y la humillación pública a la que se ve sometida durante el epitalamio cantado por éste, ${ }^{304}$ Medea reaparece en escena, tal como ocurría con Clitemnestra, mostrando cierta ambivalencia en su ánimo. Esta fluctuatio animi se manifiesta en las preguntas retóricas que caracterizan el pasaje (Med. 117 y ss.) y en su deseo de absolver a Jasón de culpa y cargo cuando se dirige a su propio dolor e intenta descargar las culpas en Creón:

melius, a melius, dolor furiose, loquere. si potest, uiuat meus, ut fuit, Iason; si minus, uiuat tamen memorque nostri muneri parcat meo. Culpa est Creontis tota

(Med. 139-143)

Mejor, habla mejor, dolor furioso, si es posible, que viva mío, como lo fue, Jasón; si no, viva también, y recordándome guarde nuestro regalo. La culpa toda es de Creón.

Se revela aquí un detalle de la interioridad de Medea que la diferencia claramente de la Medea de Eurípides. La Medea senequiana está enamorada aún de Jasón, mientras que la heroína ática se rebela ante la injusticia, o adikía, a la que se la somete. ${ }^{305} \mathrm{La}$ fluctuación del ánimo de Medea se debe a que en ella luchan dos sentimientos

\footnotetext{
${ }^{302}$ Dupont, Fl. (2000), 47: "Le monde del héros mythologiques béit à une morale inverse de celle de l'humanité: le crime y apporte la gloire. Le héros furieux nie systématiquement tout ce qui constitue les relations humaines, relation à soi, aux autres, au monde. La seule valeur sociale intacte c'est la volonté d'être d'exister aux yeux des autres, de donner le spectacle de Médée criminelle; la seule valeur est l'individu contre la société."

${ }^{303}$ Costa, C. (1973), 67-69; Medea decide el modus operandi de su venganza sólo cuando Jasón revela cuánto ama sus hijos, cf. SEN. Med. 549-550: "Sic natos amat?/ bene est, tenetur, uulneri patuit locus."

${ }^{304}$ Trinacty, Ch. (2007), 69-70.

${ }^{305}$ Pociña, A. (2001), 142-143: "A acçâo de Jasâo, e da qual Medeia é vítima, define-se, pois, de forma insistente como adikía, atimía y prosdosía."; Trinacty, Ch. (2007), 76.
} 
encontrados, que incluso varias escuelas filosóficas considerarían como dos pasiones, la ira y el amor: $:^{306}$

"But in the Stoics' opinion, all emotions are excessive and irrational, since they erroneously place value on external 'goods'- wealth, possessions, power, and even personal relationships, not to mention life itself. These things are not 'up to us' (eph'hemin), and therefore are not entirely within our control, but rather hostages of fortune. Since we should be entirely without error, according to their moral ideal, the Stoics believe that all passions should be extirpated ( $S V F$ ii 443-55). The wise man should rely on nothing outside himself: he should value only internal goods, that is, virtue and the state of his soul. It follows that the wise man will be completely free of all passions (apathes). The Stoics divide pathe into four main types: desire (eputhumia) and fear (phobos), pain (lupe) and pleasure (hedone). [...] The eupatheiai all depend upon a correct evaluation of what is genuinely worth, and to this extent, the sage's

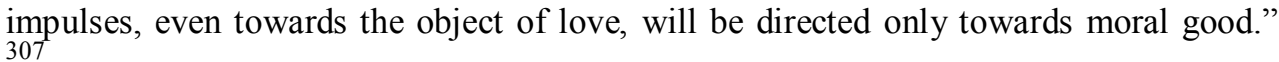

Las operaciones de los diversos cuidados de sí (cura sui ${ }^{308}$ van tomando mayor profundidad y teniendo un impacto aún mayor en el desarrollo trágico, pues no sólo controlan y encaminan los vaivenes y las fluctuaciones del alma sino que también logran armonizar los dos impulsos principales que pugnaban por el control de las acciones del individuo: ira y amor. ${ }^{309}$ La paradoja, en términos filosóficos, es clara: la razón se ha utilizado para lograr un uso instrumental de las pasiones. ${ }^{310}$ Cabe destacar que para los estoicos las pasiones no deben jamás ser utilizadas ni siquiera en sus mínimas expresiones ni en las circunstancias más extremas. ${ }^{311}$ La autoafirmación de Medea sobre sí misma logra que la tragedia avance inexorablemente hacia su fin cuando, según la perspectiva del coro, ambos impulsos destructivos unen sus fuerzas: ${ }^{312}$

Frenare nescit iras

Medea, non amores;

nunc ira amorque causam

iunxere: quid sequetur?

(Med. 866-869)

No sabe refrenar su ira, Medea, ni su amor.

\footnotetext{
${ }^{306}$ Betensky, A. (1980), 291-292 \& 2296-298; Caston, R. (2006), 272-275.

${ }^{307}$ Caston, R. (2006), 273-274.

${ }^{308}$ Foucault, M. (1996), 44 y ss.

${ }^{309}$ Graver, M. (2007), 185: "Enough survives [of the Stoics], however, to show that the prevailing position on love was strongly positive, so long as that love is of the right sort, experienced without false convictions and expressed without obsessiveness or exploitation. Our second-hand reports indicate that there were in fact two different conceptions of what erotic love is. The clearest statement is the following: 'There are two senses in which one may speak of the 'erotic person'; one in reference to virtue, as one quality of the righteous person, and one in reference to vice, as if blaming someone for love madness' (Stobaeus, Ecl. 2.7.5b9 (65W))."

${ }^{310}$ Horkheimer, M. (1969), 15-24.

${ }^{311}$ SEN. Ira. I, I, 14-18.

${ }^{312}$ Trinacty, Ch. (2007), 73; Costa, C. (1973), 148.
} 
Ahora ira y amor han unido

sus causas. ¿Qué seguirá?

A través de las técnicas y procedimientos ya detallados, los personajes senequianos logran encauzar, domesticar y dirigir los impulsos que conturban sus almas y enfocarlos así en un uso instrumental de las mismas. Sin embargo, a través de una decisión eminentemente racional y meditada los protagonistas dirigen este curso desenfrenado hacia fines claramente antiestoicos.

El propio Foucault señalaba que estas tecnologías del yo tenían como fin último cierto estado elevado del espíritu:

"We must understand that there are four types of these 'technologies', each a matrix of practical reason: (1) technologies of production, which permits us to produce, transform or manipulate things; (2) technologies of sign systems, which permits us to use signs, meaning, symbols or signification; (3) technologies of power, which determine the conduct of individuals and submit them to certain ends or domination, an objectivising of the subject; (4) technologies of the self, which permits individuals to affect by their own means or with the help of others a certain number of operations on their own bodies and souls, thought, conduct and way of being, so as to transform themselves in order to attain a certain state of happiness, purity, wisdom, perfection or immortality.",313

Por lo tanto, en un ejercicio de hermenéutica anacrónica, podemos ver que la operación senequiana de subversión de los paradigmas filosóficos resulta ser efectiva incluso sobre las afirmaciones del propio Foucault, ya que los protagonistas logran, a través de estas técnicas, transformar sus propias subjetividades, sus almas, sus conductas y su formas de existir para alcanzar no un estado de pureza o felicidad sino un estado de auto-afirmación existencial basado en la imagen criminal que ellos mismo conciben y consideran adecuada para sí mismos.

Durante el agón con la nodriza Medea despliega en su lenguaje una serie de dicta de claro contenido filosófico que resultan desestabilizados y subvertidos por las propias condiciones de enunciación:

Medea Fortuna fortes metuit, ignauos premit.

Nutrix Tunc est probanda, si locum uirtus habet.

Medea Numquam potest non esse uirtuti locus.

Nutrix Spes nulla rebus monstrat adflictis uiam.

Medea Qui nil potest sperare, desperet nihil.

$[\ldots]$

Medea Fortuna opes auferre, non animum potest.

(Med. 159-163)

(Med. 176)

Med. A los fuertes le teme la Fortuna, a los cobardes los aplasta.

Nod. Si hay lugar para la virtud, entonces debe ser apreciada.

${ }^{313}$ Foucault, M. (1988), 18. 
Med. Nunca puede no haber lugar para la virtud.

Nod. Ninguna esperanza muestra el camino en circunstancias afligidas.

Med. Quien nada puede esperar, en nada desespere.

$[\ldots]$

Med. La Fortuna puede arrebatarme las riquezas, nunca mi ánimo.

Se vislumbra, dentro del uso de esta retórica eminentemente estoica, ${ }^{314}$ una connotación furiosa de la virtus, ${ }^{315}$ una subversión del sentido primigenio de término, que se yuxtapone con la aplicación de las metodologías de auto-evaluación y auto-vigilancia propias de un sabio, tal como lo veremos más adelante en nuestro análisis de Pharsalia: Medea se sitúa por sobre las circunstancias que la vida o la Fortuna puedan ofrecer. Su proclama "Fortuna fortes metuit" es prácticamente una afirmación nietzscheana de su Wille zum Macht y de la imperturbabilidad y seguridad que, pese a sus fluctuaciones sentimentales, ella posee. Medea es consciente de su situación pero también es consciente de sí misma, Medea es el mundo y, aun en su crítica condición existencial de mujer desterrada, abandonada y extranjera, logra afirmarse a sí misma en su propia subjetividad: ${ }^{316}$

Medea Medea superest: hic mare et terras uides ferrumque et ignes et deos et fulmina.

(Med. 166-167)

Medea: Queda Medea: Aquí ves el mar y la tierra, y el hierro y el fuego y los dioses y el rayo.

Séneca cita, en su epístola IX a Lucilio, el caso de Estilbón como el exemplum del sabio que, tal como lo refiere Epicuro, se mantiene imperturbable aun cuando su familia haya sido asesinada y su ciudad arrasada por Demetrio I de Macedonia:

Nihilominus cum sit amicorum amantissimus, cum illos sibi comparet, saepe praeferat, omne intra se bonum terminabit et dicet quod Stilbon ille dixit, Stilbon quem Epicuri epistula insequitur. Hic enim capta patria, amissis liberis, amissa uxore, cum ex incendio publico solus et tamen beatus exiret, interroganti Demetrio, cui cognomen ab exitio urbium Poliorcetes fuit, num quid perdidisset, 'omnia' inquit 'bona mea mecum sunt'. Ecce vir fortis ac strenuus! ipsam hostis sui victoriam vicit. 'Nihil' inquit 'perdidi': dubitare illum coegit an vicisset. 'Omnia mea mecum sunt': iustitia, virtus, prudentia, hoc ipsum, nihil bonum putare quod eripi possit.",317

"Por más que sea muy amante de sus amigos, aunque los compare consigo mismo e incluso los prefiera, el sabio delimitará todo bien dentro de sí y dirá lo que dijo aquel Estilbón, a quien la carta de Epicuro reprocha. Éste, aun cuando su patria había sido

\footnotetext{
${ }^{314}$ Costa, C. (1973), 87-88; Littlewood, C. (2004), 48-50.

315 Dupont, Fl. (2000), 41-42; Porter, J. (2006), 550: "In its most impressive form, the will to power is nothing less than the (somewhat diffusely argued) amorphous nature of the world and the totality of its activities, presented under a terrifying aspect."

${ }^{316}$ Dupont, Fl. (2000), 19.

${ }^{317}$ SEN. Ep. IX, 18-19.
} 
capturada, sus hijos perdidos, perdida su esposa, mientras salía del incendio general solo y sin embargo dichoso, a Demetrio, llamado Poliorcetes por todas las ciudades que había destruido, que le preguntó si había perdido algo, le contestó: a todos - dijo- mis bienes los tengo conmigo. ¡He aquí un varón fuerte y valeroso! Venció al enemigo aun es su propia victoria. 'Nada -dijo- he perdido', obligó a aquel a dudar si acaso había vencido. 'Todos mis bienes están conmigo': justicia, virtud, prudencia y esto mismo: no considerar bueno nada que pueda ser arrebatado."

La operación que Séneca alaba en este sabio es la misma que lleva a cabo Medea en Corinto. ${ }^{318}$ Sin embargo las virtutes seleccionadas son claramente distintas. La virtus de Medea hace referencia al poder y al mundo en su totalidad mientras que los bona de Estilbón son eminentemente conceptuales. La siguiente frase de Medea no desentonaría en absoluto en boca de este sabio:

Medea Fortuna semper omnis infra me stetit.

(Med. 520)

Medea: Siempre estuvo por debajo de mí toda Fortuna.

Dice Littlewood respecto de este pasaje:

"The rhetoric of Stoicism and tyranny are both distinguished by paradox, inversion, and negation. Thus there is also a narrowly formal resemblance. Stichomythia, where this stylized speech is particularly prominent in the tragedies, accommodates the isolation of the Stoic or a tyrant, the disengagement of a frivolous disputant or of passionate suicide. [...] In Medea 157f. Stoic rhetoric is perceived as madness, and juxtaposed with the crimes of Medea's past. Taken with Medea's calculated posturing elsewhere, the effect is a staging of the fragility of Stoic self-representation. Nothing can touch the sapiens in his philosophical retirement, but the representation of his victory is not equally inviolable.",319

La perspectiva de C. Littlewood interpreta de modo diferente al nuestro estos pasajes. Sin embargo coincide, al menos, en que el paradigma estoico está problematizado, aun cuando el grado de esta problematización sea evaluado de manera distinta. Creemos que Séneca profundiza, en su análisis, no sólo los métodos de representación estoicos, tal como analizaremos un poco más adelante, sino que va más allá y su mirada se posa sobre la posibilidad, perturbadora, de que un tirano pueda actuar como un estoico (i.e. Atreo). Tal como ya afirmamos, creemos que Séneca realiza una profunda inquisición sobre los aspectos más perturbadores de su pensamiento, al punto de plantear la paradójica posibilidad de la firme construcción estoica de un criminal o incluso de un

\footnotetext{
${ }^{318}$ Costa, C. (1973), 88: “176. That Fortune could rob the sapiens of his wealth and leave him unimpaired was a characteristic Stoic doctrine, argued at length in de vita beata (e.g. 'sapientis quisquis abstulerit divitias omnia illi sua relinquet...' 26.4)."

${ }^{319}$ Littlewood, C. (2004), 48-49:
} 
tirano, personajes cuya existencia resulta en la crítica y en la confutación de sus propios paradigmas constitutivos. ${ }^{320}$

Séneca nos muestra los vaivenes emocionales de una mente esquizofrénicamente fracturada que se debate entre la ira y cierto amor perverso. ${ }^{321}$ Es necesario, ante estas circunstancias extremas, que el protagonista se supere a sí mismo y que se afirme en su identidad criminal: ${ }^{322}$

Medea Egone ut recedam? si profugissem prius, ad hoc redirem. nuptias specto nouas. quid, anime, cessas? sequere felicem impetum. pars ultionis ista, qua gaudes, quota est? amas adhuc, furiose, si satis est tibi caelebs Iason. quaere poenarum genus haut usitatum iamque sic temet para: fas omne cedat, abeat expulsus pudor; uindicta leuis est quam ferunt purae manus. incumbe in iras teque languentem excita penitusque ueteres pectore ex imo impetus uiolentus hauri. quidquid admissum est adhuc, pietas uocetur. hoc age! et faxo sciant quam leuia fuerint quamque uulgaris notae quae commodaui scelera. prolusit dolor per ista noster: quid manus poterant rudes audere magnum, quid puellaris furor? Medea nunc sum; creuit ingenium malis:

(Med. 893-910)

$$
[\ldots]
$$

stulta properaui nimis:

ex paelice utinam liberos hostis meus aliquos haberet quidquid ex illo tuum est, Creusa peperit. placuit hoc poenae genus, meritoque placuit: ultimum magno scelus animo parandum est: liberi quondam mei, uos pro paternis sceleribus poenas date.

(Med. 919-925)

¿Que yo retroceda? Si hubiese huido antes volvería para esto. Contemplo bodas novedosas. ¿Por qué, ánimo, te frenas? Sigue tu impulso dichoso. ¿Está terminada esta parte de la venganza, con la que te regocijas? Amas aún, enloquecido, si es suficiente para ti

\footnotetext{
${ }^{320}$ Porter, J. (2006), 551: "Less hyperbolic readings [of the will to power], content somehow to envisage the will to power as a basic world-shaping activity, face the same consequence, namely that the will to power is structured like a subject in every way but one: it is not a subject, but the antithesis of one, indeed its critique."

${ }^{321}$ Rudich, V. (1997), 4-5: “The divorce between verba and acta, a sort of socio-political 'schizophrenia,' now came to form one of the primary characteristic in both collective and individual behavior which from now on became fraught with ambivalences and ambiguities on all levels of interaction - a key factor for understanding both the history and the literature of the time. As regards the upper echelon of society, this 'schizophrenic' dilemma was exacerbated by the fiction of the senate's partnership in the government while in fact it was deprived of any independence and freedom of initiative. [...] By the time of Nero, this predicament was further aggravated by the reign of terror." Griffin, M. (1986b), $195-198$.

${ }^{322}$ Dupont, Fl. (2000), 38-39.
} 
un Jasón soltero. Busca un tipo de castigo inusitado y prepárate ya a ti mismo:

ceda toda piedad, que se aleje expulsado el dolor;

Liviana es la venganza que pueden realizar unas manos puras.

Apóyate en la ira y excítate si languideces

y extrae de lo más profundo de tu pecho

los antiguos ímpetus: que todo lo que he hecho hasta ahora

sea llamado piadoso. Yo haré que sepan

cuán leves y de qué vulgar calaña fueron

los crímenes que cometí. Nuestro dolor se ha ejercitado

con estos: ¿A qué cosa magna habían podido atreverse

unas manos inexpertas? ¿A qué el furor de una doncella?

Ahora soy Medea; creció mi ingenio con las desgracias.

$[\ldots]$

Tonta me he adelantado demasiado,

ojalá mi enemigo tuviera algunos hijos

de mi rival, los que tú tienes con él,

los parió Creusa. Me agrada este tipo de castigo,

y me agrada con razón: el crimen último debe ser preparado

con un ánimo magno: niños antes míos,

pagad vosotros el castigo de los crímenes paternos.

La racionalización de la ira como instrumento constitutivo esencial de la venganza alcanza su punto máximo en los versos 924-925. En ese preciso punto, la inmensidad el crimen hace que ella misma flaquee en su impetus:

Cor pepulit horror, membra torpescunt gelu

pectusque tremuit. ira discessit loco

materque tota coniuge expulsa redit.

egone ut meorum liberum ac prolis meae

fundam cruorem? melius, a, demens furor!

incognitum istud facinus ac dirum nefas

a me quoque absit;

(Med. 926-932)

El horror sacudió mi corazón, mis miembros están insensibles

del frío y tembló mi pecho. La ira abandonó su lugar

y la madre regresa, expulsada la esposa.

¿Que yo misma derrame la sangre de mis hijos

y de mi prole? mejor, ah furor demente,

que se aleje de mí este crimen desconocido

y esta cruel impiedad!

Pueden distinguirse en Medea dos aspectos básicos en su desdoblamiento: uno netamente emocional, el amor a sus hijos (distinto a su amor furiosus por Jasón) ${ }^{323}$ y el otro caracterizado por la ratio desequilibrada que argumenta con un lenguaje de tono claramente judicial:

quod scelus miseri luent?

scelus est Iason genitor et maius scelus

${ }^{323}$ Costa, C. (1973), 151 \& 154; Graver, M. (2007), 175-177. 
Medea mater++occidant, non sunt mei;

pereant, mei sunt. crimine et culpa carent,

sunt innocentes, fateor: et frater fuit.

(Med. 932-936)

¿Qué crimen expiarán los desdichados?

El crimen es su padre Jasón y mayor crimen aún

su madre Medea - Mueran, no son míos;

perezcan, son míos. Carecen de culpa y cargo,

son inocentes, lo reconozco: también lo fue mi hermano.

En el preciso momento en que Medea aplica la ratio para intentar apartarse de su furor el resultado es exactamente el contrario: Medea logra racionalizar como causa de su crimen precisamente su condición de madre. Es entonces cuando aparecen de modo efectivo las estrategias de auto-admonición y auto-evaluación. Medea se dirige a su ánimo, lo exhorta, lo examina y lo impreca. El tono imperativo propio del lenguaje del yo ordena el discurso:

quid, anime, titubas? ora quid lacrimae rigant

uariamque nunc huc ira, nunc illuc amor

diducit? anceps aestus incertam rapit;

ut saeua rapidi bella cum uenti gerunt,

utrimque fluctus maria discordes agunt

dubiumque feruet pelagus, haut aliter meum

cor fluctuatur: ira pietatem fugat

iramque pietas ++ cede pietati, dolor.

(Med. 937-944)

¿Por qué, ánimo, dudas? ¿Por qué las lágrimas riegan

tu rostro y, ya la ira ya el amor, te llevan inconstante

de aquí para allá? Una marea doble me arrastra indecisa;

como cuando los vientos desenfrenados hacen cruel guerra, y las corrientes contrarias agitan el mar por todos lados, y hierve inseguro el piélago, no de otro modo fluctúa mi corazón: la ira pone en fuga a la piedad

la piedad a la ira - cede a la piedad, dolor!

Medea, a diferencia de Clitemnestra, no entrega su nave al dominio de la furiosa tempestad, sino que se mantiene como capitán de su propia interioridad convulsionada: el desfile triunfal de las furias y el fantasma de su hermano nos indican que Medea se ha hundido finalmente en la locura, pero cabe destacar varios aspectos que hacen al andamiaje interno del personaje y lo alejan de ser un mero títere de las fuerzas infernales. En primer lugar, Medea, al igual que Atreo, recibe con alegría a esta turba insana:

quem trabe infesta petit

Megaera? cuius umbra dispersis uenit incerta membris? frater est, poenas petit:

dabimus, sed omnes. fige luminibus faces, lania, perure, pectus en Furiis patet. 
Discedere a me, frater, ultrices deas

¿A quién busca Megera con su antorcha terrible? ¿(A quién ese) cuya sombra llega vacilante con sus miembros dispersos? Es mi hermano, busca el castigo: Se lo ofreceremos, pero completo. Clava tus antorchas en mis ojos, desgárrame, quémame, mi pecho se abre a las Furias.

Ordena, hermano, que las diosas vengadoras me abandonen $\mathrm{Y}$ regresen seguras a los manes profundos.

La aceptación de la locura es, entonces, un acto racional y meditado. A diferencia de personajes como Turno o Amata, quienes son receptores pasivos del furor de Alecto en Eneida, ${ }^{324}$ Medea abre su interioridad a las divinidades infernales.

Medea se ha construido en tanto individuo a través de medios eminentemente estoicos y, cuando ha sufrido alguna fluctuatio animi, ha sabido encauzar sus pasiones, dirigirlas y enfocarlas hacia un objetivo claro y racional, es decir, su venganza. Medea se reivindica a sí misma en términos de poder, sexualidad y criminalidad e incluso demuestra poseer una concepción espectacular del crimen verdaderamente profunda, tal como lo veremos más adelante: ${ }^{325}$

rediere regna, rapta uirginitas redit.

o placida tandem numina, ofestum diem, o nuptialem! uade, perfectum est scelus ++ uindicta nondum: perage, dum faciunt manus. quid nunc moraris, anime? quid dubitas? potens iam cecidit ira? paenitet facti, pudet. quid, misera, feci? misera? paeniteat licet, feci. uoluptas magna me inuitam subit, et ecce crescit. derat hoc unum mihi, spectator iste. nil adhuc facti reor: quidquid sine isto fecimus sceleris perit.

(Med. 984-994)

\section{$[\ldots]$}

Perfruere lento scelere, ne propera, dolor: meus dies est; tempore accepto utimur.

Regresó el reino, regresó mi virginidad robada. ¡Oh divinidad al fin apacible! ¡Oh día festivo! ¡Oh (día) nupcial! ¡Vamos! se ha cometido el crimenno aún la venganza: continúa, mientras tus manos puedan. ¿Por qué te retrasas ahora, ánimo? ¿Por qué dudas? si eres capaz de esto ¿ya cedió tu ira? Me apena lo hecho, me avergüenza.

¿Qué he hecho, desdichada? ¿Desdichada? Aunque te apene,

\footnotetext{
${ }^{324}$ Un desarrollo mayor de este tema se encuentra en nuestro análisis de la conformación del personaje de Atreo, un poco más adelante. Cf. Vizzotti, M. (2009), 312 y ss.

${ }^{325}$ Trinacty, Ch. (2007), 74-75.
} 
hecho está. Una gran satisfacción me invade aunque no quiera, y más aún, crece! Sólo esto me faltaba, ese como espectador. Considero que nada he cometido hasta ahora:

Todo lo que hicimos sin ese (espectador) se ha perdido.

$[\ldots]$

Disfruta, dolor, con este lento crimen, no te apresures:

El día es mío; aprovechamos el tiempo dado.

Estamos, entonces, ante una autoafirmación del sujeto en tanto criminal, con clara conciencia de su kléos, de su timé y del lugar que él mismo considera que merece en tanto sujeto arrojado a un mundo hostil y al cual es consciente que debe superar para reivindicarse a sí mismo. ${ }^{326}$

Atreo es, quizás, el personaje mejor logrado y en el cual se manifiestan con mayor profundidad las diversas operaciones senequianas, tanto en el nivel de la construcción del mismo como en el de la representación y la meta-representación. ${ }^{327}$ La entrada a escena del personaje no nos lo muestra dubitativo o en medio de una fluctuatio animi, al contrario, Atreo expone lo que podríamos considerar un diagnóstico preciso de su situación espiritual:

Ignaue, iners, eneruis et (quod maximum probrum tyranno rebus in summis reor) inulte, post tot scelera, post fratris dolos fasque omne ruptum questibus uanis agis iratus Atreus?

(Thy. 176-180)

Cobarde, inútil, débil y (lo que considero el mayor oprobio para un tirano en sus altos asuntos) sin venganza, ¿Luego de tantos crímenes, luego de los engaños fraternos y roto todo pacto sagrado, te revuelves en vanas cuestiones, Atreo enfurecido?

Como puede apreciarse, Atreo se define a sí mismo desde su entrada a escena como un verdadero tyrannus y expone las razones de su ira. ${ }^{328}$ Atreo no expresa dudas respecto de su venganza sino que su fluctuación y sus meditaciones se concentran en el género y el modo apropiados para su venganza, desplegando una conciencia estética propia de un artista o, más precisamente, de un tragediógrafo. Durante nuestro análisis del personaje

\footnotetext{
${ }^{326}$ SEN. Ep. I, 1; Dupont, Fl. (2000), 20-21; Tarrant, R. (1985), 129: “271 dignum: Seneca's characters have an acute, if twisted, sense of dignitas, and insist on committing only those crimes appropriate for it, cf. HF 111-112 facere si quidquam apparo/ dignum noverca, Med. 50 maiora iam me scelera post partus decent, Ag. 124 (n). Atreus pays Thyestes the converted compliment of treating him as an equal in this respect."

${ }^{327}$ Schiesaro, A. (2003), 1 y ss. $13-15$ \& 26 y ss.

328 Tarrant, R. (1985), 117: "177 tyranno: Atreus makes no apology for being a dictator, and appeals several times to the 'rules' of tyrannical behavior, cf. 205-218, 247-48. 312-313. Other Senecan tyranni, such as Lykus (HF 511-13) and Aegysthus (Ag. 995), are similarly open about their status and methods."
} 
en esta parte del trabajo haremos mención a ciertos elementos meta-teatrales que desarrollaremos un poco más adelante, pero que no podemos dejar de destacar aun cuando nuestro foco sea, aquí, las estrategias de construcción estoicas del protagonista, pues ambos están íntimamente relacionadas.

La cuestión que preocupa al rey no es el qué del crimen, sino el cómo, el grado con que debe ejercitarse el mismo:

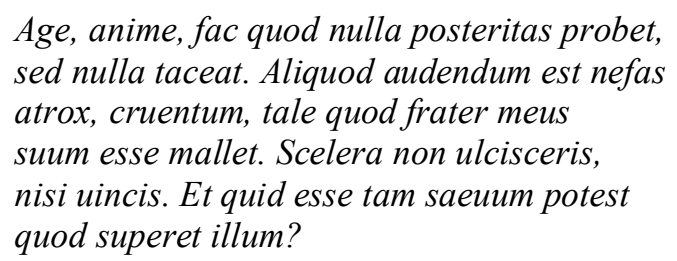

Vamos, ánimo, haz lo que ninguna posteridad apruebe, pero que ninguna calle. Hay que atreverse a otra impiedad, atroz, cruenta, tal que mi hermano quisiese que sea suya. No vencerás los crímenes si no los superas. ¿Y qué puede ser tan cruel que supere a aquel?

El rey no recurre a la auto-admonición para encauzar su ira hacia el objetivo criminal, pues la decisión está tomada. Al contrario, Atreo enfoca su ratio en la concepción del crimen, en el modo, la forma y, quizás lo que considera más importante, en el grado del mismo e incluso en el kléos que éste le deparará ante la posteridad. En el caso de Atreo, los recursos y las estrategias de construcción subjetivas van constantemente acompañadas por un discurso caracterizado por la presencia de comparativos de grado, particularmente maior, peius, atrocius, sustantivos como inausa y verbos como audere, pergere, vincere, superare. ${ }^{329}$

El horror del crimen trágico se basa más en la cuidada construcción de éste que en lo cruento y morboso que resulta el mismo. Atreo se construye como un artista cuya inteligencia y razón están abocadas a la concepción, ejecución y exposición del crimen en tanto obra maestra. El criminal artista es consciente, ${ }^{330}$ como Medea y Clitemnestra, de la existencia de una tradición criminal familiar, sin embargo Atreo toma esta serie de asesinatos intrafamiliares como influencias e inspiración artística:

Quid stupes? tandem incipe animosque sume: Tantalum et Pelopem aspice; ad haec manus exempla poscuntur meae. profare, dirum qua caput mactem uia.

\footnotetext{
${ }^{329}$ Park Poe, J. (1969), 363; Littlewood, C. (2004), 30 \& 182-183; Tarrant, R. (1985), 119.

${ }^{330}$ Schiesaro, A. (1994), 196-210.
} 
¿Por qué quedas atónito? Empieza por fin

y toma ánimos: Contempla a Tántalo y a Pélope;

Hacia estos ejemplos son llamadas mis manos.

Dime, por qué medio deberé sacrificar su cabeza?

Tántalo y Pélope son exempla paradigmáticos para este criminal artista, ${ }^{331}$ así como Catón, Escipión, Régulo, Estilbón et al. lo son para el proficiens estoico. El último verso marca la entrada del satelles que acompaña al rey y que, en realidad, resulta ser casi una encarnación de la tímida ratio de Atreo, por lo que la escena podría considerarse casi como un monólogo interior de éste. Entender al siervo como vocero de la razón sometida nos permite, por un lado, ver hasta qué punto Atreo es dueño de sí mismo y por otro externaliza la leve fluctuatio animi que el rey sobrelleva con gran facilidad. Cuando el siervo recomienda el hierro como instrumento de la venganza, Atreo responde:

De fine poenae loqueris; ego poenam uolo. perimat tyrannus lenis: in regno meo mors impetratur.

Del fin del castigo hablas; yo deseo el castigo (en sí).

Que mate el tirano mesurado, bajo mi reino, la muerte es algo que se ruega.

La atención de Atreo está puesta en el proceso del castigo, que equivale al proceso de concepción y representación de la tragedia propiamente dicha y que, tal como lo han señalado varios autores, es un reflejo meta-teatral del proceso de composición de la misma.

El tyrannus lenis es, precisamente, aquel que deja que su ira lo controle. ${ }^{332}$ Séneca comienza su tratado sobre la ira respondiendo una pregunta de Novato respecto de este tema: Exegisti a me, Nouate, ut scriberem quemadmodum posset ira leniri (Ira I, I, 1). ${ }^{333}$

\footnotetext{
${ }^{331}$ Tarrant, R. (1985), 125.

${ }^{332}$ Tarrant, R. (1985), 125-126: "247-48 in ... impetratur: that is, for Atreus death is not a punishment but a favor to be begged for. Seneca's other tyranni expound the same view, cf. HF 511-12, Ag. 995 rudis est tyrannus mortem qui poenam exigit (n). Roman listeners might have been reminded of Tiberius or Gaius, cf. Suet. Tib. 61.5 mori volentibus vis adhibita vivendi. Nam mortem .. leve supplicium putabat, Sen. NQ 4A pr. 17 sciebam olim sub illo [sc. Gaio] in eum statum res humanas decidisse ut inter misericordiae opera haberetur occidi."

${ }^{333}$ Otros pasajes donde se hace referencia a la necesidad de iram lenire en Ira. son I, XVII, 5: “incipit magno impetu, deinde deficit ante tempus fatigata, et, quae nihil aliud quam crudelitatem ac noua genera poenarum uersauerat, cum animaduertendum est, iam [ira] fracta lenisque est." \& III, énXXXIX, 1: "Contigit iam nobis, Nouate, bene componere animum: aut non sentit iracundiam aut superior est. Videamus quomodo alienam iram leniamus; nec enim sani esse tantum uolumus, sed sanare." Cf. También SEN. Ira, II, XV, 3; II, XXXIII, 6; III, IX, 1; III, XII, 1; III, XXXVIII, 1 \& III, XXXIX, 2-3.
} 
Atreo realiza un severo control de sus pasiones y no deja lugar en su alma para virtud alguna, ${ }^{334}$ llegando incluso a invocar al ejército de las Furias para que oficien de Musas para su crimen:

Excede, Pietas, si modo in nostra domo umquam fuisti. Dira Furiarum cohors discorsque Erinys ueniat et geminas faces Megaera quatiens. Non satis magno meum ardet furore pectus, impleri iunat maiore monstro.

Fuera, piedad, si alguna vez estuviste en nuestra casa. Que venga la cohorte terrible de las Furias y Erinis, la Discordia, y Megera agitando sus antorchas gemelas. No arde en nuestro pecho un ardor lo suficientemente grande, deseo colmarlo con una monstruosidad mayor!

Jasper, en el prefacio a su traducción de Troas, Thyestes y Hercules furens, escribe los siguientes versos: $:^{335}$

This said, I felt the Fury's force enflame me more and more, and ten times more nowchaf'd I was than ever yet before, My hair stood up, I waxed wood, my sinews all did shake, And as the Fury had me vex'd my teeth began to ache. And thus enflam'd me with force of her, I said it should be done, and down I sat with pen in hand, and thus my verse began.

La asociación entre Megera y la inspiración senequiana es diáfana, por lo que no es casual que el propio Atreo la invoque específicamente como su musa inspiradora, junto a Erinis y a sus hermanas.

A diferencia de Medea, quien acepta la cohorte de Furias casi al final de la tragedia, Atreo las invoca activamente, desde un principio, para inspirarlo en su criminal propósito. Atreo no sólo controla su furor sino que busca acrecentarlo e incluso se regodea (iuvat) en alimentarlo, pues considera que su impetus no es suficientemente grande aún para la obra que debe acometer. Séneca representa en escena el proceso de concepción y composición del crimen junto con el análisis minucioso por parte del protagonista de los antecedentes criminales que debe considerar como parte de una tradición criminal:

fiat hoc, fiat nefas

quod, di, timetis. SATELLES: Facere quid tandem paras?

ATREVS: Nescio quid animo maius et solito amplius

\footnotetext{
${ }^{334}$ Tarrant, R. (1985), 126.

335 En Rosenmeyer, Th. (1989), 3: "In the last lines of his preface to his translation of Thyestes (1560), Jasper Heywood reports his feelings after waking up from a dream meeting with Seneca."
} 
supraque fines moris humani tumet

instatque pigris manibus - haud quid sit scio,

sed grande quiddam est. Ita sit. Hoc, anime, occupa

dignum est Thyeste facinus et dignum Atreo,

quod uterque faciat. Vidit infandas domus

Odrysia mensas - fateor, immane est scelus, sed occupatum; maius hoc aliquid dolor

inueniat. Animum Daulis inspira parens

sororque; causa est similis; assiste et manum

impelle nostram. Liberos auidus pater

gaudensque laceret et suos artus edat.

bene est, abunde est: hic placet poenae modus

tantisper.

Cométase, cométase esta impiedad,

Que (vosotros), dioses, teméis. Si. Finalmente, ¿Qué te dispones a hacer?

Atr. Lo ignoro, algo más grande que mi ánimo y que lo acostumbrado

y que supera los límites de las costumbres humanas crece

e incita mis manos perezosas - No sé qué sea,

pero sin duda es enorme. ¡Sea así! Aprópiate, ánimo, de esto,

digno es este crimen de Tiestes y digno de Atreo,

cualquiera de los dos que lo cometa. Ya contempló estas mesas infames

el palacio Odrysio- lo reconozco, enorme es el crimen,

pero ya fue ejecutado; que mi dolor encuentre algo

aún mayor. Inspirad a mi ánimo, Madre y hermana

de Daulis; la causa es similar; apoyadme

y empujad nuestras manos. Que el padre desgarre ávido

y alegre a sus hijos y devore sus miembros.

Está bien, es suficiente: este tipo de castigo me complace,

por ahora.

Atreo verbaliza los procesos internos de su mente y su obsesiva preocupación por el grado y la dimensión del crimen. ${ }^{336}$ Volvemos a destacar que, según nuestra perspectiva, no existe la ruptura del verosímil dramático que algunos críticos ven en la referencia a la venganza de Procne y Filomena sobre Tereo, sino que, aun si Atreo demuestra una verdadera conciencia de la tradición criminal (aunque siempre en el plano diegético) y despliega cierta angustia de las influencias, los significantes del entramado dramático actúan no sobre el emisor sino sobre el receptor del mensaje, disparando casi pavlovianamente sus conocimientos literarios y sus capacidades enciclopédicas, que ya hemos mencionado, y poniendo en juego una compleja red de asociaciones intra y extra dramáticas. Esta operación es particularmente efectiva, entonces, en el plano extradiegético.

${ }^{336}$ Tarrant, R. (1985), 128-131, también 129: "tumet: Atreus practically diagnoses himself as an iratus in Stoic terms by speaking of his swollen animus, cf. 519-520, Pho. 352 tumet animus ira, Cic. Tusc. sapientis ...animus semper vacat vitiis, numquam turgescit, numquam tumet; at Irati animus eiusmodi est." 
Lo que distingue a Atreo de otros personajes como Medea y, particularmente, Clitemnestra son ciertas características específicas que despliega en el dominio efectivo de sus pasiones. En efecto, el rey prácticamente no fluctúa en su decisión de tomar venganza, sino que su preocupación se enfoca en concentrar el impulso creativo para llevar a cabo la obra que su ratio desencajada ha concebido:

Tam diu cur innocens uersatur Atreus? tota iam ante oculos meos imago caedis errat, ingesta orbitas in ora patris - anime, quid rursus times et ante rem subsidis? Audendum est, age!: quod est in isto scelere praecipuum nefas, hoc ipse faciet.

(Thy. 280-286)

¿Por qué Atreo permanece tanto tiempo inocente? Ya pasa ante mis ojos el espectáculo de la matanza, la perdida entera (de los hijos) en la boca del padre- ánimo, ¿por qué temes nuevamente y retrocedes ante la obra? Vamos, hay que atreverse! La principal impiedad que hay en este crimen, él mismo la cometerá.

Proyectada su obra, Atreo no puede soportar su estado de gracia e inocencia y exhorta a su ánimo a emprender este proyecto y ya se regodea, incluso, en el costado estético del mismo, ${ }^{337}$ pues el objeto y el instrumento de la venganza serán uno y el mismo, es decir, Tiestes.

${ }^{337}$ Tarrant, R. (1985), 128. 


\section{RECAPITULACIÓN Y CONCLUSIONES PARCIALES}

Nos hemos concentrado en sólo tres tragedias a lo largo de esta sección del trabajo ya que en las restantes las estrategias de subjetivación y las tecnologías del yo no cumplen un rol central en la conformación y construcción de los protagonistas. En las demás tragedias se exploran otros aspectos trágicos, filosóficos y literarios: Hércules, al igual que Edipo, no manifiesta una pasión particular o una combinación de pasiones internas como los personajes de Atreo, Medea o incluso Fedra. ${ }^{338}$ En el peor de los casos estos personajes manifiestan un exceso de confianza en sus respectivas personae. En el caso de Hércules, dice J. Fitch:

"The closest he [Hercules] comes to self-recognition is the moving lines 1226-29. [...] Here he perceives that his inability to weep is a failure, caused by the rigidity of his heroic persona; and the immediately subsequent proposal to destroy the weapons suggests a desire to destroy that persona, along with his life. But we cannot read into it a recognition that his heroic attitude led directly to the deeds. It is also very short-lived, for he is soon immersed again in the Herculean persona, and calling for the weapons to use them punitively against himself (124ff.) The usual inflexibility of that persona is strikingly illustrated in the way in which he reduces the issue to the familiar formula of labors, monster-slayer versus monster (1279-81) [...] Of course the present situation, with its complex moral questions, is utterly different from the simple pattern of labors, but Hercules' heroism can operate in a single, rigid mode. Similarly the task of living on has to be categorized as another Herculean labor, done under a command, in order to become acceptable (1315ff.)." ${ }^{, 339}$

Edipo y Hércules rara vez recurren al lenguaje imperativo del yo y solo Edipo, hacia el final de la tragedia, utiliza alguna de las modalidades de auto-admonición analizadas. ${ }^{340}$ Hercules furens indaga más en la naturaleza ambivalente del héroe, ${ }^{341}$ mientras que Oedipus se centra en las problemáticas relacionadas con el ejercicio del regnum. ${ }^{342}$ En el caso de Phoenissae, la acción dramática se centra en la degeneración del amor filial en una guerra fratricida y en las distintas actitudes adoptadas por Edipo y Yocasta ante la inminencia del conflicto. ${ }^{343}$ El cuadro del sufrimiento de los vencidos que es Troades y el foco sobre la muerte y la venganza de los muertos que caracteriza esta tragedia hacen que no resulten operativas las estrategias de subjetivación señaladas.

Sólo Ulises hace uso de estos procedimientos en un solo pasaje:

\footnotetext{
${ }^{338}$ Fitch, J. (1987), 37-44.

${ }^{339}$ Fitch, J. (1987), 37.

${ }^{340}$ SEN. Oed. 880-881, 930-934, 999-1003, 1046 \& 1057-1061.

${ }^{341}$ Papadopoulou, Th. (2004), 257-259 \& 268 y ss.

${ }^{342}$ Fitch, J. (1987), 15 y ss.

${ }^{343}$ Frank, M. (1995), 4-5.
} 
Quid agis, Ulixe? Danaide credent tibi

Tu cui?

(Tro. 607-608)

$[\ldots]$

Nunc advoca astus, anime, nunc fraudes, dolos.

Nunc totum Ulixen.

¿Qué haces, Ulises? Los Dánaos te creen a ti,

Tú, ¿a quién?

$[\ldots]$

¡Invoca ahora tu astucia, ánimo, ahora los fraudes, los engaños!

¡Ahora a Ulises entero!

Ulises se construye según una imagen acorde a su timé y a su condición pública de versutus y se afirma en tanto tal, ${ }^{344}$ sin embargo esta afirmación posee también ciertos elementos desestabilizadores del paradigma épico, pues la astucia del héroe implica necesariamente dolos y fraudes. La repetición obsesiva del nombre acrecienta la efectividad de este procedimiento.

Séneca aconseja a Lucilio en su epístola LXXV, 16-18:

"'Ego vero' inquis 'spero me posse et amplioris ordinis fieri.' Optaverim hoc nobis magis quam promiserim: praeoccupati sumus, ad virtutem contendimus inter vitia districti. Pudet dicere: honesta colimus quantum vacat. At quam grande praemium expectat, si occupationes nostras et mala tenacissima abrumpimus! Non cupiditas nos, non timor pellet; inagitati terroribus, incorrupti voluptatibus, nec mortem horrebimus nec deos; sciemus mortem malum non esse, deos malo non esse. Tam inbecillum est quod nocet quam cui nocetur: optima vi noxia carent. Expectant nos, $<$ si $>$ ex hac aliquando faece in illud evadimus sublime et excelsum, tranquillitas animi et expulsis erroribus absoluta libertas. Quaeris quae sit ista? Non homines timere, non deos; nec turpia velle nec nimia; in se ipsum habere maximam potestatem: inaestimabile bonum est suum fieri. Vale."

"'Yo en verdad espero - me dices- poder hacerme parte también de una categoría mayor.' Desearía yo esto para nosotros más que prometerlo: Se nos han adelantado, tendemos hacia la virtud a rodeados por los vicios. Avergüenza decirlo: cultivamos lo honesto cuando tenemos tiempo libre. Y qué premio tan grande nos aguarda si nos liberamos de nuestras preocupaciones y nuestros vicios más tenaces! Ni la codicia ni el temor nos impulsarán: inaccesibles al terror, incorruptibles ante los placeres, ni la muerte ni los dioses nos aterrarán; sabremos que la muerte no es un mal, que los dioses no poseen capacidad para el mal. Tan pusilánime es quien daña como quien es dañado, lo óptimo carece de fuerza para ser nocivo. Nos aguardan, si algún día nos evadimos de este cieno hacia aquello sublime y excelso, la tranquilidad del ánimo y, expulsados los errores, la libertad absoluta. Preguntas cómo es ella. No temer ni a los hombres ni a los dioses, ni desear nada indecente ni excesivo, tener la máxima potestad sobre uno mismo: inestimable bien es hacerse a uno mismo."

La contracara trágica de este discurso que exhorta hacia la virtud es el personaje de Medea, quien no teme ni a hombres, ni a reyes ni a dioses y posee el más profundo control sobre ella misma. Medea parece refutar en el plano dramático la aseveración

${ }^{344}$ Fantham, E. (1982), 299-300; Goldberg, S. (2005), 431-432. 
optima vi noxia carent de las epístolas y, de hecho, ella logra "hacerse a sí misma" tal como lo promete en el verso 171.

Los personajes trágicos utilizan, entonces, de manera racional y meditada las herramientas y métodos de subjetivación, construcción del yo y autoafirmación del sujeto en tanto individuo recomendadas al proficiens estoico en su búsqueda de la virtud para lograr objetivos claramente anti-estoicos y criminales. Clitemnestra, Medea y Atreo, particularmente, no dudan en vigilar y analizar atentamente los movimientos internos de sus almas con el objetivo de detectar e individualizar cualquier fluctuación en ellas $\mathrm{y}$, tan pronto como alguna es identificada como tal, recurrir al arsenal de las tecnologías del yo y técnicas de sí a su alcance para afirmarse existencialmente como individuos criminales conscientes de su condición de tales. Los protagonistas se esfuerzan en aplicar toda su voluntad y razón no para refrenar y apagar el ímpetu de las pasiones que agitan sus almas; al contrario, las pasiones son, en mayor o menor grado, de acuerdo a cada personaje, encauzadas, dirigidas, controladas e incluso alentadas, mientras que los tibios resabios de virtud, como la pietas o el pudor, son arrancados como si de malas hierbas se tratasen. La interioridad de los personajes es un constructo firme y racional donde elementos tales como la constantia y la voluntad están puestos al servicio de fines criminales $y$, por lo tanto, anti-estoicos. 


\title{
IV. El ESPECTÁCULO DEL HORROR COMO SUBVERSOR DE LOS MECANISMOS DE REPRESENTACIÓN.
}

\author{
'La obra de arte no es un objeto \\ que esté frente a un sujeto que es para sí. \\ La obra de arte tiene más bien su ser \\ en convertirse en experiencia \\ que transforma al que experimenta",345
}

CONFIGURACIÓN ESPECTACULAR DE LA FIGURA DEL HÉROE ESTOICO EN SÉNECA.

El estoicismo (al igual que otras escuelas filosóficas, especialmente la cínica) siempre alentó los despliegues dramáticos de su doctrina y de la enseñanza de la misma: ${ }^{346}$ el sabio debe ser, en todo momento, un exemplar, ${ }^{347}$ sus actos deben enseñar e inspirar a los otros. El héroe estoico, figura siempre asimilable al sapiens, literalmente actúa su papel, su heroísmo es altamente planeado, consciente de sí mismo, comprometido e intelectualizado: el héroe se comporta como un actor ante un público (ya sea éste de hombres o de dioses), y esta actitud hace que sus acciones adquieran sentido en tanto performances, pues están concebidas como experiencias estéticas. ${ }^{348} \mathrm{El}$ mundo se convierte entonces en un anfiteatro donde los dioses contemplan extasiados cómo Catón enfrenta y sobrelleva la adversidad. Séneca, por su parte, ejecuta el mandato fatal de Nerón de forma tal que quede grabado como ejemplo último de su doctrina y punto culminante de su vida. ${ }^{349}$

La dramatización y el histrionismo que marcan estos momentos dan muestra de cuán profunda es la conciencia que el sabio tiene de su papel: al volver sus actos un ejercicio de afirmación existencial el héroe se regodea en prolongarlos, ${ }^{350}$ controlarlos, articularlos e incluso disfrutarlos. El héroe estoico hace de su muerte una producción. ${ }^{351}$

\footnotetext{
${ }^{345}$ Gadamer, H-G. (1996), 98.

${ }^{346}$ Rosenmeyer, Th. (1989), 47-48: "Stoicisms prompts theatrical tropes. The Roman stoics focus on playacting in the presence of others, they do so specially at the point where the play draws to its conclusion; the plethora of possible mask has been discarded for the one authentic role and the snuffing out of life has to be cast in the heroic mould."

${ }^{347}$ Hijmans Jr. B. (1966), 237 \& SEN. Prov. VI, 3.

${ }^{348}$ Rosenmeyer, Th. (1989), 48.

349 TAC. Ann. XV, 60-63.

${ }^{350}$ Rosenmeyer, Th. (1989), 52: "The character intense recognition that he is creating his role for the dereliction and the horror of others, and that their presence adds sustenance to his standings, is also a kind of existential exercise."

${ }^{351}$ Rosenmeyer, Th. (1989), 59: "The stoic hero makes his death a production. He insist on controlling, prolonging, hastening, enjoying, protesting his death. Even Jason or Aegystus, in all else cowards confessed, shows a readiness for death equal of the hardiest."
} 
El suicidio de Catón de Útica fue un acto fundacional que instauró en la sociedad romana y en su imaginario el modelo paradigmático de la voluntaria mors. ${ }^{352}$ Su muerte conjuga diversos factores y circunstancias que la convierten en el exemplum paradigmático de la eúlogos exagogé, es decir, de la salida racional de la vida. ${ }^{353}$ Es evidente que Catón concibió y ejecutó su muerte de manera dramática: la cena erudita y amena donde se discuten paradojas estoicas, el paseo habitual después de la misma, la despedida un poco más efusiva y amistosa que de costumbre a sus hijos y amigos, el reclamo de la espada arrebatada y, sobre todo, la lectura del Fedón enmarcan su decisión dentro de una tradición ética y filosófica específica. ${ }^{354}$ Los elementos teatrales desplegados en la muerte del general son diáfanos, así como también el carácter público de su decisión; no es el acto solitario y desesperado con el que solemos asociar el suicidio en estos tiempos: ${ }^{355}$ amigos y familiares están presentes e intentan disuadir a Catón, pero finalmente sus serenos argumentos y su iusta causa prevalecen. Sin embargo, es la lectura del Fedón lo que termina de enmarcar filosóficamente la decisión de escoger esta eúlogos exagogé. La identificación consciente con Sócrates no pasó desapercibida ni para sus contemporáneos ni para los autores posteriores. ${ }^{356}$ Cicerón destaca, además de la incredibilem gravitatem del general, ${ }^{357}$ la identificación con Sócrates, resaltando la iustam causam que los dioses habían ofrecido a ambos varones para llevar a cabo el suicidio:

"Cato autem sic abiit e vita, ut causam moriendi nactum se esse gauderet. Vetat enim dominans ille in nobis deus iniussu hinc nos suo demigrare; cum vero causam iustam deus ipse dederit, ut tunc Socrati, nunc Catoni, saepe multis, ne ille me Dius Fidius vir sapiens laetus ex his tenebris in lucem illam excesserit, nec tamen ille vincla carceris ruperit - leges enim vetant -, sed tamquam a magistratu aut ab aliqua potestate legitima, sic a deo evocatus atque emissus exierit. ${ }^{, 358}$

"Catón sin embargo se marchó de esta vida de tal modo que se alegraba por haber encontrado una causa para morir. Aquel dios que reina en nosotros nos prohíbe

\footnotetext{
${ }^{352}$ Griffin (1986b), 195: "It was the way in which the younger Cato chose to stage his end and the way in which others celebrated it thereafter that explain why political opponents of the Emperors, who were ordered to kill themselves or even were actually executed, came to be thought of, and probably thought of themselves, as following the great Stoic Cato in his death.” También 198: "[...] philosophy, again via Cato, helped to provide the etiquette and style for suicide."

${ }^{353}$ Griffin, M. (1986a), 72.

${ }^{354}$ Griffin, M. (1986b), 195-196; Reydams-Schils, G. (2005), 45-47.

${ }^{355}$ Griffin, M. (1986a), 65-66.

${ }^{356}$ Rist, J. (1995), 253.

${ }^{357}$ CIC. Off. I, 112.

${ }^{358}$ CIC. Tusc. I, 74.
} 
retirarnos de aquí sin su consentimiento; cuando en verdad este dios haya otorgado una causa justa, como antes a Sócrates, ahora a Catón y a menudo a muchos, el varón sabio, -ipor el dios fidio!- saldrá dichoso desde estas tinieblas a la luz. No romperá las cadenas de su cárcel -se lo prohíben las leyes- pero saldrá llamado por el dios como si algún magistrado u otra potestad legítima le llamasen."

A mediados del siglo I. d.C. Catón ya estaba consagrado como el mártir político por excelencia, ${ }^{359}$ y encarnaba el ideal de coherencia entre verba y acta en una época donde, como hemos dicho, la disociación de estos conceptos alcanzaba quizás su mayor expresión. Séneca lleva el suicidio de Catón a extremos estéticos y dramáticos impensables en escritores del siglo I a.C., y quizás también inconcebibles en otro período que no sea a mediados del siglo I d.C. Sin embargo el punto donde Séneca muestra una visión particular y específica dentro de este contexto más tradicional se encuentra a partir del parágrafo II, 7 de providentia:

"Miraris tu, si deus ille bonorum amantissimus, qui illos quam optimos esse atque excellentissimos uult, fortunam illis cum qua exerceantur adsignat? Ego uero non miror, si aliquando impetum capiunt spectandi magnos uiros conluctantis cum aliqua calamitate."

“ ¿Te maravillas de que, si ese dios amante de los hombres buenos, que quiere que ellos sean óptimos y excelentísimos, les asigne [a estos] una suerte contra la cual ejercitarse? Yo, en verdad, no me maravillo si cada tanto tienen el impulso de contemplar a los grandes hombres combatir con alguna desgracia."

Se esboza aquí la existencia de un impulso de índole estético y una necesidad de este dios amante de los hombres probos de contemplar (impetum spectandi) un espectáculo particular. Pero antes Séneca debe determinar con precisión qué tipo de espectáculo es digno del interés de los dioses. ${ }^{360}$ De este modo arribamos al exemplum por excelencia, el suicidio de Catón:

"Ecce spectaculum dignum ad quod respiciat intentus operi suo deus, ecce par deo dignum, uir fortis cum fortuna mala compositus, utique si et prouocauit. Non uideo, inquam, quid habeat in terris Iuppiter pulchrius, si <eo $>$ conuertere animum uelit, quam ut spectet Catonem iam partibus non semel fractis stantem nihilo minus inter ruinas publicas rectum." 361

He aquí un espectáculo digno para que un dios lo contemple atento a su obra, he aquí algo igual de digno que dios, el varón fuerte plantado ante la mala fortuna, incluso también si la ha provocado. No encuentro - diré- qué habría en la tierra que Júpiter pueda considerar más bello, si quisiera posar su mirada [aquí], como contemplar a Catón, ya derrumbado más de una vez su partido, alzándose sin embargo recto entre las ruinas de la república.

\footnotetext{
${ }^{359}$ Griffin, M. (1986b), 196.

${ }^{360}$ SEN. Prov. II, 8: "Non sunt ista quae possint deorum in se uultum conuertere, puerilia et humanae oblectamenta leuitatis"

361 SEN. Prov. II, 9.
} 
Catón es presentado como el varón firme y tenaz en su propósito que Horacio canta en su oda III, 3 (vv. 1- 8) impertérrito e impávido ante la caída del orbe entero y que Cicerón había prefigurado en De officiis I, $116:{ }^{362}$

"Atque haec differentia naturarum tantam habet vim, ut non numquam mortem sibi ipse consciscere alius debeat, alius [in eadem causa] non debeat. Num enim alia in causa M. Cato fuit, alia ceteri, qui se in Africa Caesari tradiderunt? atqui ceteris forsitan vitio datum esset, si se interemissent, propterea quod lenior eorum vita et mores fuerant faciliores; Catoni cum incredibilem tribuisset natura gravitatem, eamque ipse perpetua constantia roboravisset semperque in proposito susceptoque consilio permansisset, moriendum potius quam tyranni vultus aspiciendus fuit."

Y esta diferencia de naturaleza posee tanta fuerza, que uno, en un caso, nunca debería decretarse la muerte, y otro, en el mismo caso, sí. ¿Fue acaso una la causa para M. Catón y otra distinta para aquellos que se entregaron a César en África? Pero estos quizás habrían cometido un crimen, si se hubiesen matado, pues su vida era más suave y sus costumbres más disolutas; como la Naturaleza había otorgado a Catón una increíble seriedad, y el mismo la había fortalecido con una constancia perpetua y siempre se había mantenido firme en su propósito y seguro en su decisión, hubo de morir antes que tener que contemplar el rostro del tirano.

Séneca resalta con gran precisión el libre albedrío y la serenidad con la que el general emprende su acto final: Aggredere, anime, diu meditatum opus, eripe te rebus humanis (Prov. II, 9). Esta calma y esta serenidad se constituyen como características necesarias de toda eúlogos exagogé en el mundo romano. Termina el discurso y reaparece la voz de Séneca narrando el gratísimo espectáculo:

"Liquet mihi cum magno spectasse gaudio deos, dum ille uir, acerrimus sui uindex, alienae saluti consulit et instruit discedentium fugam, dum studia etiam nocte ultima tractat, dum gladium sacro pectori infigit, dum uiscera spargit et illam sanctissimam animam indignamque quae ferro contaminaretur manu educit. ${ }^{364}$

"Tengo muy claro que los dioses contemplaron con enorme goce, mientras aquel varón, severísimo vengador de sí mismo, se ocupa de la salvación ajena y prepara la huida de los disidentes; mientras se dedica al estudio incluso en la última noche; mientras la espada lastima el sacro pecho, mientras desparrama sus vísceras y libera esa alma santísima e indigna de ser mancillada por el hierro con su propia mano."

Destaca el epíteto del general, que coincide con la exhortación que hace Séneca a Lucilio en su primera epístola: ${ }^{365}$ Catón, vindex sui, muestra su sangre fría y su disposición anímica al garantizar la seguridad y la vida de todos los que lo rodean. Estos actos no sólo realzan la profunda humanidad del general sino que reafirman y atestiguan

\footnotetext{
${ }^{362}$ Nisbet, R. \& Rudd, N. (2004), 39.

${ }^{363}$ CIC. De Officiis, I, 116.

${ }^{364}$ SEN. Prov. II, 11.

${ }^{365}$ Vindica te tibi es la orden con la que Séneca abre su primera carta a Lucilio. SEN. Ep. I, 1.
} 
hasta qué punto la decisión tomada es fruto de la voluntad y la razón y no obra de la desesperación, hecho puntual y central en la disposición y ejecución de las acciones eminentemente espectaculares que analizaremos un poco más adelante, particularmente el suicidio de los soldados cesarianos en Pharsalia IV.

La calma y la securitas del general se revelan en los dos 'compañeros' escogidos para pasar su última noche: el libro y la espada. Ambos objetos poseen una función connotativa central. La lectura del Fedón, particularmente, enmarca la escena y agrega a la representación todo un conjunto de significados y connotaciones que apelan directamente a la competencia enciclopédica de los espectadores y de la posteridad, identificando y adscribiendo la muerte de Catón a la de Sócrates.

El ímpetu estético que empuja a los dioses a volver su rostro hacia este theatrum mundi se apodera entonces del propio narrador:

"Inde crediderim fuisse parum certum et efficax uulnus: non fuit dis inmortalibus satis spectare Catonem semel.",366

Incluso creería que la herida fue poco certera y eficaz: no fue suficiente para los dioses inmortales contemplar a Catón una sola vez.

Enmascarando su propio impetum spectandi detrás de la figura de los dioses, el narrador no duda en reformular el hecho histórico en favor de una mayor efectividad dramática. La muerte del general requirió, según Plutarco, dos pasos para ser completada, ya que el dolor de la herida desvaneció a Catón. Séneca reformula el material histórico para transformarlo en un hecho teatral en el cual el énfasis está puesto sobre la relación que se establece entre el actor y la audiencia. ${ }^{367}$

\section{DE PROVIDENTIA: EL SUICIDIO COMO SPECTACULUM.}

En este tratado Séneca no duda en ningún momento de la existencia de una providencia benévola: ${ }^{368}$ su intención no es convencer a Lucilio de la existencia y realidad de la misma, sino dar al joven argumentos que aclaren sus dudas sobre este

\footnotetext{
${ }^{366}$ SEN. Prov. II, 12.

${ }^{367}$ De Marinis, M. (1997), 8: "Sólo con su cooperación [i.e. las contribuciones de las ciencias humanas y sociales] el estudioso del teatro puede proceder a refundar seriamente los estatutos de su disciplina e intentar de ese modo dar cuentas efectivamente del hecho teatral no sólo, o principalmente, como producto, objeto, resultado, sino también, y especialmente como proceso o, mejor aún, como conjunto de fenómenos interconectados: lo que además quiere decir dar cuenta de él como fenómeno de significación y de comunicación, es decir, como un hecho esencialmente relacional."

${ }^{368}$ Setaioli, A. (2007), 349.
} 
espinoso asunto. ${ }^{369}$ La tesis central del tratado Sobre la providencia es presentada del siguiente modo:

"Quaesisti a me, Lucili, quid ita, si prouidentia mundus regeretur, multa bonis uiris mala acciderent." $"$ "370

“Quare multa bonis uiris aduersa eueniunt?' Nihil accidere bono uiro mali potest: non miscentur contraria. Quemadmodum tot amnes, tantum superne deiectorum imbrium, tanta medicatorum uis fontium non mutant saporem maris, ne remittunt quidem, ita aduersarum impetus rerum uiri fortis non uertit animum: manet in statu et quidquid euenit in suum colorem trahit; est enim omnibus externis potentior. [...] Marcet sine aduersario uirtus: tunc apparet quanta sit quantumque polleat, cum quid possit patientia ostendit. Scias licet idem uiris bonis esse faciendum, ut dura ac difficilia non reformident nec de fato querantur, quidquid accidit boni consulant, in bonum uertant; non quid sed quemadmodum feras interest. ${ }^{, 371}$

"Me preguntaste, Lucilio, por qué, si la Providencia gobierna al mundo, muchos males le ocurren a los hombres buenos."

“¿Por qué le ocurren muchas adversidades a los hombres buenos? Nada malo puede sucederle al hombre bueno: no se mezclan los contrarios. Del mismo modo que ni tantos arroyos ni tantas lluvias lanzadas desde lo alto, ni toda la fuerza de las fuentes medicinales cambian el sabor del mar y ni siquiera lo diluyen; del mismo modo el ímpetu de las cosas adversas no doblega el ánimo del varón fuerte: se mantiene firme y todo lo que le acontece lo adapta a su situación; es por lo tanto más poderoso que todo evento externo. [..] Se marchita la virtud sin adversarios: se revela entonces cuán grande y cuán eficaz es cuando muestra cuánto puede soportar. Sabes sin embargo que lo mismo deben hacer los hombres buenos, de modo que no retrocedan ante las dificultades y las desgracias ni se quejen del hado; los hombres buenos analizan todo lo que les ocurre para volverlo algo bueno. No importa qué te sucede, sino cómo lo sobrellevas."

Los males y las desgracias se presentan, entonces, como oportunidades para que el hombre honesto cultive, practique $\mathrm{y}$, sobre todo, ponga a prueba su virtus y su constantia:

"Nec hoc dico, non sentit illa, sed uincit, et alioqui quietus placidusque contra incurrentia attollitur. Omnia aduersa exercitationes putat. [...] Patrium deus habet aduersus bonos uiros animum et illos fortiter amat et 'operibus' inquit 'doloribus damnis exagitentur, ut uerum colligant robur.' Languent per inertiam saginata nec labore tantum sed motu et ipso sui onere deficiunt. Non fert ullum ictum inlaesa felicitas; at cui adsidua fuit cum incommodis suis rixa, callum per iniurias duxit nec ulli malo cedit, sed etiam si cecidit de genu pugnat." ${ }^{372}$

\footnotetext{
${ }^{369}$ Narducci, E. (1979), 67-67; Setaioli, A. (2007), 362-364; SEN. Prov. I, 1-6. Especialmente I, 2: "Superuacuum est in praesentia ostendere non sine aliquo custode tantum opus" \& I, 5-6: "In gratiam te reducam cum dis aduersus optimos optimis. Neque enim rerum natura patitur ut umquam bona bonis noceant; inter bonos uiros ac deos amicitia est conciliante uirtute. [...] bonum uirum in deliciis non habet, experitur indurat, sibi illum parat."

${ }^{370}$ SEN. Prov. I, 1.

${ }^{371}$ SEN. Prov. II, 1 \& II, 4.

${ }^{372}$ SEN. Prov. II, 2 \& II, 6.
} 
Y no digo esto- que no los siente-, sino que los vence; y además sereno y tranquilo se impone a las desgracias que le ocurren. Considera toda adversidad un ejercicio. [...] Dios tiene el ánimo de un padre para con los hombres buenos y los ama valerosamente. "Que los hostiguen - dice- el trabajo, las penas y el dolor para que adquieran una verdadera fortaleza". La gordura languidece en la pereza y se desalienta no tanto por el esfuerzo, sino por su propio peso. No sobrelleva un solo golpe la dicha que nunca fue puesta a prueba. Pero la que tuvo asiduas batallas contra la adversidad logró callos en sus heridas y no cedió ante ningún mal y, si alguna vez cayó, luchó incluso de rodillas.

Catón es representado como el varón firme y tenaz en su propósito que Horacio cantaba impertérrito e impávido ante la caída del orbe entero. ${ }^{373}$ Los paralelismos lingüísticos y la cercanía de las imágenes utilizadas son diáfanas:

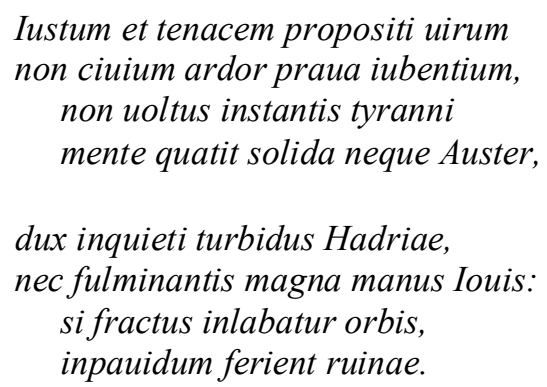

Al varón justo y tenaz en su propósito

ni el ciego ardor de los ciudadanos que desean cosas malvadas ni el rostro del tirano amenazante; ni el Austro, señor tempestuoso del agitado Adriático,

ni la poderosa mano del fulminante Júpiter

lo inquietan en su sólida mente:

si el orbe se derrumbase destrozado

impávido lo cubrirán las ruinas.

Entre las ruinas de la república y los escombros de su partido sólo queda en pie la figura erguida y solemne del general. Asediado por el tirano, ${ }^{374}$ Catón calmo y tranquilo medita cuál es el camino hacia la libertad. Resulta particularmente interesante ver cómo los agentes hostiles al iustum virum de Horacio pueden ser asimilados a la figura de César creada por Lucano. En Pharsalia César es presentado casi como una fuerza elemental: su identificación con el rayo aúna de manera genial su celeridad y precisión para la acción, así como también su capacidad de destrucción. ${ }^{375}$ Los autores del siglo I

\footnotetext{
${ }^{373}$ Narducci, E. (1979), 139-140.

${ }^{374}$ Nisbet, R. \& Rudd, N. (2004), 39.

375 LUC. I, 143- 157. César aparece también como un ser superior a los elementos, por ejemplo en su desafío a la tempestad en V, 403-721. Ahl, F. (1976), 191-192 \& 197-209; Narducci, E. (2002), 187-190 \& 247-248.
} 
d.C. se caracterizan por su particular utilización y subversión de los paradigmas poéticos augusteos a través de operaciones tan sutiles como profundas: ${ }^{376}$ en este caso el varón justo y tenaz, amenazado por la manifestación terrena de todos los poderes hostiles que enumera Horacio, se yergue incólume entre las ruinas de Roma. ${ }^{377}$ Pero debido a la conturbación universal que se ha apoderado del mundo, ${ }^{378}$ la amenaza es ahora, en otra genial subversión barroca de Lucano, la clementia Caesaris y el perdón, ${ }^{379}$ mientras que sólo la muerte se presenta como única garante de la libertas. ${ }^{380}$

Retomemos el cierre de providentia II, 9, así como en sus tragedias Séneca gusta de cerrar ciertos desarrollos trágicos con certeras sentencias, el final de este párrafo concentra imágenes e ideas desarrolladas en todo la segunda sección: Catón, stantem rectum entre las ruinas de la República, es el exemplar del vir que calmo y tranquilo (Prov. II, 1) enfrenta las desgracias que le acaecen - incurrentia- (Prov. II, 2). Es, además, el más bello espectáculo que este mundo puede ofrecer a la mirada de los dioses, amantes, según la prosa de Séneca, de los varones justos (Prov. II, 7).

\section{SUICIDIO Y TEATRALIDAD: EL TEXTO-ESPECTACULAR}

La representación despliega un theatrum mundi donde una audiencia divina disfruta, con una fruición estética, de un espectáculo particular y específico: un gran hombre sobrellevando valientemente las desgracias (Prov. II, 7-8). Séneca nos presenta el clímax de esta tragedia. Catón ha tomado ya su decisión y se apresta a llevarla a cabo:

"Licet' inquit 'omnia in unius dicionem concesserint, custodiantur legionibus terrae, classibus maria, Caesarianus portas miles obsideat, Cato qua exeat habet: una manu latam libertati uiam faciet. Ferrum istud, etiam ciuili bello purum et innoxium, bonas tandem ac nobiles edet operas: libertatem quam patriae non potuit Catoni dabit. Aggredere, anime, diu meditatum opus, eripe te rebus humanis. Iam Petreius et Iuba concucurrerunt iacentque alter alterius manu caesi, fortis et egregia fati conuentio, sed quae non deceat magnitudinem nostram: tam turpe est Catoni mortem ab ullo petere quam uitam.",381

"Aunque todo- dice- haya sido abandonado a la voluntad de uno solo, [aunque] las tierras sean vigiladas por legiones, los mares por flotas y el soldado de César se siente

\footnotetext{
${ }^{376}$ Vizzotti, M. (2009), 528-535; Vizzotti, M. (2006), 528-535.

377 En Farsalia, IX, 385, Catón alienta a los soldados a recorrer un duro camino hacia las leyes y el amor por la patria derrumbada. (durum iter ad leges patriaeque ruentis amores.)

${ }^{378}$ LUC. I, 72-80; Lapidge, M. (1979), 281-296; Sklenáŕ, R. (1999), 281-283.

${ }^{379}$ Leigh, M. (2009), 249.

${ }^{380}$ Ahl, F. (1976), $241 \& 247-252$.

${ }^{381}$ SEN. Prov. II, 10.
} 
frente a las puertas, Catón tiene por donde escapar: con esta mano construirá un amplio camino hacia la libertad. Este hierro, puro e inmaculado -incluso en la guerra civil-, completará al fin una tarea noble y buena, dará a Catón la libertad que no pudo darle a la patria. Emprende, ánimo, una obra largamente meditada, arráncate de los asuntos humanos. Ya Petreyo y Juba se enfrentaron y yace cada uno abatido por la mano del otro, egregio y valiente pacto de muerte; pero que no convendría a nuestra grandeza: tan vergonzoso es para Catón implorar a otro tanto la muerte como la vida."

El discurso es clara y profundamente dramático. El mundo se ha cerrado sobre Catón: un tirano domina ahora el mundo y sus legiones asuelan las puertas de Útica, pero el sabio siempre tiene una vía de escape. La tensión dramática va in crescendo y se prefiguran de modo sutil las cruentas heridas que el general se autoinfligirá abriendo ese amplio camino hacia la libertad en sus propias entrañas. Luego, casi a modo de una didascalia interna, ${ }^{382}$ aparece en escena la espada - pura e impoluta- que, gracias al principio de semiotización, adquiere, en este cuadro despojado, una función significativa fundamental: ${ }^{383}$ la espada se transforma en una alter ego del general, la única persona -según la tradición- que atravesó la guerra civil sin mancharse ni deshonrarse. El principio de movilidad y polivalencia permite que la espada aparezca también como un personaje redentor. ${ }^{384}$ Este recurso es explotado por Séneca con gran efectividad y maestría en Phaedra, cuando la espada abandonada por Hipólito en su huida se transforma en el testigo acusador y en el elemento probatorio central del ardid de la reina. ${ }^{385}$

El desdoblamiento general/ espada es claro y efectivo: el general se reivindicará a sí mismo a través de su arma innocens. ${ }^{386}$ Caída la república y perdida la libertad

\footnotetext{
382 Golopentia, S. (1993), 475- 492 ; Vizzotti, M. (2007), 57-59.

${ }^{383}$ De Marinis, M (1997), 19: "Principio de artificialización (o semiotización): A este principio se refieren los procedimientos mediante los cuales la escena artificializa (semiotiza) al adjudicarles una función significativa, todo tipo de elementos, incluso reales (por ejemplo, un objeto de verdad) o no producidos intencionalmente (por ejemplo alguna característica física del actor)."

${ }^{384}$ De Marinis, M (1997), 19-20: "Principio de movilidad. Este principio se refiere al fenómeno semiótico de la independencia mutua existente entre los dos juntivo de un signo (expresión-contenido), fenómeno que -en la situación particular consistente en la pluralidad de materias expresivas y de sistemas sígnicos que caracteriza el espectáculo teatral- se traduce en dos hechos específicos y complementarios entre sí: a) la intercambiabilidad funcional entre signos de sistemas de significación diferentes (por ejemplo, la función décor puede ser asumida, además por los elementos escenográficos, también por fragmentos musicales, indicaciones escritas, réplicas verbales o acciones gestuales; b) la polivalencia de un mismo elemento expresivo, el cual, en distintos contextos o circunstancias, puede asumir no sólo diferentes significados (lo que es propio de cualquier signo, no solamente de los teatrales), sino que también puede desempeñar distintas funciones y roles ( por ejemplo, un objeto, un accesorio, puede convertirse en un sujeto activo, un 'personaje' en definitiva, al mismo nivel que un actor de carne y hueso: por ejemplo el puñal de Macbeth y el pañuelo de Otelo."

${ }^{385}$ Segal, Ch. (1986), cf. el capítulo "Desire, Silence, and the Speech of the Sword", 150-179.

${ }^{386}$ SEN. Ep. I, 1.
} 
inherente a cada ciudadano romano, ${ }^{387}$ Catón, precisamente por su incredibilem gravitatem, ${ }^{388}$ sólo puede tomar esta decisión. No hay, sin embargo, determinismo; la elección de Catón es libre y meditada. Las paradójicas presentaciones de Lucano resultan útiles para comprender cómo era considerado y representado Catón a poco más de un siglo después de su muerte. En Pharsalia Catón, aún más que los propios dioses, es el garante de la justicia y sólo él formó parte de la contienda civil conducido por la virtus paradojal que rige Pharsalia: ${ }^{389}$

uictrix causa deis placuit sed uicta Catoni.

'summum, Brute, nefas ciuilia bella fatemur, sed quo fata trahunt uirtus secura sequetur. crimen erit superis et me fecisse nocentem.

(LUC. II, 287-288)

La causa victoriosa complació a los dioses, pero la vencida a Catón

Reconocemos, Bruto, que guerra civil es la más alta impiedad, pero la virtud irá segura a donde los hados la arrastren.

Será un crimen de los dioses el hacerme también a mí culpable.

Séneca destaca con gran precisión el libre albedrío y la serenidad con la que el general emprende su acto final: Aggredere, anime, diu meditatum opus, eripe te rebus humanis. Hemos destacado ya cómo esta calma y esta serenidad se constituyeron características necesarias de toda eúlogos exagogé en el mundo romano. El exemplum de la fortis et egregia fati conventio de Juba y Petreyo (Prov. II, 10) conforman y delimitan con exactitud la particularísima situación del general. Tal como lo destacaba Cicerón un siglo antes que Séneca, tales pactos, aunque valientes y egregios, no convenían a la dignidad del último ciudadano romano libre: sed quae non deceat magnitudinem nostram: tam turpe est Catoni mortem ab ullo petere quam uitam.

Termina el discurso del general y reaparece la voz de Séneca narrando el gratísimo espectáculo:

"Liquet mihi cum magno spectasse gaudio deos, dum ille uir, acerrimus sui uindex, alienae saluti consulit et instruit discedentium fugam, dum studia etiam nocte ultima tractat, dum gladium sacro pectori infigit, dum uiscera spargit et illam sanctissimam animam indignamque quae ferro contaminaretur manu educit.",390

\footnotetext{
${ }^{387}$ LUC. I, 67 y ss.

${ }^{388}$ CIC. Off. I, 112.

${ }^{389}$ Getty, R. (1940), 46; Fantham, E. (1992), 132; Narducci, E. (2002), 384-387.

${ }^{390}$ SEN. Prov. II, 11.
} 
"Tengo muy claro que los dioses contemplaron con enorme goce, mientras aquel varón, severísimo vengador de sí mismo, se ocupó de la salvación ajena y preparó la huida de los disidentes; mientras se dedica al estudio incluso en la última noche; mientras clava la espada en el sacro pecho, mientras desparrama sus vísceras y libera ese alma santísima e indigna de ser mancillada por el hierro con su propia mano."

Catón, vindex sui, muestra su sangre fría y su disposición anímica al garantizar la seguridad y la vida de todos los que lo rodean. Estos actos no sólo muestran la profunda humanidad del general sino que reafirman y atestiguan, de manera similar a lo que ocurrirá en Masada en el 73 d.C., hasta qué punto la decisión tomada es fruto de la voluntad y la razón y no obra de la desesperación.

Este spectaculum, que ofrece un enorme placer estético a los dioses (magno gaudio) se describe de modo tan efectivo como económico a través de un crescendo estructurado por la conjunción dum, desarrollando, para fruición de los espectadores, en cuatro cuadros dramáticos el último gran acto de Catón:

- Dum ille vir [...] fugam: Tal como mencionamos anteriormente, al garantizar la seguridad de sus subalternos, Catón enaltece su decisión final.

- Dum studia [...] tractat: la constantia del general no sólo reafirma la racionalidad de su decisión sino que también la enmarca dentro de una tradición filosófica específica.

- Dum gladium [...] infigit: Séneca, buscando un mayor efecto teatral y una economía dramática más acorde a su sensibilidad artística que al hecho en sí, conjuga en una sola y efectiva acción las dos etapas que, según Plutarco, requirió la muerte del general.

- Dum viscera [...] educit: Como es habitual en las manifestaciones artísticas del siglo I d.C., se exacerban ciertos elementos que privilegian la expresividad en detrimento de un pretendido realismo. La espada, aunque pura e impoluta, sólo puede abrir la latam viam en el sacro pecho, pero el alma de Catón debe ser liberada por la propia mano del general.

El ímpetu estético que empuja a los dioses a volver su rostro hacia este theatrum mundi se apodera entonces del propio narrador:

"Inde crediderim fuisse parum certum et efficax uulnus: non fuit dis inmortalibus satis spectare Catonem semel."391

"Incluso creería que la herida fue poco certera y eficaz: no fue suficiente para los dioses inmortales contemplar a Catón sólo una vez."

Séneca reformula el material histórico para transformarlo en un hecho teatral en el cual el énfasis está puesto en la relación que se establece entre el actor y la audiencia que completa las potencialidades significativas del acto. ${ }^{392}$

\footnotetext{
${ }^{391}$ SEN. Prov. II, 12.

392 De Marinis, M. (1997), 8: "Sólo con su cooperación [i.e. las contribuciones de las ciencias humanas y sociales] el estudioso del teatro puede proceder a refundar seriamente los estatutos de su disciplina e
} 


\section{RECAPITULACIÓN Y CONCLUSIONES PARCIALES}

En De providentia se construye la muerte de Catón como un fenómeno esencialmente relacional. Su muerte se despliega como objeto, producto y, principalmente, resultado de un proceso comunicativo, donde el Fedón y la espada se transforman en signos de objeto $^{393}$ que son ostentados como disparadores de las competencias enciclopédicas del espectador. Séneca complejiza el hecho histórico exacerbando los aspectos dramáticos inherentes al mismo. Gracias a esta operación de apropiación y reformulación de la historia, la muerte de Catón sólo cobra sentido y existe, en este contexto, en tanto hecho estético y semiótico si y sólo si es completado y significado por uno o varios receptores con las competencias culturales y enciclopédicas necesarias. Se produce, además, un doble proceso de recepción: el texto espectacular despliega un theatrum mundi donde los dioses son garantes de la significación del espectáculo de la virtud, pero a su vez aparece, en un plano extra-textual y como figura análoga, el propio lector del tratado, quien finalmente completa y hace efectiva esta relación comunicativa con el texto en sí.

La concepción espectacular de las acciones virtuosas y la profunda conciencia estética de los actos del hombre honesto resultan de gran importancia para nuestra perspectiva de análisis pues son la piedra fundamental sobre la que se construyen los horrorosos espectáculos desplegados en la tragedia de Séneca y en la épica de Lucano. Tal como ya hemos mostrado, los héroes trágicos senequianos están construidos sobre un sólido andamiaje estoico desplegando la misma disposición dramática con que el exemplar estoico concibe y realiza sus actos y enseñanzas pero aplicando estos preceptos a actos criminales que subvierten y trastruecan el propio paradigma que los sustenta. Lo mismo ocurre, con ciertos matices, en Pharsalia, donde el horror que permea las bravías acciones de los soldados resulta el agente de dispersión y disolución sígnica y conceptual de los valores más caros al vir Romanus, tales como la virtus y la pietas.

Este procedimiento es uno de los pocos, quizás el único, en el cual Lucano no logra ir más allá en su despliegue teórico y literario que Séneca, si bien su uso en

intentar de ese modo dar cuentas efectivamente del hecho teatral no sólo, o principalmente, como producto, objeto, resultado, sino también, y especialmente como proceso o, mejor aún, como conjunto de fenómenos interconectados: lo que además quiere decir dar cuenta de él como fenómeno de significación y de comunicación, es decir, como un hecho esencialmente relacional."

${ }^{393}$ De Marinis, M. (1997), 19. 
Pharsalia no deja de ser extremadamente innovador y vanguardista. Atribuimos esta particularidad a una cuestión inherente al género de la representación, pues, claramente, el teatro ofrece un campo de experimentación y desarrollo de estos conceptos mucho más amplio y rico que la épica. Como hemos visto, Atreo y Medea pueden considerarse verdaderas contrafiguras trágicas, en mayor o menor medida, del propio Séneca como tragediógrafo, mientras que en Pharsalia, Vulteyo y Esceva demuestran una profunda conciencia estética y una concepción espectacular de las acciones las cuales, caracterizadas por el horror y la truculencia, resultan en la subversión y disolución de las propias virtutes que despliegan. De este modo, la concepción espectacular de los actos, paradigma básico del accionar estoico, es el elemento fundamental de espectáculos eminentemente antiestoicos que resulta, paradójicamente, el catalizador principal del proceso de disolución sígnica que corroe inexorablemente sus paradigmas rectores, resultando entonces parte fundamental de ciertas operaciones poéticas que problematizan, subvierten o confutan los propios elementos constitutivos del entramado poético. 
ATREO: LA CONSTRUCCIÓN ESTÉTICA DEL CRIMEN Y LA SUBVERSIÓN DE LA FIGURA DEL HÉROE ESTOICO

El personaje de Atreo es, aunque superficialmente parezca lo contrario, uno cuyo andamiaje literario y cuya estructura profunda responde más fielmente a concepciones y puntos de vista estoicos, aun más que los de Fedra e Hipólito: ${ }^{394}$ Atreo se apoya y se nutre de las concepciones de esta escuela filosófica para configurar su violenta venganza. Los personajes desmesurados, irascibles y violentos presentan, contrariamente a los personajes en apariencia persuasivos, ${ }^{395}$ una fuerte estampa estoica, una muy coherente estructura profunda hondamente enraizada en la doctrina que, como ya citamos poco antes, ofrece una certera y firme construcción de específicos aspectos anti-estoicos. Atreo está construido a partir de premisas que responden al ideal estoico de heroísmo, tal como lo hemos desarrollado en el apartado anterior.

Atreo se construye en tanto individuo a través de las metodologías y estrategias estoicas y su concepción de cómo debe ser y cómo debe ejecutarse su venganza están firmemente enraizadas dentro de la tradición estoica del sabio como exemplar de la virtud. ${ }^{396}$ Los elementos dramáticos y metadramáticos desplegados por Atreo demuestran una profunda conciencia estética por parte del rey: en lo que respecta a la tradición criminal en la que busca inscribirse y a la que pretende superar, sus acciones se basan en la particular articulación que los personajes senequianos hacen de los conceptos de timé y kléos. Dentro de los hechos “diegéticamente contemporáneos" a la acción dramática, Tántalo y Pélope aparecen como la tradición familiar que ofrece el impulso creativo y presentan, junto con la venganza de Procne y Filomela sobre Tereo, los modelos a emular y superar. En el plano extra-diegético, como ya señalamos, Séneca logra que los significantes actúen como disparadores de las competencias enciclopédicas del receptor y que se genere una plétora de asociaciones sintagmáticas inmediatas con diversas obras teatrales y literarias de la tradición Grecolatina.

\footnotetext{
${ }^{394}$ Galán, L. (2002), 61 y ss.

${ }^{395}$ Rosenmeyer, Th. (1989), 22.

${ }^{396}$ Hijmans Jr. B. (1966), 237.
} 
Si algo aterra del crimen del rey en Thyestes es el placer que éste le provoca y la meticulosa y obsesiva planificación estética del mismo, es decir, el regodeo en la disposición ordenada y racionalizada del crimen, antes, durante y después. Incluso sin saber aún cuál será el método elegido para llevarlo a cabo, Atreo es consciente de la magnitud que deberá tener y hasta qué punto deberá llegar, pues su audiencia será la posteridad: ${ }^{397}$

[Atr]: Age, anime, fac quod nulla posteritas probet, sed nulla taceat.

¡Vamos ánimo!, Haz algo que ninguna posteridad apruebe pero que ninguna calle.

El perverso sentido de timé y kléos de Atreo refleja el deseo programático de la poética senequiana - y seguramente de la de todo tragediógrafo- de superar los modelos prestigiosos de sus predecesores. Atreo es la imagen en negativo del Cato Uticensis senequiano, el lado oscuro y perturbador de la doctrina configurado a través de las operaciones poéticas y trágicas.

Una de las características particulares del héroe barroco es, según F. Warnke, su pasividad. Los movimientos barrocos conciben el heroísmo de forma más bien pasiva y a la voluntad como algo que debe ser dirigido no hacia un resultado sino hacia una resistencia. El ideal heroico como una voluntad de resistir es consistente, por ejemplo, en la obra de Milton: el héroe barroco soporta, estoicamente, una lucha que sabe no puede ganar: se lucha para poder persistir en la lucha y la victoria es sólo no desfallecer, nunca vencer. Personajes como Lucifer en Paradise Lost o la pasión de Cristo en la cruz en Voicy-l'homme reflejan esta concepción particular del héroe. ${ }^{398}$ Catón, tanto en

\footnotetext{
397 Tarrant, R. (1985), 119: “192-93 age ... taceat: Seneca's Medea also aims for undying renown in crime, cf. 432-33 faciet, hic faciet dies/ quod nullus umquam taceat, but the sardonic opposition of probet and taceat gives Atreus' lines a sharper point, cf. Tro. 1128 odit scelus spectatque. Atreus' wish is recalled in the words of the messenger, 753-54 o nullo scelus/ credibile in aevo quodque posteritas neget."

398 Warnke, F. (1970), 157; Milton, J. Paradise Lost, I, 87-108: "if he whom mutual league/ United thoughts and counsels, equal hope/ And hazard in the glorious enterprise/ Joined with me once, now misery hath joined/ In equal ruin; into what pit thou seest/ From what height fallen: so much the stronger proved/ He with his thunder; and till then who knew/ The force of those dire arms? Yet not for those/ Nor what the potent Victor in his rage/ Can else inflict, do I repent, or change/ Though changed in outward lustre, that fixed mind/ And high disdain from sense of injured merit/ That with the Mightiest raised me to contend/ And to the fierce contentions brought along/ Innumerable force of Spirits armed/ That durst
} 
Séneca como en Lucano, particularmente en el libro IX, es el héroe de la patientia, quien sobrelleva todo lo que debe ser sobrellevado y aún más; la virtus no está en vencer, sino en continuar y soportar:

serpens, sitis, ardor harenae

dulcia uirtuti; gaudet patientia duris;

laetius est, quotiens magno sibi constat, honestum. $\quad$ (LUC. IX, 402-404)

serpientes, sed, el calor de la arena

son delicias para la virtud; la resistencia se complace con las desgracias

Más satisfactorio es lo honesto cada vez que se consigue a un alto precio.

Atreo, en cambio, al igual que César en Pharsalia, es un héroe activo y, lo que resulta quizás más relevante, creativo. ${ }^{399} \mathrm{Al}$ igual que César, ambos encarnan una fuerza dinámica que no duda en abrirse camino con la ruina y se regodean en derribar todo obstáculo que se interponga entre ellos y su objetivo. Ellos son quienes generan el caos en todos los niveles de la creación y las turbulencias perturbadoras del orden universal. Atreo no es un objeto pasivo de contemplación estética; todo lo contrario, es un agente activo creador de representaciones estéticas que deben ser contempladas y completadas para poder existir como tales. Atreo busca espantar a la misma audiencia divina que se regodeaba con el severo suicidio de Catón ((Thy. 265-266) y a través de su crimen busca su propia reafirmación existencial, ratificando no sólo su condición de rey sino su pertenencia a la casa de Pélope, caracterizada por traiciones y crímenes atroces. ${ }^{400} \mathrm{Al}$ igual que Medea, el crimen es un medio para alcanzar no sólo sus fines, sino para reafirmar su propia existencia ante los demás. ${ }^{401} \mathrm{El}$ solo hecho de permanecer inocente, una vez decidido el método a seguir, le resulta insoportable:

bene est, abunde est: hic placet poenae modus tantisper. Vbinam est? Tam diu cur innocens uersatur Atreus?

Está bien, es suficiente. Este tipo de castigo me complace. por ahora, ¿dónde está? ¿Por qué permanece tanto tiempo aún inocente Atreo?

dislike his reign, and, me preferring/ His utmost power with adverse power opposed/ In dubious battle on the plains of Heaven/ And shook his throne. What though the field be lost? / All is not lost--the unconquerable will/ And study of revenge, immortal hate/ And courage never to submit or yield."

${ }^{399}$ Leigh, M. (2009), 239 \& 247.

${ }^{400}$ Rosenmeyer, Th. (1989), 89: "The more violent the king, the kinglier he is. "; SEN. Thyestes, $240 \mathrm{y}$ ss.; 249 y ss. \& 270 y ss.

${ }^{401}$ Rosenmeyer, Th. (1989), 52: "Self dramatization, the character intense recognition that he is creating his role for the dereliction and the horror of others, and that their presence adds sustenance to his standings, is also a kind of existential exercise. Medea wishes to become Medea, and Hercules Hercules, to conform both to their own expectations and to those of their enemies and friends." 
Atreo se encarga él mismo del crimen, pero lo acompaña una turba de esclavos y el mismo nuntius que narrará los hechos al coro. Su relato, rico en detalles, hace repetidas veces hincapié en el obsesivo y meticuloso actuar del rey:

[Nun.] seruatur omnis ordo, ne tantum nefas non rite fiat. Cho: Quis manum ferro admouet?

Nun: Ipse est sacerdos, ipse funesta prece

letale carmen ore violento canit.

stat ipse ad aras, ipse deuotos neci

contrectat et componit et ferro admouet;

attendit ipse - nulla pars sacri perit.

Todo se lleva a cabo con orden y cuidado, para que un crimen tan grande no se realice fuera del rito. [Co.]:¿Qué mano blande el hierro? [Men.]: Él mismo oficia de sacerdote, él mismo entona el canto letal con boca violenta. Él mismo se alza junto al altar, él mismo manipula a los condenados los ordena y blande el hierro él mismo dispone todo - ninguna parte del rito es descuidada.

El mensajero pronuncia palabras claves precisas y específicas, las palabras ordo y rite no pueden traducirse sin perder parte de su carga semántica. La ceremonia re realiza con orden racional y premeditado, pues un crimen tan grande que espante incluso a los dioses no puede carecer de un carácter sacro y numinoso. La repetición obsesiva del pronombre ipse refuerza la preocupación y la dedicación de Atreo, quien se encarga de todos los aspectos importantes; ningún detalle es ignorado u olvidado. ${ }^{402}$ A medida que se acerca la hora final las señales y los prodigios se suceden uno tras otro, ${ }^{403}$ pese a lo cual Atreo persiste inconmovible:

sic dirus Atreus capita deuota impiae speculatur irae. Quem prius mactet sibi dubitat, secunda deinde quem caede immolet. nec interest, sed dubitat et saeuum scelus iuuat ordinare.

Así Atreo contempla cruel las cabezas consagradas a su impía ira. Duda a quién sacrificará primero y a quién inmolará después. No importa, pero duda y se complace en disponer ordenadamente un crimen cruel.

Este pasaje nos trae a la memoria al Velázquez de "Las Meninas", ligeramente alejado de su modelo, volcándose hacia su costado, suspendido en un kairós artístico entre la tela y el pincel, con su brazo en alto contemplando su obra, a punto de desplegar el

\footnotetext{
402 Tarrant, R. (1985), 190-191.

${ }^{403}$ SEN. Thy. 696 y ss.
} 
volumen del espectáculo al dar la primera o última pincelada. ${ }^{404} \mathrm{El}$ artista toma una pequeña distancia para abarcar con su mirada la obra a realizar (Dirus Atreus [...] speculatur vv. 712-713) y surge entonces la duda, pero nada tiene ésta que ver con el remordimiento o el miedo, no nace de una contradicción ética, moral o legal: la duda es estética. El asesino se regodea en organizar y disponer de manera ordenada, meticulosa - artística, al fin- los elementos constitutivos de su obra: ¿Quién cae primero? ¿Quién después? En el verso 715 polemizan de manera irreconciliable el plano ético y el estético, en detrimento del primero, por supuesto: nec interest, sed dubitat. No importa moral o éticamente quién caiga primero, ${ }^{405}$ no hay remordimiento o pena alguna, la duda pertenece al plano del arte, al espacio de la performance. ${ }^{406}$ He aquí la inversión absoluta del héroe estoico: se han trastrocado el orden y las prioridades, pero el armazón está intacto y estructura al personaje y su conducta. En vez de morir dignamente y de modo inspirador para el mundo, Atreo mata cruelmente y aterra a la posteridad; sin embargo el sustrato estoico es común. Puede apreciarse entonces otro de los puntos fundamentales de la tragedia y la poética senequiana el poner en escena las paradojas y las problemáticas estoicas, los aspectos de la doctrina que preocupaban al filósofo y, quizás a su pesar, regodeaban al pensador y al poeta.

Culminada su obra, Atreo pronuncia las siguientes palabras, cuyos ecos horacianos son evidentes:

Aequalis astris gradior et cunctos super altum superbo uertice attingens polum.

Igual que un astro avanzo y por encima de todos, alcanzando el alto polo con mi cabeza soberbia.

En la Oda I, 1 Horacio proclama que, si Mecenas lo considerase como un miembro de la cofradía de los poetas, el tocaría las estrellas con su cabeza enhiesta. ${ }^{407}$ Las figuras del asesino triunfal y la del vate consagrado se vuelven, gracias a las operaciones poéticas senequianas, análogas y equivalentes. A través de la alusión a Horacio, Séneca logra dos operaciones literarias importantes: en primer lugar instaurar la figura de Atreo como

\footnotetext{
${ }^{404}$ Foucault, M. (1999), 13-25; Sarduy, S. (1974), 78-80.

${ }^{405}$ Meltzer, G. (1988), 352-326.

${ }^{406}$ Rosenmeyer, Th. (1989), 77.

407 Tarrant, R. (1985), 217: "Aequalis astros gradior: saying that one can touch the sky is a proverbial expression of felicity (cf. 'feeling on top of the world), cf. CIC. Att. 2.1.7 nostri autem príncipes digito se caelum putant attingere, Hor. C.1.1.36 sublimi feriam sidera uertice (with Nisbet-Hubbard's note). Atreus gives the commonplace a new twist: aequalis means 'as high as' (cf. 643) but also implies 'of equal status with'; since the stars are divine (cf. 844 sacris ... astris), Atreus is implicitly claiming equality with the gods, as he will do openly in 911 (cf. 545, 713)." Cf. HOR. Carm. I 1, 35-36: "Quod si me lyricis uatibus inseres, / sublimi feriam sidera uertice.” Nisbet, R. \& Hubbard, M. (1970), 14-16.
} 
artista consagrado y, en segundo lugar, desestabilizar y subvertir radicalmente la representación primigenia de la poesía augustea.

Atreo entra en escena igual que un astro y tocando soberbiamente el cielo: se ha consagrado como artista y su obra ha sido concluida, pero eso no es suficiente. El rey es el artista creador de un espectáculo capaz de producir la huida de los propios dioses y la caída del cielo y de los signos zodiacales; pero la profunda conciencia artística y semiótica de Atreo va aun más allá. El autor es, simultáneamente, crítico y receptor de su obra y como tal expresa el deseo explícito de lo que podríamos llamar la "recepción" de su obra:

libet uidere, capita natorum intuens, quos det colores, uerba quae primus dolor effundat aut ut spiritu expulso stupens corpus rigescat.Fructus hic operis mei est. miserum uidere nolo, sed dum fit miser.

Me agrada contemplar esto: al ver las cabezas de sus hijos, qué colores tomará, qué palabras proferirá su primera pena o cómo su cuerpo sin aliento se quedará rígido. Este es el fruto de mi trabajo no deseo verlo desdichado, sino cómo se vuelve desdichado.

Atreo desea contemplar los efectos que su obra causa en su destinatario, el fruto de su trabajo será apreciar, estéticamente, la reacción del receptor. La palabra colores no sólo hace alusión al talante de Tiestes. Es, en realidad, un término muy específico del campo de la retórica que hace referencia a ciertos aspectos y características particulares del discurso. Colores es una palabra cuyo sentido técnico no podía pasar desapercibido a una audiencia romana competente en este campo. Color hace referencia, específicamente, a los diferentes aspectos de la construcción del discurso y la declamación pública tales como la postura, el lenguaje corporal y demás cuestiones actitudinales específicas de la oratoria. ${ }^{408}$

\footnotetext{
${ }^{408}$ Goldberg, S. (1996), 272; contra, cf. Tarrant, R. (1985), 219: quos det colores: 'what complexion he shows' (i.e., how his face turns red and pale by turns), perhaps based on Verg. Aen, 12.69 talis virgo dabat ore colores; for alternating blushes and pallor as signs of violent emotion cf. Med. 858-61 with Costa's note."
} 


\section{RECAPITULACIÓN Y CONCLUSIONES PARCIALES}

La conciencia estética, como ya señalamos, es uno de los rasgos que más acercan al rey al paradigma del héroe estoico. Hasta tal punto llega que, cuando se percata de que su audiencia de inmortales ha huido y de que su obra se ha quedado sin público, pronuncia las siguientes palabras:

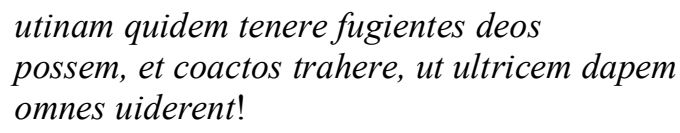

En este pasaje puede apreciarse la inversión absoluta de la representación senequiana del suicidio de Catón en De providentia, donde los dioses contemplaban extasiados la valentía y la eúlogos exagogé del general republicano vencido, quien se transformaba en un objeto estético por excelencia. Atreo, por el contrario, pone a los dioses en fuga pero, percatado de que su obra carece entonces de una audiencia divina que complete y garantice la significación de su espectáculo, desea poder arrastrarlos nuevamente a este theatrum mundi como si de sus súbditos se tratase. ${ }^{409} \mathrm{Si}$ el héroe estoico prolongaba, articulaba e incluso disfrutaba de los momentos más terribles de su vida, cuando se ponía a prueba su temperamento, Atreo hace exactamente lo mismo al otro lado del espectro. En Atreo podemos encontrar un sistemático y obsesivo despliegue de estos recursos y elementos en la consecución de su obra: prolonga, dispone cuidada y ordenadamente, analiza y lleva a cabo de un modo estético su cruel venganza.

El sólido, aunque profundo, andamiaje estoico de este personaje, paradigma del gobernante violento e irascible, antítesis del iustus rex anhelado por Séneca, es un vehículo ideal para plantear y problematizar los más controvertidos aspectos del pensamiento de Séneca.

\footnotetext{
${ }^{409}$ Tarrant, R. (1985), 218: "893-95 utinam ... viderent: Atreus would like to treat the gods as he does his own subjects, forcing them to do what they most want to avoid (cf. 212 quod nolunt velint)."
} 


\section{EL CRIMEN COMO ESPECTÁCULO Y EL EXPRESIONISMO DEL HORROR.}

EL ESPECTÁCULO DEL HEROÍSMO ESTOICO Y SU SUBVERSIÓN POR LA POÉTICA DEL HORROR.

Desde sus más tempranas épocas la sociedad romana invistió los ritos fundantes de su cultura y sus prácticas sociales con una clara concepción teatral: funerales, sacrificios, celebraciones, procesos judiciales, casamientos, procesiones religiosas o triunfales, etc. se desarrollaban a la manera de hechos teatrales, presuponiendo una audiencia específica, un escenario definido y numerosos actores cumpliendo roles claramente asignados. ${ }^{410}$ Estas características fueron exacerbadas en el convulsionado siglo I d. C., cuando la separación irreconciliable entre verba y acta alcanza, como afirma Vassily Rudich, niveles casi esquizofrénicos y las actividades públicas y políticas adquirían prácticamente el carácter de una representación teatral. ${ }^{411}$

Séneca y Lucano reflejan, exacerban y ponen en juego esta concepción espectacular de los actos. Lucano dispone las furiosas acciones de Vulteyo y Esceva de tal modo que resultan espectáculos circenses, con una audiencia privilegiada y una disposición espacial verdaderamente consecuente con el theatri mos. Esto, que de por sí resulta interesante, se ve potenciado y profundizado por la conciencia que poseen sus personajes de formar parte de un espectáculo y por el cuidado estético con el que conciben y llevan a cabo sus furiosas acciones, las cuales requieren ser contempladas para adquirir completa existencia, significación e inteligibilidad. Todo hecho teatral resulta ser mucho más que un mero objeto o resultado sino que es, en realidad, el producto de un proceso de fenómenos interconectados eminentemente relacional. Por lo tanto el hecho teatral constituye, en tanto conjunto de procesos y de relaciones, un fenómeno fundamentalmente comunicativo y significativo. ${ }^{412}$ El espectáculo carece de existencia autónoma, ya que requiere necesariamente un receptor que actualice sus potencialidades sígnicas:

"Las diferentes disciplinas, semiológicas y otras, que se han ocupado en los últimos años de la textualidad (no sólo literaria), ya han aclarado de manera definitiva que todo

\footnotetext{
${ }^{410}$ Boyle, A. (1997), 3-7.

${ }^{411}$ Vieira, B. (2011), 40-41; Rudich, V. (1997), 4 y ss.; Griffin, M. (1986b), 195-198.

${ }^{412}$ De Marinis, M. (1997), 7-9.
} 
texto siempre es incompleto, y exige a su destinatario (lector, espectador) completarlo, actualizando sus potencialidades significativas y comunicativas. [...] Considerándolo bien, el espectáculo ni siquiera tiene una existencia verdaderamente autónoma, de entidad finita y completa en sí misma: al contrario, adquiere sentido, se hace inteligible, comienza realmente a existir en cuanto tal, esto es, como hecho estético y semiótico, sólo en relación con las ya mencionadas instancias de su producción y de su recepción (mejor dicho, de sus recepciones)." ${ }^{, 413}$

Analizaremos en primer lugar las ejecuciones de Astianacte y Polixena (Troyanas), que ofician de transición entre los episodios de Pharsalia elegidos y las tragedias senequianas, para retornar luego a la cuidada y profunda disposición estética de la venganza que llevan a cabo Medea y Atreo, ambas pergeñadas y ejecutadas con el cuidado, como ya vimos, y la conciencia trágica de verdaderos dramaturgos.

La obra trágica de Séneca intenta, más que enseñar o convencer, plantear y ahondar en los aspectos más controvertidos y espinosos de la doctrina estoica. ${ }^{414} \mathrm{Como}$ él mismo lo dice en una de sus epístolas, busca transitar campamentos ajenos y extraños, no como desertor sino como explorador. ${ }^{415}$ La riqueza de sus personajes trágicos radica no en una adecuación servil a los moldes impuestos por la doctrina estoica, ${ }^{416}$ sino en la problematización e indagación de sus aspectos más controvertidos y perturbadores. Así los personajes principales, ${ }^{417}$ más cercanos (en su superficie) al estoicismo, como Edipo, Tiestes o Hipólito, poseen en su estructura profunda sutiles inconsistencias que desestabilizan el paradigma estoico. ${ }^{418}$ Los personajes desmesurados, irascibles y violentos presentan, como ya dijimos, una fuerte impronta estoica y una muy coherente estructura profunda hondamente enraizada en la doctrina que ofrece una certera construcción estoica de específicos aspectos anti-estoicos. ${ }^{419}$ Lucano, por su parte, despliega en Pharsalia un universo eminentemente estoico, donde las imágenes, el vocabulario y la terminología específica pertenecen a esta escuela de pensamiento. ${ }^{420}$ Sin embargo, en una paradoja muy del gusto de Lucano, la cosmovisión estoica y su vocabulario filosófico sirven al poeta para construir un universo en disolución que pone en juego y desestabiliza todos los fundamentos de la propia doctrina.

\footnotetext{
${ }^{413}$ De Marinis; M. (1997), 25.

${ }^{414}$ Rosenmeyer, Th. (1989), 43.

${ }^{415}$ SEN. Ep. II, 5.

${ }^{416}$ Park Poe, J. (1989), 355-356.

${ }^{417}$ Rosenmeyer, Th. (1989), 8 y ss.

418 Galán, L. (2002), 72.

${ }^{419}$ Rosenmeyer, Th. (1989), 22.

${ }^{420}$ Lapidge, M. (1979), 334-370; Sklenáŕ, R. (1990), 281-296.
} 
Los elementos constitutivos del héroe estoico se ven desestabilizados y subvertidos por las operaciones poéticas desplegadas en los entramados textuales, mostrando espectáculos horrorosos donde conceptos centrales como los de virtus, vir y pietas se ven vaciados de significado y se transforman en macabros remedos de lo que alguna vez fueron o representaron. Por otro lado, la profunda conciencia teatral del sabio estoico se ve trastrocada y subvertida por los cruentos monimenta que despliegan los personajes y, sobre todo, por el puntilloso y minucioso cuidado estético con el que conciben, planean y ejecutan las matanzas.

\section{VULTEYO, ESCEVA Y TROYANAS: EL TEATRO DEL HORROR}

En el libro IV de Pharsalia, una pequeña embarcación cargada de soldados cesarianos queda atrapada y es arrastrada hasta una peligrosa bahía rodeada de acantilados que se inclinan amenazantes (LUC. IV, 455-461). Estas rocas ofrecen un punto de observación privilegiado para la contemplación del combate:

hanc omni puppes statione solutae

circumeunt, alii rupes ac litora conplent.

(LUC. IV, 463-464)

detegit orta dies stantis in rupibus Histros

pugnacesque mari Graia cum classe Liburnos.

(LUC. IV, 529- 530)

La rodean naves procedentes de todos los puertos, otros llenan las costas y los despeñaderos.

El día mostró a los Histros de pie sobre las rocas y junto a la flota griega, a los combativos Libarnos sobre el mar.

La arenga del comandante a sus jóvenes soldados deja entrever esta conciencia estética que hemos destacado:

non tamen in caeca bellorum nube cadendum est
aut cum permixtas acies sua tela tenebris
inuoluent. conferta iacent cum corpora campo,
in medium mors omnis abit, perit obruta uirtus:
nos in conspicua sociis hostique carina
constituere dei; praebebunt aequora testes,
praebebunt terrae, summis dabit insula saxis,
spectabunt geminae diuerso litore partes.
nescio quod nostris magnum et memorabile fatis
exemplum, Fortuna, paras. quaecumque per aeuum
exhibuit monimenta fides seruataque ferro
militiae pietas, transisset nostra iuuentus.

No hay que caer, sin embargo, en la oscura nube de la guerra o cuando las armas envuelven en las tinieblas 
a los ejércitos entremezclados. Cuando yacen los cuerpos diseminados por el campo, la muerte desaparece en medio de todos, muere la virtud oculta: Los dioses nos han colocado en una nave claramente visible para nuestros compañeros y para nuestros enemigos; el mar ofrecerá los testigos, las tierras los ofrecerán, nos los dará esa isla con sus altas rocas, Los bandos hermanos nos contemplarán desde costas opuestas. Ignoro, Fortuna, qué ejemplo magno y memorable deparas para nuestras muertes. Cuantos monumentos a través de los siglos ha exhibido la lealtad y la piedad militar conseguida con el hierro, los superará nuestra juventud.

La visibilidad del acto resulta primordial para que éste pueda perdurar en la memoria y convertirse en un exemplum o un monimentum. ${ }^{421}$ El comandante cesariano no sólo es consciente de la necesidad de espectadores y testigos (perit obruta virtus, IV, 491) sino también del cuidado artístico con el que debe llevarse a cabo el magnum et memorabile exemplum (IV, 496-497), su monumento póstumo a la militiae pietas. ${ }^{422}$ La preocupación estética implica tanto la concepción del acto como su ejecución. En su discurso Vulteyo considera las circunstancias que harán aún más admirable el sacrificio:

o utinam, quo plus habeat mors unica famae, promittant ueniam, iubeant sperare salutem, ne nos, cum calido fodiemus uiscera ferro, desperasse putent.

Ojalá, para que nuestra muerte única posea una mayor fama, nos prometan el perdón, que nos ordenen esperar la salvación, para que, cuando excavemos nuestras vísceras con el cálido hierro, no piensen que estábamos desesperados.

Finalmente, el combate previo al suicidio en masa es sólo un aporte exquisito al monimentum que están realizando, la pincelada final que garantiza, tal como quería el comandante, que el atroz espectáculo resulte un meditado -aunque perverso- acto racional, nunca fruto de la desesperación:

utque satis bello uisum est fluxisse cruoris uersus ab hoste furor.

Cuando consideraron que la sangre derramada en el combate era suficiente, desvían su furia del enemigo.

${ }^{421}$ Leigh, M. (1997), 182-183.

${ }^{422}$ Ahl, F. (1976), 117-120; 149 \& 201; Asso, P. (2010), 203: "498 monimenta fides By affirming that his generation already surpasses any other monimenta fides and 499 militae ... pietas, Vulteius (metapoetically) points to the imminent act of self-annihilation as an even greater memorial for his men and himself." 
Satisfechos con su obra, los soldados vuelven sus armas contra sus propios compañeros.

El horror de sus acciones despliega un espectáculo monstruoso que subvierte su virtus y su pietas, ${ }^{423}$ precisamente aquello que los convierte en indomitos viros (IV, 505): ${ }^{424}$

nec uolnus adactis

debetur gladiis: percussum est pectore ferrum

et inguli pressere manum. cum sorte cruenta

fratribus incurrunt fratres natusque parenti,

haud trepidante tamen toto cum pondere dextra

exegere enses. pietas ferientibus una

non repetisse fuit.

(LUC. IV, 560-566)

La herida no se debe a las espadas

dispuestas: El hierro fue golpeado por los pechos

y los cuellos presionaron las manos. Cuando la suerte cruenta hace que

los hermanos se enfrentan a sus hermanos y el hijo a su padre,

las espadas cumplieron sin embargo con todo su peso y no temblaron las manos:

La única piedad que tuvieron estos [hombres] enfurecidos fue

no repetir el golpe.

Los soldados se regocijan en su propia desesperación, en la creación de estos pignora amoris que domina la escena: ${ }^{425}$

despectam cernere lucem

uictoresque suos uoltu spectare superbo

et mortem sentire iuuat.

(LUC. IV, 568- 570)

Les complace contemplar

la luz despreciada, mirar con rostro altanero a sus vencedores y sentir la muerte.

Otro despliegue de valentía subvertida por el horror inherente a ella se produce en el libro VI: la increíble aristeia de Esceva, que enfrenta él solo a las tropas de Pompeyo cuando intentan romper el asedio, se lleva a cabo ante un público admirado que, curiosamente, luego de escuchar la arenga del soldado (LUC. VI, 150-165), es movido a la contemplación estética de la matanza y no a participar en ella:

mouit tantum uox illa furorem, quantum non primo succendunt classica cantu, mirantesque uirum atque auidi spectare secuntur scituri iuuenes, numero deprensa locoque an plus quam mortem uirtus daret.

(LUC. VI, 165-169)

${ }^{423}$ Esposito, P. (1999), 27 \& 32.

${ }^{424}$ Rudich, V. (1997), 133-134: "There exists yet another psychological dimension hinted at by the seductive appeal of suicide for the caesarian warriors. It suggest, despite the appearance of political and personal loyalty, an emotional anarchism and an existential nihilism, a passion for destruction, and selfdestruction for its own sake, an involvement with danger and risk, 'on the verge of the abyss.' as inner spiritual need. Again, it is not necessary to claim that Lucan himself was necessarily conscious of it".

${ }_{425}$ Asso, P. (2010), 211. 
A tanta locura los movió aquella voz, cuanto no encienden las trompetas con su primer canto, admirados y ávidos de contemplarlo, los jóvenes lo siguen para saber si la virtud, sorprendida en inferioridad numérica y en posición desfavorable, ofrecería algo más que la muerte.

A diferencia del discurso de Vulteyo, cargado de contenido filosófico y de sentencias estoicas, las palabras de Esceva son directas y propias de un curtido soldado: apela a la vergüenza de huir y faltar de los túmulos (LUC. VI, 150-154). Si en la batalla naval frente a Marsella los vencedores se admiraban de la capacidad de César de generar estas lealtades monstruosas, Esceva resulta el exemplum por excelencia de esta furiosa fides: ${ }^{426}$

iam strage cruenta

conspicitur cumulata ratis, bustisque remittunt corpora uictores, ducibus mirantibus ulli esse ducem tanti.

(LUC. IV, 570- 572) $[\ldots]$

iste dies ierit. peterem felicior umbras

non paruo sanguine Magni

Caesaris in uoltu: testem hunc fortuna negauit:

Pompeio laudante cadam.

(LUC. VI, 157- 160)

ya se ve la nave sangrienta

cargada de muerte, y los vencedores recogen

los cadáveres para las piras, mientras los comandantes se admiran de que un solo general genere tantos soldados como estos.

$[\ldots]$

No pasará este día

con poca sangre del Magno. Buscaría feliz las sombras

ante el rostro de César: la Fortuna me ha negado este espectador, caeré ante Pompeyo alabándome.

El soldado es consciente de la presencia necesaria e imperativa de un público espectador e incluso desea, de manera similar a Medea, un espectador específico y particular.

Esceva encarna esta virtus vaciada de contenido y completamente resignificada por el accionar del discurso lucaniano. ${ }^{427}$ La virtud, para este soldado, resulta ser sólo un amor mortis:

\footnotetext{
${ }^{426}$ Rosenstein, N. (2009), 97; Leigh, M. (2009), 243-246, esp. 243: “Caesar's biographers and historians of his campaigns repeatedly emphasize the mutual devotion of the general and his troops. To Caesar those fighting for him are not soldiers (milites) but comrades (commilitones), and the worst name he can call them is citizens (quirites, Suet. Iul. 67.2, 70.2; App. B civ. 2.93.392; Luc. 5.358).

${ }^{427}$ Rudich, V. (1997), 133: "In the poet's eyes, Scaeva's heroism predictably manifested the perversion and corruption of the major value, virtus, a commitment to the service of civitas. It is to him that one of
} 
incaluit uirtus, atque una caede refectus

'soluat' ait 'poenas, Scaeuam quicumque subactum

sperauit. pacem gladio si quaerit ab isto

Magnus, adorato summittat Caesare signa.

an similem uestri segnemque ad fata putatis?

Pompei uobis minor est causaeque senatus

quam mihi mortis amor.

(LUC. VI, 240-246)

Se reavivó su virtud, reanimado por esta sola muerte,

"que pague su pena, dice, cualquiera que espere ver

a Esceva vencido. Si el Magno busca la paz de esta espada,

que entregue sus insignias, venerando a César.

¿Acaso pensáis que yo soy igual a ustedes?

¡Vuestro amor por Pompeyo y la causa del Senado

es menor que mi amor por la muerte!"

La virtus de Esceva es extrema, desmesurada y monstruosa: sólo un remedo deformado del concepto primigenio. Su propio cuerpo despedazado se transforma en el reflejo del horror que encarna y, al mismo tiempo, despliega a modo de un espectáculo horroroso:

fortis crebris sonat ictibus umbo,

et galeae fragmenta cauae conpressa perurunt

tempora, nec quicquam nudis uitalibus obstat

iam praeter stantis in summis ossibus hastas.

(LUC. VI, 186- 195)

El duro escudo resuena con los numerosos golpes

y los fragmentos abollados del hueco casco abrasan

sus sienes comprimidas, nada retiene sus órganos desnudos

excepto las lanzas clavadas en lo profundo de sus huesos.

En medio del combate, una flecha se clava en su ojo izquierdo pero él, en una desafiante muestra de valentía, la arranca, con el órgano aún clavado en ella, y la pisotea ante la mirada atónita de los soldados de Pompeyo. Su rostro es el fiel reflejo de la ira y el furor que alimentan su horrorosa virtud:

ille moras ferri neruorum et uincula rumpit

adfixam uellens oculo pendente sagittam

intrepidus, telumque suo cum lumine calcat

(LUC. VI, 214-219)

$[\ldots]$

perdiderat uoltum rabies, stetit imbre cruento

informis facies

(LUC. VI, 224-225)

Él rompe las trabas del hierro y las ataduras de los nervios, arrancando la flecha con su ojo colgando, e intrépido pisotea el proyectil junto con su ojo.

$[\ldots]$

La rabia le había arrebatado el rostro, la cara se desfiguró

a causa de la lluvia de sangre.

Lucan's best dictums applies: 'virtue in civil war is a heinous crime' (in armis/ Quam magnum virtus crimen civibus esset, 6, 148)." 
La llegada del ejercito cesariano libra a los pompeyanos de la vergüenza de haber sido vencidos por un solo vir y los hombres de César levantan a Esceva como la viva imagen de la virtud: vivam magnae speciem virtutis adorant (LUC. VI, 254). ${ }^{428}$ Los personajes despliegan un muy coherente andamiaje estoico en su estructura profunda; sin embargo sus acciones son furiosas y desmesuradas, resultando personajes subversores $\mathrm{y}$ confutadores del propio paradigma que los constituye discursivamente. La consciente espectacularidad de sus actos está profundamente enraizada en la concepción estoica de heroicidad, pero sólo son capaces de dar macabros y truculentos espectáculos que, lejos de ser monumentos a la pietas y a la virtus, despliegan horrorosos y deformados remedos de estos conceptos centrales para la conformación del vir Romanus.

En Troyanas puede apreciarse también un procedimiento análogo. Ulises ha decretado la muerte de Astianacte, que será arrojado desde la alta torre de Príamo y Polixena, por su parte, debe ser sacrificada como ofrenda al fantasma de Aquiles para que la flota griega pueda zarpar. Tanto la alta torre de Príamo como la tumba de Aquiles poseen las características de los antiguos anfiteatros. Las muertes de estos jóvenes son narradas por el mensajero a una desesperada Hécuba:

$\quad$ undique adfusa ducum
plebisque turba cingitur; totum coit
ratibus relictis vulgus. His collis procul
aciem patenti liberam praebet loco,
his alta rupes, cuius in cacumine
erecta summos turba libravit pedes.
Hunc pinus, illum laurus, hunc fagus gerit
extrema montis ille praerupti petit,
semusta at ille tecta vel saxum imminens
muri cadentis pressit, atque aliquis (nefas)
tumulo ferus spectator Hectoreo sedet.

Colmada por todos lados es rodeada por la turba de jefes y soldados, todo el pueblo se reúne, abandonadas las naves. A estos una colina alejada les permite ver con una amplia perspectiva, a aquellos, una alta roca en cuya cima se amontonan muchos en puntas de pie. A éste lo sostiene un pino, a aquel un laurel, a otro una encina, ése busca la parte más alta del bosque sacudido, uno cuelga de un techo quemado o de una roca que sobresale de un muro en ruinas, y algún salvaje espectador (impiedad!) se sienta sobre el túmulo de Héctor.

${ }^{428}$ Esposito, P. (1999), 12-13; Leigh, M. (1997), 159-160. 
Cada espectador busca caóticamente la mejor locación para contemplar el espectáculo, ${ }^{429}$ quizás emulando el comportamiento del bullicioso público romano de la época imperial. Hacen luego su entrada los "actores": Ulises conduce al joven que, feroz y soberbio, desafía al jefe griego y en un último acto de valentía, se arroja desde lo alto de la torre aun antes de ser empujado (vv. 1091-1103). La actuación de Astianacte, su hidalguía y su valor, literalmente conmueven al público:

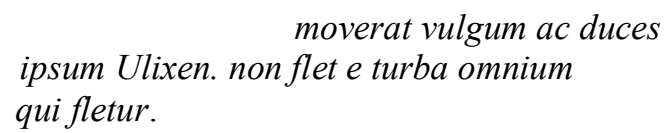

Había conmovido al pueblo y a los caudillos, y al mismo Ulises. No llora, de toda la multitud, quien es llorado.

Establecida la relación teatral, ${ }^{430}$ el horror hace su aparición en escena, el cuerpo del indefenso joven es destrozado y esparcido por la caída. ${ }^{431}$ Se describe entonces el proceso de la dispersión y la pérdida total de la forma de su cuerpo:

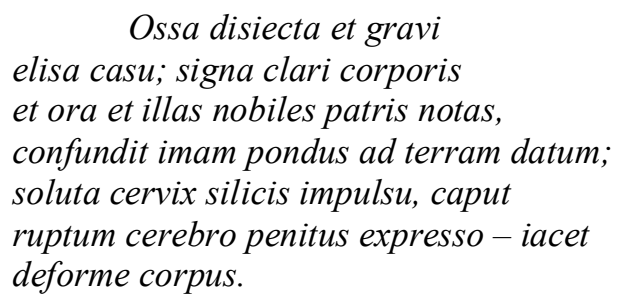

Ossa disiecta et gravi elisa casu; signa clari corporis et ora et illas nobiles patris notas, confundit imam pondus ad terram datum; soluta cervix silicis impulsu, caput ruptum cerebro penitus expresso - iacet deforme corpus. (Tro. 1111-1117)

Sus huesos yacen esparcidos y destrozados por la pesada caída, la forma de su hermoso cuerpo su rostro y aquellos [rasgos] de su padre, los confundió arrojado como un peso a la tierra profunda; su cuello se rompió por la caída contra las rocas, su cráneo fue destrozado y su cerebro aplastado - sólo queda un cuerpo deformado.

Terminado este espectáculo, el público se apresura a buscar otro punto de observación privilegiado para la segunda "función". El paisaje ofrece nuevamente las condiciones necesarias para contemplar cómodamente el rito: ${ }^{432}$

[tumulumque Achillis]

\footnotetext{
${ }^{429}$ Fantham, E. (1982), 369-370.

${ }^{430}$ De Marinis, M. (1997), 26-27: "Paralelamente, la relación teatral consiste también en una participación activa del espectador, quien puede ser considerado plenamente como 'coproductor' del espectáculo: él es, en efecto, el constructor, parcialmente autónomo, de sus significados."

${ }^{431}$ Fantham, E. (1982), 374-375.

${ }^{432}$ Fantham, E. (1982), 377: "1121-25 [...] The description, which is not ambiguous, owes something to Virgil's natural theater for the Sicilian games at Aen. 5.528f."
} 
adversa cingit campus et clivo levi

erecta medium vallis includens locum

crescit theatri more, concursum frequens

implevit omne litus.

(Tro. 1123-1126)

La otra parte (de la tumba de Aquiles) la ciñe

una llanura y un valle inclinado en una suave pendiente

que rodea, a la manera de un teatro,

su centro; una nutrida concurrencia

llenó toda la costa.

Otra vez el mensajero define a la audiencia como spectatores que se conmueven ante la belleza y el valor de la víctima: ${ }^{433}$

\author{
magna pars vulgi levis \\ odit scelus, spectatque. \\ $[\ldots]$ \\ stupet omne vulgus, et fere cuncti magis \\ peritura laudant. hos movet formae decus \\ hos mollis aetas, hos vagae rerum vices; \\ movet animus omnes fortis et leto obvius.
}

(Tro. 1128-1129)

(Tro. 1143-1146)

Una gran parte del vulgo inconstante

odia el crimen, y lo contempla.

$[\ldots]$

Queda estupefacto el vulgo y casi todos

alaban a quien está por morir. A estos los conmueve

su noble hermosura, a aquellos su juventud,

a otros la condición inconstante de las cosas;

a todos conmueve su ánimo fuerte y dispuesto a la muerte.

Se constituye, entonces, la relación teatral donde los espectadores se admiran y compadecen a la víctima (mirantur ac miserantur, Tro. 1148). ${ }^{434}$ Inmediatamente se repiten las condiciones sacrificiales: la víctima indefensa marcha gallardamente e

\footnotetext{
${ }^{433}$ Boyle, A. (1997), 20 y ss.

${ }^{434}$ Fantham, E. (1982), 380: "1143-46. The amazement of the crowd and their dazed silence must be contrasted with attonitos tenet at 1136; there attonitos cannot mean dazed (as does in 442, 736) but mean possessed by terror. Only now can Seneca risk his fullest description of the crowd's reaction to her. Here too he creates an antithesis; some are amazed at her beauty, some her youth (mollis aetas, almost his only concession to the weaker aspects of his heroine). But all alike recognize her animus ... fortis et leto obvius. We have come to the point where heroism is stressed matching the accumulated adjectives that honored Astianax before his death leap (1098), and Seneca does honor Polyxena with a rare phrase borrowed from Lucretius' exaltation of Democritus' suicide, 3.1041: sponte su aleto caput obvius obtulit ipse."
} 
increpa feroz a su verdugo (audax virago non tulit retro gradum;/ conversa ad ictum stat truci vultu ferox, - Tro. vv. 1151-1152), desafiando tanto a su asesino como a la propia tumba del futuro esposo:

\author{
Ut dextra ferrum penitus exacta abdidit, \\ subitus recepta morte prorupit cruor \\ per vulnus ingens. Nec tamen moriens adhuc \\ deponit animos; cecidit, ut achilli gravem \\ factura terram, prona et irato impetu.
}

Cuando su mano hundida profundamente extrajo el hierro, fluyó la sangre por la enorme herida y recibió la muerte. Tampoco entonces depuso su ánimo, cayó, y para hacer más pesada la tierra para Aquiles, se arrojó sobre ella con enfurecido ímpetu.

La cruenta inmolación de esta muchacha indefensa por parte del guerrero más salvaje de los argivos, da paso a una abominación y a un horror aún mayor:

non stetit fusas cruor,

Humove summa fluxit; obduxit statim

Saevusque totum sanguinem tumulus bibit.

(Tro. 1162-1164)

La sangre derramada no se estancó

ni fluyó sobre el montículo de tierra; inmediatamente la succionó la tumba salvaje y se bebió toda la sangre.

La tumba cobra vida y se vuelve una monstruosa encarnación de la sed de sangre de su dueño, ${ }^{435}$ tal es la potencia de ésta que trasciende los límites de la muerte y aterra a los espectadores.

Cabe destacar que, si bien esta tragedia despliega escenarios propicios para estos espectáculos del horror, no se produce una subversión tan radical del paradigma estoico de heroicidad como la que ocurre en los episodios de Vulteyo y Esceva, simplemente porque tanto Astianacte como Polixena no actúan acorde a los requisitos mínimos necesarios para esta operación poética: en ambos falta el componente activo que caracteriza la preparación minuciosa de las performances $\mathrm{y}$, al no tener la posibilidad de expresarse en escena, tampoco pronuncian sentencias o conceptos estoicos donde sustentar su actuación, aunque hagan un admirable despliegue de valentía y constantia. ${ }^{436}$ En Troyanas el mundo resulta un teatro donde el heroísmo posee una condición sacrificial y la valentía se revela sólo como patientia. Este teatro del horror,

\footnotetext{
${ }^{435}$ Ahl, F. (1976), 84-87.

${ }^{436}$ Star, Ch. (2006), 208-209.
} 
cuyas características barrocas de representación son claras, ${ }^{437}$ abre las puertas y allana la escena para la entrada de su más profundo, radical y subversivo exponente en la figura de Atreo.

Entre el teatro del horror desplegado en Troyanas y la figura de Atreo como artista del mismo aparece la figura de Medea. En ella se manifiesta por primera vez, ${ }^{438}$ de manera inequívoca, una profunda conciencia teatral presente en la preparación y ejecución de su venganza. Sin embargo, tal como destacamos anteriormente en Troyanas, su naturaleza furiosa y las pasiones que la empujan no la convierten en una figura asimilable al sapiens estoico. El magistral verso odit scelus, spectatque resume, en cierta medida, el estado interno de Jasón y de la audiencia, el espectador por excelencia que requiere la venganza de Medea. La propia bruja es consciente de la necesidad de un público para que sus acciones posean significación y aprobación:

Nunc hoc age, anime; non in occulto tibi est perdenda virtus; approba populo manum.

(Med. 976-977)

¡Vamos, ánimo, hazlo! Tu virtud no debe perderse en secreto; aprueba tu obra con el pueblo.

Más tarde, se pone en juego una representación dentro de la misma representación cuando Medea, la malorum machinatrix facinorum (Med. 266), ${ }^{439}$ aparece en un nivel superior del escenario, sobre un tejado, debatiéndose entre continuar o no su terrible venganza y cediendo en su impulso asesino (vv. 982-991), pero la aparición de Jasón reaviva las llamas de su furor:

Voluptas magna me invitam subit

Ecce et crescit. derat hoc unum mihi, spectator iste. nil adhuc facti reor: quidquid sine isto fecimus sceleris perit.

(Med. 992-994)

Una gran alegría me invade aunque no lo quiera, es más, aumenta. Sólo esto me faltaba, ese como espectador. Considero que nada he hecho hasta ahora, cualquier crimen que haya cometido sin que ese lo vea, no ha existido.

\footnotetext{
${ }^{437}$ Warnke, F. (1970),

438 Seguimos, como ya dijimos en nuestra introducción, la cronología relativa de J. Fitch (1981), que organiza las tragedias en tres grupos: Tragedias tempranas (Edipo, Agamenon e Hipólito), tragedias medias (Troyanas, Medea y Hércules furioso) y tragedias tardías (Tiestes y Fenicias). Cf. también Vizzotti, M. (2007), 76-77.

439 También Ulises es llamado machinator fraudis et scelerum artifex por Andrómaca (Tro. 750). Según Costa (Costa, C. (1973), 96) en ambos casos Séneca evoca el epíteto dado por Cicerón a Catilina en Cat. III, 6: horum omnium scelerum improbissimum machinatorem. Cf. también Fantham, E. (1982), 313-314.
} 
Al igual que Vulteyo, Medea es consciente de que los despliegues de esta desfigurada virtus vaciada de significado se pierden y carecen de sentido si no son ejecutados ante una audiencia de espectadores que den cuenta de ellos. ${ }^{440}$

Medea se regodea en una voluptuosidad estética, su obra será ontológicamente confirmada en tanto representación gracias a la presencia de espectadores $\mathrm{y}$, específicamente, de uno en particular. El objeto estético, o la representación, sólo adquiere sentido en tanto se instaure una relación teatral que complete y actualice sus posibilidades significativas, Medea resume estos complejos conceptos relacionales de manera precisa: si no es visto, no adquiere existencia válida. La profundidad de su conciencia teatral allana el camino para que, en la figura Atreo, Séneca pueda desplegar todo el alcance poético y metapoético de su proyecto creador.

\footnotetext{
${ }^{440}$ Lucano somete a sus lectores a una operación idéntica en el cuerpo del poema a través de los constantes e intrusivos apóstrofes del narrador, dice Paolo Asso: "The apostrophic gesture requires two persons, the speaker and the addressee who 'receives' the apostrophe, but for the intrusion to be noted, a third person is necessary, i.e., an audience that assents to the demand of the trope and agrees to accept the narrative intrusion. The triangulation of apostrophizing, apostrophized, and audience is syntactically indicated by a jussive or imperative verb and may or may not be accompanied by a vocative case denoting the entity addressed. Although in 'witnessing' the apostrophe the audience (and/or reader) cannot be syntactically marked in the text, it inevitable receives the second-person address as if directed towards the audience itself, even though the address is actually directed to the apostrophized entity internal to the text. The second-person address therefore encourages the external audience (and/ or reader) to identify with the apostrophized entity." en Asso, P. (2009), 162-163; cf. también 172-173.
} 


\section{RECAPITULACIÓN Y CONCLUSIONES PARCIALES}

Así como Catón, en De providentia, despliega su muerte como el más hermoso espectáculo que los dioses puedan contemplar, los personajes estudiados llevan a cabo sus crímenes con una profunda concepción teatral y son conscientes de formar parte de un spectaculum que debe ser observado, completado y significado por un público espectador. Este público es condición necesaria para la existencia e inteligibilidad de estos espectáculos del horror representados en el marco de la épica lucaniana y la tragedia de Séneca.

Lucano lleva al extremo las posibilidades dramáticas del género épico: Vulteyo y Esceva despliegan sus furiosas acciones a la manera de textos espectaculares ante públicos ávidos de contemplar el desmesurado espectáculo de su militiae pietas. El horror que enmarca estas acciones, que en otro contexto hubiesen sido nobles y valientes, transfigura y convierte en grotescos criminales a estos varones empujados por una ratio desequilibrada y furiosa. Las virtudes y los conceptos estoicos en los que se sustenta y justifica esta concepción de heroicidad se ven vaciados de significado por el horror espectacular que caracteriza las acciones de estos soldados.

El género trágico, por su parte, ofrece un mayor y más rico abanico de posibilidades para explorar la espectacularidad de las acciones y los límites de la representación dentro de la representación. En Troyanas Séneca construye un verdadero teatro del horror que, si bien no desestabiliza el paradigma estoico de heroicidad de manera tan radical, pone en juego el procedimiento del teatro dentro del teatro, que ofrece un amplio abanico de posibilidades escénicas. ${ }^{441}$ En las obras estudiadas puede apreciarse un claro crescendo, tanto en la profundidad de la conciencia teatral de los personajes como en el grado de desestabilización y subversión de los paradigmas filosóficos y poéticos que enmarcan las acciones: entre los cruentos sacrificios de las víctimas inocentes en escenarios naturales dispuestos theatri mos de Troyanas y la figura de Atreo aparece la figura de Medea quien, si bien presenta una voluntad expresa de establecer una relación teatral para que sus crímenes cobren una significación completa, no posee la potencia desestabilizadora ni la profundidad subversiva de este último.

\footnotetext{
${ }^{441}$ Fitch, J. (1981), passim.
} 
Las acciones se conciben y ejecutan como espectáculos que resultan siempre incompletos si carecen de destinatarios que actualicen sus potencialidades significativas y comunicativas. ${ }^{442}$ Los personajes conciben estéticamente sus acciones hasta el mínimo detalle, dando -como Velázquez en Las Meninas- ese paso atrás que permite abarcar con la mirada la obra en progreso, buscando la perspectiva que les permita aplicar la pincelada precisa que culmine la obra. Por otro lado, las matanzas son puestas en escena sobre escenarios muy específicos y particulares y ante audiencias necesarias, requeridas incluso por los mismos actores. Esceva, el rudo soldado cesariano, se contenta, a falta de César como testigo, con caer ante la mirada de los soldados de Pompeyo, ya que no ha tenido, como Medea, la suerte de poder ejecutar su obra ante su espectador anhelado.

Atreo, finalmente, es el artista del horror por excelencia, ${ }^{443}$ resultando casi un alter ego furioso del propio Séneca. Aparece en el texto como el creador de una truculenta acción y despliega todas las características de un dramaturgo profesional, considerando la existencia y los requerimientos de una tradición mítica y literaria, la necesidad imperiosa de innovar sobre la misma -fateor, immane est scelus, / sed occupatum; maius hoc aliquid dolor/ inueniat. (Thy. 272-275)- y exigiendo de manera casi diabólica la presencia de un público que dé existencia y validez ontológica a su horroroso espectáculo. Los crímenes sólo existen y cobran sentido en tanto se establezca una relación teatral entre las partes implicadas, o incluso de manera más radical, tal como lo dice la propia Medea, no adquieren siquiera existencia si no son contemplados y significados por una audiencia competente. Quizás la característica más interesante e innovadora de las poéticas senequiana y lucaniana sea la profunda representación autoreflexiva de las performances, tanto teatrales como criminales, donde la disposición y ejecución de las matanzas se realizan a la manera de textos espectaculares: ${ }^{444}$ desde los exempla virorum desplegados por Vulteyo y Esceva hasta la obra maestra de Atreo, donde las figuras del héroe estoico, del autor y del criminal se ven amalgamadas y superpuestas en un complejísimo juego de espejos deformantes, pasando por las

\footnotetext{
442 De Marinis, M. (1997), 25: “Considerándolo bien, el espectáculo ni siquiera tiene un existencia verdaderamente autónoma, de entidad finita y completa en sí misma: al contrario, adquiere sentido, se hace inteligible, comienza realmente a existir en cuanto tal, esto es, como hecho estético y semiótico, sólo en relación con las ya mencionadas instancias de su producción y de su recepción (mejor dicho, de sus recepciones). Incluso se podría decir que lo que realmente existe, al menos desde el punto de vista semiótico, no es el espectáculo sino la relación teatral, entendiendo por ello sobre todo la relación actorespectador, y además los otros diversos procesos comunicativos e interrelacionales del cual un espectador es estímulo y ocasión desde su primera concepción hasta la fruición del público.”

${ }^{443}$ Schiesaro, A. (1994), 196-210.

${ }^{444}$ De Marinis, M. (1997), 23-24.
} 
tragedias (Troyanas y Medea) que preparan la escena e instauran las condiciones necesarias para la ejecución de esta representación dentro de la representación, los textos-en-la-historia ofrecen en su interior estos textos-en-situación en los cuales es posible detectar un crescendo en la conciencia teatral de los personajes. ${ }^{445}$ Esta conciencia teatral, esta seguridad de formar parte de un espectáculo eminentemente relacional, vincula a los actores con el paradigma estoico de heroicidad, pero sólo para subvertirlo de manera radical a través del horror que despliega el espectáculo.

${ }^{445}$ De Marinis, M. (1997), 24: "En la práctica es claro que el contexto general (o cultural) se convierte en el más importante cuando se trabaja sobre acontecimiento del pasado, y lo mismo sucede con el contexto inmediato, o espectacular, cuando el objeto de estudio está constituido por acontecimientos contemporáneos. En el primer caso, podríamos hablar, por lo tanto, de textos-en-la-historia y en el segundo, de textos-en-situación (comunicativa) pero no hay que olvidar jamás que todo texto espectacular es siempre ambas cosas a la vez." 
VI. DISOLUCIÓN UNIVERSAL Y SYMPÁTHEIA TÔN HOLÔN: VIRTUS, PIETAS

Y CORPUS.

PNEÛMA, TÓNOS Y SYMPÁTHEIA TÔN HOLÔN

La crítica lucaniana ha sido absolutamente dispar a lo largo de los siglos y sus diferentes valoraciones de Pharsalia son un fiel reflejo de las variadas aproximaciones axiológicas de cada momento. ${ }^{446}$ Las radicales innovaciones respecto del género, la forma y el contenido que Lucano ejecuta en su épica (ausencia de aparato divino, uso del material histórico, estilo barroco y retorización, inter alia ${ }^{447}$ generaron, a lo largo de la historia numerosas hipótesis e interpretaciones ${ }^{448}$. También otra poderosa communis opinio dominó la producción académica de los últimos dos siglos: el poeta no sólo estaba influido por la doctrina estoica sino que era, él mismo, un consagrado estoico que expone su doctrina a través de los discursos de Catón. ${ }^{449}$

En los últimos cuarenta años ha habido un cambio radical en las interpretaciones de Lucano. Los trabajos de W. R. Johnson, J. Henderson y J. Masters rechazaron las lecturas estoicoreduccionistas y mostraron cómo en Pharsalia se construye un universo oscuro y tenebroso -absurdo en muchos casos- y se despliega un cosmos caótico y fragmentado $^{450}$ en inexorable disolución. ${ }^{451}$ Esta corriente crítica, que podríamos denominar "interpretación irónica", representa un notable avance sobre la ortodoxia

${ }^{446}$ Holgado Redondo, A. (1984), 36- 50.

447 von Albrecht, M. (1997), 920-921; Rudich, V. (1997), 107:"'It was repeatedly claimed by scholars that his epic does not respond to our expectations of structural coherence, and that many episodes are painfully overwrought, overblown and even inadvertently comical; that his style, with a few exceptions, appears extremely artificial, and that his many pointed and convoluted sententiae often verge on obscurity and even nonsense. There have been long stretches of time when his accomplishment was appreciated by the great - from Dante to Marlowe to Corneille to Goethe to Shelley- and he was extolled as an exemplar of Latin letters, a young genius who tragically fell victim to a tyrant. Only in very recent years has Lucan started to enjoy a remarkable revival which may be explained as a belated recognition that his desperate vision of the world won over by evil is akin in many respects to the fashionable existential pessimism of the present day. Furthermore, much of what earlier was dismissed as Lucan's literary vice is indeed characteristic of modern aesthetics, including incoherence and self-indulgence as well as fascination with the horrible and the absurd."

${ }^{448}$ El propio Quintiliano lo recomendaba a los oradores más que a los poetas (QUINT. Inst. X, 1, 70), cf. Herrero Llorente, V-J. (1967), xv- xxv.

${ }^{449}$ Sklenár̆, R. (1990), 281-282; Lapidge, M. (1979), 344-346.

${ }^{450}$ Sklenáŕ, R. (1999), 281.

${ }^{451}$ Lapidge, M. (1979), 346:"It can be shown, I think, that Lucan thoroughly conversant with stoic cosmology as it was represented by his contemporaries, and that his familiarity with this cosmology found expression in a recurrent series of images which one might (for the sake of convenience) the imagery of cosmic dissolution. I shall attempt to show that this imagery of cosmic dissolution is central to the meaning of the first seven books of the Pharsalia." 
preliminar y enriquece las lecturas de Lucano aunque suele desestimar muchas de las riquísimas paradojas de la obra, reduciéndolas a un simple uso irónico del material poético. Por otro lado, para que un pasaje resulte verdaderamente irónico, más allá de la voluntad del intérprete, deben existir marcas textuales que indiquen la presencia de una ironía. Así, la Apokolocyntosis de Séneca anuncia desde su título una voluntad expresa de ironía. En cambio, la muerte de un soldado atravesado simultáneamente por dos rostra, más allá de lo grotesco de la escena, no ofrece, creemos, ninguna marca o indicio que indiquen una aproximación de este tipo.

Uno de los pocos puntos de encuentro entre los críticos, más allá de si Lucano era o no un fiel adepto al estoicismo, es la innegable cosmovisión estoica que estructura el universo de Pharsalia. La cosmología estoica organiza la configuración discursiva del poema en su totalidad -imágenes, vocabulario, terminología específica, etc. ${ }^{452}$ de manera tal que el concepto de disolución universal es central para el desarrollo del poema. En una paradoja muy del gusto de Lucano, la cosmovisión estoica y su vocabulario filosófico sirven al poeta para construir un universo en disolución que pone en juego todos los fundamentos de la escuela que sustenta la conpages del mismo, prefigurando la paradoja miltoniana de "construir una ruina". ${ }^{453}$ En definitiva, Pharsalia parece desplegar un universo nihilista y absurdo, ${ }^{454}$ donde los dioses, si existen, son minaces (I, 524) o, en el mejor de los casos, absolutamente indiferentes a los sufrimientos de los hombres. ${ }^{455}$

\footnotetext{
${ }^{452}$ Lapidge, M. (1979), 334-370; Sklenáŕ, R. (1999), 281-296; Getty, R. (1936), 55-63.

${ }^{453}$ Milton, J. Paradise Lost, IV, 521-522:"O fair foundation laid whereon to build/ Their ruin."

${ }^{454}$ LUC. II, 12-15:"siue nihil positum est, sed fors incerta uagatur/ fertque refertque uices et habet mortalia casus,/ sit subitum quodcumque paras; sit caeca futuri/mens hominum fati; liceat sperare timenti."; Sklenár, R. (1999), 289: "Quo fata trahunt virtus secura sequetur would be, in itself, an unexceptionable Stoic dictum: fata, as we have seen, stands for the divine ordinance, and since it is the mark of the sapiens to live in accordance with it, his virtus remains secura (in the technical sense of Stoic securitas) when he does so. The problem for Cato is that providence leads him toward the greatest of moral wrongs, and thus draws virtus inexorably towards its own opposite. This would imply something quite unacceptable to Stoic doctrine, namely that providence can ordain a moral wrong. ${ }^{454}$ Yet Cato arrives at the same conclusion with crimen erit superis et me fecisse nocentem, since superis stands for the same providential concept as fata. He thus makes it clear, in this most explicit rejoinder to Brutus, that the path of the sapiens leads to civil war and to the merging of Cato's virtus with nefas"

${ }^{455}$ LUC. VII, 445-447: "sunt nobis nulla profecto/ numina: cum caeco rapiantur saecula casu,/ mentimur regnare Iouem.”, y VII, 454-455: "Mortalia nulli/ sunt curata deo". Rudich, V. (1997), 118: "Lucan's treatment of the gods, in part due to the operations of the rhetoricized mentality, is exasperatingly confusing: they are, at best, presented as none-existent or impotent, and, at worst, as wicked and destructive."
} 
La cosmología estoica, desde Crisipo, concebía el universo interconectado por agentes cohesivos, como un ser vivo donde el pneûma y el tónos mantenían unidas las diferentes partes gracias a la sympátheia: ${ }^{456}$

"The central doctrine of Chryssipus cosmology was that concerning the cosmic pneûma. For his predecessors, Zeno and Cleanthes, the principal cosmic agent had been creative fire (pûr technikón). However, the conception of creative cosmic fire brought many difficulties in its train, particularly concerning question of cosmic stability. Chryssipus attempted to solve these difficulties with his conception of a cosmic pneûma. Earlier Stoics had taught the notion of a bodily pneûma (a notion derived ultimately from Aristotle) and had also conceived the universe as a living being (Zôon), but Chryssipus was apparently the first to see that the concept of bodily pneuma, through which the animated body was held together and vitalized, could be applied by analogy to the universe. Just as the bodily pneûma held all bodily parts together by creating an internal tension (tónos), so Chryssipus argued that the universe was held together by the coherent force and tensional movements of the all-pervasive cosmic pneûma. [...] From medical theory Chryssipus borrowed the metaphorical notion that all parts of a living body were in 'sympathy' (sympathéa) with one another, whence he could speak of cosmic 'sympathy', sympátheia. And because the cosmic pneûma created a tension in all things which held the universe in its spherical shape, Chryssipus could speak of the resultant cosmic tension as syntonía." 457

Todas estas nociones eran familiares para Lucano, según Lapidge, a través de tres fuentes: Manilio, Cornuto (su maestro) y Séneca (su tío y mentor). ${ }^{458}$

\section{LA DISOLUCIÓN DEL CUERPO SOCIAL E INDIVIDUAL}

El motivo de la disolución universal lleva aparejado una compleja cuestión que los críticos han tratado de dilucidar, resultando en diversas interpretaciones sobre el "nihilismo lucaniano" 459 y la adecuación o no de la ética catoniana y el mos maiorum a este universo absurdo:

"But Lucan deposits Cato into a Universe devoid of reason, 'one wholly without purpose or meaning' (Johnson 1987, 10), marked by 'the blatant absence of any design' -in short, a nihilistic universe, where the cosmological prerequisites for Catonian ethics necessarily fail. Cato's pursuit of the Stoic ideal is in a literal sense doomed from the start, as Lucan assigns a predominant section of the Bellum Civile's long proem to an exposition of his anti-rational cosmology." 460

\footnotetext{
${ }^{456}$ Setaioli, A. (2007), 335-340.

${ }^{457}$ Lapidge, M. (1979), 346- 348.

${ }^{458}$ Lapidge, M. (1979), 351 y ss.

${ }^{459}$ Sklenář, R. (1999); Lapidge, M. (1979); Tarrant, R. (2002), 349-360.

${ }^{460}$ Sklenář, R. (1999), 282.
} 
Sin embargo, como ya hemos señalado, el universo de Pharsalia se construye con conceptos eminentemente estoicos a través de las nociones de pneûma, tónos y sympátheia. El universo aparece como un organismo armónico en el cual una disonancia o una alteración significativa en alguna de sus partes constitutivas repercuten en la totalidad. En Pharsalia el ordo mundi ha sido trastrocado, Roma se derrumba sobre sí misma y el mos maiorum es sólo una fachada esquizofrénica. ${ }^{461}$ La disolución de los valores fundantes del vir Romanus ${ }^{462}$ tiene su correlato, vía sympátheia, en el cuerpo de los individuos y cómo este proceso va acompañado de una absoluta corrupción de la virtus, que es asimilada entonces al nefas más absoluto. ${ }^{463}$

\section{LA BATALLA NAVAL FRENTE A MARSELLA}

La descripción de la batalla naval presenta una cuidadísima progresión que encontraremos también en los otros tres episodios analizados en este apartado. El desarrollo del combate es desplegado de manera gradual: se describe el entorno y la composición de ambas flotas (vv. 509-527) y el propio amanecer preanuncia la violencia por venir:

ut matutinos spargens super aequora Phoebus

fregit aquis radios et liber nubibus aether

et posito Borea pacemque tenentibus Austris

seruatum bello iacuit mare,

(LUC. III, 521-524)

Cuando Febo rompió sus rayos matutinos al esparcirlos

sobre las aguas y el cielo estaba libre de nubes,

calmado el Boreas y manteniéndose los Austros en reposo,

el mar yació dispuesto para la batalla.

El mar en calma, en cuyas aguas se destrozan los rayos del sol, es el escenario perfecto para la matanza que se avecina. Se despliegan las flotas enemigas (vv. 528-537) y

${ }^{461}$ Gowing, A. (2005), 18: "In the Augustan period the degree to which Rome celebrated its past was unprecedented. In some cases this is unsurprising; periods of renewal after revolutions are often marked by intense recollection. The paradox of the Augustan period was that it sought to assert the continuity of the republic while at the same time claiming to be a new beginning." Rudich, V. (1997), 4-5.

${ }^{462}$ Rudich, V. (1997), 6:"As for virtus, the concept had been gradually disintegrating and this threatened the traditional model of the universe with final collapse. The original meaning of virtus had been an irrevocable commitment to the service of the community, civitas, and now this presented irreconcilable choices for those concerned."

${ }^{463}$ Rudich, V. (1997), 127:"There is little or nothing in the Bellum Civile to substantiate a preference for the old republican form of government. What is important is the existence of viri ('men') like Cato and mores ('morals') like this, and the belief that only through one's own virtus can one's own libertas be achieved and secured." Sin embargo, como veremos en el desarrollo del trabajo, son personajes como Esceva o Vulteyo y sus seguidores los que reciben la denominación de viri. 
comienza la batalla, en esta ocasión griegos contra romanos. Pero Lucano reformula uno de los versos del proemio - pares aquilas et pila minantia pilis. (LUC. I, 7)- en el verso 544, "ut primum rostris crepuerunt obuia rostra", lo cual nos coloca, a través de esta alusión, nuevamente en el marco del Bellum Civile.

La batalla continúa in crescendo y los romanos logran su objetivo: trabar el sagaz maniobrar de las naves griegas y proponer el combate cuerpo a cuerpo, donde son superiores. La lucha es generalizada, las muertes son impersonales y la magnitud de la matanza se revela en las aguas escarlatas y cubiertas de cuerpos: ${ }^{464}$

$$
\text { nauali plurima bello }
$$

ensis agit. stat quisque suae de robore puppis

pronus in aduersos ictus, nullique perempti

in ratibus cecidere suis. cruor altus in unda

spumat, et obducti concreto sanguine fluctus.

et, quas inmissi traxerunt uincula ferri,

has prohibent iungi conferta cadauera puppes.

(LUC. III, 569-575)

En una batalla naval, se agitan numerosísimas espadas. Cada uno se alza sobre la cubierta de su nave inclinado contra los golpes del enemigo, ningún moribundo cayó sobre su nave. La sangre oscura hace espuma sobre las olas y las aguas se oscurecen con la sangre coagulada. Los cadáveres amontonados prohíben que se toquen esas naves que las cadenas de hierro arrojado unieron.

Sigue luego la minuciosa descripción de variadas formas de muerte, esta vez personalizadas, donde se narra cómo los cuerpos son atravesados, aplastados, mutilados y despedazados.

Si para el estoicismo el pneûma y el tónos mantenían la cohesión interna del universo y de los cuerpos, en Pharsalia los cuerpos son sometidos a tensiones y presiones monstruosas que los deforman y destrozan. Cato, Telón y Giareo son atravesados por proyectiles que se alojan en sus pechos y caderas. Particularmente Cato, cuando intentaba arrancar un palustre griego, es atravesado por dos lanzas que chocan en medio de su pecho. Es ésta una primera muestra de cómo los cuerpos son sometidos a tensiones y presiones extraordinarias:

cuius dum pugnat ab alta puppe Catus Graiumque audax aplustre retentat, terga simul pariter missis et pectora telis transigitur: medio concurrit corpore ferrum, et stetit incertus, flueret quo uolnere, sanguis, donec utrasque simul largus cruor expulit hastas diuisitque animam sparsitque in uolnera letum.

(LUC. III, 585-591)

${ }^{464}$ Hunink, V. (1992), 221-222. 
Mientras lucha desde lo alto de la proa,

Cato arranca valiente el aplustre de una nave de los griegos, es atravesado al mismo tiempo por la espalda y el pecho por flechas lanzadas simultáneamente: chocó el hierro en medio del cuerpo y la sangre se detuvo sin saber por qué herida salir, hasta que el abundante caudal expulsó ambas lanzas, dividió su alma y esparció la muerte por las heridas.

Estas muertes preparan la escena para otra en donde aparecen, de manera seminal, varios motivos que serán desarrollados por Lucano más adelante: hacen su aparición la militiae pietas y la gradual pero inexorable degradación de la virtus en nefas. ${ }^{465}$

La muerte de uno de los gemelos ni siquiera tiene, en este universo absurdo, el consuelo de que al menos uno de los hermanos haya sobrevivido, pues será una aeternis causam lacrimis; tenet ille dolores/ semper et amissum fratrem lugentibus offert (LUC. III, 606-607). Su deceso ocurre luego de ser horriblemente mutilado:

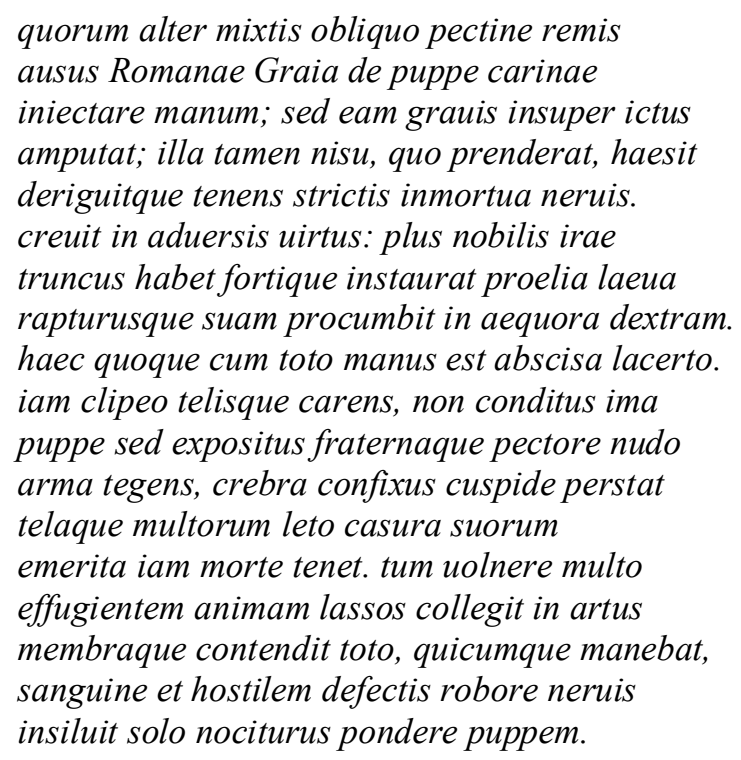

(LUC. III, 609- 625)

Uno de los cuales, al enredarse los remos en peine oblicuo, se atrevió a estirar su mano desde la popa griega hacia una nave romana; pero un pesado golpe la amputa desde lo alto; ella sin embargo queda aferrada por el esfuerzo con que se había agarrado, y muerta mantiene sus nervios crispados. Creció la virtud en la adversidad: mutilado posee aún más de noble ira y renueva el combate con su izquierda; para recuperar su mano derecha se inclina sobre las aguas.

Esta mano también fue cortada junto con su brazo.

Ya despojado del escudo y las armas, no se esconde en lo profundo del barco sino que protege las armas fraternas exponiendo su pecho desnudo, atravesado por numerosos proyectiles se mantiene firme y recibe las flechas que hubieran causado la muerte de muchos compañeros,

${ }^{465}$ Rudich, V. (1997), 129-130. 
cumplida ya su muerte. Entonces concentró en sus piernas cansadas su alma moribunda por las numerosas heridas, tensó sus músculos con toda su sangre, la poca que le quedaba, y saltó con sus nervios carentes de fuerzas a la nave enemiga para dañarla sólo con su peso.

En esta descripción abundan imágenes que serán recurrentes a lo largo de la obra -como las manos mutiladas aún apretando las armas y asiendo los bordes o una militae pietas que busca no desperdiciar la propia muerte-, pero hay una frase que es central para nuestro trabajo: creuit in aduersis uirtus: plus nobilis irael truncus habet. Podría hacerse aquí una larga disquisición respecto de la adecuación al estoicismo de este concepto, más cercano a la visión aristotélica de la ira. ${ }^{466}$ Sin embargo lo que nos interesa es cómo una actitud que parece necesariamente virtuosa -el valor en la adversidad- sólo conduce, en este universo, a actos furiosos de inmolación. En esta primera aparición sólo se vislumbra un costado absurdo del valor pero este fenómeno se hará cada vez más patente, llegando a su summum en la aristeia de Esceva. ${ }^{467}$

La virtus no ofrece una muerte gloriosa sino que alimenta las características furiosas de la militiae pietas: un desesperado arrojo cuya única intención es causar la mayor ruina posible - solo nociturus pondere puppem (LUC. III, 626)-. La nave que atacó este joven con su cuerpo (otra subversión lucaniana del paradigma épico que veremos constantemente a lo largo de Pharsalia: el cuerpo enloquecido atacando las armas) es destrozada en medio del fragor de la batalla:

et, postquam ruptis pelagus conpagibus hausit, ad summos repleta foros descendit in undas uicinum inuoluens contorto uertice pontum.

(LUC. III, 629-631)

y, luego de que el mar la atravesó, destrozada su estructura, descendió repleta hasta lo más alto del puente hacia las aguas envolviendo el ponto cercano en un retorcido remolino.

La palabra clave aquí es conpages, pues el proemio de Pharsalia anuncia expresamente que se canta, entre otras cosas, la conpage soluta del universo que está íntimamente relacionada con la disolución de Roma y de los valores que cohesionan el cuerpo social latino. Dice Michael Lapidge al respecto:

"Only in Stoic writers is the word conpages used in cosmological contexts; for them, apparently, the word carried connotations of the pneumatic or aetherial bonds which maintain the structure of the universe. The word presumably carries these connotations

\footnotetext{
${ }^{466}$ Reydams-Schils, G. (2005), 49-50; Séneca, Ira. I, 8-17.

${ }^{467}$ Hömke, N. (2010), 91 y ss.
} 
for Lucan as well. At all events, the conflagration occurs when the conpages has been dissolves (solute). I have suggested earlier the word solvo was used by the Romans Stoics to render analúo a word employed by Greek Stoics to connote the 'dissolution' of the universe at ekpýrosis. Lucan states, however, that the universe will dissolve into antiquum chaos, not fire. [...] Lucan clearly employed the Stoic imagery of dissolution because it was germane to a central theme of his poem: that the destruction of the state through civil war is a disaster on a scale commensurable with the dissolution of the universe at ekpýrosis."

Este proceso repercute de manera directa tanto en los cuerpos como en las estructuras construidas por los hombres. ${ }^{469}$

Los motivos reaparecen al final del pasaje en las últimas muertes. Tirreno es alcanzado por un pesado proyectil que destroza su cráneo (la frágil estructura que protege el cerebro - male defensum fragili conpage cerebrum - LUC. VI, 177) y, convertido ya en una mera máquina de guerra, sólo quiere causar el mayor daño al enemigo:

'uos', ait 'o socii, sicut tormenta soletis, me quoque mittendis rectum conponite telis. egere quod superest animae, Tyrrhene, per omnis bellorum casus. ingentem militis usum hoc habet ex magna defunctum parte cadauer: uiuentis feriere loco.' sic fatus in hostem caeca tela manu sed non tamen inrita mittit.

"Vosotros, -dice- oh camaradas, como soléis hacer con las ballestas, apuntadme hacia donde hay que arrojar las flechas.

Aprovecha, Tirreno, lo que te queda de aliento, en todos los azares de la guerra. Este cadáver, en gran parte muerto, tiene un enorme uso de soldado: será herido en lugar de los vivos." Así dijo y arrojó contra el enemigo la lanza con mano ciega pero sin embargo no vana.

Empezamos a vislumbrar las características de la militiae pietas: una furiosa obsesión por producir el mayor daño posible al enemigo al mismo tiempo que el cuerpo se cosifica, transformado en arma, en un mero obstáculo más para los ataques enemigos.

Esta actitud ante la muerte encuentra su fuerza en la virtus:

\footnotetext{
${ }^{468}$ Lapidge, M. (1979), 361-362.

469 Lapidge, M. (1979), 360-361: "The parallel between the destruction of the state and the cosmic dissolution is drawn explicitly by Lucan in the beginning of Book I. (I, 72-80). In this passage Lucan has consciously and carefully chosen terminology drawn from and informed by Stoic cosmological tradition. Consider conpages which dissolves at ekpýrosis. This word originally meant 'putting together' (con + pingo) and hence 'structure' or 'framework' (of a ship, for example). However, in the first century A.D. the word was used by stoic poets to denote the structure of the universe: Manilius at one point states that the world is restrained or reinforced by aetheriis conpagibus $(2,803)$. Only in Stoic writers is the word conpages used in cosmological contexts; for them, apparently, the word carried connotations of the pneumatic or aetherial bonds which maintain the structure of the universe. The word presumably carries these connotations for Lucan as well.” También Sklenáŕ, R. (1999), 282-283.
} 
nec cessat naufraga uirtus:

tela legunt deiecta mari ratibusque ministrant incertasque manus ictu languente per undas

exercent; nunc, rara datur si copia ferri,

utuntur pelago: saeuus conplectitur hostem

hostis, et inplicitis gaudent subsidere membris

mergentesque mori.

(LUC. III, 690-696)

Y no desaparece la virtud náufraga:

recogen las armas dispersas por el mar y las alcanzan a las naves,

exigen sus manos inseguras entre el oleaje con golpes cada vez más débiles;

luego, si les es dada una pobre cosecha de hierro,

utilizan el mar: el enemigo abraza furioso al enemigo

y se regocijan en descender con los miembros enredados

y en morir hundiéndose.

Resalta aquí el uso del verbo gaudere, que nos muestra otra faceta aún más enferma de esta desesperante condición existencial. ${ }^{470}$

Ya analizamos, de manera inicial, el contenido del discurso poético. Ahora nos concentraremos en detectar cómo este discurso, que desarrolla el proceso de disolución universal e individual y la persistente degradación de los valores fundantes de Roma, resulta ser, paradójicamente, un discurso aglutinante, denso, masivo, lo que nos permite hablar, entonces, de un discurso con características barrocas. ${ }^{471}$ Se han señalado como rasgos característicos del Barroco el tratamiento del material artístico a través de masas, agrupaciones y agregados, la constitución de una forma turbulenta, cuyo origen es usualmente otra turbulencia, la tendencia de la materia a desbordar el espacio, a conciliarse con lo fluido y a agruparse en masas molares. ${ }^{472}$

El pasaje puede dividirse de la siguiente manera:

- Preparación para la batalla: vv. 509- 537.

- Batalla generalizada/ combate cuerpo a cuerpo: vv. 538- 583.

- Muertes destacadas: vv. 584- 660. Cato (584-591), Telón (592-599), Gyereo (600-603), geminus frater (604- 625), "muerte" de un navío (627-634), Lycidas (635-646), natans (647-661).

- Muertes caracterizadas por la desesperación y el furor: vv. 670-696.

- Muertes individualizadas: El Foceo, Tierreno, Argos y su padre.

El discurso se organiza en masas molares que a su vez están constituidas por unidades independientes pero a su vez interconectadas, cada una presentando alguno de

\footnotetext{
${ }^{470}$ Hunink, V. (1992), 250: "gaudent: Joy is a very suspect emotion in BC; cf. already on 82 and 360. For the connection of joy and death cf. e.g. 4, 278; 520; 570 mortem sentire iuvat; 7, 602-3. The combination is not merely paradoxical as BROUWERS 19892b, 78 says but it is intimately related to the concept of amor mortis, for which see on 134 and 240."

${ }^{471}$ Charles Segal, entre otros, ha destacado la importante similitud entre las manifestaciones artísticas romanas del siglo I d. C. y las de Barroco del siglo XVI. Segal, Ch. (1984).

${ }^{472}$ Maraval, J. (1990), 421-422; Deleuze, G. (2005), 13-14; Valverde, J. (1985), 7-8.
} 
estos varii miracula fati (LUC. III, 634) que conforman un collage donde cada tipo específico de muerte forma parte de una visión de conjunto, de un entramado significativo y coherente. Se logra entonces una representación estética que compone una forma particular y específica. Cada turbulencia discursiva corresponde a una muerte particular y abre las puertas para el despliegue de la que le sigue. Al modo de una estructura fractal, la microestructura genera la macroestructura: la lanza arrojada ciegamente por Tirreno hiere a Argos, provocando el suicidio desesperado del padre de éste.

Este cuadro conjuga de manera admirable varias operaciones típicamente lucanianas: en primer lugar pone en escena la subversión del paradigma estoico al mostrar un suicidio motivado por un estado de desesperación extrema, una muerte decidida a partir del pathos y no ex ratione. En segundo lugar pone en funcionamiento un barroco juego de inversiones existenciales. Los suicidios nunca son virtuosos o ejemplares, sino furiosos y desesperados, son ejemplos de esta tendencia el suicidio del padre de Aulo, el del soldado picado por una dípsada o el de los soldados cesarianos, guiados por Vulteyo. Heródoto ya había destacado que la guerra misma producía una inversión del orden natural, pues en ella los padres entierran a sus hijos y no viceversa (HER. I, 87, 4). Lucano invierte esta inversión, pero de ninguna manera esto vuelve más tranquilizadora la situación; al contrario, la vuelve aún más absurda y desesperada. En el universo de Pharsalia los individuos adoptan actitudes extremas y el discurso plasma esta condición existencial de manera magistral a través de tensiones irresolubles que aparecen poco antes de cada episodio:

hic recipit fluctus, extinguat ut aequore flammas, hi, ne mergantur, tabulis ardentibus haerent. mille modos inter leti mors una timori est qua coepere mori $[\ldots]$

non perdere letum

maxima cura fuit: multus sua uolnera puppi

adfixit moriens et rostris abstulit ictus.

(LUC. III, 706-708)

Este acepta las aguas para extinguir las llamas con el mar, aquellos, para no hundirse, se abrazan a tablas ardientes. Entre mil modos de perecer, es motivo de temor sólo la muerte por la que se ha comenzado a morir.

$[\ldots]$

No desperdiciar la muerte fue la máxima preocupación: muchos moribundos colgaron sus heridas a las naves y amortiguaron los golpes del espolón. 
Estas tensiones irresolubles acentúan la terrible desesperación del individuo sumergido en un caos casi primigenio. ${ }^{473}$ Se produce este barroco juego de inversión de inversiones: ${ }^{474}$ el padre morirá antes que su hijo moribundo, pero las operaciones del texto convierten este gesto en algo monstruoso.

El genitor ve caer a su hijo herido de muerte - funere viso (LUC. III, 730)- y se acerca desesperado; allí, presa del dolor queda estupefacto y sufre lo que podríamos llamar una antianagnórisis:

nox subit atque oculos uastae obduxere tenebrae, et miserum cernens agnoscere desinit Argum.

Se alza una noche y vastas tinieblas velaron sus ojos y, contemplando al desgraciado, deja de reconocer a Argos.

A los que siguen unos versos de una extraña ternura:

ille caput labens et iam languentia colla uiso patre leuat; uox faucis nulla solutas prosequitur, tacito tantum petit oscula uoltu inuitatque patris claudenda ad lumina dextram.

Este, al ver a su padre levanta su débil cabeza y su cuello ya languideciente; ninguna voz salió de boca abierta, sólo pide un beso con su rostro silencioso e invita a la mano de su padre a cerrar sus ojos.

Sin embargo, en Pharsalia no hay lugar para semejantes gestos tranquilizadores: en un desesperado intento por imponer algún grado de orden en estos acontecimientos el anciano decide no perder el poco tiempo dado por los crueles dioses y suicidarse en un absurdo intento por que su hijo moribundo lo sobreviva:

\footnotetext{
${ }^{473}$ Hunink, V. (1992), 252; También Sklenář, R. (1999), 283-284: “Lucan formulates this reality in such a way as to contradict the Stoa's rationalistic conception of fatum. A cornerstone of Stoic doctrine is that nothing is arbitrary; thus fatum, casus, fortuna, natura, in Stoic Latin signify the providential order and are regularly interchangeable with terms for divinity itself, god being inseparable from nature and reason (logos). Lucan, by contrast, postulates a fatum whose destruction of Rome corresponds to the return of primeval chaos, a concept which has no place in the stoic scheme."

${ }^{474}$ Hunink, V. (1992), 258 (nota 1) \& 259-260; Esposito, P. (2004), 44-45, esp. 45: "Invece, tutto è sconvolto da una ribellione ad un dovere insopportabile, che è anche volontà di fuoriuscire da uno schema rappresentativo tradizionale. Di questa operazione è ancora una volta spia e filo conduttore la negazione, con cui vengono segnalate dapprima la mancata esternazione rituale del dolore, poi il non corrisponde alle richieste del figlio, quindi, a la fine, l'anomalo Desiderio do ottenere, con un gesto clamoroso, che la morte di padre e figlio non fosse simultanea. Il paradosso conosce qui, con indubbia coerenza strutturale, un'ulteriore conferma, dal momento che l'anomalia di questo innaturale conflitto civile si ripercuote, come in questo caso, in tutte le innumerevoli scene con immediatezza antitetico rispetto ad agni logica comportamentale ed etica, in quanto bisogna mostrare una realtà in cui i principi e le regole sono stati sconvolti e vanificati da una scelta sciagurata, che ha infranto la norma e reso tutto di fatto lecito e possibile."
} 
'non perdam tempora' dixit

'a saeuis permissa deis, iugulumque senilem

confodiam. ueniam misero concede parenti,

Arge, quod amplexus, extrema quod oscula fugi.

nondum destituit calidus tua uolnera sanguis,

semianimisque iaces et adhuc potes esse superstes.'

sic fatus, quamuis capulum per uiscera missi

polluerit gladii, tamen alta sub aequora tendit

praecipiti saltu: letum praecedere nati

festinantem animam morti non credidit uni.

(LUC. III, 742-751)

No desperdiciaré el tiempo - dijo-

dado por los crueles dioses, atravesaré mi cuello senil. Concede, Argos, este perdón a tu desdichado padre, que rehúye tu abrazo y tu último beso.

La cálida sangre aún no ha abandonado tus heridas, yaces moribundo y todavía puedes sobrevivirme."

Así habló, y aunque manchó la empuñadura de su espada

empujada a través de sus vísceras, se arrojó, sin embargo,

al profundo mar con un precipitado salto: no confió a una sola muerte

su alma apresurada por preceder la desgracia de su hijo.

\section{VULTEYO Y SUS HOMBRES}

La batalla naval nos ofrece una puesta en escena de los motivos que estructuran el desarrollo poético de Pharsalia: la disolución y desmembramiento del cuerpo, la degradación inexorable de la virtus, la desesperada militiae pietas y la subversión de los paradigmas épicos, estéticos y filosóficos. Al comienzo de este episodio los soldados de la nave atrapada luchan valientemente, mostrando una virtus que podríamos llamar "tradicional":

frustra qui uincula ferro

rumpere conatus poscit spe proelia nulla

incertus qua terga daret, qua pectora bello.

hoc tamen in casu quantum deprensa ualebat

effecit uirtus

(LUC. IV, 466- 470)

quien en vano se esfuerza por romper

las cadenas de hierro, busca sin esperanza alguna la batalla, dudando por dónde dar la espalda, por dónde ofrecer el pecho al combate. En esta situación la virtud atrapada hizo cuanto podía.

La batalla se detiene con la llegada de la noche y las tinieblas traen una dubiam pacem (LUC. IV, 472-473). Comienzan entonces las operaciones discursivas de subversión de 
los paradigmas: las palabras de Vulteyo despliegan conceptos y sentencias de pura cepa estoica:

'libera non ultra parua quam nocte iuuentus, consulite extremis angusto in tempore rebus. uita breuis nulli superest qui tempus in illa quaerendae sibi mortis habet; nec gloria leti inferior, iuuenes, admoto occurrere fato.

(LUC. IV, 476-480)

$[\ldots]$

non cogitur ullus

uelle mori. fuga nulla patet, stant undique nostris intenti ciues iugulis: decernite letum,

et metus omnis abest. cupias quodcumque necesse est. (LUC. IV, 484-487)

Juventud que no será libre más que esta corta noche, deliberemos sobre nuestra última actuación en este breve tiempo.

No le queda una vida breve a quien tiene el tiempo para buscar su propia muerte; y no es inferior la gloria de su caída por correr al encuentro de la ruina que se avecina.

$[\ldots]$

Nadie puede ser forzado a querer morir. Ninguna salida se abre a nuestro alrededor, por todo nuestro alrededor se alzan ciudadanos que acechan nuestras gargantas: escoged la muerte, y todo miedo desaparece. Desea lo que es inevitable.

Hasta aquí vemos un desarrollo racional y virtuoso: Vulteyo exhorta a sus soldados a dejar un magnum et memorabilem exemplum fatis (LUC. IV, 496), a superar los monimenta que la fides o la militiae pietas hayan ofrecido al mundo (LUC. IV, 497499), pero inmediatamente se revela en sus palabras el furor existencial que empuja sus "sabias" palabras:

namque suis pro te gladiis incumbere, Caesar, esse parum scimus; sed non maiora supersunt obsessis tanti quae pignora demus amoris. abscidit nostrae multum fors inuida laudi, quod non cum senibus capti natisque tenemur.

(LUC. IV, 500- 504)

Sabemos que no es suficiente arrojarnos sobre las espadas por ti, César; pero nada más grande queda para los asediados que ofrecernos como prenda de un amor tan grande. La suerte envidiosa nos priva de muchas de nuestras alabanzas, pues no estamos sitiados con nuestros ancianos y nuestros hijos.

Sale a la superficie la desesperación latente en los corazones de estos indomitos viros (LUC. IV, 505) con morti faciles animos (LUC. IV, 506). Estos viri se aferran obsesivamente a un ideal como único medio para dar sentido a sus vidas y ejecutan 
actos espectaculares y casi sobrehumanos. Sin embargo, todos estos actos ejemplares están teñidos de un matiz monstruoso, insano hasta el límite de lamentarse por no poder ultimar a sus padres e hijos junto con ellos.

Comienza otro complejísimo y barroco juego de sentidos que se desdibujan; una disolución etimológica de dos conceptos claves: la virtus y el vir, cuyo clímax está, como ya dijimos, en la aristeia de Esceva. Si el valor fundante del varón romano, del vir bonus de los estoicos, ${ }^{475}$ es subvertido y trastrocado, entonces el vir ya no es un varón o un héroe, sino que deviene un enloquecido criminal. Se subvierten los paradigmas épico y filosófico. Pius Aeneas dice ante la desgracia inminente: "una salus victis nullam sperare salutem" (A. II, 354). Vulteyo, por su parte, afirma:

o utinam, quo plus habeat mors unica famae, promittant ueniam, iubeant sperare salutem, ne nos, cum calido fodiemus uiscera ferro, desperasse putent. magna uirtute merendum est, Caesar ut amissis inter tot milia paucis hoc damnum clademque uocet.

Ojalá que, para que nuestra única muerte tenga mayor fama, nos prometan el perdón, que se les ordene esperar nuestra salvación, para que, cuando excavemos nuestras entrañas con el cálido hierro, no piensen que hemos desesperado. Gracias a nuestra magna virtud mereceremos que César, perdidos unos pocos entre tantos miles, llame a esto una desgracia y una calamidad.

La valentía resignada de Eneas, cuya virtus creuit in aduersis, no es la misma que la de Vulteyo y sus hombres. Hay aquí un regodeo en la desesperación, un retorcido deleite en la autoafirmación de la propia ferocidad similar a los manifestados por Medea y Atreo en la tragedia de Séneca, por nombrar los casos más resonantes. ${ }^{476}$

La decisión está tomada:

stabat deuota iumentus damnata iam luce ferox securaque pugnae promisso sibi fine manu, nullique tumultus excussere uiris mentes ad summa paratas; innumerasque simul pauci terraque marique sustinuere manus: tanta est fiducia mortis.

Se alzaba feroz, ya condenada su vida,

\footnotetext{
475 SEN. Prov. VI, 7 \& Ira, III, 15, 4.

${ }^{476}$ SEN. Med. vv. 155- 163: "Me. Leuis est dolor, qui capere consilium potest/ et clepere sese: magna non latitant mala./ libet ire contra. Nvt. Siste furialem impetum,/ alumna: uix te tacita defendit quies./ Me. Fortuna fortes metuit, ignauos premit./ Nvt. Tunc est probanda, si locum uirtus habet./ Me. Numquam potest non esse uirtuti locus./ Nvt. Spes nulla rebus monstrat adflictis uiam./ Me. Qui nil potest sperare, desperet nihil". También los renombrados versos Medea superest (166), [Medea] fiam (171) y Medea nunc sum (910); véase también Thyestes vv. 190 y ss. y 804 y ss.
} 
la juventud consagrada y decidida a la lucha,

que había prometido su fin a su propia mano. Ningún tumulto

conmovió la mente de los varones preparadas para morir;

estos pocos aguantaron ataques simultáneos

por tierra y por mar: tanta confianza hay en la muerte.

En medio del fragor del combate, hasta se permiten un detalle estético en la construcción de su monimentum: sólo cuando han derramado lo que consideran suficiente sangre enemiga llevan a cabo el pacto suicida. Se despliega entonces un espectáculo atroz y particularmente monstruoso precisamente por la valentía e hidalguía con la que se realiza:

\author{
primus dux ipse carinae \\ Vulteius iugulo poscens iam fata retecto \\ 'ecquis' ait 'iunenum est cuius sit dextra cruore \\ digna meo certaque fide per uolnera nostra \\ testetur se uelle mori?' nec plura locuto \\ uiscera non unus iam dudum transigit ensis. \\ conlaudat cunctos, sed eum cui uolnera prima \\ debebat grato moriens interficit ictu. \\ concurrunt alii totumque in partibus unis \\ bellorum fecere nefas.
}

(LUC. IV, 540-549)

Primero el propio capitán de la nave, Vulteyo, reclama la muerte con su cuello ya desnudo, "¿Acaso - dice- hay alguien entre esta juventud cuya diestra sea digna de mi sangre y atestigüe con lealtad cierta que yo quise morir por estas heridas?" Sin decir más, no sólo una espada atravesó de inmediato sus vísceras.

Alaba a todos, pero a aquel a quien debía el primer golpe el moribundo lo mató con un golpe agradecido.

La fides y la pietas son ahora fraternos golpes asesinos; la alabanza y la gratitud se expresan a través de un grato ictu; la camaradería es un pacto suicida donde ninguno de los involucrados duda en absoluto (LUC. IV, 556- 559). El furor de quienes pactaron su muerte (LUC. IV, 556-557) revierte el orden natural de la batalla y entonces los pechos atacan el hierro y son los cuellos los que se lanzan contra las espadas:

nec uolnus adactis debetur gladiis: percussum est pectore ferrum et iuguli pressere manum. cum sorte cruenta fratribus incurrunt fratres natusque parenti, haud trepidante tamen toto cum pondere dextra exegere enses. pietas furientibus una non repetisse fuit.

(LUC. IV, 560-566)

La herida no se debe a las espadas dispuestas: El hierro fue golpeado por los pechos y los cuellos presionaron las manos. Cuando por causa de una suerte cruenta los hermanos encontraron a sus hermanos y el hijo al padre, 
las espadas cumplieron sin embargo con todo su peso y no temblaron las manos: La única piedad que tuvieron los enloquecidos

fue no repetir el golpe.

Los soldados se regocijan en su propia desesperación, en la creación de estos pignora amoris que dominan la escena:

\author{
despectam cernere lucem \\ uictoresque suos uoltu spectare superbo \\ et mortem sentire iuuat.
}

Les complace contemplar

la luz despreciada, mirar con rostro altanero a sus vencedores

y sentir la muerte.
(LUC. IV, 568- 570)

Lo monstruoso de este sacrificio es la ratio desequilibrada que lo sustenta; la entereza y bravura de esta juventud que los lleva a cometer todos los crímenes de la guerra civil (alii totumque in partibus unis/ bellorum fecere nefas (LUC. IV, 548-549)), cuya realización resulta mucho más impía por sus propias condiciones de ejecución y su desesperada motivación. La virtus y la pietas que los convierten en indomitos viros son subvertidas y estos exempla virorum (LUC. IV, 575) resultan ser un canto al totum nefas bellorum. $^{477}$

Estructuralmente el discurso vuelve a aglutinar los conceptos que son diluidos y degradados por sus operaciones. Los valores centrales como la virtus (LUC. IV, 470, 491, 512, 558 y 581), la pietas (LUC. IV, 499, 565), el vir (LUC. IV, 505, 557 y 575) у la fides (LUC. IV, 438, 498 y 543) pierden progresivamente su significación primigenia y se disuelven en este universo absurdo. Esta operación de aglutinación discursiva y disolución semántica de los elementos constitutivos alcanza su máxima expresión en el episodio de Esceva.

\section{ESCEVA}

La aristeia de Esceva es una demostración de la maestría con la que Lucano logra conjugar la valentía y el furor y aquí es donde los conceptos de virtus y vir son finalmente subvertidos y vaciados de contenido, volviéndose algo monstruoso que se

477 Rudich, V. (1997), 133-134:"There exists yet another psychological dimension hinted at by the seductive appeal of suicide for the Caesarean warriors. It suggest, despite the appearance of political and personal loyalty, an emotional anarchism and an existential nihilism, a passion for destruction, and selfdestruction for its own sake, an involvement with danger and risk, 'on the verge of the abyss.' as inner spiritual need. Again, it is not necessary to claim that Lucan himself was necessarily conscious of it." 
encuentra en las antípodas de su significación primigenia. Esceva es presentado como un vir indómito y decidido:

quem non mille simul turmis nec Caesare toto
auferret Fortuna locum uictoribus unus
eripuit uetuitque capi, seque arma tenente
ac nondum strato Magnum uicisse negauit.
Scaeua uiro nomen: castrorum in plebe merebat
ante feras Rhodani gentes; ibi sanguine multo
promotus Latiam longo gerit ordine uitem,
pronus ad omne nefas et qui nesciret in armis
quam magnum uirtus crimen ciuilibus esset.

(LUC. VI, 140- 148)

Aquel lugar que ni Fortuna con mil trompetas ni con todo el ejército de César hubiera arrebatado a los vencedores, uno solo se los quitó e impidió que sea tomado; declaró que, mientras él empuñara un arma y se mantuviera firme, el Magno no vencería. Esceva se llamaba ese varón: militaba como soldado raso del cuartel antes de la campaña contra los fieros pueblos del Ródano; allí fue promovido a centurión por sus muchas heridas y condujo las largas filas, dispuesto a toda impiedad e ignorante de qué gran crimen es la virtud en los combates civiles.

Un valiente podrá más que un ejército. Se destaca su individualidad - unus- y su militancia bajo las órdenes de César; se explicita además que la virtus en estas circunstancias resulta un magnum crimen. Esceva se lanza decidido al crimen que Catón profetizaba: sed quo fata trahunt uirtus secura sequetur./ crimen erit superis et me fecisse nocentem. (LUC. II, 287-288).

A diferencia del discurso de Vulteyo, cargado de contenido filosófico y sentencias estoicas, las palabras de Esceva son directas y propias de un curtido soldado: apela a la vergüenza de huir y faltar de las tumbas (LUC. VI, 150-154), pero por sobre todo impreca a los demás soldados, ya que, aunque la pietas vacile, al menos la ira debería invitar a resistir:

non ira saltem, iuuenes, pietate remota

stabitis?

(LUC. VI, 155-156)

al fallar la lealtad, jóvenes, ¿no resistiréis

al menos por ira?

Si en la batalla naval los vencedores se admiraban de la capacidad de César de generar lealtades monstruosas ${ }^{478}$-iam strage cruental conspicitur cumulata ratis, bustisque

\footnotetext{
${ }^{478}$ César había probado repetidas veces su propia valentía y coraje a sus soldados luchando codo a codo con ellos en los momentos más sensibles de varias batallas (en Alesia (CEAS. Gal. VII, 87-88) o en la batalla del río Sambro (CAES, Gal. II, 25), por ejemplo), cf. Rosenstein, N. (2009), 97-98: “This willingness to share their toils endeared him to his men and forged a powerful bond between the soldiers
} 
remittunt/ corpora uictores, ducibus mirantibus ulli/ esse ducem tanti (LUC. IV, 570572), Esceva es el exemplum por excelencia:

\author{
non paruo sanguine Magni \\ iste dies ierit. peterem felicior umbras \\ Caesaris in uoltu: testem hunc fortuna negauit: \\ Pompeio laudante cadam.
}

(LUC. VI, 157-160)

No pasará este día

con poca sangre del Magno. Buscaría feliz las sombras

ante el rostro de César: Fortuna me ha negado este espectador, caeré mientras Pompeyo me alaba.

Esceva alienta a golpear las espadas con el cuello, a romper los proyectiles con el pecho, en una clara alusión al momento de mayor furor de los hombres de Vulteyo, con la esperanza de que este clamor llegue a oídos de César (LUC. VI, 163). El gusto de Lucano por la paradoja se refleja en el cierre de su discurso: vincimus ... dum morimur (LUC. VI, 164-165).

La valentía de Esceva es extrema, desmesurada, y a medida que avanza la acción él mismo se convierte en un arma contra el enemigo:

ille ruenti
aggere consistit, primumque cadauera plenis
turribus euoluit subeuntisque obruit hostis
corporibus, totaeque uiro dant tela ruinae,
roboraque et moles hosti seque ipse minatur.

(LUC. VI, 169- 173)

Él se atrincheró

en la empalizada que se desplomaba. Primero empujó los cadáveres desde las torres repletas y aplastó con cuerpos a los enemigos que las escalaban, las ruinas enteras dan armas al varón, Él amenaza al enemigo con maderas, con piedras y consigo mismo.

Todo el pasaje se articula recurrentemente a través de los conceptos virtus (LUC. VI, $132,148,169,229,240,254$ у 262) у vir (LUC. IV, 144, 153, 167, 172, 192 у 226.). La raíz uir aparece un total de 13 veces en sólo 144 versos, ${ }^{479}$ lo cual nos da una ratio de 1 : 11.08, es decir aparece estructurando el discurso cada 10 versos aproximadamente.

and their general that was key to Caesar's military success (Suet. Iul. 57; Plut. Caes. 17-1-3). [...] He was devoted to his men, and they responded in kind (Suet. Iul. 67, 1-70). The steadfast loyalty of his legions and their determination not to fail short in his estimation placed in Caesar's hands as formidable a military instrument as any Roman general - or any other general, for that matter- ever wielded."

${ }^{479}$ Ernout, A \& Meillet, A. (1979), 738-739. Destacamos los siguientes párrafos: "Vir, viri (m): $2^{\circ}$ homme digne de ce nom, héros.", p. 738; "Virtus, virtutis (f): Virtus est avec vir dans le même rapport de dérivation que iuventus, senectus avec iuvenis, senex. Comme ceux deux mots, il marque l'activité et la qualité.”, p. 739. 
A medida que la gesta de Esceva se vuelve más grande y más "heroica" se produce un complejo proceso de resemantización que corre progresivamente el significado y la propia naturaleza etimológica del signo hacia lugares completamente paradójicos y contradictorios: la virtus, en la guerra civil, se transforma en nefas, en un magnum crimen $^{480} \mathrm{y}$, por lo tanto, el vir, encarnación de la virtus y personificación de las vires, sólo puede ser entonces un criminal furioso aun cuando demuestre un coraje y una valentía sobrehumana. ${ }^{481}$ Cuando los cuerpos alcanzan las alturas del muro, Esceva salta como un leopardo sobre las lanzas hacia lo más denso de las tropas enemigas que se amedrentan ante su sola mirada (LUC. VI, 180-185).

Las condiciones existenciales constitutivas de las cosas se han disuelto: el vir ya no es un héroe, la espada ha perdido su filo y es un remedo de sí misma, pese a que sigue cumpliendo de manera monstruosa su función. El propio cuerpo del soldado se deshace progresivamente, destruida su conpages:

iamque hebes et crasso non asper sanguine mucro
[percussum Scaeuae frangit, non uolnerat, hostem;]
perdidit ensis opus, frangit sine uolnere membra.
illum tota premit moles, illum omnia tela,
nulla fuit non certa manus, non lancea felix;
parque noum Fortuna uidet concurrere, bellum
atque uirum. fortis crebris sonat ictibus umbo,
et galeae fragmenta cauae conpressa perurunt
tempora, nec quicquam nudis uitalibus obstat
iam praeter stantis in summis ossibus hastas.

Ya embotada y roma por la sangre coagulada [la espada de Esceva quiebra al atacado, no lo hiere] la espada perdió su uso, rompe los miembros sin cortarlos. La masa entera lo aplasta, toda flecha lo alcanza, toda mano fue certera, toda lanza dio en el blanco; Fortuna contempla un nuevo enfrentamiento: un ejército contra un varón. El duro escudo resuena con los numerosos golpes y los fragmentos abollados del hueco casco abrasan sus sienes comprimidas, nada retiene sus órganos desnudos excepto las lanzas clavadas en lo profundo de sus huesos.

Este varón que lucha contra todo un ejército se convierte entonces en un fuerte muro, (stat non fragilis pro Caesare murus/ Pompeiumque tenet - LUC. VI, 201-202), lo que nos recuerda la notable sentencia de Esquilo:

\footnotetext{
${ }^{480}$ Rudich, V. (1997), 133.

${ }^{481}$ Sobre la Übermenschlichkeit de los soldados de César, véase Rudich, V. (1997), 133 -134. De hecho nada nos dice que Esceva muera pues, aunque al final del episodio aparece labentem y defectum et uiuam magnae speciem Virtutis, reaparece, sin embargo, en el cierre del poema (LUC. X, 540-546).
} 


$$
\square v \delta \rho \square v \gamma \square \rho \square v \tau \omega v \square \rho \kappa o \varsigma \square \sigma \tau \square v \square \sigma \varphi \alpha \lambda \dot{\varepsilon} \varsigma^{482}
$$

Pues habiendo varones, las murallas son infranqueables.

Pero mientras Esquilo celebra una virtud cívica y militar, Esceva resulta ser la encarnación de la furiosa militiae pietas.

El ímpetu sobrehumano del soldado se refleja también en su cuerpo despedazado: él mismo se automutila en una demostración de fiereza y su rostro refleja los signos inequívocos de la ira: ${ }^{483}$

Dictaea procul, ecce, manu Gortynis harundo tenditur in Scaeuam, quae uoto certior omni in caput atque oculi laeuom descendit in orbem. ille moras ferri neruorum et uincula rumpit adfixam uellens oculo pendente sagittam intrepidus, telumque suo cum lumine calcat.

\section{$[\ldots]$}

perdiderat uoltum rabies, stetit imbre cruento informis facies

he aquí que desde lejos una saeta gortinia es lanzada contra Esceva por una mano dictea que, más certera que cualquier voto, desciende sobre su cabeza y la órbita de su ojo izquierdo. Él rompe los nervios que retienen el hierro arrancando valeroso la flecha clavada con el ojo colgando y pisotea el proyectil junto con su ojo.

\section{$[\ldots]$}

La rabia le había desfigurado el rostro, su cara se deformó a causa de la lluvia de sangre.

Sigue el ardid de Esceva para emboscar a los pompeyanos y resulta revelador que el "héroe" no oculta la ira sino su virtus para dirigirse a sus conciudadanos:

ille tegens alta suppressum mente furorem, mitis et a uoltu penitus uirtute remota, 'parcite', ait 'ciues

El, ocultando el furor contenido en lo profundo de su mente, dócil y alejada la virtud de su rostro dice: "deteneos, ciudadanos"

Pero Esceva nunca se rendirá e increpa duramente a los enemigos, del mismo modo que los soldados de Vulteyo, por pensar siquiera que un soldado cesariano considere

\footnotetext{
${ }^{482}$ ESQ. Per. 349.

${ }^{483}$ SEN. Ira. I, 1, 3 y I, 20, 1.
} 
rendirse, ya que se diferencia de ellos precisamente por la militiae pietas y la fanática fides que César genera en sus seguidores: ${ }^{484}$

incaluit uirtus, atque una caede refectus

'soluat' ait 'poenas, Scaeuam quicumque subactum

sperauit. pacem gladio si quaerit ab isto

Magnus, adorato summittat Caesare signa.

an similem uestri segnemque ad fata putatis?

Pompei uobis minor est causaeque senatus

quam mihi mortis amor.

(LUC. VI, 240-246)

Se reavivó su virtud y reanimado por esta sola muerte, "que pague su pena, dice, cualquiera que espere ver

a Esceva vencido. Si el Magno busca la paz de esta espada, que entregue sus insignias, venerando a César.

¿Acaso pensáis que yo soy igual a vosotros?

¡Vuestro amor por Pompeyo y la causa del Senado

es menor que mi amor por la muerte!"

La virtud es un amor mortis. La llegada del ejército cesariano libra a los pompeyanos de la vergüenza de haber sido vencidos por un solo vir y los hombres de César levantan a Esceva como la viva imagen de la virtud: vivam magnae speciem virtutis adorant (LUC. VI, 254). ${ }^{485}$

Las operaciones discursivas transforman las palabras y sus valores en significantes vacíos, quizás mejor, vaciados. A mayor aglutinación de ciertos significantes específicos en el entramado textual, más corrosiva es la acción de esta operación lucaniana: la alta concentración de conceptos relacionados con la virtus y el vir acelera el proceso de dispersión y transfiguración de estos valores en horrendas caricaturas de sí mismos:

"In 6. 138-262 - and possibly holding the compositional central position of the workLucan again picks up his leitmotiv of the inversion of ius and virtus into scelus caused by the civil war and presents us with its incarnation: He introduces Cassius Scaeva, Caesar's distinguished centurion, who virtually single-handedly deflects the attempted break-out of the Pompeians during the siege of Dyrrachium- despite being severely injured- until Caesarian cohorts arrive to provide reinforcements. [...] The replacement of the ethical parameters ius and virtus by nefas and crimen applies as much to Scaeva as to the Bella plus quam civilia, and Scaeva consequently appears as the perfect embodiment of the civil war. " 486

Ambos episodios (el de Esceva y el de Vulteyo) se cierran con un lamento del poeta ante tanta hombría derrochada. Los exempla virorum desplegados por los soldados de Vulteyo no llegarán a las ignavae gentes (LUC. IV, 576-577) que ignoran

\footnotetext{
${ }^{484}$ Rosenstein, N. (2009), 98.

${ }^{485}$ Bartsch, Sh. (2005), 497-498.

${ }^{486}$ Hömke, N. (2010), 91.
} 
que las espadas fueron creadas para que nadie sea esclavo (LUC. IV, 579). Fuera del contexto de la carnicería ocurrida poco antes, el pasaje sería un canto a la valentía indómita y a la apacible resignación estoica. Pero no es así: el paradigma filosófico ha sido subvertido desde sus mismos fundamentos por un discurso que aglutina los elementos constitutivos de cada registro semántico con la intención de socavar paulatinamente sus componentes esenciales y ofrecer de este modo un universo paradójico y quizás absurdo, donde los valores, los cuerpos y los ideales están en constante disolución y en un permanente estado de inadecuación. ${ }^{487}$

\section{LAS SERPIENTES Y LOS CUERPOS}

Este famoso pasaje que ha dado lugar a numerosas interpretaciones y suscitado airadas polémicas merece, per se, un breve status quaestionis. La visión más tradicional entiende este pasaje como una batalla entre Catón y las serpientes que peca de excesiva y anecdótica. Heitland lo considera parte de la "plaga de catálogos" que entorpecen el flujo narrativo de la Pharsalia mientras otros atribuyen los "excesos" del episodio a la macabra y barroca obsesión de Lucano con la muerte. ${ }^{488}$ En estudios más recientes se sostiene que el pasaje es una demostración de la virtus de Catón aunque cada uno aduce diversas faltas que vuelven al pasaje un experimento fallido. ${ }^{489}$ Batinski y Sklenář, por su parte, consideran el episodio la prueba de la inadecuación de la figura del general a las condiciones de existencia de este universo nihilista. ${ }^{490}$

Sin embargo, más allá de que la figura del sabio estoico es omnipresente a lo largo de todo el libro IX, el papel de Catón en los ataques de las serpientes es, a lo sumo, secundario. Su nombre aparece a lo largo del libro 22 veces, ${ }^{491}$ de las cuales sólo cuatro ocurren en el episodio del ataque ofídico. Muchas veces el número de apariciones de una palabra no es garantía de su falta o no de importancia, ya que lo central es la relevancia que ésta posee para la interpretación del pasaje. En este caso Catón es nombrado sólo cuatro veces, y nunca forma parte directa de la acción o está implicado

\footnotetext{
${ }^{487}$ Sklenár̆, R. (1999), 282.

${ }^{488}$ Heitland, W. (1971), lxxii y ss.; Hunink, V. (1992), xi-xii.

${ }^{489}$ Batinski, E. E. (1991), 71-73.

490 Batinski, E. E. (1991), 73:“The paradoxical nature of the Civil War excludes Cato's participation within this epic world.[...] Cato bows he will not withdraw from the political scene until he embraces the dead Republic and follows libertas, which has now become a shadow (2. 297-303). [...] Now that Pompey is dead so is the sham of Republicanism." Cf. también Sklenár. R. (1999), passim.

${ }^{491}$ Lucano, Pharsalia, IX, 18, 50, 97, 119, 166, 188, 219, 221, 227, 250, 291, 299, 371, 410, 444, 546, 555 y 941 fuera del episodio en cuestión, y IX, 764, 747, 761 y 807 dentro de él.
} 
directamente en ella. Luego del catálogo de las serpientes, aparece el general con sus soldados: has inter pestes duro Cato milite siccum/ emeritur iter - LUC. IX, 734-735).

Durante la muerte de Aulo, intenta contener sin éxito al joven desesperado (non decus imperio, non maesti iura Catonis/ ardentem tenuere virus - LUC. IX, 474-478)) y luego simplemente ordena levantar las insignias que abandonara el moribundo (iussit insignia propere Cato - LUC. IX, 761). Su última aparición ocurre en la descripción de una de las víctimas, un joven admirador de Catón ([Tullo] magnanimo iuveni miratorique Catonis - LUC. IX, 807)). La verdadera muestra de la valentía y la sabiduría de Catón están, creemos, en los episodios que enmarcan el ataque de las serpientes, ${ }^{492}$ frente al templo de Amón y en el oasis en cuyas aguas descansan los reptiles: ${ }^{493}$

\begin{abstract}
"The scene at the temple of Ammon furnishes a perfect representation of the Stoic life of wisdom, a transcendent vision of the universe governed by a flawlessly rational divine logos, but to understand which is the only goal of our striving on this earth. But that vision still remains irremediably contrary to the world in which it takes place, for we are obligated to read this scene in conjunction with Lucan's unrecanted nihilistic cosmology. If all that is, is god, then god is civil war and everything associated with it: perversion, corruption, fratricide, summum nefas, as even Cato has acknowledged. The desperate absurdity of his plight is, now all too clear: he is condemned as much to his own reason and rectitude as to his existence in an universe with no rational, and therefore no moral, center. This unresolved and insoluble conflict also contains the terrible explication of Lucan's famous sententia, victrix causa deis placuit sed victa Catoni (1. 128). In a Stoic universe, the antithesis between Catoni and deis would not be possible, since the goodness of Cato's actions would necessarily reflect the goodness of the divine order. Cato struggles against that antithesis by attempting to conform to what he understands as an immoral divine mandate. In the end, however, he can neither escape nor, as a stoic, fully accept the reality into which Lucan has placed him: the reality of a universe governed by no providence at all, benevolent or malign. Not the forces of evil, but the forces of chaos, are the gods whom it has pleased that Caesar should prevail." ${ }^{494}$
\end{abstract}

Otra forma de aproximación que, creemos, puede explicar la relevancia estructural de este pasaje es nuestra perspectiva de la disolución corporal. Lapidge sostiene que la atmósfera de disolución cósmica en Pharsalia cesa abruptamente en el libro VII, considerando la batalla el clímax del proceso de disolución del estado. ${ }^{495} \mathrm{Si}$

\footnotetext{
${ }^{492}$ Heitland, W. (1971), xxxiii-xxxiv.

${ }^{493}$ Narducci, E. (2002), 416-417.

${ }^{494}$ Sklenáŕ, R. (1999) 293-294; Narducci, E. (1979), 137-138.

495 Lapidge, M. (1979), 370:“After Book VII, where the ultimate destruction of the Roman republic is described, there is no further function for imagery of dissolution, and as far as I am aware, there is no occurrence of the image in the final three books. Lucan henceforth turns his attention to other matters, to the death of Pompey and the agôn of Cato. During the first seven books, however, the imagery of dissolution occurs in an amazing variety of forms, and it is not misleading to describe it as central to the meaning of the poem. Its use in the Pharsalia does not demonstrate that Lucan was a doctrinaire Stoic, but
} 
bien coincidimos con los parámetros generales de su perspectiva, creemos que el proceso de disolución es constante a lo largo de todo el poema y que socava permanentemente todos los niveles intra, extra y metatextuales de Pharsalia. En el nivel diegético se desarrolla la lenta pero inexorable disolución del estado romano, de sus valores y del universo, cuya acción se inscribe en el cuerpo de los hombres. Por otro lado el discurso subvierte todos sus paradigmas constitutivos: el épico, el filosófico y el estético, cuyos más altos exponentes (Virgilio, Séneca, Ennio, César, Homero, inter al.) son aludidos, citados, expandidos, desbordados y reformulados para lograr un nuevo tipo de escritura innovadora y original, donde prima una estética de la desmesura, un espacio discursivo hiperbólico que despliega un universo paradójico. ${ }^{496}$ Todo esto se logra a través de una escritura aglutinante y barroca, que se articula por medio de densos grupos turbulentos, de cuyos motivos y alteraciones se nutren los grupos que le siguen. ${ }^{497}$ De este modo, Pharsalia presenta un entramado textual complejo y vital, que se retroalimenta de la propia entropía que genera, ${ }^{498}$ de su pólemos intrínseco y de la constante interacción dinámica de elementos antagónicos.

Muchos estudiosos han notado que el ataque de las serpientes está construido con elementos de los catálogos virgilianos y homéricos: se nombra al combatiente e inmediatamente sigue un breve comentario sobre su areté y sus características distintivas. El áspid nos ofrece su veneno in nulla plus est serpente coactum - LUC. IX, 703; el hemorroo despliega sus anillos; la tórrida dípsada, el iáculo volador y el ávido prester de humeantes fauces anuncian en el nomen su facies mortis, al igual que el tabífico seps, por nombrar sólo aquellos cuyos ataques son los elegidos por el poeta has inter pestes. Las serpientes, entonces, concretizan en el entramado poético el poder de matar de la palabra: el propio nombre conlleva etimológicamente el modo de muerte.

Cierra el catálogo en lugar preponderante el $d u x$ de este ejército que, como dirán los soldados, pro Caesare pugnat. Queremos destacar otro interesante juego de paradojas que tanto agradan a Lucano: el basilisco, rey de estas huestes que atacan a los desdichados soldados de Catón, es el único que falla en el intento de matar a su víctima y, de hecho, es muerto por ella - LUC. IX, 828 y ss.). Comienzan entonces los tristia

it suggests at least that he was the inheritor of a rich tradition of Stoic cosmological vocabulary stretching back to Chryssipus, and that in the application of this Stoic vocabulary, he displayed striking originality." ${ }^{496}$ Las polémicas discusiones eruditas de la antigüedad (y del siglo XIX también) respecto de la pertenencia o no de Lucano al círculo de los poetas, su falta de adecuación a la "norma", se deben, en gran medida, a este complejo e innovador juego de fuga constante de las convenciones que plantea su poética. Concessa pudet ire via dice el poeta en LUC. II, 446.

${ }^{497}$ Deleuze, G. (2005), 13.

${ }^{498}$ Afortunadamente, la literatura no está sujeta a las leyes de la termodinámica. 
fata et insolitas parvo cum volnere mortes - LUC. IX, 735- 736), cuya estructura es particular y compleja: la concatenación de ataques se desarrolla de manera tal que el lector tiene la sensación de estar ante una batalla continua. ${ }^{499}$ Esto se logra a través de un delicado y barroco procedimiento narrativo que privilegia la expresividad en detrimento de un pretendido realismo. ${ }^{500}$

Si bien se ha destacado cómo Lucano utiliza recursos y formulas homéricas y virgilianas -la identificación de los adversarios, su areté respectiva, su apariencia distintiva, etc.- creemos que esta perspectiva se ajusta al texto sólo en principio pues, si bien respeta la dicción homérica, inmediatamente entran en juego las operaciones subversivas del autor:

"The battle itself employs a full panoply of epic devices: a catalogue of the enemy, formulaic scenes and epic similes. In addition there are the requisite echoes of Homer and Vergil which establishes a poetic genealogy and should enhance the scene. Yet these conventions serve only to heighten the grotesque element which pervades the contest with the serpents. Fifteen of the scaly opponents are listed. Twelve are identified by their Greek name, establishing their position as a foreign enemy and therefore providing that they are a suitable enemy for a Roman soldier. Each is named, and its distinguishing arete is mentioned. The types of characterization - appearance, movement, weapon- are all representatives of the qualities found in Homer's and Vergil's catalogues of warriors." 501

Lucano recurre a un procedimiento tan certero como económico: no existe combate alguno y rara vez el soldado siente la picadura mortal (vix dolor aut sensus dentis fuitLUC. IX, 739); en caso contrario, la serpiente es fácilmente muerta por su víctima LUC. IX, 763-765). En ningún momento se desarrolla un combate donde los adversarios midan sus fuerzas uno contra otro.

Aulo, el joven portaestandarte, no siente la mordida que acabará con su vida (LUC. IX, 739) y hasta tal punto pasa inadvertida la causa de su mal que la acción del veneno es confundida con la sed:

nec sentit fatique genus mortemque ueneni, sed putat esse sitim; ferroque aperire tumentis sustinuit uenas atque os inplere cruore.

(LUC. IX, $758-760)$

No percibe el género de su mal ni la muerte del veneno, sino que piensa que es sólo sed; osó abrir con el hierro sus venas hinchadas y llenó su boca con sangre.

\footnotetext{
${ }^{499}$ Batinski, E. (1991), 76:"With each death a new enemy and a new Roman soldier immediately enter the field. As soon as Aulus rushes of, the seps confronts Sabellus, mors erat ante oculos (9. 763). Ecce announces the prester as well as the iaculus which later slays Paulus $(9.789,822)$. The narrative structure of the battle induces the reader to accept this passage as a single battle."

${ }^{500}$ Valverde, J. (1985), 25-27.

${ }^{501}$ Batinski, E. (1991), 75-76.
} 
Tenemos aquí otro suicidio antiestoico impulsado por una desesperación monstruosa. El juego perturbador del paradigma filosófico posee un componente que acentúa esta operación: el abrirse las venas era la metodología habitual de los suicidios meditados, contrariamente a lo que ocurre en el poema; de hecho Lucano y su tío Séneca lo llevan a cabo con hidalguía y ánimo sereno. ${ }^{502}$ Aulo, por su parte, lo ejecuta movido por la desesperación: la imagen final del joven bebiendo su propia sangre es una prueba cabal del furor que motiva su decisión. ${ }^{503}$

La horrible muerte de Sabello es quizás el más claro ejemplo de disolución corporal:

parua modo serpens, sed qua non ulla cruentae tantum mortis habet. nam plagae proxima circum fugit rupta cutis pallentiaque ossa retexit; iamque sinu laxo nudum sine corpore uolnus. membra natant sanie, surae fluxere, sine ullo tegmine poples erat, femorum quoque musculus omnis liquitur, et nigra destillant inguina tabe. dissiluit stringens uterum membrana, fluuntque uiscera; nec, quantus toto de corpore debet, effluit in terras, saeuum sed membra uenenum decoquit, in minimum mors contrahit omnia uirus.

Serpiente pequeña, pero ninguna posee tanto poder para matar cruentamente. Pues la piel rota, cercana a la herida, desapareció y descubrió los blancos huesos; y ya hay una herida desnuda carente de cuerpo en la amplia cavidad. Sus miembros nadan en pus, las pantorrillas se derritieron, sus rodillas quedan sin piel, todos los músculos de las piernas se licuan y sus ingles destilan una oscura putrefacción. Reventó la tensa piel del estómago y fluyeron las vísceras y no manchó la tierra lo que quedaba del cuerpo, sino que el cruel veneno consume los miembros. La muerte lo reduce todo a un mínimo de ponzoña.

La terrible licuefacción de este joven sine corpore es, literalmente, la encarnación del proceso de disolución social, cósmica e individual que se desarrolla en el texto. Este proceso de descorporización continúa con un catálogo anatómico (LUC. IX, 777-783) y finalmente Sabello se derrite como las nieves ante el cálido Austro o la cera expuesta al sol. Una disolución tal no puede lograrla siquiera el fuego:

sed quis rogus abstulit ossa? haec quoque discedunt, putrisque secuta medullas

${ }^{502}$ TAC. Ann. XV, 60-63 (Séneca) \& 70 (Lucano); Narducci, E. (2002), 7-8.

${ }^{503}$ Batinski, E. (1991), 77: "Slashing the wrists was a common form of suicide. In Seneca, suicide always offers an avenue to freedom. However, Aulus does not assume a grand philosophic posture. He simply attempts to quench his thirst." 
nulla manere sinunt rapidi uestigia fati.

Cinyphias inter pestes tibi palma nocendi est:

eripiunt omnes animam, tu sola cadauer.

(LUC. IX, 784- 788)

Pero ¿qué hoguera arrebata los huesos?

Estos también se disolvieron, siguiendo a las médulas

podridas, no queda ningún vestigio de la rápida muerte.

Entre las pestes cinífeas, para ti es esta palma de matar:

Todas arrebatan el alma, sólo tú el cadáver.

He aquí un importante dato que sustenta la lectura de que en Pharsalia no nos encontramos ante una disolución cósmica generativa, una ekpyrôsis en la cual el pûr technikón regenera el universo, ${ }^{504}$ sino ante un proceso de disolución antiestoico que desemboca en el caos primigenio. ${ }^{505}$

Si en Sabello se imprimen los signos de esta disolución universal, en Nasidio se concentran los rasgos distintivos de la poética lucaniana: un discurso aglutinante que construye su impetus poético sobre sus propias excrecencias y acumulaciones discursivas.

La figura de Nasidio comienza a deformarse hasta volverse algo monstruoso:

illi rubor igneus ora

succendit, tenditque cutem pereunte figura

miscens cuncta tumor; toto iam corpore maior

humanumque egressa modum super omnia membra

efflatur sanies late pollente ueneno;

ipse latet penitus congesto corpore mersus,

nec lorica tenet distenti pectoris auctum.

(LUC. IX, 791-797)

Un rubor encendido

le inflama el rostro, la hinchazón estira su piel mezclándolo todo

mientras su forma muere; una putrefacción más grande

que el cuerpo entero y que rebasa los límites humanos se expande

al potenciarse el veneno; él mismo queda oculto, sumergido en lo profundo de su cuerpo inflamado, y la coraza no puede contener el crecimiento del pecho hinchado.

${ }^{504}$ Lapidge, M. (1979), 346-347; Sklenár̆, R. (1999), 283-285.

${ }^{505}$ Sklenáŕ, R. (1999), 283-284:"Lucan formulates this reality in such a way as to contradict the Stoa's rationalistic conception of fatum. A cornerstone of Stoic doctrine is that nothing is arbitrary; thus fatum, casus, fortuna, natura, in Stoic Latin signify the providential order and are regularly interchangeable with terms for divinity itself, god being inseparable from nature and reason $(\log o s)$. Lucan, by contrast, postulates a fatum whose destruction of Rome corresponds to the return of primeval chaos, a concept which has no place in the stoic scheme. Like everything else in Stoic cosmology, ekpyrôsis is a rational process, part of a regular cycle of death and regeneration." 
El cuerpo desborda su forma armónica del mismo modo que la materia poética sobrepasa los límites impuestos por la coraza del decus clásico y se entrega a un juego de alusiones y transformaciones de sus referentes literarios más importantes $:^{.506}$

spumeus accenso non sic exundat aeno undarum cumulus, nec tantos carbasa Coro curuauere sinus. tumidos iam non capit artus informis globus et confuso pondere truncus. intactum uolucrum rostris epulasque daturum haud inpune feris non ausi tradere busto nondum stante modo crescens fugere cadauer.

No se derrama así en el caldero hirviente el cúmulo espumoso de agua ni las velas se hinchan en cavidades tan grandes a causa del Coro. Ya no contiene los miembros hinchados el deforme globo ni el tronco con su masa sin perfiles. $\mathrm{Al}$ cadáver, que no fue tocado por el pico de los buitres y que alimentaría, no sin daño a las fieras, no se atrevieron a entregarlo a la hoguera.

Lucano, evidenciando su maestría y genio poético, imprime en el ámbito corporal lo que Virgilio despliega en el plano emocional y, redoblando la apuesta, evoca inversamente nada menos que el proemio de Ilíada, ${ }^{507}$ tal como desarrollamos en el apartado 'LA REPRESENTACiÓN DE LA MUERTE EN SÉNECA Y LUCANO’. En Pharsalia las turbulencias cósmicas y discursivas se inscriben en el cuerpo de los soldados quienes, a diferencia de los héroes homéricos, ni siquiera serán pasto de las aves.

Tullo es mordido por un áspero hemorroo, brindando unos maiora spectacula (LUC. IX, 809-814). Si antes el cuerpo se disolvía por completo o se deformaba en masas superpuestas, aquí, de manera maquínica, el cuerpo se vuelve sólo herida:

sanguis erant lacrimae; quaecumque foramina nouit
umor, ab his largus manat cruor; ora redundant
et patulae nares; sudor rubet; omnia plenis
membra fluunt uenis; totum est pro uolnere corpus.

Sangre eran las lágrimas; cualquier orificio que utilizan los humores, de estos mana abundante sangre; le desborda su boca y sus fosas nasales; el sudor enrojece; todos sus miembros fluyen a venas abiertas; el cuerpo entero es una herida.

Las muertes de Levo y Paulo son, en cambio, instantáneas: el poderoso veneno del áspid actúa de manera fulminante. Paulo, por su parte, es atacado por un iáculo, único animal que no recurre al veneno para cumplir su cometido y única serpiente con

\footnotetext{
${ }^{506}$ Batinski, E. (1991), 77-78; Ketterer, R. (2003), 1: "Moreover, the Baroque age, as Robert Harbison has written, 'is set apart from what precedes it by an interest of movement above all, movement which is a frank exhibition of energy and escape from classical restraint'.,

${ }^{507}$ VERG. A. VII, 464-466; HOM. Il. I, 4-5.
} 
etimología latina en este episodio. Llegamos finalmente al basilisco, paradójicamente el rey de las serpientes, que no puede siquiera herir a su víctima, aunque su potente veneno alcanza la mano de Murro iniciando el contagio:

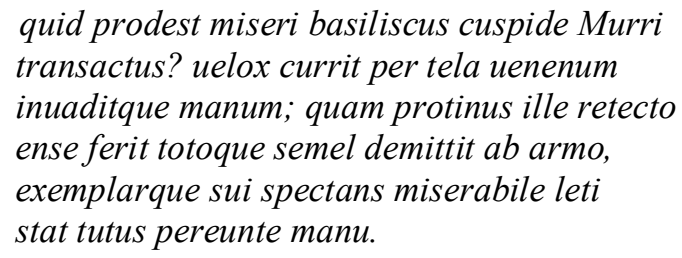

Reaparece la imagen de las manos cercenadas, en este caso pereciendo pro corpore. Se produce nuevamente un juego lucaniano de reformulación de los elementos constitutivos de su discurso poético.

Las serpientes son una manifestación más del caos engendrado por la disolución del estado romano y de los valores de éste, hasta tal punto que los soldados preferirían regresar a la mismísima batalla de Farsalia:

'reddite, di,' clamant 'miseris quae fugimus arma, reddite Thessaliam. patimur cur segnia fata in gladios iurata manus? pro Caesare pugnant dipsades et peragunt ciuilia bella cerastae.

¡Devolved, dioses, - exclaman- a estos desdichados las armas de las que huimos, devolvednos Tesalia! ¿Por qué padecemos muertes deshonrosas, si somos una tropa que ha jurado sobre las espadas? ¡Por César luchan las dípsadas y completan las guerras civiles las cerastas!

El ataque de las serpientes se adecua de modo más natural al desarrollo de Pharsalia si se lo considera como una manifestación particular y específica del proceso de disolución universal más que como una manifestación de la virtus de Catón, quien sólo aparece muy marginalmente en la narración. El episodio es, específicamente, un ataque contra los corpora de los duros soldados. Lucano selecciona las muertes más espectaculares para confeccionar, con una técnica expresionista, este collage macabro. Sin embargo también deja entrever que éstas no son las únicas amenazas que enfrentan 
los soldados, que se exponen a otras horribles y variadas formas de muerte (LUC. IX, 833- 846). El poder deformador de las serpientes es una manifestación más de la guerra civil que revela la magnitud extrema de este proceso de disolución de toda conpages. ${ }^{508}$

${ }^{508}$ Bexley, E. (2010), 140-142. 


\section{RECAPITULACIÓN Y CONCLUSIONES PARCIALES}

Lucano despliega en Pharsalia una épica paradójica, enérgica y muchas veces contradictoria. El desorden del mundo y el caos inherente a la guerra civil repercuten en el lenguaje de manera directa de modo que el horror de este enfrentamiento fratricida se plasma tanto en el cuerpo de la escritura como en el de los individuos de maneras diametralmente opuestas: en el plano diegético el universo y el cuerpo, tanto social como individual, se ven sometidos a un inexorable y progresivo proceso de disolución mientras en el plano discursivo se produce una aglutinación sígnica cuyas operaciones crean un constante efecto de fuga y de subversión de sus paradigmas constitutivos.

Vimos cómo en los pasajes estudiados se despliega progresivamente, a través de un lenguaje hiperbólico y desmesurado, los elementos lingüísticos que, sometidos a las corrosivas operaciones discursivas, se ven metamorfoseados no in nova corpora sino en cosas informes y monstruosas. Se subvierten entonces los paradigmas constitutivos del poema, el épico, el filosófico y el estético: los cuerpos se ven sometidos a tensiones y fuerzas que, contrariamente al efecto cohesivo que poseían el pneûma y el tónos en la cosmología estoica, los mutilan y dispersan al mismo tiempo que nos permiten vislumbrar las características furiosas de la militiae pietas y de la virtus.

A lo largo del poema, toda estructura, universal, artificial o corporal, es destrozada, mutilada, aplastada, disuelta o deformada. El pneûma universal que cohesiona los elementos y que origina el tónos y la sympátheia de todas las formas hace que macro y microcosmos sufran consecuencias análogas y equivalentes, dándose, en términos de los diversos niveles de la conpages, la siguiente relación:

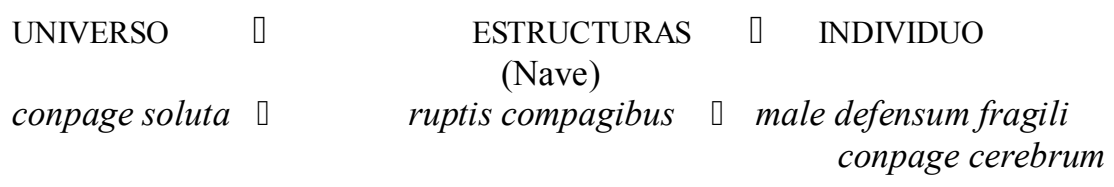

Los episodios de la batalla naval y el suicidio de los hombres de Vulteyo aglutinan los elementos que forman parte del proceso de disolución y subversión, que alcanzan su punto máximo en la aristeia de Esceva y el ataque de las serpientes.

Esceva es la encarnación de una virtus vaciada de contenido y completamente resignificada por el accionar del discurso lucaniano. El episodio de las serpientes en el 
libro IX despliega, por su parte, la inscripción objetiva de la disolución universal en la carne. Las serpientes son una manifestación más de la guerra civil y su ataque se enmarca como una agresión contra la integridad de los cuerpos de los soldados; los efectos de los variados virus reflejan las características distintivas del discurso poético. Las muertes de Sabello y Nasidio resultan paradigmáticas: sus cuerpos encarnan los efectos de la disolución (en el plano diegético) y de la aglutinación masiva (en el plano discursivo). El efecto del veneno sobre el cuerpo de Nasidio reproduce la violencia ejercida por las operaciones lucanianas sobre la lengua poética: el discurso se vuelve sobre sí mismo y desborda su forma agrupándose en masas superpuestas. Los episodios estudiados muestran cómo Pharsalia despliega un discurso donde la disolución del cuerpo social e individual se lleva a cabo a través de operaciones discursivas aglutinantes y corrosivas que se vuelven contra los elementos constitutivos del entramado poético, creando así una estética paradójica, original y personal. 


\title{
VII. LOS DIOSES Y EL APARATO DIVINO: EL SILENCIO DE DIOS
}

\author{
"Suele decirse que el poeta, o el genio, \\ se adelanta a su época. Es cierto, \\ pero solamente debido a que también es \\ un ser profundamente de su época."
}

\section{INGMAR BERGMAN Y EL SILENCIO DE DIOS}

La recuperación y reevaluación de las obras de Séneca y Lucano en las décadas de postguerra no resulta fortuita. Lucano es un poeta cuya obra resuena poderosamente a la luz de los hechos ocurridos en el siglo XX, pródigo en horrores. Tampoco extraña que el interés por una obra como Pharsalia haya cobrado renovado vigor luego de la Segunda Guerra Mundial. Al respecto dice Shadi Bartsch:

"The collapse of the autonomous individual amid the wreck of linguistic systems and subject-object relations, the hopelessness of meaningful narrative in a meaningless world, the impossibility of representing the trauma of Romans killing Romans [...] All these are undeniable aspects of Lucan's epic world, and for readers of our times I think they more than undeniable: they ring true with an evocation of particular horrors of the twentieth century. Lucan's attempt to convey what he would represent as the unspeakable physical and psychological brutalities of the civil wars of the first century B.C. fastens, uncannily enough, upon the actual truths of what happened to the human subject in extremis and on the realities of the social and psychic results of the totalitarian agenda, and so he produces a picture that has curious resonances in the history of our own century."

El siglo XX no se diferencia de otros siglos por las muertes y los asesinatos, si bien los supera en número, sino por las novedosas y particulares formas de matar que despliega: Hiroshima, Nagasaki, Nankín o Auschwitz se destacan, lamentablemente, en una plétora de genocidios y matanzas avaladas, usualmente, por los distintos estados nacionales e internacionales y llevadas a cabo a través de un uso eminentemente instrumental de la razón. ${ }^{511}$ La afinidad entre la situación existencial del individuo lanzado a un mundo absurdo representada en la obra de Séneca y Lucano y la sensibilidad subjetiva de los años de posguerra resulta perturbadoramente cercana. La violencia textual de Pharsalia, tanto a nivel diegético de la representación como en el nivel morfológico y sintáctico, encuentra en nuestro tiempo una caja de resonancia particularmente receptiva a estas

\footnotetext{
${ }^{509}$ Miller, H. (1993), 7.

${ }^{510}$ Bartsch, Sh. (1997), 66.

${ }^{511}$ Vattimo, G. (1991), 16-17.
} 
operaciones poéticas, las cuales podemos analizar como precursoras de importantes e innovadoras corrientes artísticas y filosóficas del siglo XX. La angustia del individuo ante el absurdo de la existencia que proclamaban los existencialistas franceses puede encontrarse constantemente presente en boca del narrador del poema. Según Camus, lo absurdo nace de la confrontación irremediable e irresoluble entre el llamado a comprender el mundo por parte del hombre y el silencio irremediable de éste: ${ }^{512}$

"Esta razón universal, práctica o moral, este determinismo, estas categorías que explican todo son como para hacer reír al hombre honrado. Nada tienen que ver con el espíritu. Niegan su verdad profunda: que está encadenado. En este universo indescifrable y limitado adquiere en adelante un sentido distinto del hombre. Una multitud de elementos irracionales se ha alzado y lo rodea hasta su fin último. [...] Todo lo que se puede decir es que este mundo, en sí mismo, no es razonable. Pero lo que resulta absurdo es la confrontación de ese irracional y ese deseo desenfrenado de claridad cuyo llamamiento resuene en lo más profundo del mundo. Es por el momento su único lazo. Une el uno al otro como sólo el odio puede unir a los seres. Eso es todo lo que puedo discernir claramente en este universo sin medida donde tiene lugar mi aventura." 513

La angustia del individuo ante lo absurdo del mundo es un rasgo que la obra de Lucano despliega casi mil novecientos años antes de que los primeros pensadores existencialistas escribieran sus obras, a mediados del siglo XIX. ${ }^{514}$

A principios de la década del 60 Ingmar Bergman estrena su trilogía "El Silencio de Dios", cuyos títulos son: Såsom $i$ en spegel, "Como en un espejo" (1961), Nattvardsgästerna, "Luz de Invierno"/ "Los comulgantes" (1962) y Tystnaden, "El silencio" (1963). No nos interesa particularmente realizar un estudio comparativo entre la obra de Bergman y las de Séneca y Lucano sino resaltar las cercanías y afinidades de las correspondientes representaciones del universo existentes entre estos disímiles artistas. Estas representaciones, separadas por mil novecientos años, resultan perturbadoramente cercanas: los personajes se encuentran enfrentados a un mundo absurdo y sin sentido aparente y en el cual los dioses están, cuanto menos, ausentes. Los

\footnotetext{
${ }^{512}$ Camus, A. (1951), 38; Sherman, D. (2006), 276-278.

${ }^{513}$ Camus, A. (1951), 31-32.

${ }^{514}$ Dreyfus, H. \& Wrathall, M. (2006), 3-5, cf. especialmente 4: “[...] existentialism as a movement starts its analysis with the existing individual - the individual engaged in a particular world with a characteristic form of life. Thus an emphasis on the body (see Chapter 17) and on the effective rather than the rational side of human being (see Chapter 16) are characteristic of existentialism. For existentialist thinkers, the focus is on uncovering what is unique to that individual, rather than treating her as a manifestation of a general type. Existentialism thus tend to be anti-essentialist, to deny that there are essential features or properties that determine the being of a thing. Many go further and insist that the world is not just lacking essence, but absurd, and thus incapable of being made sense (see Chapter 19). Indeed, existentialist like Sartre and Camus argue, human being itself is rendered meaningless and absurd by the inevitability of death (see Chapter 20). With their focus on the individual and a denial of any meaningful sense of what constitutes an essential or absolute goal for human existence, existentialism emphasize human freedom and responsibility (see Chapter 18), and hold that the only goal consistent with that freedom and responsibility is to live authentically.” Cf. también Dreyfus, H. (2006), 159.
} 
personajes de Bergman son individuos enfermos, no sólo física y psíquica sino también espiritualmente. La trilogía sobre el silencio de Dios no trata ni indaga específicamente sobre la existencia o no de éste sino que es una brutal mirada a la desesperada condición humana y a los procesos de incomunicación que en ella tienen lugar. ${ }^{515}$ El universo de Bergman es atroz y angustiante y, en él, Dios no existe o, en caso contrario, hace oídos sordos a las plegarias desesperadas de sus fieles: es un Dios-eco, un dios monstruoso o un Dios inexistente, de acuerdo con la visión personal de cada personaje. ${ }^{516}$

En Nattvardsgästerna, el silencio de Dios derrumba la vida del pastor protestante que ha perdido la fe y cuya existencia se ha convertido, tal como lo muestra la magnífica secuencia inicial de la película, en un rito vaciado de significado pero ejecutado sin embargo con rigurosa mecanicidad, de modo similar quizás, a las sesiones del senado durante el siglo I d.C. La trilogía resulta una representación despiadada del absurdo de la existencia donde la única y remota posibilidad de redención -que se puede encontrar en Såsom i en spegel - se da cuando el hijo de David, Minus, pronuncia las palabras finales plenas de un profundo simbolismo: “(Mi/El) Padre me ha hablado (Father talked to me)". ${ }^{517}$ Nada de esto ocurre en Nattvardsgästerna, donde no se vislumbra posibilidad de redención alguna para los personajes atrapados en las redes de sus propias imposibilidades existenciales, y cuya conclusión inexorable podemos ver plasmada en la infernal relación de las dos hermanas atrapadas en el hotel de Timoka:

"La pasividad de Dios ante la atrocidad que rodea a Tomas tiene su conclusión lógica en El silencio. La imposibilidad de la existencia de un ser superior es nuevamente trasladada a la pantalla por medio del silencio del todopoderoso ante una realidad angustiosa y asfixiante. El silencio del tren en que comienza la acción mientras, al otro lado de sus ventanas, estallan las bombas de una guerra distante e incierta, permite a Bergman situar la historia en un mundo literalmente dejado de la mano de Dios. La imaginaria ciudad de Timoka pasa así a convertirse en una suerte de espacio simbólico de nuestro planeta, con sus conflictos bélicos, su incomunicación, su falta de amor y, especialmente, con su silencio de Dios. ${ }^{„ 518}$

$[\ldots]$

"Winter Light, though commercially unsuccessful, seems to me the strongest of the three films. Directly related to its predecessor, it is again a story of the way God is destroyed. The opening scene takes place in a church. Thomas Ericsson, the pastor prays. '... Thy will be done on earth as it is in heaven...' and the camera shifts to a series

\footnotetext{
${ }^{515}$ Alexander, W. (1974), 32; Adams, R. (1975), 226-227.

${ }^{516}$ López Laboreiro, J. (2008): “La certeza de la que habla Bergman en 'Imágenes' no se convertirá en desvelada hasta que el pastór dé el paso conceptual de un Dios monstruoso a un Dios-eco, únicamente capacitado para devolverle sus angustiadas preguntas. Ese Dios-eco del que se extrae necesariamente el silencio divino del que se vale Marta Lundberg (Ingrid Thulin) para justificar la no existencia de un ser superior - y que aparece sintetizado en la demoledora frase 'Dios no existe', con la que la feligresa golpea figuradamente al pastor en un momento del filme-.."

${ }^{17}$ Steene, B. (1970), 29-30.

${ }^{518}$ López Laboreiro, J. (2008), passim.
} 
of exterior scenes of snow and cold. This is the condition on earth; this is the climate of the human heart. [...] In Winter Light there is no positive example of conversion such as Minus constitutes in the prior film. [...] The Silence concludes the trilogy - a trilogy that begun with the examination of the nature and obligations of human freedom, continued with a story about man's failure to use that freedom, and finishes with a depiction of the hell to which such failures leads." ${ }^{\circ 519}$

En el mundo devastado de la trilogía, uno de los temas preponderantes resulta ser la imposibilidad de comunicación: ${ }^{520}$

“These children are growing into the terrible reality of Bergman's world, a world without Mother and Father, where God is silent, perhaps indifferent or hostile. [...] In the world of Sweden's brief northern winter light; as the camera moves to a close-up of Thomas' eyes and mouth, and as Thomas cries 'Why has Thou forsaken me' [luego de haber desestimado el desesperado pedido de ayuda del pescador y empujarlo al suicidio] this light intensifies and intensifies the aloneness, loss, and doubt. It is a world of cold, uncaring nature - at the rapids we cannot distinguish the body among other objects at first, we remain at a distance, cannot hear voices drowned by wind and water, and watch the slow passing of the man, while our lives dwindle. It is a world where fathers study disintegration of their children, where perhaps the closest positive relation leads to incest, where people shred the psyches of others and lovemaking has been hollowed into mere sexual shell. It is the world of Jona's atomic bomb and hating Chinese, of tanks in the streets of Timoka, of the Spanish Civil War, whose God, Tomas inadvertently reveals, can only be a hateful, ugly Spider God. It is a world which makes it very difficult for one to answer Jona's piercing question, 'Why must we live?' Bergman's children face this world." 521

No abundan los niños en la tragedia de Séneca, y cuando aparecen, es sólo para morir. Sin embargo, personajes como Tiestes o Hipólito se encuentran, en los momentos de mayor pathos, ante el silencio de los dioses o, más precisamente, ante estos dioses-eco.

\section{LOS DIOSES-ECO EN SÉNECA}

Las tragedias de Séneca despliegan características y procedimientos que luego son retomados y exacerbados en la épica de Lucano: de modo que la representación de la angustia y la desesperación de los personajes durante los momentos culminantes de la acción dramática es retomada en Pharsalia a través de la voz del narrador. La tragedia de Séneca nos muestra universos vacíos o vaciados de la confortable presencia de númenes y dioses: las palabras finales de Jasón (Med. 1026-1027) son un claro ejemplo de la condición del sujeto abandonado en un universo de estas características. Creemos que la representación divina, tanto en las tragedias como en Pharsalia, a través del

\footnotetext{
${ }^{519}$ Adams, R. (1975), 228-229. Cf. También Steene, B. (1970), 24.

${ }^{520}$ Steene, B. (1970), 32-33.

${ }^{521}$ Alexander, W. (1974), 25-26.
} 
procedimiento que Thomas Rosenmeyer ha denominado the syntax of deflection, posee enormes afinidades con lo que Bergman ha llamado el silencio de Dios y con lo que ha plasmado en su trilogía homónima. Dice Rosenmeyer al respecto:

"The syntax of deflection is an extraordinary interesting topic. I said earlier that Seneca's supposed rant is not a matter of diction but a function of his syntax and the emotional energies heralded by the syntax. The character of that syntax may be summarized by saying that it forsakes assertion or description for modalities. Of the many striking modes of the grammar of tirade, six may be singled out and illustrated by pointing to the lines in the outburst of Thyestes cited above. First, there are the imperatives (1015), addressed to gods, to environmental bodies, and to the speaker's own organs and faculties as if they were independent of his control and cognate with the cosmic faculties (which, of course, as we have seen, they are). These vast bulk of imperatives in Seneca are not practicable orders or request urged upon plausible executors, but 'rhetorical' imperatives, that is, imaginary, inoperable, and channeled towards levels of authority unresponsive to the 'speaker's wishes, precisely because the distance between the speaker and the addressee is unfathomable. Second, there are the jussives and injunctives (1016-1019), third-person imperatives directed at the same addresses as the second-person imperatives, and equally unpromising, but by dint of the impersonality of the construction investing less of the agents' ego in the pronouncements. The third variety is one signaled by words like debet or decet, in the present or the past tense (1011-12), a formulation marking off the speaker's sense of what moral or aesthetic standards would seem to demand. Like the other moves it pleads a demonic decorum: a monstrous event is invoked as befitting a sense of monstrous passion." ${ }^{, 522}$

El indignado discurso de Hipólito luego de que Fedra le revela sus verdaderas intenciones para con él es un buen ejemplo de este procedimiento particular:

Magne regnator deum, tam lentus audis scelera? tam lentus uides? et quando saeua fulmen emittes manu, si nunc serenum est? omnis impulsus ruat aether et atris nubibus condat diem, ac uersa retro sidera obliquos agant retorta cursus. tuque, sidereum caput, radiate Titan, tu nefas stirpis tuae speculare? lucem merge et in tenebras fuge. cur dextra, diuum rector atque hominum, uacat tua, nec trisulca mundus ardescit face? in me tona, me fige, me uelox cremet transactus ignis: sum nocens, merui mori: placui nouercae. dignus en stupris ego?

(Phaed. 671-684)

Gran rey de los dioses, ¿Tan lento escuchas estos crímenes? ¿Tan lento los contemplas? ¿Cuándo lanzarás tu rayo con mano cruel, si ahora el cielo está despejado? Que todo el eter caiga derrumbado y esconda el día con negras nubes,

${ }^{522}$ Rosenmeyer, Th. (1989), 182. 
y que los astros regresen, recorriendo hacia atrás

sus oblicuos cursos. y Tú, cabeza de los astros,

radiante Titán, contemplas la impiedad de tu estirpe?

Hunde tu luz y huye hacia las tinieblas.

¿Por qué, señor de los dioses y de los hombres, está vacía

tu mano y no arde el mundo con tu triple antorcha?

Truena contra mí, atraviésame, que, atravesado, me reduzca a cenizas

tu fuego veloz: soy culpable, merezco morir.

Enamoré a mi madrastra. ¿Acaso yo te he parecido digno de estupro?

¿Dónde están los dioses? ¿Por qué Júpiter no actúa ante tamaña monstruosidad? Un indignado Hipólito lanza estos interrogantes desesperados a los cielos vacíos y sus preguntas e imprecaciones no reciben respuesta alguna excepto el eco silencioso de los dioses ausentes, inexistentes o indiferentes. Luego, él mismo se propone como víctima expiatoria, tal como Catón lo hace en el libro II de Pharsalia, a través del ritual de la devotio (LUC. II, 680-686).

Tiestes, por su parte, al contemplar el cielo vaciado de estrellas y constelaciones, sospecha lo peor:

uix lucet ignis; ipse quin aether grauis inter diem noctemque desertus stupet. quid hoc? magis magisque concussi labant conuexa caeli; spissior densis coit caligo tenebris noxque se in noctem abdidit: fugit omne sidus. Quidquid est, fratri precor natisque parcat, omnis in uile hoc caput abeat procella. Redde iam natos mihi!

Apenas alumbra el fuego; es más, el propio éter, pesado y desierto vacila entre el día y la noche ¿Qué es esto? Se derrumba más y más la bóveda conmovida del cielo; una oscuridad más espesa que las densas tinieblas se levanta y la noche se repliega en la noche: huye todo astro. Cualquier cosa que sea, ruego que perdone a mi hermano y a mis hijos, ique caiga la tormenta entera sobre esta vil cabeza!

Sigue a este pedido uno de los momentos de mayor innovación teatral que muestra a las claras hasta qué punto Séneca es un autor trágico técnicamente impecable y cuyo manejo de las convenciones del género le permite incluso subvertir uno de los procedimientos trágicos por excelencia, la anagnórisis: agnosco fratrem dice Tiestes en el verso 1006. A diferencia del Edipo Rey, donde Sófocles combina anagnórisis y peripecia de manera simultánea en un momento culminante de pathos, Thyestes ofrece un proceso externo e inverso: el personaje no se reconoce a sí mismo o descubre un 
aspecto específico de su subjetividad, sino que reconoce a un "otro" que se revela en todo su esplendor criminal. El discurso del personaje no se dirige, en un primer momento, a los superi, sino que apela a divinidades ctónicas y primigenias: ${ }^{523}$

\section{Sustines tantum nefas}

gestare, Tellus? non ad infernam Styga tenebrasque mergis rupta et ingenti uia ad chaos inane regna cum rege abripis? non tota ab imo tecta conuellens solo uertis Mycenas? stare circa Tantalum uterque iam debuimus. Hinc compagibus et hinc reuulsis, si quid infra Tartara est auosque nostros, hoc tuam immani sinu demitte uallem nosque defossos tege Acheronte toto. Noxiae supra caput animae uagentur nostrum et ardenti freto Phlegethon harenas igneus totas agens exilia supra nostra uiolentus fluat immota tellus pondus ignauum iacet, fugere superi.

¿Soportas, tierra, que se geste una impiedad tan grande? ¿No te hundes en la infernal Estigia $\mathrm{y}$ en las tinieblas y destrozada en un enorme pozo arrastras hacia el caos inane al reino junto con el rey? ¿No derrumbas Micenas arrancando todos los techos desde sus profundos cimientos? Ambos debimos ya estar junto a Tántalo. Destrozadas las estructuras por aquí y por allá, si algo existe debajo del Tártaro y de nuestro abuelos, arroja tu valle en un enorme agujero y cúbrenos sepultados por el Aqueronte entero. Que vaguen las almas impuras sobre nuestras cabezas y que el ígneo Flegetón de aguas ardientes, arrastrando toda su arena, fluya violento sobre nuestro exilio. La tierra, inconmovible, yace como un peso muerto. han huido los dioses.

Destrozada la estructura del universo, el individuo, lejano a los dioses, anhela hundirse en las tinieblas primigenias y refugiarse en las profundidades más absolutas de la creación, aun por debajo de los infiernos. Al contemplar los restos de sus hijos, dice:

${ }^{523}$ Tarrant, R. (1985), 230: “1006-21 The first of three impassioned speeches by Thyestes as the full horror of the crime comes home to him (the others are 1035-51 and 1068-96) each appeals for a response to his enormous evil: this speech invokes Earth and the underworld, the second turns to Atreus and Thyestes himself (1043-47), and the third call on every realm of the world (1068-72) before addressing itself to Jupiter (1077-92). These appeals are all unheard or thwarted, and each of these speeches consequently ends in frustration and incompleteness, reflected in the weak rhetoric of their closing lines. Thyestes is denied the verbal satisfaction of a powerful sententia as he is the emotional support of seeing the world react as he would want it to." 
Hoc est deos quod puduit, hoc egit diem auersum in ortus. Quas miser uoces dabo questusque quos? quae uerba sufficient mihi?

(Thy. 1035-1037)

Esto fue lo que avergonzó a los dioses, esto obligó al día a regresar a su nacimiento. ¿Qué voces alzaré desdichado, qué lamentos? ¿Qué palabras me serán suficientes?

Ignorados sus gritos por las divinidades y por los espacios ctónicos, Tiestes vuelve sus plegarias e imprecaciones hacia la Naturaleza toda, hacia la Noche, hacia los dioses e incluso, nuevamente, hacia los propios infiernos que desoyeron sus plegarias anteriores: ${ }^{.24}$

\section{Clausa litoribus uagis}

audite maria, uos quoque audite hoc scelus, quocumque, di, fugistis; audite inferi, audite terrae, Noxque Tartarea grauis et atra nube, uocibus nostris uaca (tibi sum relictus, sola tu miserum uides, tu quoque sine astris), uota non faciam improba.

pro me nihil precabor - et quid iam potest pro me esse? Vobis uota prospicient mea. tu, summe caeli rector, aetheriae potens dominator aulae, nubibus totum horridis conuolue mundum, bella uentorum undique committe et omni parte uiolentum intona, manuque non qua tecta et immeritas domos telo petis minore, sed qua montium tergemina moles cecidit et qui montibus stabant pares Gigantes, hac arma expedi ignesque torque. Vindica amissum diem, iaculare flammas, lumen ereptum polo fulminibus exple. Causa, ne dubites diu, utriusque mala sit; si minus, mala sit mea: me pete, trisulco flammeam telo facem per pectus hoc transmitte. Si natos pater humare et igni tradere extremo uolo, ego sum cremandus.

(Thy. 1068-1092)

Escuchad, mares atrapados por costas imprecisas, escuchad vosotros también este crimen, Dioses, a dónde quiera que hayáis huido; escuchadme Dioses infernales, escuchad, tierras y tú, noche tartárea, también densa por negras nubes, recibid nuestros gritos, (He sido abandonado para ti, tú sola me contemplas desdichado, tú también carente de astros), No haré votos ímprobos, no pediré nada para mí, y qué podría haber para mí? Mis votos pedirán por vosotros. Tú, alto señor del cielo, poderoso dueño de los espacios etéreos, envuelve al mundo entero en horridas nubes, desata por todos lados la guerra

${ }^{524}$ Tarrant, R. (1985), 237-241. 
de los vientos y truena violento por todas partes,

con tu mano, no con la que atacas con tus rayos menores

los techos y las casas inocentes, sino aquella por la que cayó

la triple mole de los montes y los gigantes que se alzaban

iguales a los montes, con ésta prepara las armas

y agita tus fuegos. Venga el día perdido,

arroja tus llamas y llena con tus rayos la luz

arrebatada al polo. Ambas causas, no lo dudes más,

son malvadas, al menos, la mía es malvada:

atácame, atraviesa tu llama de triple punta

por este pecho. Si como padre quiero enterrar

a mis hijos y entregarlos al fuego último,

yo debo ser cremado.

La estructura de la plegaria es, en general, paralela a la de Hipólito: se invoca a dioses ausentes, inexistentes o indiferentes cuya respuesta es el silencio o el eco por lo que, ante la pasividad divina frente a tan horrendo crimen, el individuo se ofrece a sí mismo como blanco de la violencia de los dioses, pues ésta es preferible a su indiferencia o a su inexistencia. Sin embargo, hasta este magro consuelo le está vedado al hombre: ${ }^{525}$

Si nihil superos mouet

nullumque telis impios numen petit, aeterna nox permaneat et tenebris tegat immensa longis scelera. Nil, Titan, queror, si perseneras.

Si nada conmueve a los dioses y ningún numen castiga a los impíos con sus flechas, que permanezca eterna la noche y se cubran los crímenes inmensos con largas tinieblas. De nada me quejo, Titán, si perseveras.

No existe para los dioses preocupación alguna por los asuntos mortales ni escuchan sus plegarias, son, en la tragedia, dioses ausentes, dioses-eco o si no, tal como sucede en Como en un espejo, dioses monstruo. ${ }^{526}$ El narrador de Pharsalia comparte y exacerba este sentimiento de angustia ante el absurdo de la existencia:

\footnotetext{
${ }^{525}$ Volk, K. (2006), 194.

${ }^{526}$ Tarrant, R. (1985), 241: “1092-93 si ... petit: Thyestes retreats another step; nihil and nullus show that he has given up looking for any response from the gods."; Steene, B. (1970), 29-30: "How we experience God depends on the parental image we carry with us through life. In Through a Glass darkly, David, the father and writer-in-crisis, is crucial to the way his two children feel about God. To Karin, the sick girl who is exploited by her father as an interesting literary subject, God appears as an enormous spider coming out of the closet to devour her. [...] Winter Light's main character, the pastor Tomas Ericsson, has to face one of his parishioners, the suicidal fisherman Jonas Persson. But instead of offering the frightened Jonas any Word of consolation, Tomas, the father of the flock, tells his parish 'child' of his own doubts and of the time when his God changed from a 'security God' to a 'spider God': '[...] Every time I confronted God with the reality I saw, he became ugly, revolving, a spider god - a monster'.”
} 


\author{
sunt nobis nulla profecto \\ numina: cum caeco rapiantur saecula casu, \\ mentimur regnare Iouem. spectabit ab alto \\ aethere Thessalicas, teneat cum fulmina, caedes? \\ scilicet ipse petet Pholoen, petet ignibus Oeten \\ inmeritaeque nemus Rhodopes pinusque Mimantis, \\ Cassius hoc potius feriet caput? astra Thyestae \\ intulit et subitis damnauit noctibus Argos: \\ tot similis fratrum gladios patrumque gerenti \\ Thessaliae dabit ille diem? mortalia nulli \\ sunt curata deo.
}

(LUC. VII, 445-455)

Sin duda no existe dios alguno

para nosotros: cuando las generaciones son arrasadas por el ciego azar nos mentimos al afirmar que Júpiter gobierna el mundo. ¿Contemplarás desde el alto éter, mientras retienes tus rayos, las masacres tesálicas? Seguramente él mismo atacará el Foloe, atacará al Eta con sus fuegos y a los inocentes bosques del Ródope y a los pinos del Mimante, en cambio, ésta cabeza la herirá antes Casio? Se llevó los astros para Tiestes y condenó a Argos a una súbita noche: a Tesalia, que porta tantos gladios iguales de hermanos y padres, él mismo le concederá el día? No tienen los dioses preocupaciones mortales.

Sólo el genio de Lucano, a quien incluso el propio Quintiliano le reconocía una superlativa capacidad para componer sentencias (ardens et concitatus et sententiis clarissimus, lo llama), ${ }^{527}$ puede resumir un estado existencial tan complejo e inasible en sólo tres palabras - mentimur regnare Iovem. El narrador de Pharsalia impreca constante y obsesivamente a los dioses, dice La Fico Guzzo al respecto:

"La señal más evidente, que nos alerta acerca de la estrechez de una interpretación que considere racionalista y antropocéntrica a la Farsalia, es el hecho de que, aunque los dioses no intervienen como personajes, es llamativa la constante referencia a ellos, que a lo largo de la obra llega a manifestarse como una verdadera obsesión del poeta. Ya sea para reprocharles, suplicarles, dudar acerca de su existencia, de su moralidad o desear que se manifiesten, las referencias a los dioses constituyen un hilo conductor a lo largo de toda la trama de la epopeya (ejs.: Phars. VII 58-59; VII 869-870; VII 657-658). Las consultas a los oráculos (Delfos, Phars. V 65-236; Júpiter Hamón, Phars. IX 511-586), las interpretaciones de augurios por parte de adivinos (Arrunte, Phars. I 584-638), la presencia de astrólogos (Nigidio Fígulo, Phars. I 639-672), bacantes (Phars. I 673-695), sacerdotes (Acoreo, Phars. X 172-331), hechiceras (Ericto, Phars. VI 413-830), la manifestación de prodigios divinos (Phars. I 523-583; Phars. VII 151-213), las narraciones de relatos míticos (Hércules y Anteo, Phars. IV 593-655; Medusa, Phars. IX 619-699; Apolo y Pitón, Phars. V 71-85; Tritón, Palas, Hércules y el jardín de las Hespérides, Phars. IX 348-358), la aparición de Roma como la diosa Cibeles (Phars. I 183- 192), las plegarias o imprecaciones dirigidas a los dioses ya sea individuales o grupales (ej.: César en Phars. I 193-203, en Phars. VII 311-315; en Troya, Phars. IX

${ }^{527}$ QUINT. Inst. X, 1, 90; Heitland, W. (1971), lxv-lxvii. 
990-999; imprecaciones del pueblo por la crueldad de los dioses, Phars. VII 724-725), la asignación de la categoría de dioses a determinados personajes o su equiparación con parámetros divinos (Nerón, Phars. I 63; César, Phars. V 536-537; Pompeyo, Phars. VIII 869-872; Catón, Phars. IX 601-604), y hasta la exposición de doctrinas filosóficas que incluyen nociones acerca de la divinidad (teoría de la causalidad y la casualidad expuesta por el narrador en Phars. II 7-13, epicureísmo expuesto por Bruto en Phars. II 266-273 y estoicismo representado por Catón en Phars. II 286-322, doctrina estoica del ascenso del alma en Phars. IX 1-18, doctrina estoico - panteísta sobre la divinidad y la virtud en Phars. V 86-101 y en Phars. IX 544-584), que, de una u otra manera, con mayor o menor éxito, intentan sondear las voluntades divinas, son una muestra indudable de la constante inquietud del poeta en relación con este tema.",528

La importancia y la profundidad de la indagación sobre la existencia de los dioses y de la naturaleza divina son tan importantes y omnipresentes en el desarrollo del poema que echan por tierra toda posibilidad de interpretación racionalista o antropocéntrica. ${ }^{529}$

\section{LOS DIOSES FURIOSOS E IRRACIONALES}

En la tragedia de Séneca, cuando aparecen los dioses en escena, su representación es más cercana a la de las divinidades infernales que a la de los superi: $:^{530}$ las palabras de Juno en el prólogo de Hercules furens es el ejemplo más cabal de esta operación senequiana de representación de lo divino. La malevolencia y encono de la diosa la homologan a las mismas Furias que ella misma planea enviar contra Hércules. Paradójicamente, Juno enloquece por aquello que, según Séneca en sus trabajos en prosa, debería alegrar y regocijar a los dioses, es decir, la contemplación de los actos nobles y valientes de los varones enfrentados a la adversidad (impetum [...] spectandi magnos uiros conluctantis cum aliqua calamitate): ${ }^{.31}$

quicquid horridum tellus creat inimica, quicquid pontus aut aer tulit terribile dirum pestilens atrox ferum, fractum atque domitum est. superat et crescit malis iraque nostra fruitur; in laudes suas mea vertit odia: dum nimis saeva impero, patrem probavi, gloriae feci locum

(Her. F. 30-36)

$[\ldots]$

monstra iam desunt mihi minorque labor est Herculi iussa exequi, quam mihi iubere: laetus imperia excipit,

\footnotetext{
${ }^{528}$ La Fico Guzzo, M. (2009), 5-6.

${ }^{529}$ La Fico Guzzo, M. (2009), 1-3.

${ }^{530}$ Rosenmeyer, Th. (1989), 82-85.

${ }^{531}$ SEN. Prov. II, 7.
} 
quae fera tyranni iura violenta queant

nocere iuveni? nempe pro telis gerit

quae timuit et quae fudit: armatus venit

leone et hydra

(Her. F. 40-46)

Cuantos monstruos horrorosos crea la tierra enemiga, cuantos monstruos gesta el mar y el éter, terribles, salvajes, pestilentes, atroces, feroces, han sido quebrados y sometidos. Supera los males y crece con ellos, se regocija con nuestra ira, en alabanzas ha transformado mi odio: al ordenar tareas en extremo crueles, he revelado a su padre y otorgado lugar a su gloria.

\section{$[\ldots]$}

Ya me faltan monstruos y es menor esfuerzo para Hércules cumplir lo ordenado que para mí ordenarlo: dichoso acepta mis órdenes, ¿Qué feroces mandatos de un tirano podrían dañar su juventud? Es más, como armas lleva lo que una vez temió y venció: armado llega con el león y la hidra.

Como ya hemos destacado, no existe una hybris o una hamartía particularmente destacable en la conducta de Hércules excepto cierto exceso de confianza en sí mismo y en su persona, ${ }^{532}$ tal como lo demuestran sus palabras durante el sacrificio a Júpiter que precede a la oscura noche que Juno lanza sobre él: ${ }^{533}$

Ipse concipiam preces

Iove meque dignas, stet suo caelum loco tellusque et aequor; astra inoffensos agant aeterna cursus, alta pax gentes alat:

(Her. F. 926-929)

$[\ldots]$

venena cessent, nulla nocituro gravis suco tumescat herba, non saevi ac truces regnent tyranni; si quod etiamnum est scelus latura tellus, properet, et si quod parat monstrum, meum sit.-

(Her. F. 935-939)

Yo mismo expresaré las plegarias dignas de Júpiter y mías, que se mantenga firme el cielo en su lugar y la tierra y el mar; que los astros recorran eternos sus cursos constantes; que una profunda paz nutra a los pueblo:

$[\ldots]$

Que desaparezca el veneno y que ninguna hierba rebalse

${ }^{532}$ Fitch, J. (1987), 37 \& 132-133; Motto, L. \& Clark, J. (1994), 271; Motto, L. \& Clark, J. (1984), 101 $102 \& 108-112$.

${ }^{533}$ Fitch, J. (1987), 361. 
llena de jugos mortales, que no reinen crueles y sanguinarios

tiranos; e incluso, si hay algún crimen que la tierra

haya producido, ¡que se apresure!, y si prepara

algún monstruo, ique sea mío!

Estamos en presencia de un semidiós que acaba de completar doce trabajos de naturaleza casi suicida: no creemos que la confianza y la seguridad en sí mismo y en la virtus demostrada puedan considerarse hamartía o hybris, aunque sí es clara la presencia de cierta arrogancia. ${ }^{534}$ Sin embargo, es sólo bajo los efectos de la locura que Hércules amenaza a los cielos y a los dioses:

Perdomita tellus, tumida cesserunt freta, inferna nostros regna sensere impetus: immune caelum est, dignus Alcide labor. in alta mundi spatia sublimis ferar, petatur aether: astra promittit pater. quid, si negaret? non capit terra Herculem tandemque superis reddit, en ultro vocat omnis deorum coetus et laxat fores, una vetante. recipis et reseras polum? an contumacis ianuam mundi traho? dubitatur etiam? vincla Saturno exuam contraque patris impii regnum impotens avum resolvam; bella Titanes parent, me duce furentes;

(Her. F. 955-968)

La tierra ha sido sometida, se han rendido los henchidos mares, los reinos infernales han conocido nuestro ímpetu: (Sólo) el cielo es inmune, digno trabajo del Alcida. Seré llevado a los altos espacios del mundo superior, Sea reclamado el éter: Mi padre prometió los astros. ¿Y qué, si se negase? No alcanza la tierra a Hércules y al fin lo restituye a los superiores. ¡Por propia iniciativa me llama toda la asamblea de los dioses y me abre las puertas, sólo una se opone, ¿Me recibes y me revelas las puertas del polo? $¿ \mathrm{O}$ arranco las puertas del cielo adverso? ¿Aún hay dudas? Quitaré las cadenas a Saturno y contra el desencajado poder de un padre impío liberaré al abuelo; ¡Que preparen la guerra los titanes furiosos, yo seré su comandante!

Hércules, literalmente fuera de sí, amenaza los cielos y a los dioses y propone un regreso de los Saturnia regna muy diferente a los que Virgilio vislumbraba en su IV

\footnotetext{
${ }^{534}$ Papadopoulou, Th. (2004), 273-275, particularmente 275: "But, more importantly, Hercules himself seems to behave (perhaps due to the knowledge of his future deification) as though he were already on the same level as gods." Fitch, J. (1987), 362: "926f. Arrogance is evident in the snub to Amphitryon and in the hint that Hercules and Jupiter are equals." Cf. también 365-367.
} 
égloga. ${ }^{535}$ Sin embargo, con una extraordinaria agudeza psicológica, Séneca pone en boca del héroe enloquecido, durante su brote, no las palabras propias sino las palabras y los miedos del "otro". Furioso, Hércules se convierte en el eco humano de las preocupaciones divinas de Juno: ${ }^{536}$

levia sed nimium queror;

caelo timendum est, regna ne summa occupet

qui vicit ima: sceptra praeripiet patri.

nec in astra lenta veniet ut Bacchus via:

iter ruina quaeret et vacuo volet

regnare mundo, robore experto tumet,

et posse caelum viribus vinci suis

didicit ferendo; subdidit mundo caput

nec flexit umeros molis immensae labor

meliusque collo sedit Herculeo polus.

immota cervix sidera et caelum tulit

et me prementem: quaerit ad superos viam.

(Her. F. 63-74)

$[\ldots]$

i nunc, superbe, caelitum sedes pete,

humana temne. iam Styga et manes ferox

fugisse credis? hic tibi ostendam inferos,

revocabo in alta conditam caligine,

ultra nocentum exilia, discordem deam

quam munit ingens montis oppositi specus;

educam et imo Ditis e regno extraham

quicquid relictum est: veniet invisum Scelus

suumque lambens sanguinem Impietas ferox

Errorque et in se semper armatus Furor-

hoc ministro noster utatur dolor.

(Her. F. 89-99)

Pero me quejo de cosas demasiado leves,

hay que temer por el cielo, para que no ocupe los más altos reinos

quien venció los más profundos: arrebatará el cetro a su padre,

y no llegará a las estrellas por el camino lento, como Baco,

reclamará el camino con la ruina y querrá reinar,

luego de vaciar el mundo, se enorgullece con su fuerza probada,

$\mathrm{y}$ aprendió que el cielo puede ser vencido por sus fuerzas

cuando lo cargó, puso su cabeza debajo del mundo

y no dobló sus hombros el esfuerzo de esa inmensa mole

y se asentó mejor el polo sobre el cuello hercúleo.

Su espalda soportó inconmovible las estrellas y el cielo,

y a mí que lo aplastaba: Busca el camino a los dioses.

$[\ldots]$

Ve ahora, soberbio, busca las mansiones de los dioses celestiales,

${ }^{535}$ Clausen, W. (1994), 130-131; Coleman, R. (1977), 132; Fitch, J. (1987), 369.

${ }^{536}$ Fitch, J. (1987), 141: “63-74. In these lines we see the development of Juno's suspicion that Hercules will attack the heavens, already latent in the comparison of Dis with Jupiter $(51,53)$; note again the 'thinking aloud' character of the speech. What begins as a fear (timendum est) is no sooner voiced than it turns into an expectation (praeripiet, veniet, quaeret, volet); its likehood is then backed up by arguments (68-74) which turns it into a certainty in the present. [...] Juno seems determined to believe the worst of her stepson, and to find any excuse to intensify her persecution of him." Cf. también 115-116. 
desprecia lo humano. ¿Crees que has escapado de la Estigia feroz

y de los manes? Aquí te mostraré a los dioses infernales,

Invocaré, envuelta en una profunda oscuridad,

más allá del exilio de los condenados, a la diosa de la discordia

a la que protege la cueva enorme del monte enfrentado (a ella);

sacaré y extraeré de los más profundo del reino de Dite

todo lo que ha quedado: Vendrá el crimen odiado

y la Impiedad feroz lamiendo su propia sangre,

y el Error y el Furor siempre armado contra sí mismo,

Nuestro dolor se servirá de este servidor.

El prólogo de Hercules furens es verdaderamente uno de los locus senequianos doctrinalmente más revulsivos y confutadores de la concepción estoica del universo. Hemos visto cómo Séneca indaga en perturbadoras posibilidades del pensamiento estoico y en usos extremos de las herramientas propias de la doctrina, como que un tirano posea una sólida estructura estoica o que ciertas virtudes, como la constantia, puedan ser aplicadas a fines eminentemente antiestoicos. La representación de individuos fuertes y poderosos que aplican su ratio desbocada para encauzar y utilizar su ira y sus pasiones con fines criminales es una clara operación de desestabilización y subversión del paradigma filosófico, pero la aparición de un dios aplicando estas herramientas de autoadmonición y autocontrol para entregarse a la pasión y a la locura a través de un acto racional y meditado resulta en la confutación de éste: ${ }^{537}$

non sic abibunt odia; vivaces aget violentus iras animus et saevus dolor aeterna bella pace sublata geret.

(Her. F. 27-29)

$[\ldots]$

ut possit animo captus Alcides agi, magno furore percitus, vobis prius insaniendum est. Iuno, cur nondum furis? me, sorores, mente deiectam mea versate primam, (Her. F. 106-111)

No desaparecerán así mis odios: Mi ánimo agita violento vivaces iras y mi cruel dolor hará la guerra eterna, suprimida la paz.

\footnotetext{
537 Tarrant, R. (1985), 126: “250-54 dira ... monstro: In calling on hellish spirits of vengeance to augment the violence of his own heart, Atreus resembles the Juno of $H F$ (86-112). Atreus' case is more complex, however, since his appeal inevitably recalls the first scene, where it has been, so to speak, fulfilled in advance, note in particular 253-54 impleri iuvat/ ... monstro and 53 imple Tantalo ... domum, 252-54 non ... monstro and 85-86 concute ... tumultu, and see above 85. Other vision of the Furies in Seneca (Med. 958-66, Ag. 759-64) are clearly projections of the character's own hopes or fears."
} 
¡Para que el Alcida pueda ser conducido capturado su ánimo, sacudido por un enorme furor, primero debéis enloquecer vosotras! Juno, ¿Por qué aún no enloqueces?

a mí, a mí, hermanas, trastornadme a mi primera

¿Puede un dios, en un universo estoico, enloquecer? ¿Puede, dentro de este rígido marco de pensamiento, entregarse a la ira y a la locura a través de la razón tal como lo hace esta Juno infernal?:

"Juno's jealousy and vindictiveness are so unbalanced that one is forced to ask whether this is really the queen of the gods, Juno Caelestis herself. Tantaene animis caelestibus irae? asks Vergil in a similar situation. In fact, as she appeals to the Furies to madden her, she herself becomes something of an infernal power, a Juno Inferna. The fact that she appears at night strengthens this impression. It is noteworthy that Seneca's other supernatural prologue figures, in $A g$. and Thy., are indeed from the underworld; further, these extravagant and erring spirits vanish at dawn, just as Juno does (cf. Tarrant on $\mathrm{Ag}$. 56). This infernal aspect of Juno is obviously consistent with the emphasis throughout this play on the power of the underworld." 538

Esta representación de la divinidad nos coloca ante un universo eminentemente antiestoico, donde el individuo sospecha angustiado la no existencia de lo divino o la perturbadora posibilidad de la existencia de dioses irracionales y furiosos. Jorge Luís Borges plantea algo similar en su cuento "El inmortal":

"Emergí a una suerte de plazoleta; mejor dicho, de patio. Lo rodeaba un solo edificio de forma irregular y altura variable; a ese edificio heterogéneo pertenecían las diversas cúpulas y columnas. Antes que ningún otro rasgo de ese monumento increíble, me suspendió lo antiquísimo de su fábrica. Sentí que era anterior a los hombres, anterior a la Tierra. Esa notoria antigüedad (aunque terrible de algún modo para los ojos) me pareció adecuada al trabajo de obreros inmortales. Cautelosamente al principio, con indiferencia después, con desesperación al fin, erré por escaleras y pavimentos del inextricable palacio. (Después averigüé que eran inconstantes la extensión y la altura de los peldaños, hecho que me hizo comprender la singular fatiga que me infundieron.) Este palacio es fábrica de los dioses, pensé primeramente. Exploré los inhabitados recintos y corregí: Los dioses que lo edificaron han muerto. Noté sus peculiaridades y dije: Los dioses que lo edificaron estaban locos. Lo dije, bien lo sé, con una incomprensible reprobación, que era casi un remordimiento, con más horror intelectual que miedo sensible. A la impresión de enorme antigüedad se agregaron otras: la de lo interminable, la de lo atroz, la de los complejamente insensato. Yo había cruzado un laberinto, pero la nítida Ciudad de los Inmortales me atemorizó y repugnó. Un laberinto es una casa labrada para confundir a los hombres; su arquitectura, pródiga en simetrías, está subordinada a ese fin. En el palacio que imperfectamente exploré, la arquitectura carecía de fin. Abundaban el corredor sin salida, la alta ventana inalcanzable, la aparatosa puerta que daba a una celda o a un pozo, las increíbles escaleras inversas, con los peldaños y balaustrada hacia abajo. Otras, adheridas aéreamente al costado de un muro monumental, morían sin llegar a ninguna parte, al cabo de dos o tres giros, en la

${ }^{538}$ Fitch, J. (1987), 117. 
tiniebla superior de las cúpulas. Ignoro si todos los ejemplos que he enumerado son literales; sé que durante muchos años infestaron mis pesadillas; no puedo saber ya si tal o cual rasgo es una transcripción de la realidad o de las formas que desatinaron mis noches. Esta Ciudad (pensé) es tan horrible que su mera existencia y perduración, aunque en el centro de un desierto secreto, contamina el pasado y el porvenir y de algún modo compromete a los astros. Mientras perdure, nadie en el mundo podrá ser valeroso o feliz. No quiero describirla; un caos de palabras heterogéneas, un cuerpo de tigre o de toro, en el que pulularan monstruosamente, conjugados y odiándose, dientes, órganos y cabezas, pueden (tal vez) ser imágenes aproximativas." 539

Es interesante destacar cómo en el intento final de describir la naturaleza enloquecida de lo divino, Borges recurre a estrategias de representación grotescas como las que hemos estudiado en los apartados anteriores.

${ }^{539}$ Borges, J. (1974), 537-538. 


\section{RECAPITULACIÓN Y CONCLUSIONES PARCIALES}

La supresión del aparato divino en Pharsalia no representa un alejamiento de la cuestión divina, más bien todo lo contrario: el poema resulta una profunda y perturbadora inquisición sobre la naturaleza de los dioses y sobre las consecuencias en el ámbito humano de su ausencia, desinterés o inexistencia. Lucano retoma las problemáticas planteadas por la tragedia de Séneca y las exacerba planteando, a través de paradójicas sentencias y de las intervenciones de la voz del narrador, la inadecuación de los ideales fundantes de la concepción estoica y de la religión romana en general. Las estrategias de representación de lo divino, tanto en la tragedia de Séneca como en la épica de Lucano, problematizan e incluso confutan las concepciones tradicionales de la religio Romana ${ }^{540}$ y ponen de manifiesto una muy original visión de la condición humana que prefigura las variadas posturas existencialistas de los siglos XIX y XX.

En el universo trágico senequiano, a diferencia de las representaciones áticas, los dioses no son garantes de un orden que se instaura como real incluso si resulta incomprensible para los humanos, sino que el individuo sospecha o intuye la imposibilidad de comunicación con lo divino: si existen, los númenes son sordos a las cuestiones o a las preocupaciones humanas, son dioses-eco en el mejor de los casos, o dioses-monstruos en el peor. La posibilidad de existencia de dioses que no garanticen los costados morales o éticos de las acciones humanas, tal como lo entienden la tradición platónica y la tradición judeo-cristiana, ${ }^{541}$ despliega un universo disoluto y absurdo en el cual el individuo queda desamparado y angustiado. Sí los dioses son los garantes de la causa vencedora, enemiga de la Libertas, el hombre sólo puede aferrarse a ideales que sabe ya perimidos y cuya defensa lo arrastra inexorablemente al comune nefas que se combate. Nuevamente, Lucano logra condensar una cuestión tan espinosa en la magnífica sentencia ya analizada, victrix causa deis placuit sed victa Catoni (LUC. I, 128).

\footnotetext{
${ }^{540}$ Beard, M.; North, J. \& Price, S. (1998), 215-221, Heitland, W. (1971), xlix-li.

${ }^{541}$ Dreyfus, H. (2006), 138: "[For the Jews] The ultimate authority is God, not reason. The difference this makes can be seen by looking at Plato's Euthyphro. Socrates asks Euthyphro whether an action is pious because the gods love it, or if the gods love it because it is pious. Euthyphro's Greek answer is: the gods approve what is pious. For the Greeks, what is pious or good is determined by rational criteria that are binding on all men, and even on the gods. The Hebrews answer is just the opposite: an action is good because God approves it or commands it, and what is good is different for each individual. God's command that Abraham should kill Isaac does not mean that all good fathers should kill their sons, but it was the right thing for Abraham as an individual to do."
} 


\section{SEGUNDA PARTE: REPRESENTACIÓN DE LOS}

PARADIGMAS LITERARIOS. 


\section{REPRESENTACIÓN DE LA HISTORIA}

\section{LA AUSENCIA DE LA REPRESENTACIÓN HISTÓRICA EN LA TRAGEDIA DE SÉNECA}

Como ya hemos destacado en nuestra introducción, uno de los factores centrales que operan en la problemática datación de las tragedias de Séneca es la ausencia absoluta de referencias a eventos históricos contemporáneos al autor. El estudio, ya mencionado, de Nisbet (2008) es un claro ejemplo de la oscuridad y elusividad de las supuestas referencias históricas que operarían dentro de las tragedias. Por ejemplo, Nisbet encuentra en el siguiente pasaje una clara alusión a la situación política de Medio

Oriente a principios de la década del $60:{ }^{542}$

ille qui donat diadema fronti, quem genu nixae tremuere gentes, cuius ad nutum posuere bella et Dahae Parthis equitem minati, anxius sceptrum tenet et mouentes cuncta diuinat metuitque casus mobiles rerum dubiumque tempus.

Aquel que regala diademas a su frente, ante el cual tiemblan las naciones con su rodilla flexionada ante cuyo gesto abandonaron la guerra incluso los dahas, que compiten con los partos como jinetes, sostiene angustiado el cetro y desconfía de todas las cosas inconstantes y teme al azar cambiante de las cosas y al dudoso tiempo

El autor llega a la siguiente conclusión:

"The Dahae who have abandoned their wars lived in the east of the Caspian, on the northen frontier of the Parthian empire; here they are said to have threatened the Parthians with their cavalry, the very weapon in which the Parthian excelled. The exemplum is so specific and so irrelevant to anything in the play that it must allude to events in Seneca's own time., ${ }^{, 43}$

La referencia es tan sutil y velada que nos parece imposible discutirla, ya sea para intentar refutarla o apoyarla. Las conclusiones, si bien válidas, resultan más cercanas a una Glaube sólo válida en tanto subjetiva.

\footnotetext{
${ }^{542}$ Nisbet, R. (2008), 357-360. Por su parte, R. Tarrant no hace mención alguna sobre posibles conexiones entre el contenido de la oda y su contexto histórico en su comentario, cf. Tarrant, R. (1985), 176-177.

${ }^{543}$ Nisbet, R. (2008), 358.
} 
Creemos que la a-historicidad de la tragedia de Séneca implica, de por sí, una postura estética e ideológica verdaderamente operativa y que el autor claramente evita de manera programática cualquier mención o alusión, clara o velada, a cualquier suceso sociopolítico de su época. Resulta imposible hablar con autoridad respecto de las intenciones personales de cualquier autor, antiguo o contemporáneo, al omitir o destacar ciertos aspectos propios de su obra, pero sí resulta posible y relevante intentar comprender cómo aparecen y operan estas presencias o ausencias dentro de una obra según las propias reglas de formación, de la lógica (o las lógicas) de enunciación y de las leyes que rigen su funcionamiento autónomo en busca de los planteos, exigencias y presupuestos teóricos de la poética particular que los despliega. Si bien la investigación minuciosa que requiere este tema en particular excede los límites de nuestro trabajo, nos permitiremos aventurar, sin embargo, cierta hipótesis tentativa y operativa desde el punto de vista de nuestra perspectiva hermenéutica: la ausencia, absoluta, de referencias históricas identificables puede ser entendida como un intento de desanclar la inquisición filosófica y la exploración de los límites de la doctrina estoica del ámbito cotidiano y situar las cuestiones problematizadas en un plano puramente abstracto de representación.

\section{ÉPICA E HISTORIA}

La separación tajante entre épica e historia en la Antigüedad grecolatina resulta ser una concepción contemporánea más que una problemática propia de los autores antiguos, quienes centraban la cuestión no sobre la forma sino sobre el contenido. ${ }^{544} \mathrm{El}$ género de una obra estaba ligado al objetivo o función, estética o pragmática, buscado por el autor: si primaba una búsqueda de la delectatio y la voluptas, la obra se categorizada entonces dentro del campo de la épica. Si, en cambio, prevalecía la voluntad de docere y de movere, la obra se situaba del lado de la historiografía. ${ }^{545} \mathrm{La}$ concepción, prevalente en las interpretaciones hegemónicas de los últimos siglos, de considerar a estos géneros como categorías formales inconexas e irreconciliables parece surgir de una sujeción al prefacio de Tito Livio (Ab Urbe Condita, Praef.), donde el autor busca explícitamente apartar su obra de la de los poetas. ${ }^{546}$ Es de fundamental

\footnotetext{
${ }^{544}$ Goldberg, S. (2010), 167-168; Wiseman, T. (2002), 338 y ss.

${ }^{545}$ Lorenzo, J. (2011), 9-11 \& 15-17; Goldberg, S. (2010), 178.

${ }^{546}$ Wiserman, T. (2002), 331-332.
} 
importancia considerar que Tito Livio, si bien importante y prestigioso, es un autor cuya concepción particular de lo que debería ser y los temas sobre los que debería tratar la historia no parece haber sido compartida ni aceptada unánimemente por los demás autores de la Antigüedad:

\begin{abstract}
"So Varro, Cicero, Dionysius, Plutarch and Valerius Maximus have brought us to an unexpected conclusion. Livy's comment on what is appropriate to poet's stories, far from being a truism, turns out to be a partisan statement of philosophical skepticism. Other historians took the opposite view, and did accept miracle stories, and divine epiphanies as proper part of their subject matter. The issue was one not of literary convention but of teleological belief. [...] For Livy, divine intervention was not appropriate to 'uncorrupted' history - but we know that other historians thought it was." 547
\end{abstract}

Los eventos sobrenaturales y las intervenciones divinas eran tratados por los historiadores antiguos a través de diversos procedimientos discursivos: el propio Tito Livio, al verse enfrentado a la necesidad de narrar este tipo de eventos, recurría a una estrategia de distanciamiento, introduciéndolos a través de verbos como dicitur, ferunt o traditur. Otros autores, como Varrón, San Agustín o Dionisio de Halicarnaso, cuya concepción de la historia era diferente a la de Livio, utilizaban un procedimiento de racionalización de los mitos que narraban y ofrecían una interpretación histórica de los hechos referidos. ${ }^{548}$

Cicerón se pregunta, en su tratado De legibus (II, 115), por qué habría de creerle más a Herodoto que a Ennio: Herodotum cur veraciorem ducam Ennio ${ }^{549}$ Esta frase nos permite entrever cómo, para los antiguos, la distinción entre el historiador y el poeta no pasaba por el tamiz de la prosa o el verso sino que estaba íntimamente relacionada a la intencionalidad prevalente en la obra:

“[...] se trata de dos géneros literarios - es importante insistir en ello, máxime en el caso de la historiografía clásica grecolatina- estrechamente relacionados entre sí, tan unidos, ya para los antiguos, que no deja de ser significativo, como he dicho, que la ejemplificación que da Cicerón de 'historia' ('Appius indixit Carthaginensibus bellum') es una cita de los Annales de Ennio [Enn. Ann. 7, 216]; por eso, no parece equivocado afirmar que, aun reconociéndole una serie de marcas propias, la épica es el género literario que mantiene vínculos más estrechos con la historiografía. [...]Los dos géneros persiguen el objetivo de proclamar las kléa andrôn ("las acciones gloriosas de los hombres"). La Eneida de Virgilio y la monumental obra de Tito Livio, por poner dos ejemplos paradigmáticos, composiciones literariamente diferentes, son "l'expression

\footnotetext{
${ }^{547}$ Wiseman, T. (2002), 353 \& 361-362.

${ }^{548}$ Raaflaub, K. (2005), 67-69; Wiseman, T. (2002), 334- 336 para el caso de Varrón y Agustín, 343-347 para el caso de Dionisio y Plutarco y 339-342 \& 352-354 para el enfoque ciceroniano de estas problemáticas.

${ }^{549}$ CIC. Div. II, 56, 116.
} 
d'un même sentiment national, patriotique. [...] nul genre littéraire n'est davantage destiné à être le réceptacle de ce sentiment que l'épopée ou l'histoire, lorsque celle-ci est teinte d'épopée' (Foucher (2000), p. 58.)" ${ }^{550}$

Si, como afirma Raaflaub, desaparecieran nuestras fuentes históricas y sólo hubiese sobrevivido la obra de Ennio y Lucano, aun sería posible saber y conocer la historia de la República y de la guerra civil aunque, por supuesto, sin la posibilidad de cotejar las diferentes perspectivas de los relatos. Ambos géneros, entonces, coinciden en la celebración de un pasado relevante para la configuración efectiva de un presente operativo en tanto refleja las condiciones ideológicas de su producción. ${ }^{551}$

\section{PHARSALIA Y LA BATALLA DE FARSALIA}

La batalla de Farsalia, probablemente el episodio central del poema de Lucano, ${ }^{552}$ es uno de los pasajes que más polémica ha generado a causa de su virulencia y de las supuestas discrepancias e imprecisiones de la representación con respecto a las versiones históricas. ${ }^{553}$ Siendo los hechos narrados en el libro VII algunos de los más minuciosamente estudiados y conocidos de la historia, cada pequeño detalle fue puesto bajo la lupa y escudriñado en profundidad. Los críticos reconocen las intenciones poéticas de Lucano, pero inmediatamente se lanzan sobre las inexactitudes y las supuestas "faltas" del poeta: O. Dilke, por ejemplo, en su clásico comentario del libro VII de Pharsalia, detecta perspicazmente las operaciones poéticas realizadas en el texto pero no ahonda en ellas y termina, como sucede en Quintiliano o Servio, juzgando a Lucano más como un historiador que como poeta: ${ }^{554}$

\footnotetext{
"On questions of fact Lucan in not always reliable. In history, geography, mythology, and science as it was then understood, he was well-read, and it seems particularly to have been influenced by the Works of the younger Seneca. But this learning was undigested and often inexact. The occasion of Pompey's first triumph is wrongly given. The legions commanded by Lentulus were I and III, not I and IV; and Pompey's cavalry maneuver was on one wing, not on both. The poet's information on battles marked in the Fasti is incorrect. The river Timavus is not near Patavium. In some cases, such as the constant confusion of Macedonia with Thessaly and of Pharsalia with Philippi, the

${ }^{550}$ Lorenzo, J. (2011), 11-12.

${ }^{551}$ Williams, R. (1998), 137-139; Raaflaub, K. (2005), 68-69.

552 Gómez, J. (2003), 30-35; Ahl, F. (1976), 326-330; Rolim de Moura, A. (2010), 72-73.

${ }_{553}$ Dilke, O. (1960), 30-33. Cf. también Heitland, W. (1971), li-liii.

${ }^{554}$ QUINT. Inst. X, 1, 70; SERV. A. I, 382 \& II, 187; von Albrecht, M. (1997), 917 y ss.
} 
bullets that melt in their flight, the hemorrhage that forces the weapon from the wound, earlier writers were to blame for the mistakes"

Creemos que, más allá de si Lucano fue considerado, particularmente en la Antigüedad, como un historiador, su tratamiento del material histórico es eminentemente poético y que, cuando se aparta de las versiones tradicionales, en general de manera muy explícita $\mathrm{y}$ evidente, ${ }^{556}$ lo hace con intenciones precisas y particulares que responden a una necesidad estética y a una economía poética y que requieren, necesariamente, de la competencia histórica del lector para detectar y significar las divergencias entre el fluir histórico de los acontecimientos y su representación en el poema:

"Se a verdade histórica é uma construçáo (exaedificatio) até mesmo dentro daquilo que os antigos entendían por Historia, convén notar que, embora se possa subtrair da Farsália relatos históricos muito convencentes - tal como Grimal faz com o discurso de César em Ariminum (I, 299-351), e Canfora, com a figurande Pompeu decapitado-, Lucano era um 'intérprete poético da história'.",557

Lucano cuenta con la capacidad enciclopédica del lector y da por sentado que éste sabe, en menor o mayor medida, cómo se desarrolló la guerra civil y quiénes fueron sus actores. Dado que la intención de Lucano no parece haber sido falsear las versiones canónicas o inaugurar nuevas versiones de los hechos, conviene estudiar estas diferencias en función del desarrollo y las necesidades poéticas de la obra. Las flagrantes digresiones, entonces, tienen una clara intención poética y literaria más que una voluntad de ejercer cierto tipo de revisionismo histórico.

Un claro ejemplo de este procedimiento es la presencia y el discurso de Cicerón en el libro VII. Era bien sabido que el senador no estuvo presente en Tesalia. ${ }^{558}$ Sin embargo la presencia del orador republicano por excelencia le permite a Lucano condensar y conjugar la pluralidad de voces que se escuchaban en el campamento de Pompeyo, donde, según César, ocurría lo siguiente:

Iam de sacerdotio Caesaris Domitius, Scipio Spintherque Lentulus cotidianis contentionibus ad gravissimas verborum contumelias palam descenderunt, cum Lentulus aetatis honorem ostentaret, Domitius urbanam gratiam dignitatemque iactaret, Scipio affinitate Pompei confideret. [...] Postremo omnes aut de honoribus suis aut de praemiis pecuniae aut de persequendis inimicitiis agebant nec, quibus rationibus superare possent, sed, quemadmodum uti victoria deberent, cogitabant. ${ }^{559}$

\footnotetext{
${ }^{555}$ Dilke, O. (1960), 33.

${ }^{556}$ Hunink, V. (1992), xiii-xiv.

${ }_{557}^{55}$ Vieira, B. (2011), 28.

${ }^{558}$ CIC. Div. I, 68 \& Att. XI, 5, 3; Plutarco, Cic. 39.

${ }^{559}$ CAES. Civ. III, 83. Cf. También Dilke, O. (1960), 17-20.
} 
Ya Domicio, Escipión y Léntulo Espínter se enfrascaron en cotidianas discusiones, llevadas hasta gravísimas injurias públicas, sobre el sacerdocio de César, porque Léntulo ostentaba el honor de su edad, Domicio resaltaba su influencia en la ciudad y su dignidad y Escipión confiaba en su cercanía con Pompeyo. [...] En fin, todos polemizaban o sobre sus honores o sobre el reparto de las riquezas o sobre la persecución de sus enemigos y no pensaban con qué estrategias podían vencer, sino de qué modo debían utilizar la victoria.

La situación es resumida, con la habitual maestría de Lucano, en el verso VII, 66: in Pompeianis votum est Pharsalia castris. Expuesta la situación del campamento, hace su aparición en el poema el Romani maximus auctor [...] eloquii (VII, 62-63). Su discurso, lejos de mostrar la claridad y el decoro propios de la obra ciceroniana, despliega la sintaxis quebrada y la ambigüedad semántica características de la pluma de Lucano. ${ }^{560}$ Cicerón es verdaderamente sarcástico en sus palabras a Pompeyo ${ }^{561}$ y se enfoca principalmente en la aparente pasividad del general atacando su estrategia de diferir el enfrentamiento:

proceresque tuorum

castrorum regesque tui cum supplice mundo adfusi uinci socerum patiare rogamus.

$[\ldots]$ pudeat uicisse coactum.

si duce te iusso, si nobis bella geruntur, sit iuris, quocumque uelint, concurrere campo. [...] scire senatus auet, miles te, Magne, sequatur an comes.

Los dirigentes de tus campamentos y tus reyes, junto al mundo suplicante, te rogamos postrados que permitas que tu suegro sea vencido. $[\ldots]$

Que te avergüence vencer obligado.

Si eres comandante por nuestro mandato, si la guerra es librada por nosotros, sea lícito que se lancen al campo de batalla que deseen. $[\ldots]$ El senado quiere saber si te sigue, Magno, como soldado o como acompañante.

\footnotetext{
${ }^{560}$ Un claro ejemplo del tono eminentemente lucaniano de estos versos es la profunda polivalencia y de los significantes y la ambigüedad de la sintaxis. Jesús Gómez (2003) interpreta los versos 79-80 del siguiente modo: "Si la guerra se hace bajo tu mando legítimo, si en provecho nuestro, les sea lícito librar la batalla en el campo que deseen.". Rambaud, M., por su parte, toma el nobis como dativo agente, sugiriendo "si eres por nuestra delegación el comandante y si es nuestra la dirección de la guerra.", cf. Gómez, J. (2003), 441.

${ }^{561}$ Rudich, V. (1997), 161-163.
} 
Las corrosivas palabras del máximo orador de Roma y la tibia respuesta de Pompeyo dejan entrever la imagen de la magna y añosa encina, evocada en el prólogo, ${ }^{562}$ que está a punto de ser fulminada por la energía casi infinita del rayo de César. ${ }^{563}$ Tal densidad semántica y efecto poético sólo pueden lograrse a través del recurso literario, explicitado en el propio texto, de aunar las cunctorum voces (VII, 62) en las palabras del senador. Cicerón, entonces, se convierte en un símbolo del Estado Republicano y refuerza la representación literaria de Pompeyo Magno. Se produce, entonces, una reformulación poética del suceso histórico con una intención eminentemente estética:

"In the case of the oration attributed by Lucan to Cicero, the fake is evident: Cicero, who is depicted advocating for war, was not present in Dyrrhacium at the time and, furthermore, was an advocate of peace (7. 68-85). As a poet, Lucan mastered the technique of condensation: he possessed the ability to summarize a complex sequence in a momentous scene." 564

Esta operación puede apreciarse en otros dos episodios que despliegan procedimientos literarios y operaciones poéticas similares: la aparición de Bruto en medio de la batalla y la muerte de Domicio Ahenobarbo. Domicio aparece dos veces en toda Pharsalia (II, 478 -525 \& VII, 597-616) y en ambos episodios Lucano se aparta clara y explícitamente de sus fuentes históricas con objetivos particulares y específicos: ${ }^{565}$ resaltar, a través de este proceso de representación simbólica, el valor y la intransigencia de este antepasado de Nerón. El parentesco es relevante ya que tiñó las interpretaciones y las consideraciones sobre este pasaje durante mucho tiempo. Se consideró que el tratamiento heroico del personaje de Domicio tenía como finalidad alabar, oblicuamente, al emperador, ${ }^{566}$ oponiéndose a la acotada y desdibujada versión que da César en su Bellum Civile III, 99:

\footnotetext{
${ }^{562}$ Narducci, E. (1979), 110-111; Narducci, E. (2002), 279; Rolim de Moura, A. (2010), 86-88; LUC. I, 135-143: "stat magni nominis umbra,/ qualis frugifero quercus sublimis in agro/ exunias ueteris populi sacrataque gestans/ dona ducum nec iam ualidis radicibus haerens/ pondere fixa suo est, nudosque per aera ramos/ effundens trunco, non frondibus, efficit umbram, / et quamuis primo nutet casura sub Euro,/ tot circum siluae firmo se robore tollant, / sola tamen colitur."

563 Leigh, M. (2009), 239-242; Rosenstein, N. (2009), 87 \& 91-92; von Albrecht, M. (1997), 923; Narducci, E. (1979), 90-92; Johnson, W (1987), 76; LUC. I, 143- 155: "sed non in Caesare tantum/ nomen erat nec fama ducis, sed nescia uirtus/ stare loco, solusque pudor non uincere bello./ acer et indomitus, quo spes quoque ira uocasset,/ ferre manum et numquam temerando parcere ferro,/ successus urguere suos, instare fauori/ numinis, inpellens quidquid sibi summa petenti/ obstaret gaudensque uiam fecisse ruina,/ qualiter expressum uentis per nubila fulmen/ aetheris inpulsi sonitu mundique fragore/ emicuit rupitque diem populosque pauentes/terruit obliqua praestringens lumina flamma:/ in sua templa furit"

${ }_{564}$ von Albecht, M. (1997), 919.

${ }^{565}$ Para el episodio de Corficio (II, 475-252) cf. César, J. B. C. I, 19-24 \& CIC. M. Att. IX, 16. Para la muerte de Domicio (LUC. VII, 597-616), cf. César, J. B.C. III, 99 \& CIC. M. Phil. II, 71. Cf. también elogio177.

${ }^{566}$ Heitland, W. (1971), xxxviii.
} 
L. Domitius ex castris in montem refugiens, cum vires eum lassitudine defecissent, ab equitibus est interfectus.

"Lucio Domicio, refugiándose en el monte desde el campamento, como lo abandonaran sus fuerzas por el cansancio, fue muerto por la caballería"

El episodio es interpretado por Dilke del siguiente modo: “This undistinguished end [i.e. flying from battle] would not do for an ancestor of Nero, so our author coolly alters it." ${ }^{, 567}$ Nuevamente discrepamos respetuosamente con el prof. Dilke, pues creemos que son precisamente las manifiestas discrepancias y las resonantes alteraciones históricas las que proclaman la voluntad poética de reformular como símbolo al personaje histórico. $^{568}$

Particularmente importante es la completa ausencia de Domicio como general en la defensa de Masilia, uno de los episodios centrales del libro III. Tal omisión refuerza la hipótesis de que Lucano no desea ganarse el favor del emperador a través de la figura de su antepasado, ${ }^{569}$ sino que, muy por el contrario, el combativo Domicio ${ }^{570}$ es uno de los pocos personajes del poema asimilables a las figuras de Catón o Bruto, intransigentes y virtuosos republicanos, últimos sujetos éticos en este universo disoluto, que luchan hasta su último aliento contra el avance inexorable de la tiranía de César. Al igual que Catón, Domicio exalta su nobleza y su valor al perseverar, aun vencido, en la lucha:

uictus totiens a Caesare salua

libertate perit.

(LUC. VII, 602-603)

vencido tantas veces por César, muere, salvada su libertad.

De hecho, Domicio fue derrotado tres veces por César en esta campaña en particular y había sido subsecuentemente humillado por la clementia Caesaris ${ }^{571}$ luego de la toma de Corficio; sin embargo, con su muerte desafiante, logra salvaguardar su honor y libertad.

Bruto es otro personaje cuya presencia es central para el desarrollo del poema. Aparece en el libro II, calmo y sereno en medio del terror generalizado (at non magnanimi percussit pectora Bruti/ terror. LUC. II, 234-235) buscando las palabras de

\footnotetext{
${ }^{567}$ Dilke, O. (1960), 145.

${ }^{568}$ Ahl, F. (1976), 49-52.

${ }^{569}$ Ahl, F. (1976), 53.

${ }^{570}$ LUC. II, 479 \& VII, 600.

${ }^{571}$ Leigh, M. (2009), 248-249; Raaflaub, K. (2009), 190-191.
} 
Catón. ${ }^{572}$ Más tarde, en el libro VII, lo vemos plantado en medio del combate intentando alcanzar el cuello de César:

illic plebeia contectus casside uoltus

ignotusque hosti quod ferrum, Brute, tenebas!

o decus imperii, spes o suprema senatus,

extremum tanti generis per saecula nomen,

ne rue per medios nimium temerarius hostis,

nec tibi fatales admoueris ante Philippos,

Thessalia periture tua.

(LUC. VII, 586-591)

$[\ldots]$

uiuat et, ut Bruti procumbat uictima, regnet.

(LUC. VII, 596)

¡Allí, ocultando su rostro con un yelmo plebeyo

e ignorado por el enemigo, qué hierro, Bruto, esgrimías!

¡Honor del imperio, esperanza suprema del senado,

último nombre de una familia tan grande por todos los siglos,

no te lances en extremo temerario en medio de los enemigos

ni te acerques antes de tiempo a tu fatal Filipos,

tú que habrás de morir en tu Tesalia!

\section{$[\ldots]$}

que viva y, para que caiga víctima de Bruto, reine.

Suele marcarse a este pasaje otro de los "errores típicos" de Lucano o como otro desmesurado excursus del narrador el confundir Tesalia con Macedonia o Filipos con Farsalia. Pero, como varios autores han destacado, en Pharsalia Lucano despliega un barroco juego de repeticiones y reduplicaciones que, en ese constante volverse sobre sí mismos de los acontecimientos, conturba de manera tal las acciones y sus consecuencias que éstas resultan imposibles de discriminar e identificar con plena seguridad. ${ }^{573}$

\section{LA BATALLA SEGÚN CÉSAR}

La batalla de Farsalia ofrece una curiosa combinación de certezas e incertidumbres. Por un lado, gracias a los numerosos y confiables testimonios de la antigüedad, sabemos cómo se desarrolló qué decisiones tomó cada comandante y qué consecuencias tuvieron éstas para el desenlace final. Sin embargo, en medio de estas certezas aún se desconoce el emplazamiento real del campo de batalla y los arqueólogos no logran ponerse de acuerdo si ocurrió en la región de Pharsalia o de Palaepharsalia,

\footnotetext{
${ }^{572}$ Ahl, F. (1976), 235-236; Narducci, E. (2002), 370-371.

${ }^{573}$ Bartsch, Sh. (1997), 48-56.
} 
o incluso si el combate se llevó a cabo al norte o al sur del río Enipeo. ${ }^{574}$ De acuerdo a los testimonios antiguos, las fuerzas de César, pese a ser numéricamente inferiores, controlaban la mayor parte de la región, ${ }^{575}$ mientras que Pompeyo y sus generales dominaban Larisa y sus campos adyacentes. César, mostrando la determinación y la efectividad que luego elogiaría Lucano, marcha hacia el este, acampa en la región de Farsalia y espera el despliegue de las tropas pompeyanas (Caes. B. C. III, 81; Appian. B. C. II, 64) asegurándose así una abundante provisión de cereales y agua. Instalados los campamentos de ambos generales, se producen algunas escaramuzas entre la caballería, que son aprovechadas por César para foguear a sus nuevos reclutas mezclándolos con los veteranos y para ensayar ciertas estrategias particulares de combate, dada su inferioridad numérica (Caes. B. C. III, 84). ${ }^{576}$

Entretanto en el campamento pompeyano reinaba una absoluta confianza y una seguridad lindante con la soberbia, a tal punto que los generales ya se disputaban los despojos de la victoria (Caes. B. C. III, 83) e incluso planeaban represalias contra aquellos que no tomarían parte de la batalla, específicamente contra Cicerón, quien se había quedado atrás en Dyrrachium. ${ }^{577}$ César expone en Bellum Civile III, 83 la excesiva confianza de los republicanos reflejada en una subestimación de las tropas cesarianas (Caes. B. C. III, 87).

Las diferentes versiones sobre lo ocurrido ese día - César, B.C. III, 82-99; Plutarco, César, 42-47 \& Pompeyo, 67-72; Apiano, B.C. II, 65-82- coinciden en qué sucedió y en cómo ocurrieron los hechos. Suelen invocarse, curiosamente, ciertos “errores” en el relato de César que, supuestamente, no coincidirían con las descripciones de los otros historiadores. ${ }^{578}$ Sin embargo, un rastreo textual permite despejar las dudas y hacer coincidir, si se tienen en cuenta las diferentes perspectivas tomadas por los narradores, los relatos. Plutarco y Apiano describen la disposición previa a la batalla del siguiente modo: Pompeyo a cargo del ala derecha, Escipión en el centro y Domicio Ahenobarbo sobre el costado izquierdo de la formación. Según César, los ejércitos se desplegaron del siguiente modo:

Caesar, cum Pompei castris appropinquasset, ad hunc modum aciem eius instructam animadvertit. Erant in sinistro cornu legiones duae traditae a

\footnotetext{
${ }^{574}$ Postgate, J. (1922), 187-188; Gwatkin Jr. W. (1956), 112-115; R. Bruère, R. (1951), 111-112.

${ }^{575}$ Dilke, O. (1960), 15.

${ }^{576}$ Dilke, O. (1960), 18.

${ }^{577}$ CAES. Civ. III, 83; LIV. CXI; CIC. Div. I, 68 \& Att. XI, 5, 3; Plutarco, Cic. 39 \& Cato minor, 55.

${ }^{578}$ Gwatkin Jr. W. (1956), 109-111; especialmente p. 110: "It would appear not unreasonable, therefore, to say that Caesar as a memorandum writer was correct, but Caesar as a writer is wrong, and that the order of the battle given in the Bellum Civile is in error."
} 
Caesare initio dissensionis ex senatus conusulto; quarum una prima, altera tertia appellabatur. In eo loco ipse erat Pompeius. Mediam aciem Scipio cum legionibus Syriacis tenebat. Ciliciensis legio coniuncta cum cohortibus Hispanis, quas traductas ab Afranio docuimus, in dextro cornu erant collocatae. Has firmissimas se habere Pompeius existimabat. Reliquas inter aciem mediam cornuaque interiecerat numeroque cohortes CX expleverat. Haec erant milia XLV, evocatorum circiter duo, quae ex beneficiariis superiorum exercituum ad eum convenerant; quae tot acie disperserat. Reliquas cohortes VII castris propinquisque castellis praesidio disposuerat. Dextrum cornu eius rivus quidam impeditis ripis muniebat; quam ob causam cunctum equitatum, sagittarios funditoresque omnes sinistro cornu obiecerat. ${ }^{579}$

César, como se había aproximado al campamento de Pompeyo, advirtió que el ejército se había dispuesto de este modo. Estaban en el ala izquierda las dos legiones arrebatadas a César en el comienzo de la disensión por decisión del senado; una de las cuales era llamada la primera (legión), la otra la tercera. En ese lugar estaba el propio Pompeyo. Al cuerpo central lo dirigía Escipión con las legiones de Siria. La legión de cilicia, unida a la cohorte hispánica, las cuales explicamos que habían sido quitadas a Afranio, estaban colocadas en el ala derecha. A éstas Pompeyo las consideraba las más fuertes que él comandaba. A las restantes las había intercalado entre el cuerpo central y los flancos y alcanzaban el número de sesenta cohortes. Éstas tenían 45000 efectivos, y alrededor de dos mil reservas, que habían llegado a ellos del ejército de beneficiarios superiores; los cuales había distribuido por todo el frente. A las siete cohortes restantes las había asignado en el campamento cercano y las fortificaciones defensivas. Su ala derecha de ellos era protegida por cierto río de orillas inaccesibles; por esta causa toda la caballería, los arqueros y los honderos estaban expuestos en su ala izquierda.

Creemos que no existen contradicciones entre los autores, los desajustes surgen de las diferentes perspectivas elegidas por cada autor. César, obviamente, narra ex Caesare, es decir que, cuando se refiere al sinistro cornu, hace referencia específicamente, al ala del ejército enemigo ubicada a su izquierda, la cual equivale al ala derecha del enemigo, César narra ubicado, precisamente, contra Pompeium (B. C. III, 89, 3). Cuando la narración sufre algún cambio de perspectiva, ésta se hace patente en el texto a través de precisas e inconfundibles marcas textuales:

Dextrum cornu eius rivus quidam impeditis ripis muniebat; quam ob causam cunctum equitatum, sagittarios funditoresque omnes sinistro cornu obiecerat. ${ }^{580}$

Eodem tempore equites ab sinistro Pompei cornu, ut erat imperatum, universi procucurrerunt, omnisque multitudo sagittariorum se profudit. ${ }^{581}$

$\mathrm{Su}$ ala derecha estaba protegida por cierto río de costas inaccesibles; por esta causa toda la caballería, los arqueros y los honderos estaban expuestos en su ala izquierda.

En ese instante los jinetes, desde el ala izquierda de Pompeyo, como había sido ordenado, cargaron todos juntos, y toda la multitud de arqueros se lanzó (a la batalla).

\footnotetext{
${ }^{579}$ CAES. Civ. III, 88

${ }^{580}$ CAES. Civ. III, 88.

${ }^{581}$ CAES. Civ. III, 93.
} 
Estas precisiones aportan, paradójicamente, uno de los aspectos más discutidos y polémicos de la versión cesariana de los hechos: el rivus quidam impeditis ripis. Los historiadores y eruditos han intentado en vano identificar este río. ${ }^{582}$ Sin embargo, para nuestro trabajo sólo nos interesa el hecho en sí: el flanco derecho de Pompeyo estaba protegido por un obstáculo natural, y su flanco izquierdo ofrecía campo abierto para las operaciones de la caballería.

Podemos hacernos una clara idea de las tropas desplegadas: el ala izquierda del ejército de César, conformado por las legiones VII y IX, ${ }^{583}$ estaba al mando de Marco Antonio; el centro se encontraba bajo las órdenes de Domicio Calvino y el ala derecha, a las órdenes de Sila, contaba con la veterana X Legio ${ }^{584}$ a su lado, la curtida aunque poco numerosa caballería. César necesitó sólo un golpe de vista para desentrañar y adelantarse a los planes republicanos, muy apegados a la doctrina militar más conservadora, la cual, considerando su superioridad numérica, hubiera resultado pertinente contra cualquier otro general:

"This battle was where Caesar most clearly demonstrated his particular brand of military genius. He was a master tactician. If his strategic thinking was largely conventional -albeit boldly and swiftly executed - once combat was in the offing Caesar could display an inventiveness and extraordinary sureness of touch that set him apart from his peers. Pharsalus can stand as one striking example among many. In August 47 after several times declining Caesar's offer of battle, Pompey at last decided that it was time to move in for the kill. He commanded 11 legions to Caesar's eight, but since his tropos would not match Caesar's veteran legionaries, he placed his chief hope for victory in his far more numerous cavalry, 6,400 to Caesar's 1,000. Massing them on his left flank and supporting them with light infantry, Pompey intended their charge to drive off Caesar's horse. Pompey's cavalry would then swing around behind Caesar's lines of infantry and attack them from the rear while his own infantry held Caesar's legions in place until the trap could be sprung. This plan of attack has venerable roots stretching back to Hannibal's victory in Cannae and even earlier to the battles of Alexander the Great against Persia. It ought to have worked, and against a lesser general it would have." ${ }^{585}$

César despliega, con la velocidad y la precisión de un rayo, una cuarta columna de infantería con órdenes específicas que resultarán decisivas durante el desarrollo de los combates: ${ }^{586}$

Simul his rebus animadversis, quas demonstravimus, timens, ne a multitudine equitum dextrum cornu circumveniretur, celeriter ex tertia acie singulas cohortes detraxit atque ex his quartam instituit equitatuique opposuit et, quid fieri vellet, ostendit monuitque

\footnotetext{
${ }^{582}$ Morgan, J. (1983), 30-45; Gwatkin Jr. W. (1956), 119-121; Bruère, R. (1951), 112; Postgate, J. (1922), 187-189.

${ }^{583}$ Dando-Collins, S. (2010), 143-145 \& 150-151.

${ }^{584}$ Dando-Collins, S. (2010), 152-160.

${ }^{585}$ Rosenstein, N. (2009), 94.

${ }^{586}$ Rosenstein, N. (2009), 92-93.
} 
eius diei victoriam in earum cohortium virtute constare. Simul tertiae aciei totique exercitui imperavit, ne iniussu suo concurreret: se, cum id fieri vellet, vexillo signum daturum. ${ }^{587}$

Al mismo tiempo que advertía estas cosas que hemos demostrado, temiendo que su ala derecha fuera rodeada por la numerosa caballería, velozmente extrajo de la tercera columna filas individuales y con éstas formó una cuarta y las dispuso frente a la caballería, les explicó qué quería que hicieran y les advirtió que la victoria de ese día estaba puesta en el valor de esas cohortes. Al mismo tiempo ordenó a la tercera columna y a todo el ejército que no se lanzara a la batalla sin órdenes suyas: que él, cuando quisiera que lo hicieran, daría la señal con el estandarte.

Lo que César narra, con sospechosa y sutil naturalidad, es en realidad una maniobra absolutamente inaudita en la historia militar, no sólo en su tiempo sino también a lo largo de toda la historia de los conflictos militares:

"As the two sides deployed and Caesar watched Pompey's cavalry mass against his own, he understood immediately the threat they posed not only to his cavalry but to his infantry. To meet it, Caesar improvised. [...] It is worth dwelling on this battle at some length because it strikingly illustrates just what sets Caesar so much apart from other generals: his ability not simply to grasp what the enemy intended but to improvise a brilliant counter-stroke to meet it. Pompey's tactic at Pharsalus is often termed 'hammer and anvil,' in that the infantry, the 'anvil' holds the enemy infantry in place, while the 'hammer', the cavalry, swings around the rear and strikes it from behind. It has never, to our knowledge, been effectively countered- until Pharsalus." 588

César logra anular e incluso revertir un modelo táctico probado, cuyo modelo ideal fue desplegado por otro genio militar de la Antigüedad, Aníbal, quien aniquiló un ejército romano numéricamente superior a sus fuerzas en la batalla de Cannae (216 a.C.), paradigma de perfección militar aun en nuestros días. ${ }^{589}$

\section{LA REPRESENTACIÓN DE LA BATALLA EN PHARSALIA VII.}

La batalla, según la representación de Lucano, muestra, con nitidez, dos bandos bien definidos. Lo primero que salta a la vista y extraña, desde un punto de vista estrictamente histórico, es el despliegue caótico de las tropas de César:

stant ordine nullo,

arte ducis nulla, permittuntque omnia fatis.

(LUC. VII, 333-334)

Se disponen sin orden alguno

sin el arte bélico de su comandante y todo lo entregan al hado.

\footnotetext{
${ }^{587}$ CAES. Civ. III, 89.

${ }^{588}$ Rosenstein, N. (2009), 95. Cf. también Cagniart, P. (2007), 87-88.

${ }^{589}$ Holmes, T. (2003), 747-751.
} 
No deja de llamar la atención esta representación de las legiones cesarianas, cuya disciplina y rigor bélico eran indiscutibles. El poeta, creemos, pretende representar el combate en términos simbólicos y no históricos. ${ }^{590}$ El enfrentamiento no es representado como una lid entre dos ejércitos romanos sino entre dos encarnizados e irreconciliables gladiadores rivales: sed par quod semper habemus / libertas et Caesar, erit. (VII, 694695), ${ }^{591}$ donde César encarna toda la rabies de la tiranía. Nuevamente la representación posee una voluntad poética y un ímpetu estético; como ya dijimos, nadie ignora, ni ahora ni en la antigüedad, que el ejército de Roma y especialmente las veteranas legiones de César eran una aceitada y disciplinada maquinaria militar. ${ }^{592}$

En contraposición a las caóticas tropas cesarianas, en el ejército republicano reina el orden y la disciplina:

stetit ordine certo

infelix acies. cornus tibi cura sinistri,

Lentule, cum prima, quae tum fuit optima bello, et quarta legione datur. tibi, numine pugnax aduerso Domiti, dextri frons tradita Martis. at medii robur belli fortissima densant agmina, quae Cilicum terris deducta tenebat Scipio, miles in hoc, Libyco dux primus in orbe.

Se paró firme con certero orden la desdichada formación. El mando del ala izquierda te fue dado a ti, Lentulo, y la primera legión, que fue la mejor en la guerra, y también la cuarta. A ti, Domicio que luchaste aun siendo los dioses adversos, te fue entregado el frente derecho del combate. Se agrupan en medio del combate las fuerzas más aptas para la guerra, las cuales, traídas desde las tierras de Cilicia, las dirigía Escipión, soldado allí y general supremo en la región de Libia.

Curiosamente, el poeta narra, más allá del uso que éste haga de sus fuentes, ${ }^{593}$ la disposición de los ejércitos desde la perspectiva del propio César: Domicio en el

\footnotetext{
${ }^{590}$ Narducci, E. (1979), 103.

${ }^{591}$ Gómez, J. (2003), 94; Ahl, F. (1976), 56 \& 86-87; Bartsch, Sh. (2005), 500.

592 Cagniart, P. (2007), 93-94. Un claro ejemplo de la superioridad bélica y de la veteranía efectiva de las legiones de César puede verse en el comienzo de la batalla propiamente dicha. A modo de innovación táctica, Pompeyo había ordenado a sus tropas no cargar, con la esperanza de que los soldados cesarianos llegasen cansados a sus filas. Los soldados de César simplemente detuvieron, motu propio, su carrera a medio camino, tomaron aire y retomaron su ímpetu combativo. El propio César critica esta decisión de Pompeyo en B.C. III, 91-92. Cf. también Rosenstein, N. (2009), 96-98.

${ }^{593}$ Bruère, R. (1951), 111-112.
} 
dextrum cornu, Escipión en el centro y Lentulo en el sinistro cornu, ${ }^{594}$ donde también, sabemos, se encontraba Pompeyo.

La contraposición entre ambos ejércitos es clara: los soldados de César, encarnación de la furia y la rabia de su general, son el instrumento por excelencia de su voluntad:

o praeceps rabies! cum Caesar tela teneret, inuenta est prior ulla manus?

(LUC. VII, 474-475)

$[\ldots]$

praecipiti cursu uaesanum Caesaris agmen in densos agitur cuneos, perque arma, per hostem quaerit iter.

(LUC. VII, 496-498)

¡Oh rabia desbocada! Cuando César retenía las armas, ¿se encontró un brazo que se le adelantase?

En veloz carrera el ejército de César ataca enloquecido las densas formaciones, a través de las armas, a través del enemigo se abre camino.

El enloquecido ejército de César es el instrumento con el cual el propio general se regocija al abrirse camino con la ruina (I, 150).

Un poco más adelante, Lucano narra los momentos decisivos del combate: los ataques de las columnas reservadas por César para decidir la suerte la batalla:

cum Caesar, metuens ne frons sibi prima labaret incursu, tenet obliquas post signa cohortes, inque latus belli, qua se uagus hostis agebat, emittit subitum non motis cornibus agmen. inmemores pugnae nulloque pudore timendi praecipites fecere palam ciuilia bella non bene barbaricis umquam commissa cateruis.

Cuando César, temiendo que su primera línea ceda ante la carga, retiene a sus cohortes perpendiculares detrás de las enseñas y hacia el flanco de la batalla, por donde merodeaba el enemigo, lanza súbitamente una formación sin alterar la formación de ese flanco. ${ }^{595}$ Olvidados de la lucha y sin vergüenza de sentir miedo demostraron rápida y públicamente que las guerras civiles nunca son bien ejecutadas por huestes bárbaras.

\footnotetext{
${ }^{594}$ Apiano, B. C. II, 76.

${ }^{595}$ César había dispuesto esta cuarta columna detrás del flanco derecho, en posición oblicua para atacar por sorpresa la numerosa caballería republicana.
} 
Existe aquí, creemos, una clara operación ideológica dentro de la representación poética, una interpretación precisa y operativa de lo ocurrido: la caballería pompeyana es vencida por estar compuesta de mercenarios extranjeros; de ninguna manera se atribuye la victoria al genio militar de César. El propio César es representado de manera muy particular y específica, no como un gran general sino como la encarnación terrena de una fuerza demoníaca omnipresente en el campo de batalla. La figura del general es asimilable a la de una Furia que empuja e inspira a sus soldados a la matanza:

hic Caesar, rabies populis stimulusque furorum, nequa parte sui pereat scelus, agmina circum it uagus atque ignes animis flagrantibus addit.

Aquí César, rabia del pueblo y estímulo de su furor, para que ninguna parte carezca de crimen, recorre toda la tropa y aviva el fuego de sus ánimos en llamas.

Luego, el propio poeta implora a su mente que se retire del campo de batalla y que hunda los horrores de la guerra civil en el olvido (VII, 552-556). Sin embargo, en un juego literario muy a tono con el Lucani mos, lejos de abstenerse de narrar la batalla, el poeta se lanza de lleno en ella y, contagiado de la energía casi infinita de César, el discurso se regodea en los detalles más macabros y sangrientos del combate.

César, omnipresente, escruta las espadas, vigila de manera casi panóptica las manos, las armas, las voluntades y la devoción de cada uno de sus soldados, revisa los cadáveres y los heridos (VII, 560-579). Finalmente el mismísimo general, en una flagrante exageración poética, provee de armas a sus soldados, como si de un simple auxiliar se tratase, y los instiga a atacar Roma y a la propia Libertas:

ipse manu subicit gladios ac tela ministrat aduersosque iubet ferro confundere uoltus, promouet ipse acies, inpellit terga suorum, uerbere conuersae cessantis excitat hastae, in plebem uetat ire manus monstratque senatum: scit cruor imperii qui sit, quae uiscera rerum, unde petat Romam, libertas ultima mundi quo steterit ferienda loco.

Él mismo, con su propia mano, reparte las espadas y suministra los proyectiles, ordena desfigurar los rostros con el hierro enemigo, él mismo impulsa las líneas y empuja las espaldas de los suyos, excita a quienes se retrasan con el látigo de su lanza y les prohíbe ir contra la plebe, les señala el senado: sabe cuál es la sangre del imperio, cuáles las entrañas de la república, dónde atacar a Roma, y en qué lugar se alza para ser herida la libertad última. 
Estamos, claramente, ante una interpretación simbólica del papel de César durante la batalla: el combate se concentra en el par gladiatorial, ${ }^{596}$ Caesar et Libertas. César es ya el avatar de una fuerza histórica, sobrehumana, cuyo avance es tan inexorable como sangriento. ${ }^{597}$

${ }^{596}$ Gómez, J. (2003), 94.

${ }^{597}$ Johnson, W. (1987), 110-112 \& 122-123. 


\section{RECAPITULACIÓN Y CONCLUSIONES PARCIALES}

A los ya estudiados episodios de Bruto y Domicio Ahenobarbo sigue la descripción de los horrores de esta carnicería fratricida (VII, 617-646) y la huida de Pompeyo, ya sabedor de que los dioses se complacen con la causa de César y que Fortuna lo ha abandonado (VII, 647-649), algo que el propio general ya sospechaba, fatídicamente, antes de la batalla en su altercado con Cicerón (VII, 86-87). La posterior conmiseración del narrador por la suerte del Magno ofrece al poeta el campo ideal para desplegar las operaciones poéticas y discursivas, que desestabilizan los paradigmas épicos y filosóficos constitutivos de su discurso que organizarán los libros posteriores, particularmente el VIII y el IX. El asesinato de Pompeyo y, particularmente, la figura de Catón encuentran en estos versos los conceptos y las imágenes sobre los que se construyen. ${ }^{598}$

A través del análisis de los episodios seleccionados podemos ver cómo Lucano reformula el material histórico y sus fuentes por medio de un tratamiento eminentemente poético y con una voluntad claramente estética. El autor no duda en alterar, concentrar, expandir e incluso inventar episodios y circunstancias si esto le permite conseguir una mayor efectividad poética y alcanzar sus objetivos artísticos. Cabe destacar que, como hemos mencionado, cada vez que esto ocurre aparecen en el texto claras marcas discursivas que advierten al lector de estas operaciones poéticas. De este modo, la aparición de Cicerón en el campamento pompeyano, hecho que de por sí marca un desvío poético con la historia, está precedido por la advertencia de que el orador conjuga las cunctorum voces de los generales republicanos. La ficticia presencia de Bruto en medio del combate y la muerte de Domicio Ahenobarbo ofrecen otro claro ejemplo de cómo el poeta no duda en alterar el devenir histórico y alejarse de sus fuentes de la historia si con ello logra un mayor dramatismo y efectividad literaria.

Estas operaciones están íntimamente ligadas a ciertos aspectos enciclopédicos específicos, pues Lucano requiere de su lector una específica y completa competencia histórica que identifique y detecte las invenciones y desviaciones poéticas que separan a la representación de los hechos ocurridos. Las propias divergencias entre lo narrado y lo sabido son, específicamente, las encargadas de señalar y advertir al lector del

\footnotetext{
${ }^{598}$ Bartsch, Sh. (1997), 77-93.
} 
tratamiento eminentemente poético del material histórico. La descripción del despliegue de las tropas y la clara contraposición Ordo/ Chaos tienen como objetivo un planteo claramente estético dentro de la representación y no está, creemos, en la voluntad del narrador presentar estos episodios como hechos históricos sino como representaciones poéticas específicas y operativas dentro de la estructura interna de una obra global y aglutinante. Con esto no queremos decir que la representación sea inocente o carente de ideología, sino todo lo contrario, precisamente por la profundidad y efectividad de este tipo de operaciones el libro VII de Pharsalia es considerado por los estudiosos como el más virulento y radical de toda la obra. ${ }^{599}$

Las fuentes históricas son tratadas con subtextos o cotextos de los cuales se parte con la expresa y manifiesta intención de apartarse de ellos en momentos sensibles y relevantes de la representación para lograr efectos estéticos específicos y puntuales. Estamos, entonces, ante un uso estético-literario de las fuentes históricas, donde éstas operan a modo paradigmas literarios que resultan de este modo subvertidos y resignificados por las operaciones poéticas ya destacadas. Por lo tanto, al apartarse manifiestamente de las versiones consensuadas sobre el desarrollo de la batalla Lucano no busca inaugurar nuevas versiones históricas o revisar las ya conocidas sino que, lejos de pretender engañar al lector, ${ }^{600}$ tal como puede inferirse de la visión de O. Dilke en su comentario sobre la muerte de Domicio (v. 600): "Unfortunately for Lucan we have Caesar's account." El adverbio "unfortunately" da a entender que el comentarista interpreta las operaciones del poema de un modo completamente diferente al nuestro, leyendo en ellas una voluntad de intervenir en el desarrollo del relato de la historia y de instaurar su versión de los hechos. Lucano, al contrario, cuenta con la competencia enciclopédica del lector para que detecte, interprete y llene de significación la representación poética desplegada en el cuerpo de la obra. No estamos entonces ante una operación revisionista de la historia sino ante un proyecto creador, ante una representación poética precisa y coherente que utiliza el material histórico con fines eminentemente estéticos.

\footnotetext{
${ }^{599}$ Ahl, F. (1976), 44-46.

${ }^{600}$ Dilke, O. (1960), 145.
} 


\section{UTILIZACIÓN, REFORMULACIÓN Y SUBVERSIÓN DEL MATERIAL POÉTICO AUGUSTEO}

\section{LA REFLEXIÓN HORACIANA SOBRE LA GUERRA CIVIL}

La importancia de Horacio en los autores del siglo I d.C. ha sido usualmente eclipsada por la enorme figura de Virgilio. Si bien es cierto que en Pharsalia no abundan las referencias directas a la obra de Horacio -Frederick Ahl es uno de los pocos estudiosos que ha destacado la presencia de la Oda 2.1 en la configuración de varios episodios de Pharsalia ${ }^{601}$; sin embargo, su poesía funciona como agente cohesionador del discurso poético y ofrece un material riquísimo en imágenes que tanto Séneca como Lucano saben aprovechar en sus originales y personales proyectos creadores. ${ }^{602}$ Horacio y Lucano recorrieron trayectorias inversas en su relación con el poder de Roma. Sin embargo, tanto el escepticismo horaciano de la obra temprana como su eventual acercamiento a la figura de Augusto en las odas ofrecen a Lucano numerosas imágenes ya establecidas en el imaginario literario romano. ${ }^{603}$ Nos concentraremos en el modo en que Lucano reformula este material horaciano específico y particular para construir la enorme figura de Catón de Útica, teniendo en cuenta también: los Epodos 7 y 16, las Odas III, 3 y IV, 15 son parte fundante de la configuración lucaniana de la figura de Catón, aún más que las Odas I, 2 y II, 1 cuya presencia en Pharsalia es más patente. Tomaremos también en cuenta la imagen del general republicano que Séneca construye en su tratado De providentia y que lo convierte en un exemplum paradigmático de firmeza moral e intransigencia ética:

"He [Seneca] may hardly be said to mourn its [libertas] loss in any serious way. In contrast, Lucan's Pharsalia continually foregrounds the loss of libertas and forces us to ruminate on the consequences. In vignettes such as we encounter in Letter 14, Seneca perpetuates a very particularized memory of Cato, a memory of an essential depolitized Cato. Cato's relevance in Neronian Rome -the reason Neronian readers should remember him - lies not in his political views, but rather in the manner in which he conducted himself in trying circumstances. While it is true that Seneca admires Cato, nowhere does he admire him for his opposition to Caesar. He repeatedly comes back to Cato's fortitude, but never suggests that we should take the cause of Catonian libertas,

\footnotetext{
${ }^{601}$ Ahl, F. (1976), 23, 82-83 \& 106-107.

${ }^{602}$ Tarrant, R. (1985), 216-217; Vizzotti, M. (2006), 528-535 \& Vizzotti, M. (2009), 307-317.

${ }^{603}$ Seguimos principalmente el trabajo de la Prof. Ma. D. Buisel (2006), "La falta primigenia en la fundación de la ciudad y de la estirpe", Limes n 18, Santiago de Chile, 129-152.
} 
that is, the Republic. In short, the memory of Cato Seneca most wishes to preserve is that of a moral exemplum, not as an exemplary opponent to absolutism. ${ }^{" 604}$

La reflexión horaciana sobre la guerra civil y sus causas recorre la obra entera: ${ }^{605}$ comienza con una mirada escéptica, incapaz de concebir una salida o vislumbrar una solución a los crímenes originados por la falta primigenia de Rómulo, para luego adoptar una posición diferente: el poeta vislumbra la posibilidad de expiación a través de una restauración ética y moral que lave los delicta maiorum (Carm. III, 6, 1). Esto puede lograse en el plano humano y social gracias a la emergencia de una figura particular, la del expiator, anunciada en I, 2, 25-26 \& 29-30, pero aún no identificada explícitamente con la figura de Augusto. ${ }^{606}$

Lucano y Horacio parten desde un lugar en común: las guerras civiles tienen su origen en el fratricidio primigenio durante la fundación de la Urbs:

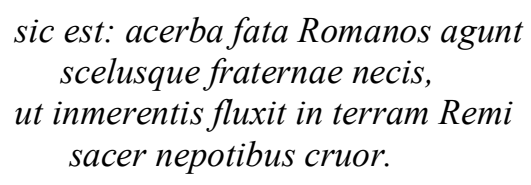

(Epod. 7, 16-20)

Así es: amargos hados y el crimen de la matanza fraterna persiguen a los romanos desde que fluyó por la tierra la sangre inocente de Remo, maldita para sus descendientes.

El vate reflexiona sólo sobre la causa y la condición culpable -scelesti (Epod. VII, 1)del pueblo romano pero no vislumbra salida alguna de esta condición histórica y existencial. Lucano, por su parte, también coloca el origen y causa del conflicto en la fundación de Roma: fraterno primi maduerunt sanguine muri -los muros primeros fueron manchados por la sangre fraterna- $(L U C . \mathrm{I}, 95) .{ }^{607}$

Resulta muy interesante ver cómo, partiendo desde el mismo origen, ambos poetas toman rumbos divergentes. Intentaremos mostrar cómo Lucano utiliza y reformula el derrotero poético horaciano que se resuelve con la figura del expiator en la oda IV, 15. Para esto nos concentraremos primero en las imágenes configuradas por Horacio.

\footnotetext{
${ }^{604}$ Gowing, A. (2005), 79.

${ }^{605}$ Buisel, M. (2006), 131.

${ }^{606}$ Buisel, M. (2006), 136-137.

${ }^{607}$ Asso, P. (2010), 163-164.
} 
Partiendo de la visión escéptica y desesperanzada del epodo VII, el poeta concibe luego una esperanza utópica. Roma ha caído víctima de sus propias fuerzas y otra generación sufre las terribles consecuencias de la guerra civil: ${ }^{608}$

Altera iam teritur bellis civilibus aetas, suis et ipsa Roma viribus ruit.

(Epod. 16, 1-12)

Otra generación se desgasta a causa de las guerras civiles y Roma misma se derrumba a causa de sus propias fuerzas.

Frente a la implosión de la ciudad, Horacio propone una fuga utópica a las islas afortunadas:

Vos quibus est virtus, muliebrem tollite luctum Etrusca praeter et volate litora, nos manet Oceanus circum vagus: arva, beata petamus, arva divites et insulas, reddit ubi cererem tellus inarata quotannis et inputata floret usque vinea, germinat et numquam fallentis termes olivae suamque pulla ficus ornat arborem, mella cava manant ex ilice, montibus altis levis crepante lympha desilit pede.

(Epod. 16, 39-48)

Vosotros que poseéis la virtud, deponed el lamento femenino y escapad más allá de las costas etruscas, nos queda el océano que todo lo rodea: busquemos los campos, los campos felices y las islas fecundas,

donde la tierra sin arar ofrece a Ceres cada año y florece constantemente la vid sin podar,

[donde] germina la rama del olivo jamás engañoso y el higo oscuro adorna su árbol,

[donde] mana la miel de la hueca encina y el manantial ligero se precipita sonoro desde los altos montes.

La única salida vislumbrada es la huida de una elite pía, (quibus est virtus) que debe, junto al poeta (nos), alcanzar los beata arva y las divites insulas fuera del ámbito de la república derrumbada. ${ }^{609}$

\footnotetext{
${ }^{608}$ La imagen de Roma víctima de su propia grandeza resuena en estos famosos versos de Lucano: inuida fatorum series summisque negatum/ stare diu nimioque graues sub pondere lapsus/nec se Roma ferens. (LUC. I, 70-72).

${ }^{609}$ Buisel, M. (2006), 134.
} 
La noción de expiación comienza a madurar en las Odas. Horacio está más cercano a la figura y al proyecto político y social de Augusto y concibe ahora la posibilidad de un proceso expiatorio. Es fundamental para esta perspectiva el favorable panorama político y social que se impuso al caos de la guerra civil luego de la batalla de Actium. ${ }^{610}$ La figura del expiator comienza a delinearse, aunque su estatus aún se encuentra en el ámbito de lo posible y deseable, matiz bien delineado en las interrogaciones que abren las estrofas 7 y 8 de la oda I, $2:^{611}$

Quem nocet diuum populus ruentis imperi rebus?

(Carm. I, 2, 25-26)

$[\ldots]$

Cui dabit partis scelus expiandi

Iuppiter?

(Carm. I, 2, 29-30)

¿A qué dios invocaría el pueblo, cuando se derrumba el imperio?

$[\ldots]$

¿A quién dará Júpiter el papel de expiar el crimen?

Existe entonces, en la concepción de Horacio, la posibilidad histórica de un proceso específico de restauración tanto política como moral encarnada en la figura del pater atque princeps (Carm. I, 2, 50). ${ }^{612}$ Este proceso es teleológico: nace como potencialidad deseable y objetivo necesario en la oda I, 2 y reaparece in medias res, en plena realización, pero aún a medio camino, en la oda III, 6 :

\section{Delicta maiorum inmeritus lues, \\ Romane, donec templa refeceris aedisque labentis deorum et foeda nigro simulacra fumo.}

(Carm. III, 6, 1-4)

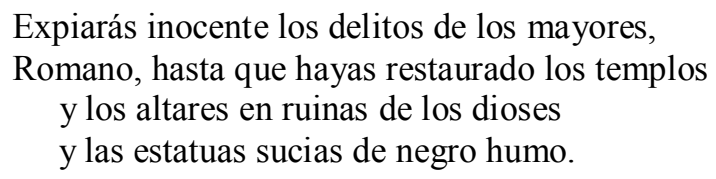

Roma debe restaurarse para dejar atrás los terribles delicta maiorum y recuperar la virtus de los varones rústicos que vencieron a Aníbal, a Pirro y a Antíoco (Carm. III, 6, $33-40)$.

\footnotetext{
${ }^{610}$ Buisel, M. (2006), 136.

${ }^{611}$ Nisbet, R. \& Hubbard, M. (1970), 28-29.

${ }^{612}$ Nisbet, R. \& Hubbard, M. (1970), 38-39.
} 
No es casual que el proceso culmine en el último poema del último libro de las Odas. ${ }^{613}$ En la oda IV, 15 la expiación es vista como algo ya logrado:

Tua, Caesar, aetas

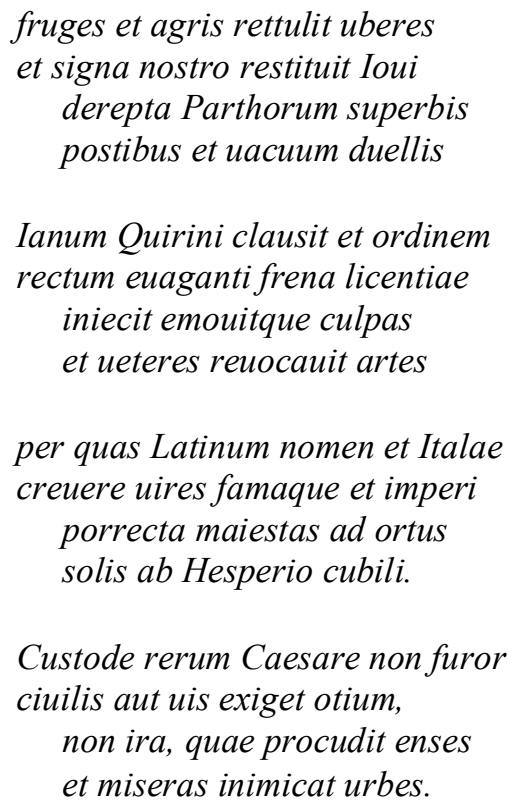

Custode rerum Caesare non furor ciuilis aut uis exiget otium,

non ira, quae procudit enses

et miseras inimicat urbes.

Tu época, César,

ha retornado las copiosas mieses a los campos y restituido a nuestro Júpiter las enseñas arrebatadas de las puertas soberbias de los partos, y, libre de combates,

ha clausurado el templo de Jano Quirino $y$ ha puesto freno a la licencia desbocada, ha removido las culpas y convocado las antiguas artes que expandieron

el nombre latino, el poderío de Italia y su fama; desde el nacimiento del Sol hasta su morada hesperia se ha alzado la majestad del Imperio.

Siendo César el custodio del estado, ni el furor civil o la violencia acosarán la paz, ni la ira que forja espadas y enfrenta ciudades desdichadas.

${ }^{613}$ Buisel, M. (2006), 144-146 
Horacio muestra su maestría poética a través de una cuidada selección léxica, donde el expiator ha logrado remover las culpas -emovitque culpas (IV, 15, 11)- de los scelesti (Epod. 7,1$)$ y ha restaurado -revocavit (IV, 15, 12)- las antiguas costumbres romanas. ${ }^{614}$ De este modo se cierra magistralmente el ciclo de crímenes fraternos y el derramamiento de sangre romana: el expiator ha logrado rescatar a Roma del furor civile y su aetas se ha impuesto a la disolución política y moral que asolaba la ciudad, amenazando con hundirla en el caos primigenio. ${ }^{615}$ Lucano, como veremos, tendrá una concepción diferente.

LA REFORMULACIÓN LUCANIANA DE LA FIGURA DEL EXPIATOR

et cuncta terrarum subacta
praeter atrocem animum Catonis. ${ }^{616}$

Pharsalia despliega un universo en pleno estado de disolución, donde la caída de la Urbs por excelencia, Roma, implica, vía sympátheia tôn holôn, ${ }^{617}$ el derrumbe del orbis entero. ${ }^{618}$ En este universo casi absurdo se alza la figura de Catón ${ }^{619}$ quien, aun cuando el camino tomado por el mundo parezca contradecir sus convicciones más profundas, ${ }^{620}$ toma partido por una causa que vislumbra vana y elige la acción: ${ }^{621}$

\footnotetext{
${ }^{614}$ Buisel, M. (2006), 145.

${ }^{615}$ Lapidge (1979), 359-361.

${ }^{616}$ HOR. Carm. II, 1, 23-24. Cf. Nisbet, R. \& Hubbard, M. (1978), 24.

${ }^{617}$ Lapidge (1979), 44 \& 348: "The central doctrine of Chryssipus cosmology was that concerning the cosmic pneûma. For his predecessors, Zeno and Cleanthes, the principal cosmic agent had been creative fire (pûr technikón). However, the conception of creative cosmic fire brought many difficulties in its train, particularly concerning question of cosmic stability. Chryssipus attempted to solve these difficulties with his conception of a cosmic pnêิma. Earlier Stoics had taught the notion of a bodily pneûma (a notion derived ultimately from Aristotle) and had also conceived the universe as a living being (Zôon), but Chryssipus was apparently the first to see that the concept of bodily pneûma, through which the animated body was held together and vitalized, could be applied by analogy to the universe. Just as the bodily pneûma held all bodily parts together by creating an internal tension (tónos), so Chryssipus argued that the universe was held together by the coherent force and tensional movements of the all-pervasive cosmic pneûma. [...] From medical theory Chryssipus borrowed the metaphorical notion that all parts of a living body were in 'sympathy' (sympathéa) with one another, whence he could speak of cosmic 'sympathy', sympátheia. And because the cosmic pneûma created a tension in all things which held the universe in its spherical shape, Chryssipus could speak of the resultant cosmic tension as syntonia."

${ }^{618}$ Lapidge (1979), 344-346 \& 359-361; Narducci, E. (1979), 36; Narducci, E. (2002), 46; Salemme, C. (1999), 158-160.

${ }^{619}$ Nos referimos por supuesto, no al Catón histórico, sino al constructo poético-literario del siglo I. d. C. cuyas humanas imperfecciones han sido depuradas y sublimadas por las operaciones poéticas de Séneca y Lucano, quienes logran instaurar finalmente la figura tradicional del mártir de Útica.

${ }^{620}$ Sklenář, R. (1999), 289.

${ }^{621}$ Gowing, A. (2005), 3: "The threatened demise of the Republic was a constant concern for Cicero, who was acutely aware that the political system to which he had devoted his life was living on borrowed time.
} 
'summum, Brute, nefas ciuilia bella fatemur, sed quo fata trahunt uirtus secura sequetur. crimen erit superis et me fecisse nocentem. sidera quis mundumque uelit spectare cadentem expers ipse metus? quis, cum ruat arduus aether, terra labet mixto coeuntis pondere mundi, compressas tenuisse manus?

(LUC. II, 286-92)

$[\ldots]$

non ante revellar

exanimem quam te conplectar, Roma; tuumque nomen, Libertas, et inanem persequar umbram.

(LUC. II, 301-303)

Reconocemos, Bruto, que guerra civil es la más alta impiedad, pero la virtud irá segura a donde los hados la arrastren. Será un crimen de los dioses el hacerme también a mí culpable. ¿Quién querría contemplar, libre de miedo, la caída del cielo y del mundo? ¿Quién, cuando se derrumbe el alto éter y la tierra se desplome mezclada con el peso del mundo conturbado podría mantener las manos atadas?

$[\ldots]$

no me arrancarán de ti

antes de abrazarte ya muerta, Roma; y tu nombre perseguiré, Libertad, y tu vana sombra.

Catón se encuentra ante una paradójica decisión: el hado lo arrastran hacia la mayor impiedad concebible, sin embargo su virtus lo seguirá segura e inconmovible. Hay en este enunciado una profunda subversión del paradigma estoico que enmarca el pasaje. Se produce una contradictio terminis irresoluble, pues la aseveración de Catón pone en crisis dos conceptos centrales del estoicismo: el asentimiento al fatum y la bondad inherente a la Providentia, ${ }^{622}$ tal como la concibe Séneca en su tratado sobre ella. ${ }^{623}$

La oscura y paradójica sentencia con la que el poeta introduce de manera concisa a Catón en el comienzo de la épica comienza, entonces, a tomar sentido: ${ }^{624}$

[scire nefas $]^{625}$, magno se iudice quisque tuetur; uictrix causa deis placuit sed uicta Catoni.

(LUC. I, 127-128)

Cada uno se ampara en un noble juez:

La causa victoriosa complació a los dioses, pero la vencida a Catón.

As he put it, his Republic was a faded picture of its former self (picturam ... evanescentem vetustate) whose moral fibre had become buried in oblivion (oblivione obsoletos, Rep. 5.1.2)."

${ }^{622}$ Edwards, P. (1967), 19 y ss.; Sansoni, G. (1967), 186 y ss.; Ferrater Mora, J. (1994), 1119 y ss.

${ }^{623}$ Narducci, E. (2002), 395-399.

${ }^{624}$ Ahl, F. (1976), 231-232; Shoaf, R. (1978), 151-152, Leigh, M. (2009), 246: “[...] indeed perhaps the greatest proof of the absence or the indifference of the gods is precisely the fact of Caesar's victory (see esp. Luc. 7. 445-59)."

${ }^{625}$ Lucano evoca, en un contexto mucho más solemne, el scire nefas horaciano (I, 11, 1-2). 
El paradigma filosófico se ve sacudido, pues el sabio no contradecirá jamás la voluntad de dios o de la Providencia. La esperanza en la República y en la Libertas no está fundada en el fatum o la razón; al contrario, se debe luchar por ellas aun cuando se tenga la plena seguridad de la derrota: de este modo, actuar katà phýsin conduce paradójica e inexorablemente al crimen. La Providencia jamás ordenaría al sabio actuar mal pues los males son ajenos al sabio ("non miscentur contraria" dice Séneca) ${ }^{626}$ y, en todo caso, existen como posibilidad de ejercicio y fortalecimiento de la propia virtud.

Es importante detenerse brevemente en el desarrollo senequiano de esta noción. Séneca no duda de la existencia de una providencia benévola y su intención en el tratado De providentia no es convencer a Lucilio de la existencia y realidad de la misma, sino dar al joven argumentos que aclaren sus dudas sobre este espinoso asunto. ${ }^{627}$ La tesis central del tratado Sobre la Providencia es presentada del siguiente modo:

"Quare multa bonis uiris aduersa eueniunt?' Nihil accidere bono uiro mali potest: non miscentur contraria. Quemadmodum tot amnes, tantum superne deiectorum imbrium, tanta medicatorum uis fontium non mutant saporem maris, ne remittunt quidem, ita aduersarum impetus rerum uiri fortis non uertit animum: manet in statu et quidquid euenit in suum colorem trahit; est enim omnibus externis potentior. [...] Marcet sine aduersario uirtus: tunc apparet quanta sit quantumque polleat, cum quid possit patientia ostendit. Scias licet idem uiris bonis esse faciendum, ut dura ac difficilia non reformident nec de fato querantur, quidquid accidit boni consulant, in bonum uertant; non quid sed quemadmodum feras interest. ${ }^{, 628}$

¿Por qué les ocurren muchas adversidades a los hombres buenos? Nada malo puede sucederle al hombre bueno: no se mezclan los contrarios. Del mismo modo que ni tantos arroyos ni tantas lluvias lanzadas desde lo alto, ni toda la fuerza de las fuentes medicinales cambian el sabor del mar y ni siquiera lo diluyen; del mismo modo el ímpetu de las cosas adversas no doblega el ánimo del varón fuerte: se mantiene firme y todo lo que le acontece lo adapta a su situación; es por lo tanto más poderoso que todo evento externo. [..] Se marchita la virtud sin adversarios: se revela entonces cuán grande y cuán eficaz cuando muestra cuanto puede soportar. Sabes sin embargo que lo mismo deben hacer los hombres buenos, de modo que no retrocedan ante las dificultades y las desgracias ni se quejen del hado: Los buenos analizan todo lo que ocurre para volverlo algo bueno. No importa qué sucede, sino cómo lo sobrellevas.

Los males y las desgracias se presentan como oportunidades para que el hombre honesto cultive, practique y ponga a prueba su virtus y su constantia (De Providentia, II, $1 \&$ II, 4).

\footnotetext{
${ }^{626}$ SEN. Prov. II, 1.

${ }^{627}$ SEN. Prov. I, 1-6. Cf. especialmente I, 2.

${ }^{628}$ SEN. Prov. II, 1 \& II, 4.
} 
La operación lucaniana de subversión del paradigma filosófico es complejísima y radical. En primer lugar, la frase quo fata trahunt (LUC. II, 287) subvierte de manera radical la traducción senequiana de Crisipo: ducunt volentem fata, nolentem trahunt, ${ }^{629}$ pues el verbo trahere se aplica, paradójicamente, a un volens vir, y como si esto no fuera suficiente para Lucano, los hados lo arrastran, se volente, hacia el summum nefas. La providentia dirige inexorablemente a Catón hacía el mayor mal concebible. ${ }^{630}$ El general es consciente de esta contradicción en la conpages del universo, pero sin embargo escoge actuar valientemente, aun cuando los signos de la disolución universal lo lleven a abandonar la securitas y confrontar las contradicciones y paradojas de sus convicciones más profundas. ${ }^{631}$ Catón preferiría entregarse, a través del ritual de la devotio, ${ }^{632}$ como chivo expiatorio, o como el pharmakos del pueblo romano y de sus costumbres disolutas:

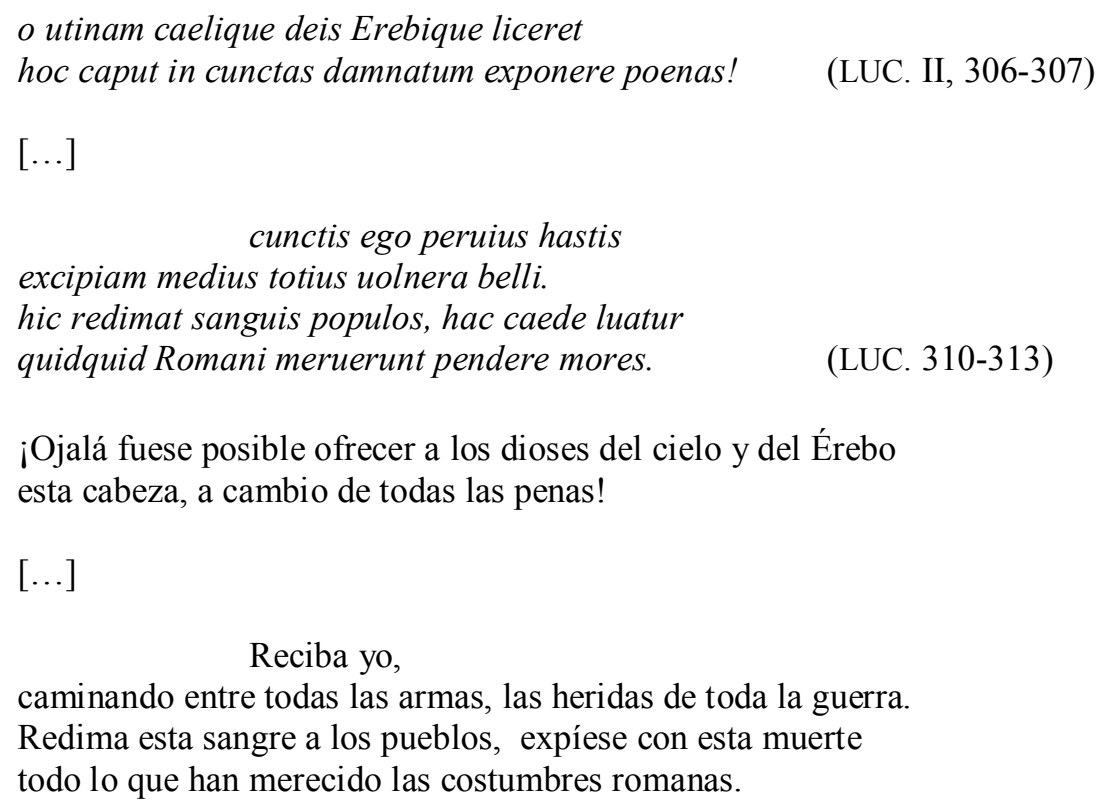

No hay aquí una figura que aliente la esperanza, el summum nefas es inminente y el universo se hunde en el caos. ${ }^{633}$ Sin embargo, en el discurso del Catón lucaniano continúan apareciendo elementos que nos permiten vislumbrar un profundo $\mathrm{y}$ desesperanzado escepticismo:

me solum inuadite ferro, me frustra leges et inania iura tuentem.

\footnotetext{
${ }^{629}$ Ahl, F. (1976), 240.

${ }^{630}$ Narducci, E. (1979), 70; Sklenář, R. (1999), 288-289.

${ }^{631}$ Sklenář, R. (1999), 290.

${ }^{632}$ Johnson, J. (1987), 41-43.

${ }^{633}$ Lapidge, M. (1979), 360-366.
} 
hic dabit hic pacem iugulus finemque malorum gentibus Hesperiis.

A mí solo atacadme con el hierro,

a mí que velo en vano por las leyes y el derecho vacío.

Este cuello otorgará la paz y el fin de los males

a los pueblos de Hesperia.

En vano Catón lucha por proteger las leyes y un derecho que ha sido entregado al crimen -iusque datum sceleri (LUC. I, 2)-. El verbo tueor nos remite al Somnium Scipionis y a la misión de los políticos romanos, "qui tuerentur illum globum, quem in hoc templo medium vides, quae terra dicitur". ${ }^{634}$ Sin embargo el adverbio frustra y el adjetivo inania resultan impensables operando junto a conceptos tan ilustres como leges y iura, tanto en Cicerón como en Horacio.

La inexorable disolución cósmica y moral desplegada en el poema hace que las virtudes fundantes del vir Romanus se vean sometidas a un proceso de erosión y de vaciamiento semántico: la militae pietas mostrada por Vulteyo y sus hombres en el suicidio masivo del libro IV (LUC. IV, 462-581) ${ }^{635}$ y la valentía y fortaleza (virtus) que Esceva exhibe en su aristeia (LUC. VI, 118-262) ${ }^{636}$ resultan monstruosos remedos de los conceptos originales. En medio de la ruina se alza la figura de Catón, incólume y seguro, ${ }^{637}$ en cuya configuración resuena, sin ser evocado de manera explícita, el varón firme y tenaz de la Oda III, 3. Si volvemos a los versos 289-292 del libro II de Pharsalia, podremos comprobar la presencia del sustrato horaciano en la configuración de este personaje:

sidera quis mundumque uelit spectare cadentem expers ipse metus? quis, cum ruat arduus aether, terra labet mixto coeuntis pondere mundi, compressas tenuisse manus? $?^{638}$

¿Quién querría contemplar, libre de miedo, la caída del cielo y del mundo? ¿Quién, cuando se derrumbe el alto éter y la tierra se desplome mezclada con el peso del mundo conturbado podría mantener las manos atadas?

\footnotetext{
${ }^{634}$ CIC. Rep. VI, 15.

${ }^{635}$ En el caso de Vulteyo, los versos siguientes resumen el grado de desesperación que permea esta militiae pietas: "cum sorte cruenta/ fratribus incurrunt fratres natusque parenti,/ haud trepidante tamen toto cum pondere dextra/ exegere enses. pietas ferientibus una/ non repetisse fuit." (LUC. IV, 562-566)

${ }^{636}$ El lamento final del poeta resume la contradicción inherente a la virtus del soldado: "infelix, quanta dominum uirtute parasti” (LUC. VI, 262).

${ }^{637}$ Séneca destaca la inocencia de Catón a través de una sinécdoque tan económica como efectiva: "Ferrum istud, etiam ciuili bello purum et innoxium, bonas tandem ac nobiles edet operas: libertatem quam patriae non potuit Catoni dabit." (Prov. II, 10)

${ }^{638}$ Fantham, E. (1992), 133.
} 
También Séneca, en su particular configuración de Catón de Útica, utiliza como sustrato poético las imágenes de la Oda III, 3:

Ecce spectaculum dignum ad quod respiciat intentus operi suo deus, ecce par deo dignum, uir fortis cum fortuna mala compositus, utique si et prouocauit. Non uideo, inquam, quid habeat in terris Iuppiter pulchrius, si $<e o>$ conuertere animum uelit, quam ut spectet Catonem iam partibus non semel fractis stantem nihilo minus inter ruinas publicas rectum. ${ }^{639}$

$[\ldots]$

Licet' inquit 'omnia in unius dicionem concesserint, custodiantur legionibus terrae, classibus maria, Caesarianus portas miles obsideat, Cato qua exeat habet: una manu latam libertati uiam faciet. Ferrum istud, etiam ciuili bello purum et innoxium, bonas tandem ac nobiles edet operas: libertatem quam patriae non potuit Catoni dabit. ${ }^{640}$

He aquí un espectáculo digno para que dios contemple atento a su obra, he aquí algo igual de digno que dios, el varón fuerte plantado ante la mala fortuna, incluso también si la ha provocado. No veo - digo- qué tiene Júpiter más bello en la tierra, si quisiera posar su mirada [aquí] como que contemplar a Catón, ya derrumbado más de una vez su partido, alzándose en nada menos recto entre las ruinas de la república.

\section{$[\ldots]$}

Aunque todo- dice- haya sido abandonado a la voluntad de uno solo, [aunque] las tierras sean vigiladas por legiones, los mares por flotas y el soldado de César se siente frente a las puertas, Catón tiene por donde escapar: con esta mano construirá un amplio camino hacia la libertad. Este hierro, puro e inmaculado incluso en la guerra civil-, completará al fin una tarea noble y buena, dará a Catón la libertad que no pudo darle a la patria.

He aquí el varón firme y tenaz en su propósito que Horacio cantaba, impertérrito e impávido ante la caída del orbe entero. Entre las ruinas de la república y los escombros de su partido sólo queda en pie la figura erguida y solemne del general. Asediado por el tirano, Catón, calmo y tranquilo, medita cuál es el camino hacia la libertad. Shadi Bartsch (1997) diferencia el Catón de Lucano del iustus vir de la Oda III, 3, pues el impavidus horaciano estaría en disonancia con las palabras del general a Bruto en el libro II, 289-290: “sidera quis mundumque uelit spectare cadentem/ expers ipse metus?" Creemos, sin embargo, que Bartsch lee demasiado literalmente el término impavidus, pues considera que se aplica a aquel que no siente miedo en absoluto y no al varón que

\footnotetext{
${ }^{639}$ SEN. Prov. II, 9.

${ }^{640}$ SEN. Prov. II, 10.
} 
no se deja conquistar por su miedo. ${ }^{641}$ Desde el punto de vista estoico, no es valiente quien no "siente" miedo, sino aquel que rechaza, mediante un acto racional, asentir a la representación del miedo que inevitablemente adviene en tal o cual situación. ${ }^{642}$ Catón, stantem rectum entre las ruinas republicanas, es el exemplar del vir fortis que calmo y tranquilo (Prov. II, 1) enfrenta las desgracias que le acaecen - incurrentia- (Prov. II, 2). La proverbial intransigencia ética de Catón fue destacada también por Cicerón al poco tiempo de su suicidio: ${ }^{643}$

Atque haec differentia naturarum tantam habet vim, ut non numquam mortem sibi ipse consciscere alius debeat, alius [in eadem causa] non debeat. Num enim alia in causa M. Cato fuit, alia ceteri, qui se in Africa Caesari tradiderunt? atqui ceteris forsitan vitio datum esset, si se interemissent, propterea quod lenior eorum vita et mores fuerant faciliores; Catoni cum incredibilem tribuisset natura gravitatem, eamque ipse perpetua constantia roboravisset semperque in proposito susceptoque consilio permansisset, moriendum potius quam tyranni vultus aspiciendus fuit. ${ }^{644}$

"Y esta diferencia de naturalezas posee tanto empuje que uno mismo nunca deba decidir su propia muerte, y otro [en la misma circunstancia] sí deba. ¿Fue una la causa para Marco Catón, y otra distinta para quienes se entregaron a César en África? Sin embargo para estos quizás hubiera sido considerado una culpa si se hubiesen matado, debido a que sus vidas 2 habían sido más livianas y sus costumbres más condescendientes. Pero para Catón, como la naturaleza le hubo dado un rigor increíble, y (que) él mismo robustecía con su constancia y manteniéndose siempre firme en su propósito y en las decisiones asumidas, fue mejor tener que morir a contemplar el rostro del tirano."

Es muy probable que Horacio haya abrevado del modelo ciceroniano para configurar el iustum et tenacem propositi virum: estos adjetivos ofrecen una precisa y certera condensación semántica de la incredibilem gravitatem, la perpetua constantia y el semper in proposito susceptoque consilio (CIC. Off. I, 112), que lo llevan a tomar la

\footnotetext{
${ }^{641}$ Bartsch, Sh. (1997), 118-120; Bartsch, Sh. (2005), 501.

${ }^{642}$ Resulta particularmente interesante ver cómo los agentes hostiles al iustum virum de Horacio se encarnan en el César de Lucano. En Pharsalia César aparece casi como una fuerza elemental (Johnson, J. (1987), 74-75.): la identificación con el rayo aúna de manera genial su celeridad y precisión para la acción con su capacidad destructiva (Ahl, F. (1976): 191-192 \& 197-209). Amenazado por la manifestación terrena de todos los poderes hostiles que enumera Horacio -el rayo, el mar embravecido, la turba de soldados populares-, el varón justo y tenaz se yergue incólume entre las ruinas de Roma y del senado. Sin embargo, debido a la conturbación universal que se ha apoderado del mundo (Lapidge, M. (1979), 334370 \& Sklenáŕ, R. (1999), 281-296), la amenaza es, paradójicamente, la benevolentia Caesaris y el perdón, mientras que, por el contrario, la muerte se presenta como única garante de la libertas.

${ }^{643}$ El suicidio de Catón de Útica fue un acto fundacional que instauró en la sociedad romana y en su imaginario el modelo paradigmático de la voluntaria mors. Su muerte conjugó diversos factores y circunstancias que la convirtieron en el exemplum por excelencia de la eúlogos exagogé. Para dos visiones diferentes sobre la importancia de este hecho véase Griffin (1986a \& 1986b).

${ }^{644}$ CIC. Off. I, 112.
} 
meditada y serena decisión de suicidarse antes que contemplar el rostro del tirano amenazante - quam tyranni vultus aspiciendus. ${ }^{645}$

EL SUSTRATO POÉTICO HORACIANO EN LA CONFIGURACIÓN DEL CATO UTICENSIS LUCANIANO.

La figura del general desaparece luego del libro II para dar lugar al conflicto entre César y Pompeyo, ${ }^{646}$ pero muerto el Magno, el poema se concentra en las vicisitudes de Catón en Libia. Del pesimismo inicial del epodo 7 y pasando por el éxodo de los virtuosos en el 16, el expiator llega a Roma, la Urbs por excelencia, primero como potencialidad, luego como proceso (infectum) y finalmente como hecho consumado, pacificado el orbe y restaurada la República (perfectum).

En Pharsalia el recorrido es inverso: las fuerzas republicanas abandonan Roma, luego Italia y finalmente acampan en Grecia. Tras la derrota el mundo se cierra para los vencidos, que se alinean no detrás de un reconocido guerrero, sino que siguen a un hombre probo, a un político intransigente. El viaje es la contracara del que profetizaba el vate en el epodo 16: se marcha hacia los límites del mundo conocido, hacia una tierra informe e indefinida, como bien lo demuestra la descripción de la naturaleza inasible y ambigua de las Sirtes y de la propia Libia. ${ }^{647}$ Nada más lejano de las Islas Afortunadas, más allá del oceanus circumvagus, donde la fertilidad de los beata arva provee espigas maduras, donde resuenan los manantiales de montaña y los árboles ofrecen sus frutos que el árido y hostil paisaje del norte africano:

'o quibus una salus placuit mea castra secutis
indomita ceruice mori, conponite mentes
ad magnum uirtutis opus summosque labores.
uadimus in campos steriles exustaque mundi,
qua nimius Titan et rarae in fontibus undae,
siccaque letiferis squalent serpentibus arua.
durum iter ad leges patriaeque ruentis amorem.
per mediam Libyen ueniant atque inuia temptent,
siquibus in nullo positum est euadere uoto,
siquibus ire sat est. neque enim mihi fallere quemquam
est animus tectoque metu perducere uolgus.

${ }^{645}$ Compárese la cercanía de los términos ciceronianos con las palabras de Catón en Pharsalia IX, 279281:"nostra quoque inuiso quisquis feret ora tyranno/ non parua mercede dabit: sciat ista iunentus/ ceruicis pretio bene se mea signa secutam." Leigh, M. (2009), 249.

${ }^{646}$ Ahl F. (1976), 231-232.

${ }^{647}$ LUC. IX, 303-510; Especialmente los versos 303-309: "Syrtes uel, primam mundo natura figuram/ cum daret, in dubio pelagi terraeque reliquia/ (nam neque subsedit penitus, quo stagna profundi/ acciperet, nec se defendit ab aequore tellus, / ambigua sed lege loci iacet inuia sedes, / aequora fracta uadis abruptaque terra profundo,/ et post multa sonant proiecti litora fluctus."; Moretti, G. (1999), 247249. Para un panorama preciso de la representación de África en Lucano, confróntese Asso, P. (2011). 
hi mihi sint comites, quos ipsa pericula ducent, qui me teste pati uel quae tristissima pulchrum

O vosotros a quienes complació, buscando mi campamento, como única salvación el morir con el cuello indómito, preparad vuestras mentes para la noble empresa de la virtud y los trabajos más arduos. Iremos por campos estériles y por las regiones calcinadas del mundo, por donde el Titán es excesivo y raras son las aguas en las fuentes, [por donde] los campos resecos se agitan con mortíferas serpientes: Un duro camino hacia las leyes y el amor a la Patria que se derrumba. A través de Libia marchen y se adentren en lugares intransitados, aquellos quienes no incluyan entre sus votos escapar a las circunstancias, aquellos para quienes ir es suficiente. Pues no está en mi ánimo engañar a nadie o conducir un pueblo ocultando el miedo.

Sean mis compañeros aquellos a quienes los guíen los peligros, quienes afirmen que es hermoso y [digno de un] romano soportar las adversidades más terribles.

Vemos aquí varias alusiones claras a Virgilio y a Horacio. El discurso se abre con una reformulación de la máxima virgiliana: "Una salus uictis nullam sperare salutem." (A. II, 354). Sin embargo morir no es suficiente; se debe morir indomita cervice y luego de recorrer un camino a través de una tierra hostil y reseca, plena de peligros. Además, como si fuera poco, el objetivo de la travesía resulta ser sólo una vana sombra y un ideal en plena disolución. Sin embargo, para aquellos que acceden a la virtud (quibus est virtus - Epod. 16, 39), basta con recorrer este camino. ${ }^{648}$

La elite pía que navegaba junto al poeta hacia las exuberantes islas afortunadas ahora sigue a Catón a través de un desierto que se convierte en la prueba última de la virtus de los pocos romanos íntegros (vv. 391-392): los scelesti han vencido y vienen tras ellos. Nuevamente Catón pide para sí el soportar las adversidades más terribles: ${ }^{649}$

at, qui sponsore salutis miles eget capiturque animae dulcedine, uadat ad dominum meliore uia. dum primus harenas ingrediar primusque gradus in puluere ponam, me aetherius feriat, mihi plena ueneno occurrat serpens, fatoque pericula uestra praetemptate meo.

(LUC. IX, 395-398)

$[\ldots]$

serpens, sitis, ardor harenae

dulcia uirtuti; gaudet patientia duris;

laetius est, quotiens magno sibi constat, honestum.

\footnotetext{
${ }^{648}$ Narducci, E. (2002), 405-406.

${ }^{649}$ Narducci, E. (1979), 144.
} 
sola potest Libye turba praestare malorum

ut deceat fugisse uiros.' sic ille pauentis

incendit uirtute animos et amore laborum,

inreducemque uiam deserto limite carpit;

(LUC. 402- 408)

Pero el soldado que necesita un garante de su salvación

y cuya alma es cautivada por los placeres, vaya hacia su amo

por un camino más propicio. Mientras yo penetre primero

en la arena y pise primero el polvo, [mientras] el éter me castigue,

y me ataque la serpiente llena de veneno, contemplad vuestros peligros

en el mío.

\section{$[\ldots]$}

las serpientes, la sed, el calor de la arena

son delicias para la virtud; la resistencia se complace en la adversidad;

más dichoso es el bien cada vez que se obtiene con un gran precio.

Sólo Libia, con su multitud de males, pudo demostrar

que huir es digno de varones. Así enciende los ánimos de los temerosos

con su virtud y su amor por los trabajos,

y emprende un camino sin regreso por los límites desiertos.

Serpientes, sed y ardores son la contracara de la inarata tellus, las vinea inputata, los verdes olivos nunca engañosos, los generosos árboles y los límpidos manantiales de Horacio (Epod. XVI, 39-48). Las adversidades son la prueba y el fin último de las virtudes romanas, no su recompensa merecida: los peligros de la tierra africana dignifican y enaltecen la huida de los soldados. ${ }^{650}$

\section{HORACIO Y LA CONFIGURACIÓN DE ATREO COMO FURIARUM SACERDOS}

Sabemos que la concepción poética de Séneca se nutría tanto de los logros y las innovaciones que los poetas del siglo I a.C. habían conseguido como de las formas clásicas de la tragedia ática. Los poetas augusteos le ofrecían un prestigioso y nutrido corpus ya establecido sobre el cual trabajar, discutir e innovar. ${ }^{651}$ De este modo, como lo demuestran los trabajos de Alessandro Schiesaro sobre Thyestes y el de Michael Putnam sobre el uso de motivos virgilianos en las tragedias, podemos ver que Séneca no sólo lee y cita a estos autores, sino que además los utiliza de modo tal que todo el prestigio, la resonancia, y muchas veces, el sentido primigenio de los pasajes aludidos

\footnotetext{
${ }^{650}$ Shoaf, R. (1978), 145-146. La subversión del paradigma épico permea toda la Pharsalia, desde el propio comienzo - victrix causa deis placuit sed victa Catoni (LUC. I, 128)- pasando por el famoso vincere peius erat en VII, 707, hasta este certero deceat fugisse uiros. (LUC. IX, 406).

${ }^{651}$ Tarrant, R. (1995), 229-230.
} 
adquieran, dentro del marco trágico, ${ }^{652}$ un nuevo matiz y una nueva dimensión. ${ }^{653}$ Dice Séneca en su epístola LXXXIV a Lucilio:

"Apes, ut aiunt, debemus imitari, quae vagantur et flores ad mel faciendum idoneos carpunt, deinde quidquid attulere disponunt ac per favos digerunt et, ut Vergilius noster ait,

liquentia mella, stipant et dulci distendunt nectare cellas.

De illis non satis constat utrum sucum ex floribus ducant qui protinus mel sit, an quae collegerunt in hunc saporem mixtura quadam et proprietate spiritus sui mutent. Quibusdam enim placet non faciendi mellis scientiam esse illis sed colligendi. Aiunt inveniri apud Indos mel in arundinum foliis, quod aut ros illius caeli aut ipsius arundinis umor dulcis et pinguior gignat; in nostris quoque herbis vim eandem sed minus manifestam et notabilem poni, quam persequatur et contrahat animal huic rei genitum. Quidam existimant conditura et dispositione in hanc qualitatem verti quae ex tenerrimis virentium florentiumque decerpserint, non sine quodam, ut ita dicam, fermento, quo in unum diversa coalescunt. Sed ne ad aliud quam de quo agitur abducar, nos quoquehas apes debemus imitari et quaecumque ex diversa lectione congessimus separare (melius enim distincta servantur), deinde adhibita ingenii nostri cura et facultate in unum saporem varia illa libamenta confundere, ut etiam si apparuerit unde sumptum sit, aliud tamen esse quam unde sumptum est appareat."

Debemos - como dicen- imitar a las abejas, que vagan y cosechan las flores idóneas para producir la miel, luego todo lo que consiguieron lo ordenan y lo distribuyen por los paneles $y$, como dice nuestro Virgilio:

'derraman líquida miel, y extienden el dulce néctar por las celdas'

De éstas no se sabe con seguridad si sacan el jugo de las flores que luego se convierte en miel, o si a lo que recogieron lo transforman en este sabor hasta cierto punto al mezclarlo con una propiedad de su espíritu. Sin embargo a algunos agrada pensar que no poseen la ciencia de producir la miel sino de recogerla. Dicen entre los indos que la miel se encuentra en las hojas de la caña, que la genera o el rocío de aquellos cielos o un humor dulce y espeso de las mismas cañas; que en nuestras hierbas también se encuentra esta capacidad pero menos manifiesta y notable, a la cual busca y extrae el insecto nacido para este asunto. Otros estiman que a través de la elaboración y la disposición se transforma en esta sustancia lo que han extraído de lo más tierno de las hojas y las flores, pero no sin cierta, por así decirlo, fermentación que funde en uno los diversos elementos. Pero para no desviarme a algo distinto de lo que hablamos, debemos nosotros también imitar a estas abejas y distinguir de las diversas lecciones

\footnotetext{
${ }^{652}$ Rosenmeyer, Th. (1989), 104-105.

${ }^{653}$ Tarrant, R. (1995), 225, "One Might fairly say that Seneca applies to tragedy the blending of genres so widely practiced by the major Augustan poets, and does so using predominantly Augustan material. From the standpoint of classical Greek practice some of the techniques thereby introduced appear "untheatrical" (for example, extended similes in the epic manner or narrative- style description of characters' appearances or actions), and consequently these features of Senecan drama have often been seen as flaws or adduced to show that Seneca did not write with stage production in mind. Another possible inference would be that Seneca's conception of tragic poetry owed at least as much to Augustan ideas of literary genre and generic innovation as to the form of classical Greek tragedy."

${ }^{654}$ SEN. Ep. LXXXIV, 3-5.
} 
que acumulamos (pues sirven mejor diferenciadas), luego, aplicada la preocupación de nuestro intelecto y con dedicación, fundir en un solo sabor aquellos variados ungüentos, para que, si resulta evidente de donde fue recogido, sin embargo parezca algo distinto a la fuente donde fue recogida.

Como puede verse, Séneca muestra una muy personal e innovadora postura respecto de la tradición literaria y también respecto al uso poético de esta tradición literaria. Podemos detectar un uso verdaderamente original de las obras de autores como Virgilio, Ovidio y Horacio, principalmente, a través de ciertos procesos de desestabilización y subversión del material poético seleccionado. Esta operación tiene como componente principal precisamente el prestigio, la popularidad y la resonancia de los textos eminentes escogidos para luego volverlos sobre sí mismos y alterar sus condiciones de enunciación dentro del marco de la tragedia para que adquieran una nueva dimensión y significación que, si bien alude al texto primigenio, resulta subvertida y trastrocada.

Hay, al menos, dos referencias directas a las Odas de Horacio en Thyestes que aparecen en dos momentos cruciales de la tragedia, ambas en boca de Atreo. Estas odas son la III, 3 y la I, 1, odas que per se brillan con luz propia y que, además de pertenecer al grupo de las odas más célebres y reconocidas, ocupan un lugar de privilegio en cualquier antología poética del corpus augusteo. Ya hemos trabajado sobre el rol y la función de la representación estoica dentro del drama senequiano y la épica lucaniana, donde la corriente filosófica provee al autor de un marco referencial y un vocabulario que ofrecen el sustrato para la problematización literaria de los aspectos más controvertidos y menos asentados de la escuela y que, al mismo tiempo, le permiten la creación poética de una obra personal e innovadora. ${ }^{655}$ Ya hemos visto la importancia de la obra de Horacio en la configuración de la figura emblemática de Catón de Útica y también cómo el propio Atreo se instaura en la obra trágica como la antítesis axiológica del general republicano, por lo que no resulta extraño que la obra de Horacio sea realmente operativa en la construcción de este personaje. Resaltamos nuevamente la distancia existente entre la figura del héroe barroco, que sobrelleva la ruina del universo y aparece como un agente pasivo dentro del proceso, con personajes como Atreo o César, agentes y principios activos que generan las turbulencias cósmicas que derrumban los órdenes establecidos, tanto sociales como individuales y subvierten los

${ }^{655}$ Rosenmeyer, Th. (1989), 43. 
fundamentos de la creación. El rey es capaz de derribar el orbe sobre su propia cabeza con tal de destruir también a su hermano:

haec ipsa pollens incliti Pelopis domus

ruat uel in me, dummodo in fratrem ruat.

(Thy. 190-191)

Que esta misma casa del famoso Pélope

se derrumbe sobre mí, con tal de que se derrumbe sobre mi hermano.

Atreo se regodea en abrirse camino con la ruina del mundo y demuestra una concepción del regnum verdaderamente pragmática $\mathrm{y}$, aunque pueda resultar un adjetivo anacrónico, maquiavélica. Su dicción es violenta y práctica: $:^{656}$

Laus uera et humili saepe contingit uiro,

non nisi potenti falsa. Quod nolunt uelint.

(Thy. 211-212)

$[\ldots]$

Sanctitas pietas fides

priuata bona sunt; qua iunat reges eant.

(Thy. 217-218)

$[\ldots]$

perimat tyrannus lenis: in regno meo

mors impetratur

(Thy. 247-248)

La alabanza verdadera alcanza a menudo al varón humilde,

la falsa sólo al poderoso. Lo que no quieren, quieran.

$[\ldots]$

la pureza, la piedad, la lealtad

son bienes privados; vayan los reyes a donde deseen.

$[\ldots]$

Que mate el tirano moderado: en mi reino

la muerte se suplica.

Sin embargo, el verdadero procedimiento de apropiación y subversión de estos textos eminentes se da a través de la homologación de las figuras del tirano y el vate sacerdote. ${ }^{657}$ Afirma Horacio en el programático comienzo de sus Odas Romanas:

Odi profanum uolgus et arceo.

Fauete linguis: carmina non prius

audita Musarum sacerdos

uirginibus puerisque canto.

(Carm. III, 1, 1-4)

${ }^{656}$ Tarrant, R. (1985), 125-126.

${ }^{657}$ Gadamer, H-G. (1998), 100-101. 
Odio al vulgo profano y lo evito.

¡Contened las lenguas! Versos no antes oídos

como sacerdote de las Musas canto

a las doncellas y a los jóvenes.

Vemos cómo el Musarum sacerdos horaciano es arrancado de su campo semántico específico y reaparece en escena transformado en un Furiarum sacerdos que entona inaudita carmina que espantan incluso a los dioses. ${ }^{658}$ Como ya vimos, Atreo opera, y es descripto, como un verdadero sacerdote:

ego destinatas uictimas superis dabo

$[\ldots]$

Ipse est sacerdos, ipse funesta prece

letale carmen ore uiolento canit.

stat ipse ad aras, ipse deuotos neci

contrectat et componit et ferro admouet;

attendit ipse - nulla pars sacri perit.

(Thy. 691-695)

Yo ofreceré las víctimas destinadas a los dioses.

\section{$[\ldots]$}

Él mismo oficia de sacerdote, él mismo entona

el canto letal con boca violenta. Él mismo se alza junto al altar,

él mismo manipula a los condenados

los ordena y blande el hierro

él mismo dispone todo - ninguna parte del rito es descuidada.

La figura de Atreo, quien está más cerca del instans tyrannus de la Oda III, 3, 3 y del bellans tyrannus del verso 7 de la oda III, $2,{ }^{659}$ es una reformulación subversora de la figura del musarum sacerdos que entona las carmina non prius audita para la juventud romana y la proyecta la representación a límites monstruosos, los cuales se despliegan en la tragedia a través de la representación grotesca y abyecta de la ceremonia de cocción de los hijos de Tiestes, cuya manifestación cósmica es la caída del cielo y del Zodíaco, que ya hemos analizado.

Atreo, como César en Pharsalia, aparece en escena como una figura gigantesca y desmesurada que supera incluso a los dioses. El rey consigue su proposito de derrumbar la creación, tal como sucede en la oda III, 3 sobre su propio hermano, pero

${ }^{658}$ Nisbet, R. \& Rudd, N. (2004), 8.

${ }^{659}$ Nisbet, R. \& Rudd, N. (2004), 25-26. 
esta vez de entre las ruinas no queda incólume la figura monolítica del varón estoico, sino que por sobre las ruinas se yergue la figura del tirano victorioso y exultante: ${ }^{660}$

Aequalis astris gradior et cunctos super

altum superbo uertice attingens polum.

nunc decora regni teneo, nunc solium patris.

dimitto superos; summa uotorum attigi.

(Thy. 885-888)

Igual que un astro avanzo y por encima de todos,

alcanzando el alto polo con mi cabeza soberbia.

Ahora poseo los honores del reino, ahora el trono paterno

ahuyento a los dioses, he alcanzado la suma de mis votos.

Nuevamente la figura de Atreo ha devorado la imagen horaciana y la ha subvertido y conturbado de manera radical: ${ }^{661}$ el Furiarum sacerdos es ahora un vate consagrado e inspirado por Megera y la terrorífica cohorte de las Furias (Thy. 250-252). Las referencias a Horacio en la obra poética de Séneca, si bien no demasiadas, son en verdad precisas y operativas. Séneca apunta a ciertos pasajes sensibles y particularmente programáticos en la obra de Horacio, como la oda I, 1: $:^{662}$

Me doctarum hederae praemia frontium

dis miscent superis, me gelidum nemus

Nympharumque leues cum Satyris chori

secernunt populo, si neque tibias

Euterpe cohibet nec Polyhymnia

Lesboum refugit tendere barbiton.

Quod si me lyricis uatibus inseres, sublimi feriam sidera uertice.

(Carm. I, 1, 29-36)

La hiedra, premio de las frentes doctas, me entremezcla con los dioses superiores, en los gélidos bosques los coros de las livianas ninfas y de sátiros me apartan del pueblo, si ni Euterpe cohíbe sus flautas ni Polimnia rehúsa a ofrecer la lira de Lesbos.

Pues si me incluyes entre los vates, heriré las estrellas con mi cabeza soberbia.

La clara y reposada dicción del poeta augusteo ha sido reemplazada por el discurso violento y desmesurado de Atreo. Séneca utiliza a este prestigioso autor romano para poner en escena un complejo juego de alusiones y contrastes, donde el contenido primigenio de las odas citadas es completamente subvertido y trastrocado, no sólo por el

\footnotetext{
${ }^{660}$ Mader, G. (2003), 635-636; Meltzer, G. (1988), 314-316.

${ }^{661}$ Tarrant, R. (1985), 216-217.

${ }^{662}$ Davis, P. (1989), 433. Cf. También Nisbet, R. \& Hubbard, M. (1970), 13-16.
} 
contexto donde se los enuncia, sino también, y quizás principalmente, por el personaje que pronuncia las palabras que remiten a estos poemas.

Atreo, hombre tenaz en su propósito, soportará impávido la caída de su palacio con tal de que este aplaste también a su odiado hermano, y llevará a cabo una venganza tal que la posteridad no podrá ignorar aunque lo desee (Thy. 192-193). Este tirano amenazante y belicoso, a quien no conmueven en su sólida mente la opinión de la plebe o la mano amenazante de los dioses, ${ }^{663}$ logrará alcanzar las estrellas con su cabeza soberbia y se mezclará, o más bien, ahuyentará a los propios dioses superiores. ${ }^{664}$ En vez de ser cantadas estas odas por el musarum sacerdos original, las alusiones estarán en la funesta boca de un sádico y sanguinario furiarum sacerdos.

\section{LA INVOCACIÓN DE LAS FURIAS}

flectere si nequeo superos, Acheronta mouebo. ${ }^{665}$

Ya hemos visto cómo Atreo hace una activa invocación a las fuerzas infernales en los versos 249-254 de Thyestes para que colmen su pecho y oficien de musas inspiradoras para su obra criminal. ${ }^{666}$ Sin embargo, este pasaje alude a un episodio central de Eneida, más precisamente el episodio de Juno y Alecto. Citas y alusiones como ésta sustentan la hipótesis que considera a Séneca uno de los primeros lectores pesimistas de los clásicos augusteos en general, y de Virgilio en particular: ${ }^{667}$

Excede, Pietas, si modo in nostra domo umquam fuisti. Dira Furiarum cohors discorsque Erinys ueniat et geminas faces Megaera quatiens. Non satis magno meum ardet furore pectus, impleri iunat maiore monstro.

¡Fuera, Piedad!, si alguna vez estuviste

\footnotetext{
${ }^{663}$ Kovacs, D. (2007), 788-789.

${ }^{664}$ Volk, K. (2006), 195-196.

${ }^{665}$ VERG. $A$.VII, 312.

${ }^{666}$ El movimiento romántico retomó este topos de la inspiración artística asociada a la figura infernal del Diablo, al menos, desde mediados del siglo XVIII, cf. Parker, F. (2011), 1: "The poetical character ", Keats wrote to his friend Woodhouse, 'has as much delight in concieving an Iago as an Imogen. What shocks the virtous philosopher, delights the chamaleon poet'." Cf. también 2-4 \& 21 y ss.; Blake, W. The Marriage of Heaven and Hell, plate 6, "The Voice of the Devil": "The reason Milton wrote in fetters when he wrote of Angels \& God, and at liberty when of Devils \& Hell, is because he was a true Poet, and of the Devil's party without knowing it."

${ }^{667}$ Tarrant, R. (1995), 225: “Two Virgilian epic episodes stand out: Alessandro Schiesaro's analysis of Thyestes in relation to the Allecto- Turnus Scene in Aeneid 7, and Michael Putman's wide ranging study of themes from the Aeneid in Senecan drama, from which it emerges that Seneca must be regarded, along with Lucan, as one of the earliest pessimist readers of Vergil."
} 
en nuestra casa. Que llegue la cohorte terrible de Furias y Erinis, la Discordia, y Megera agitando sus antorchas gemelas. No arde aun mi pecho con un furor suficientemente enorme. Me agrada llenarlo con una monstruosidad mayor.

Existen, por un lado, muchas afinidades lingüísticas $\mathrm{y}$, por otro, interesantísimas variaciones y diferencias entre ambos pasajes. Juno agita el Aqueronte y Alecto surge desde las tinieblas infernales portando guerra, iras y crímenes con la intención de remover los odios e introducir las antorchas fúnebres en el Lacio:

Haec ubi dicta dedit, terras horrenda petiuit; luctificam Allecto dirarum ab sede dearum infernisque ciet tenebris, cui tristia bella iraeque insidiaeque et crimina noxia cordi.

(A. VII, 323-326)

\section{$[\ldots]$}

tu potes unanimos armare in proelia fratres atque odiis uersare domos, tu uerbera tectis funereasque inferre faces, tibi nomina mille, mille nocendi artes. fecundum concute pectus, dissice compositam pacem, sere crimina belli; arma uelit poscatque simul rapiatque iunentus.

Cuando hubo dicho esto, horrenda se dirigió a la tierra; desde la morada de las terribles diosas y las tinieblas infernales hace salir a la luctífica Alecto, quien posee en su corazón la dura guerra, la ira, el engaño y los funestos crímenes.

\section{$[\ldots]$}

Tú puedes enfrentar en batallas a los hermanos más unidos y arrastrar las casas al odio, llevar el látigo y las antorchas funerarias a los palacios, tú posees mil nombres y mil formas de matar. Agita tu pecho fecundo, destroza la paz concertada, siembra los crímenes de guerra; que los jóvenes quieran, busquen y agiten las armas.

La furia se dirige entonces contra Amata y Turno, quienes caen bajo su poder al recibir el furor en sus pechos. ${ }^{668}$ La operación senequiana de desestabilización de los modelos prestigiosos es sutil y efectiva y nuevamente es de vital importancia la actitud de los personajes. Turno y Amata son receptores pasivos, aunque propicios, para el furor

${ }^{668}$ Plessy, F. \& Lejay, P. (1963), 586-587. 
inspirado por la Furia, mientras que Atreo manifiesta un impulso activo y voluntario en su invocación a las mismas.

En el caso de Amata, Alecto lanza una serpiente ponzoñosa contra ella:

huic dea caeruleis unum de crinibus anguem conicit, inque sinum praecordia ad intima subdit, quo furibunda domum monstro permisceat omnem. ille inter uestis et leuia pectora lapsus uoluitur attactu nullo, fallitque furentem uipeream inspirans animam; fit tortile collo aurum ingens coluber, fit longae taenia uittae innectitque comas et membris lubricus errat.

Contra ella lanza la diosa una serpiente de su cerúlea cabellera, (ésta) se introduce en su pecho hasta lo más profundo de su corazón, para que enloquecida infecte la casa entera.

Ella deslizándose entre sus ropas y sus delicados pechos se asienta sin ser sentida, e inyectando su aliento viperino engaña a la enloquecida (Amata); se convierte la enorme culebra en oro trenzado alrededor de su cuello, se convierte la víbora en una larga cinta y añade a sus cabellos y repta por sus miembros escurridizos.

Es de gran importancia la presencia del verbo conicit, que marca el carácter exterior de la fuerza infernal. La serpiente es arrojada contra Amata, se aloja en su pecho y se mimetiza con sus adornos reales. Lo mismo ocurre en el episodio de Turno, luego de un fallido intento de arengar al joven bajo el aspecto de Cálibe, Alecto se revela en todo su poder y arroja una horrenda antorcha contra el pecho del guerrero:

Talibus Allecto dictis exarsit in iras. at iuneni oranti subitus tremor occupat artus, deriguere oculi: tot Erinys sibilat hydris tantaque se facies aperit; tum flammea torquens lumina cunctantem et quaerentem dicere plura reppulit, et geminos erexit crinibus anguis, uerberaque insonuit rabidoque haec addidit ore: 'en ego uicta situ, quam ueri effeta senectus arma inter regum falsa formidine ludit. respice ad haec: adsum dirarum ab sede sororum, bella manu letumque gero.' sic effata facem iuueni coniecit et atro lumine fumantis fixit sub pectore taedas.

Ante tales palabras Alecto arde en ira. Y un súbito terror recorre los miembros del joven, se clavan sus ojos: con tantas serpientes sisea la Erinia y aspecto tan enorme revela; entonces retorciendo sus ojos llameantes rechaza al que vacila y que intenta decir más cosas, y se erizaron dos serpientes gemelas en sus cabellos, resonó su látigo y agregó estas palabras de su boca rábida: "Aquí estoy, vencida por la decrepitud, la vejez sin fuerzas 
para la verdad, a la cual faltas el respeto con falsos presagios

de guerras entre reyes. ¡Mira esto! Vengo de la sede de mis terribles hermanas, porto guerra y muerte en mis manos"

Así dijo, arrojó una antorcha contra el joven

y clavó la ardiente tea de negra llama en su pecho.

Hemos destacado ya el marcado carácter exterior que posee el furor en este pasaje de Eneida, pero Amata y Turno están lejos de ser víctimas inocentes de la diosa infernal ya que ambos presentan una marcada predisposición de ánimo para recibir la locura en sus pechos. La Furia llega al palacio y encuentra a Amata enfurecida por la llegada de los Teucros:

Exim Gorgoneis Allecto infecta uenenis principio Latium et Laurentis tecta tyranni celsa petit, tacitumque obsedit limen Amatae, quam super aduentu Teucrum Turnique hymenaeis femineae ardentem curaeque iraeque coquebant.

Desde allí Alecto rebosante del veneno de las Gorgonas se dirige al Lacio y a los altos techos del tirano laurentino y asedia el silencioso umbral de Amata, a la cual, enfurecida por la llegada de los teucros y la boda de Turno, atormentaban la preocupación y la ira femenina.

La reina se encuentra, entonces, en un estado óptimo para recibir el influjo de Alecto por su condición enfurecida y encendida.

Turno, por su parte, se muestra altanero e irreverente ante una diosa:

Hic iuuenis uatem inridens sic orsa uicissim ore refert: 'classis inuectas Thybridis undam non, ut rere, meas effugit nuntius auris; ne tantos mihi finge metus. nec regia Iuno immemor est nostri. sed te uicta situ uerique effeta senectus, o mater, curis nequiquam exercet, et arma regum inter falsa uatem formidine ludit. cura tibi diuum effigies et templa tueri; bella uiri pacemque gerent quis bella gerenda.'

El joven, burlándose de la adivina, así responde a la tentativa con su boca: 'El mensaje que una flota ha atravesado la corriente del Tibris, no ha escapado, como crees, a mis oídos; no me inventes miedos tan grandes. La regia Juno no se ha olvidado de nosotros.

Pero a ti, la vejez vencida por la decrepitud y lejana a la verdad, oh madre, te atormenta inútilmente con preocupaciones, y las armas Tu responsabilidad es cuidar las estatuas y los templos de los dioses; Que los hombres, que deben hacer la guerra, manejen la guerra y la paz. 
La respuesta de la Furia no se hace esperar:

Sic effata facem iuueni coniecit et atro

lumine fumantis fixit sub pectore taedas.

olli somnum ingens rumpit pauor, ossaque et artus

perfundit toto proruptus corpore sudor.

arma amens fremit, arma toro tectisque requirit;

saeuit amor ferri et scelerata insania belli,

ira super;

(A. VII, 456-462)

Así dijo y arroja la antorcha contra el joven y con su llama

de humo clavó la antorcha en su pecho.

A él un enorme pavor destroza su sueño, sus huesos y sus brazos

se empapan por el sudor que brota de todo su cuerpo.

enloquecido grita por sus armas, exige armas en aposentos y en su techo;

enloquece del amor al hierro y de la criminal locura de la guerra, y sobre todo de ira.

Ambos personajes son blancos y receptores pasivos del furor. Éste es enviado por un agente exterior, mientras que el caso de Atreo es diferente. El propio rey se regodea invocando a Erinis, Megera y a la legión entera de las terribles Furias, ${ }^{669}$ si algo caracteriza a Atreo es su consciente y constante desmesura, su terrible decisión de ir más allá en su crimen y en su venganza. ${ }^{670} \mathrm{Su}$ pecho ya fue colmado por el fantasma de Tántalo, quien ha logrado agitar la casa entera cumpliendo la orden dada por la Furia:

misce penates, odia caedes funera accerse et imple Tantalo totam domum.

Mezcla los penates, invoca el odio, matanzas, muertes y llena de Tántalo la casa entera.

Las imágenes relacionadas al campo semántico del colmar, superar y castigar son pervasivas ya desde el prólogo y estructuran todo el entramado poético de la tragedia: el odio y las matanzas no son suficientes para revertir el ímpetu del Rey. La insaciable sed de venganza que caracteriza a los Pelópidas lo lleva a buscar algo mucho mayor y terrible (Thy. 272-274) ${ }^{671}$ La fuerza infernal que se ha introducido en Atreo no es suficiente para lograr o siquiera alcanzar mínimamente su ideal de venganza:

\footnotetext{
${ }_{669}$ Tarrant, R. (1985), 95: “52 misce: 'throw into confusion', perhaps suggested by Verg. 7.348 (of Allecto) quo furibunda domum monstro permisceat omnem."

${ }^{670}$ Meltzer, G. (1988), 328-329; Park Poe, J. (1989), 363: "His act of murder fills him [Atreus] but does not satisfy his "hunger"; in the midst of his slaughter he is like an Armenian lion which kills and eats its victims, and seems insatiable, continuing to kill even when his hunger is vanished (733-6). Special notice should be given to the words magno, maiore and satis above. Adjectives and adverbs of size and extent are very common in this play; especially those in the comparative degree, indicating spatial increase or growth."

${ }^{671}$ Park Poe, J. (1989), 363 y ss.
} 
No arde lo suficiente aún mi pecho con una locura enorme, deseo llenarlo con una monstruosidad mayor.

Atreo no sabe aún cuál será exactamente su venganza, pero sí es consciente de la magnitud que la misma debe tener: debe atreverse a algo que aterrorice incluso a los dioses. Atreo, al igual que Juno o Erichto, es una fuerza activa que trae el infierno a la tierra y remueve el Aqueronte, si bien existe esta fuerza interna que empuja a Atreo a cumplir su cometido, él mismo va más allá:

\footnotetext{
[Furia] Ante perturba domum inferque tecum proelia et ferri malum regibus amorem, concute insano ferum pectus tumultu.
}

Antes perturba el palacio y lleva contigo a los reyes las luchas y el terrible amor al hierro, golpea ese pecho feroz con un insano tumulto.

Más allá de la natural predisposición de los Pelópidas para el crimen, es clara la actitud activa del rey en cuanto a la recepción y el uso racional y artístico del furor. En primer lugar abjura de todo vestigio de Pietas y luego comienza la invocación propiamente dicha. En una tragedia barroca y desbordada como lo es Thyestes, ${ }^{672}$ una sola deidad infernal no es suficiente, la invocación comienza con un colectivo indefinido, la dira Furiarum cohors, luego llega Erynis.

\footnotetext{
${ }^{672}$ Segal, Ch. (1984), 325.
} 


\section{RECAPITULACIÓN Y CONCLUSIONES PARCIALES}

Hemos visto cómo Lucano recurre a la imaginería horaciana para configurar la enorme figura del general republicano y cómo el propio Lucano conoce, utiliza y reformula el material poético que Horacio le proporciona para modelar la original, personal y perturbadora Weltanschauung de su Pharsalia. El trayecto horaciano desde el escepticismo hacia la restauración de la Republica es imposible en el universo de Pharsalia, pero sí está presente y es operativo en el imaginario poético de la obra: sus imágenes eminentes aportan sustancia y profundidad al desarrollo de la guerra civil en general y en particular a la figura de Catón, el iustum et tenacem propositi virum de Lucano. Horacio aporta, entonces, un importante sustrato poético: los epodos 7 y 16 son esenciales para entender el desarrollo y la estructura del libro IX y proveen, paradójicamente, la base y la materia poética para las operaciones de desestabilización y subversión de los paradigmas épicos y filosóficos. La oda III, 3, por su parte, instaura en el imaginario poético romano, de manera casi canónica, la imagen eminente del varón justo y tenaz, que evoca la intransigencia proverbial de Catón de Útica - cuncta terrarum subactal praeter atrocem animum Catonis- destacada ya en los escritos de Cicerón. ${ }^{673}$ Tanto Séneca como Lucano aprovechan fructíferamente los logros poéticos de Horacio, convirtiéndolo en una fuerza verdaderamente operativa dentro del imaginario poético de mediados del siglo I. d.C. y fundamental en el desarrollo y configuración de la figura del general republicano que se despliega tanto en Pharsalia como en De providentia. Séneca, entonces, a quien autores como Tarrant, Schiessaro y Putnam consideran como uno de los primeros lectores pesimistas de Virgilio, junto con su sobrino Lucano, lleva a cabo una operación de lectura similar con la obra de Horacio. En este caso recurre a pasajes muy específicos y prestigiosos para reformularlos y subvertir el valor y la significación original de los mismos. De este modo Séneca problematiza y discute los aspectos más controvertidos de su pensamiento filosófico a través de este formato literario, ${ }^{674}$ que le permite además poner en juego cuestiones literarias y polemizar con prestigiosos autores para lograr así una obra poética de características personales e innovadoras.

\footnotetext{
${ }^{673}$ CIC. Tusc. I, 74.

${ }^{674}$ Rosenmeyer, Th. (1989), 43.
} 
La original apropiación y reformulación del modelo prestigioso, y la personal lectura que se hace del mismo, postula a Séneca como uno de los primeros lectores pesimistas de Virgilio. La mesura virgiliana es trastrocada en el contexto desmesurado y monstruoso de Thyestes. La carga de horror, que Virgilio plasma tan sutil y magistralmente en la transformación de la serpiente en un adorno de la reina (En. VII, 352-354), es exacerbada y desproporcionada por la magnitud de la ira de Atreo. Como es propio de las representaciones barrocas, en esta obra las proporciones se distorsionan, los cuerpos se estiran grotescamente y las relaciones clásicas se disuelven en trazos inestables, oscuros y difuminados. ${ }^{675}$ Los sistemas barrocos, o anticlásicos, se caracterizan por generar turbulencias y rupturas en la simetría interna de los órdenes prescriptivos y las normativas precedentes, es decir, tal como lo afirman Wölfflin, Focillon y D'Ors, en las morfologías subyacentes de los fenómenos donde impera el orden, la simetría y la estabilidad. ${ }^{676}$

${ }^{675}$ Connelly, F. (2012), 104-106 \& 115-116.

${ }^{676}$ Calabrese, O. (1989), 197-199. 


\section{PLURIMA MORTIS IMAGO: LA REPRESENTACIÓN DE LA MUERTE Y SU INSCRIPCIÓN EN LOS CUERPOS.}

\section{ENEIDA Y FARSALIA: FORMAS DE INSCRIPCIÓN DE LA MUERTE EN LOS CUERPOS.}

La representación del cuerpo y los diferentes modos de describir las distintas formas de muerte constituyen una de las manifestaciones más diáfanas del profundo cambio psicológico e ideológico que ocurre entre mediados del siglo I a. C. y I d. C. Desde los primeros años del principado y la instauración de la pax Augusta hasta los últimos años del régimen neroniano, caracterizado por lo que Vasily Rudich denomina un estado de "esquizofrenia sociopolítica", se produce un inexorable proceso de transformación institucional y social que repercute de manera directa en todas las manifestaciones artísticas. ${ }^{677}$ Las características propias de estas manifestaciones obedecen a estéticas nacidas y generadas bajo condiciones radicalmente diferentes a las del llamado "siglo de oro" de la literatura latina y responden, consecuentemente, a diferentes paradigmas rectores. De hecho, los exponentes más importantes de cada uno de estos períodos se manifiestan precisamente en los extremos: Virgilio y Horacio como máximos referentes del decus augusteo y Séneca y Lucano como representantes emblemáticos de los últimos años del período julio-claudiano, quedando la figura de Ovidio como nexo entre ambas generaciones de artistas. ${ }^{678}$

Las supuestas "faltas" en la escritura de Lucano y Séneca son en realidad cuidadas y personales expresiones poéticas que responden a un horizonte de expectativas diferente al del público y los autores del siglo I a.C. y se enmarcan dentro de un proyecto creador que busca precisamente alejarse y diferenciarse de los modelos augusteos, reinterpretando, resignificando y subvirtiendo los paradigmas constitutivos de estos. ${ }^{679} \mathrm{Se}$ exacerban los aspectos retóricos y declamatorios, se sacrifica la plausibilidad en favor de la expresividad y se privilegia un barroco juego de oposiciones dinámicas que se manifiestan en paradójicas y muchas veces oscuras sentencias. ${ }^{680}$

\footnotetext{
${ }^{677}$ Rudich, V. (1997), 4-5; Bartsch, Sh. (2005), 499.

${ }^{678}$ Tarrant, R. (2002); Wheeler, S. (2002); Segal, Ch. (1984).

${ }^{679}$ Tarrant, R. (1995), 216.

${ }^{680}$ Rudich, V. (1997), 107.
} 


\section{LA REPRESENTACIÓN DE LA MUERTE EN ENEIDA}

La épica y la tragedia nunca se privaron de describir detalladamente cruentas mutilaciones y muertes: abundan los brazos cercenados, armas entibiándose en las entrañas o alojándose en el cráneo de las víctimas, o niños arrojados desde altas torres, por nombrar algunos de los más frecuentes. ${ }^{681}$ Creemos, sin embargo, que existe una rotunda diferencia en las diversas representaciones de la muerte entre Virgilio, Séneca y Lucano, manifiesta en el modo en que ésta se imprime en el cuerpo de los individuos. Analizaremos en primer lugar el episodio de Niso y Euríalo, que contiene, además de varias descripciones "tradicionales”, una de las muertes más bellas jamás narradas.

Cuando los guerreros masacran a los desprevenidos soldados, Virgilio no se priva de mostrarnos los cuerpos decapitados y los estertores de los moribundos: ${ }^{682}$

tris iuxta famulos temere inter tela iacentis armigerumque Remi premit aurigamque sub ipsis nactus equis ferroque secat pendentia colla. tum caput ipsi aufert domino truncumque relinquit sanguine singultantem; atro tepefacta cruore terra torique madent.

Mata casualmente a tres sirvientes que yacían entremezclados con las armas, encuentra al escudero y auriga de Remo bajo sus propios caballos y corta con el hierro su cuello colgante. Luego arrebata la cabeza al propio dueño y abandona el tronco borboteante; la tibia tierra y el lecho se empapan con negra sangre.

La muerte de otro soldado, Roeto, tampoco carece de detalles truculentos:

[Rhoetum] pectore in aduerso totum cui comminus ensem condidit adsurgenti et multa morte recepit. purpuream uomit ille animam et cum sanguine mixta uina refert moriens (A. IX, 347-350)

A quien, cuando se levantaba, le entierra contra el pecho la espada entera y la retira cargada de muerte, vomita éste su purpúrea alma y moribundo devuelve el vino mezclado con sangre.

${ }^{681}$ Batinski, E. (1991), 78. Homero, Il. 16, 323-324, 345-350, 412- 414; VERG. A. IX, 588-589, 698-701, 749-755.

${ }^{682}$ Pavlock, B. (1985), 214-216; Plessy, F. \& Lejay, P. (1963), 690. 
Hacia el final del pasaje Niso ataca a los hostigadores de Euríalo y mata a Sulmón, quien cae vomitando sangre y muere entre estertores ( $A$. IX, 412-415) y luego su lanza se entibia en el cerebro de Tago $\left(A\right.$. IX, 416-419). ${ }^{683}$

La representación virgiliana de la muerte es, si bien sangrienta, realista y carente de elementos abyectos, grotescos o monstruosos. La representación no genera, al menos para nosotros, ese desplazamiento grotesco que reifica al cuerpo y lo sitúa en las fronteras de lo animado y lo inanimado y que añade significación y perturba la representación. ${ }^{684}$ En la descripción de la estilizada, y estetizada, muerte de Euríalo, la imagen cobra vida gracias a la despojada y bella arquitectura de su representación, es decir, gracias su forma clásica. ${ }^{685} \mathrm{El}$ joven cae como una flor herida por un arado, clara evocación del carmen XI de Catulo, y su cabeza se desploma como una amapola agobiada por las fuertes lluvias:

sed uiribus ensis adactus

transadigit costas et candida pectora rumpit. uoluitur Euryalus leto, pulchrosque per artus it cruor inque umeros ceruix conlapsa recumbit: purpureus ueluti cum flos succisus aratro languescit moriens, lassoue papauera collo demisere caput pluuia cum forte grauantur.

Pero la espada empujada con fuerzas atraviesa su flanco y destroza su radiante pecho. Es arrastrado por la muerte Euríalo, y por sus hermosos miembros corre la sangre y el cuello caído se recuesta sobre sus hombros: como la flor púrpura tocada por el arado languidece moribunda, o la amapola de cuello cansado inclina su cabeza agobiada por el peso de una fuerte lluvia.

Niso arremete entonces contra los rútulos en busca de Volcente y, luego de matarlo, se desploma sobre el querido cuerpo de Euríalo en una plácida muerte:
at Nisus ruit in medios solumque per omnis Volcentem petit, in solo Volcente moratur. quem circum glomerati hostes hinc comminus atque hinc

\footnotetext{
${ }^{683}$ Plessy, F. \& Lejay, P. (1963), 694.

${ }^{684}$ Connelly, F. (2012), ix: "Ornament might be purely visual, but as Ruskin pointed out, the grotesque expresses meaning through the purely visual. Also, the grotesque truly is the image at play, and its humour and irreverence offer a welcome antidote to all forms of conventional thinking. Another characteristic of the grotesque is that it is not content to be solely the object of the aesthetic gaze. Instead, it is engaged in the world, always pushing against boundaries and raising questions. It acknowledges the individuality and particularity of viewer's responses and sometimes even speaks for those whose experiences fall outside the norm. Finally, and perhaps more importantly, there is a fundamental humility to the grotesque, rooted as it is in the living (and dying) body, an embrace of the relativity and changefulness of life as we live it."

${ }^{685}$ Calabrese, O. (1989), 205-207.
} 
proturbant. instat non setius ac rotat ensem

fulmineum, donec Rutuli clamantis in ore

condidit aduerso et moriens animam abstulit hosti.

tum super exanimum sese proiecit amicum

confossus, placidaque ibi demum morte quieuit.

Pero Niso se lanza en medio (de los enemigos) y busca entre todos sólo a Volcente, en Volcente solo se concentra.

Alrededor del cual los enemigos se lanzan al combate personal

por aquí y por allá, persiste sin descanso y gira fulminante

su espada, hasta que de frente la entierra en la boca del rútulo aullante y muriendo roba el alma a su enemigo.

entonces herido cae sobre el cuerpo exánime

de su amigo, y allí finalmente descansa en una plácida muerte.

La representación de las muertes eminentes en Virgilio tiene como característica principal su carácter plástico y plácido, como puede apreciarse en el verso 445 en especial. Estas características están presentes también en las muertes de Camila y de Turno. Ambos jóvenes caen en combate. Camila se desploma elegantemente con un gesto muy similar al de Euríalo:

simul his dictis linquebat habenas

ad terram non sponte fluens. tum frigida toto

paulatim exsoluit se corpore, lentaque colla

et captum leto posuit caput, arma relinquens, uitaque cum gemitu fugit indignata sub umbras.

(A. XI, 827-831)

Mientras decía esto soltaba las riendas

y se deslizaba sin quererlo hacia la tierra. Entonces ya congelado su cuerpo, poco a poco se desvaneció, apoyó su grácil cuello y su cabeza tomada por la muerte, abandonando las armas, $\mathrm{y}$, con un gemido, su vida huyó indignada hacia las sombras.

Turno, por su parte, es muerto por Eneas, ambas muertes están conectadas por el hermoso verso final: uitaque cum gemitu fugit indignata sub umbras:

ille, oculis postquam saeui monimenta doloris exuuiasque hausit, furiis accensus et ira terribilis: 'tune hinc spoliis indute meorum eripiare mihi? Pallas te hoc uulnere, Pallas immolat et poenam scelerato ex sanguine sumit.' hoc dicens ferrum aduerso sub pectore condit feruidus; ast illi soluuntur frigore membra uitaque cum gemitu fugit indignata sub umbras.

Él, luego de que ese monumento y trofeo de aquel cruel dolor se fijó en sus ojos, encendido por la furia y terrible de ira: '¿Acaso tú, vestido con los despojos de los míos, te me escaparás? Palante, Palante te inmola con esta herida 
y exige la pena al criminal con su sangre'

Diciendo esto hunde el hierro contra el pecho

furioso; y los miembros se le relajan por la muerte

$\mathrm{y}$, con un gemido, su vida huyó indignada hacia las sombras.

Este magnífico cierre agrega una sentida carga estética a la descripción de la muerte de los jóvenes: la sensibilidad del poeta impregna el cierre de los episodios analizados limando todo posible ribete abyecto o grotesco.

\section{LA REPRESENTACIÓN DE LA MUERTE EN SÉNECA Y LUCANO}

Comenzaremos por analizar no una muerte en sí, sino la descripción de una mutilación autoinfligida, la de Edipo, pues, tal como lo dice el mismo personaje, involucra una elección que lo sitúa en ese territorio indefinido entre la vida y la muerte: ${ }^{686}$

\author{
utere ingenio, miser: \\ quod saepe fieri non potest fiat diu; \\ mors eligatur longa. quaeratur uia \\ qua nec sepultis mixtus et uiuis tamen \\ exemptus erres: morere, sed citra patrem. \\ cunctaris, anime? subitus en uultus grauat \\ profusus imber ac rigat fletu genas- \\ et flere satis est? hactenus fundent leuem \\ oculi liquorem? sedibus pulsi suis \\ lacrimas sequantur: hi maritales statim \\ fodiantur oculi.' Dixit atque ira furit: \\ ardent minaces igne truculento genae \\ oculique uix se sedibus retinent suis; \\ uiolentus audax uultus, iratus ferox \\ iamiam eruentis; gemuit et dirum fremens \\ manus in ora torsit. at contra truces \\ oculi steterunt et suam intenti manum \\ ultro insecuntur, uulneri occurrunt suo. \\ scrutatur auidus manibus uncis lumina, \\ radice ab ima funditus uulsos simul \\ euoluit orbes; haeret in uacuo manus \\ et fixa penitus unguibus lacerat cauos \\ alte recessus luminum et inanes sinus \\ saeuitque frustra plusque quam satis est furit.
}

$[\ldots]$

rigat ora foedus imber et lacerum caput

largum reuulsis sanguinem uenis uomit.
(Oed. 947-970)

(Oed. 978-979)

${ }^{686}$ Töchterle, K. (1994), 596-597. 
Utiliza tu inteligencia, desdichado:

lo que puede hacerse repetidas veces, hágase largamente:

elige una muerte prolongada. Que se busque el camino

por el cual erres sin mezclarte con los muertos, pero excluido

sin embargo de los vivos: pero sin llegar hasta tu padre.

¿Vacilas, ánimo? De repente una lluvia profusa

agobia tu rostro y el llanto riega tus mejillas-

¿es suficiente llorar? ¿En este punto mis ojos derramarán

este escaso líquido? ¡Que arrancados de sus órbitas

sigan a sus lágrimas! ¿Que se vacíen de inmediato

estos ojos de esposo!' Dijo esto y se enciende de ira:

arden sus mejillas amenazantes con truculentas llamas

y sus ojos apenas se mantienen en su sitio;

algo violento audaz terrible y feroz hay en el rostro

de quien se lo arranca, gimió y retorció estremeciéndose

las manos contra su rostro. Sus ojos se plantaron

fieros en su contra y decididos siguieron a su mano

más allá, corren al encuentro de su herida.

Escruta ávido sus ojos con manos encorvadas,

desde su más profunda raíz arrancó por completo,

de una vez, los ojos arrojados; se ensañan las manos

en la cavidad vacía y fijas laceran en lo profundo con sus uñas

las cavidades huecas de los ojos y las órbitas vacías

y se enfurece en vano y su furor sobrepasa lo que sería

más que suficiente.

La elección de Edipo de habitar las tinieblas intermedias da paso a un crescendo de

horror y repulsión donde nuevamente cumplen un papel clave las excrecencias y los

fluidos corporales. La descripción del rey excavando y hurgando sus cavidades oculares

se trastrocan al invertirse las relaciones sujeto-objeto pues los ojos toman un papel

activo en la mutilación y se lanzan contra las manos atacantes.

La muerte de Hipólito es otro claro ejemplo de los métodos de composición

barrocos y grotescos en la obra de Séneca, tal como lo afirma Charles Segal:

'Far more than Euripides' account on the extant Hippolytus, Seneca's narrative of the death of Hippolytus emphasizes the monstrous aspect of the event. It shifts from a more or less human setting to a phantasmatic realm of changing shapes. Euripides' foreground is clearly defined by its geographical coordinates; Seneca proceeds with discontinuous jumps and abrupt changes of perspective. Seneca's narrative build up the climatic event as a monstrous cataclysm; in Euripides we are still in touch with a rationally intelligible world, even though it is a world into which divine violence may suddenly erupt. [...] Ovid wittily undercuts the horror by giving his story a fanciful enframing context: his hero is addressing the nymph Egeria, whom he invites to engage in comparison of their respective sufferings (530f.). The exercise is to be a consolatio for her loss of Numa (cf. consolantia verba, 15, 491). In this mixture of tones Ovid too approaches something of a baroque style; but he keeps a strong unity of perspective by the simplest of all focusing devices, the first-person singular narration."

${ }^{687}$ Segal, Ch. (1984), 314. 
El estilo senequiano aprovecha la descripción física del paisaje para lograr un efecto barroco de exageración y la distorsión del referente desestabilizando las proporciones y los puntos de vista lógicos, procedimiento que logra su máxima expresión en la tragedia con la descripción del híbrido y multiforme monstruo marino, conformado por masas molares que oscilan entre estados de existencia líquidos y sólidos. ${ }^{68}$ Sin embargo es en la descripción de la muerte de Hipólito donde pueden apreciarse las características grotescas y barrocas de representación:

Praeceps in ora fusus implicuit cadens laqueo tenaci corpus et quanto magis pugnat, sequaces hoc magis nodos ligat. sensere pecudes facinus--et curru leui, dominante nullo, qua timor iussit ruunt. talis per auras non suum agnoscens onus Solique falso creditum indignans diem Phaethonta currus deuium excussit polo. Late cruentat arua et inlisum caput scopulis resultat; auferunt dumi comas, et ora durus pulcra populatur lapis peritque multo uulnere infelix decor. moribunda celeres membra peruoluunt rotae;

(Phaed.1085-1097)

$[\ldots]$

Errant per agros funebris famuli manus, per illa qua distractus Hippolytus loca longum cruenta tramitem signat nota, maestaeque domini membra uestigant canes. necdum dolentum sedulus potuit labor explere corpus--hocine est formae decus? qui modo paterni clarus imperii comes et certus heres siderum fulsit modo, passim ad supremos ille colligitur rogos et funeri confertur.

(Phaed. 1105-1114)

$\mathrm{Al}$ caer de cabeza queda tendido boca abajo, enredó su cuerpo en un lazo tenaz y cuanto más lucha más lo aprietan los nudos cómplices.

Advirtieron las bestias su crimen - y estando el carro liviano y sin conductor, por donde el miedo los empujó, corrieron.

Del mismo modo por los aires, al no reconocer como suyo el peso, e indignado por habérsele confiado el día a un Sol falso, el carro extraviado expulsó a Faetón del cielo. Ensangrienta ampliamente los campos y rebota su cabeza contra las piedras; se roban sus cabellos las espinas, y la dura piedra arrasa su bello rostro y muere su desdichada belleza con las muchas heridas.

${ }^{688}$ Segal, Ch. (1984), $317-320$. 
Vagan por el campo los siervos como una pompa fúnebre, por aquellos lugares donde Hipólito destrozado marca su largo derrotero con cruentas huellas.

Las perras afligidas rastrean los miembros de su dueño. Y aún el sedulus trabajo de los dolientes no pudo recuperar el cuerpo - ¿Ésta es la gloria de la belleza? Quien hasta hace poco, preclaro compañero del poder paterno y seguro heredero, brilló como las estrellas, ese es recogido por todas partes para la última pira $\mathrm{y}$ es recompuesto para el funeral.

La descripción es vívida y dinámica, el cuerpo es arrastrado y dispersado por lo campos, su cabeza rebota contra las piedras y las espinas reclaman su parte del botín. Es interesante destacar que antes de la muerte del cuerpo se produce la muerte de la belleza, de la forma del joven, cuyo cuerpo es también una metáfora de la tragedia en sí. Los constantes cambios de foco y la alternancia entre movimiento frenético y calmas repentinas tienen su punto culminante en los siguientes versos:

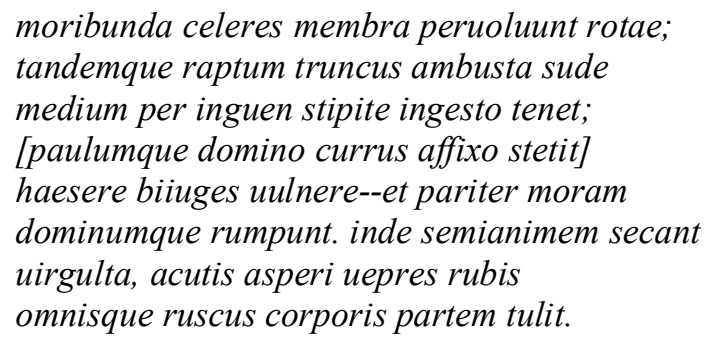

(Phaed. 1097-1104)

Las ruedas veloces revuelcan los miembros moribundos hasta que un tronco cortado con una estaca quemada lo atraviesa en medio de su ingle con su punta alzada; [por un instante se paró carro, clavado su conductor] se detuvieron los caballos con la herida- y, a un mismo tiempo, destrozan el obstáculo y a su dueño. Luego, casi sin vida, lo laceran los matorrales y las agudas zarzas con sus ásperas espinas, toda planta se quedó con parte de su cuerpo.

La frenética descripción se detiene abruptamente en un kairós de patetismo cuya imagen congelada bien podría ser un cuadro expresionista: las líneas y la forma del cuerpo de Hipólito se han difuminado en este proceso de deformación y desnaturalización corporal y además la alternancia entre energía y stasis otorga características barrocas a la representación. La tensión generada por la yuxtaposición de las líneas de fuga a las que es expuesto el joven - praeceps, fusus, cadens, celeres rotae- se contrapone a la 
abundancia de términos relacionados con la sujeción, implicuit, tenaci, nodos ligat. ${ }^{689}$ Se han invertido los papeles por completo: el joven cazador que perseguía salvajes fieras y disponía astutas trampas por los bosques en el prólogo de la obra se ha convertido ahora en la presa enredada cuyos intentos por escapar aprietan aún más los nudos de sus lazos. ${ }^{690}$

Ya hemos hablado de la cruenta y grotesca ceremonia de cocción de los hijos de Tiestes por parte de Atreo, donde los cuerpos se vuelven mercancías edibles y la individualidad de los jóvenes es diseccionada y reducida a órganos internos que se cocinan sobre un fuego ritual. El cuerpo de Astianacte es también reducido a una masa informe cuya forma es conturbada hasta el punto de ya no poseer la entidad como cuerpo humano:

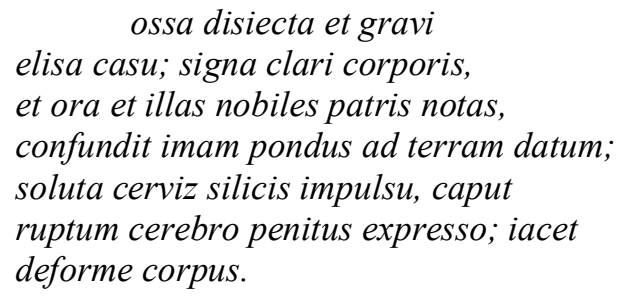

Sus huesos yacen esparcidos y destrozados por la pesada caída, la forma de su hermoso cuerpo su rostro y aquellos [rasgos] de su padre, los confundió arrojado como un peso a la tierra profunda; su cuello se rompió por la caída contra las rocas, su cráneo fue destrozado y su cerebro aplastado - sólo queda un cuerpo deformado.

En estos pocos versos, Séneca logra reificar por completo el hermoso cuerpo del príncipe y las facciones heredadas de su padre y convertirlo en un mero pondus deforme cuyos órganos internos se esparcen fuera de los límites ordenados de las fronteras corporales. $^{691}$

Si en Eneida se despliegan numerosísimas imágenes de muerte (plurima mortis imago, A. II, 369) y en la tragedia de Séneca los cuerpos pierden su forma intrínseca y se vuelven grotescos abyectos, Pharsalia, por su parte, nos ofrece formas de muerte únicas y extravagantes (multaque ponto/ praebuit ille dies uarii miracula fati, LUC. III,

\footnotetext{
${ }^{689}$ Segal, Ch. (1984), 323-324.

${ }^{690}$ Rivoltella, M. (1998), 413-417.

${ }^{691}$ Connelly, F. (2012), 115-116.
} 
633-634 \& unica diri/ conspecta est leti facies, LUC. III, 652-653). ${ }^{692}$ La primera muerte que analizaremos es la de un anónimo soldado durante la batalla naval frente a Marsella:

tunc unica diri
conspecta est leti facies, cum forte natantem
diuersae rostris iunenem fixere carinae.
discessit medium tam uastos pectus ad ictus,
nec prohibere ualent obtritis ossibus artus se
quo minus aera sonent; eliso uentre per ora
eiectat saniem permixtus uiscere sanguis.

(LUC. III, 652- 658)

Entonces se vio una manera única de horrenda muerte, cuando por casualidad dos naves de espolones enfrentados atravesaron a un joven nadador.

Se le abrió el pecho al medio con golpe tan vasto $\mathrm{y}$, pulverizados sus huesos, los miembros no pudieron impedir ni siquiera que resuenen los bronces; aplastado el vientre lanza por su boca una masa de sangre mezclada con vísceras.

La distancia con los soldados de Virgilio que mueren vomitando su "purpúrea alma" no puede ser mayor, Lucano exacerba la imagen casi ad absurdum haciendo que el desdichado arroje literalmente las entrañas por su boca. ${ }^{693} \mathrm{La}$ representación de la muerte de este joven anónimo es de por sí ya una subversión e inversión del paradigma épico; ${ }^{694}$ sin embargo lo que separa esta muerte de otras representaciones es el componente grotesco y abyecto de la misma. El joven nadador no vomita su sangre sino que, literalmente, se vomita abyectamente a sí mismo:

"I expel myself, I spit myself out, I abject myself within the same motion that through which 'I' claim to establish myself. That detail, perhaps an insignificant one, but one that ferret out, emphasize, evaluate, that trifles turns me inside out, guts sprawling; it is thus that they see that 'I' am in the process of becoming other at the expense of my own death." 695

La representación del proceso de disolución del universo, que se imprime no sólo en el cuerpo de los individuos sino también en el cuerpo social a través de la sympátheia tôn holôn, es una constante en la representación lucaniana. ${ }^{696}$ Nos concentraremos ahora en dos paradigmáticas e insólitas muertes producidas por el ataque de las serpientes, episodio que analizaremos en profundidad en el cap. IX.

Un tabífico seps muerde a Sabelo y los efectos del veneno son horrorosos:

\footnotetext{
${ }^{692}$ Hunink, V. (1992), 212.

${ }^{693}$ Batinski, E. E. 1991, 78.

${ }^{694}$ Sklenáŕ, R. (2003), 17-22.

${ }^{695}$ Kristeva, J. (1982), 2-3.

${ }^{696}$ Lapidge, M. (1979), 370; Bartsch, Sh. (2005), 497.
} 
membra natant sanie, surae fluxere, sine ullo tegmine poples erat, femorum quoque musculus omnis liquitur, et nigra destillant inguina tabe.

(LUC. IX, 770- 772)

Sus miembros nadan en pus, las pantorrillas se derritieron, sus rodillas quedan sin piel, todos los músculos de las piernas se licuan y sus ingles destilan una oscura putrefacción.

La licuefacción es total y absoluta: la cabeza y el cuello de Sabelo no caen suave y estetizadamente como en el caso de Euríalo ( $A$. 434-435) sino que fluyen corruptos sobre él:

manant umeri fortesque lacerti, colla caputque fluunt

(LUC. IX, 780-781)

Se derriten sus hombros y sus fuertes brazos, su cuello y su cabeza se disuelven.

La disolución de los límites de la carne y del cuerpo en tanto las fronteras de la identidad, a través de las propias excrecencias corporales, es radical y total, pues el cuerpo se vuelve sólo excrecencia en un proceso de disolución capaz de transgredir los límites de la corporalidad. ${ }^{697}$

Otro tipo de transgresión de los límites de la carne se da con la muerte de Nasidio:

toto iam corpore maior humanumque egressa modum super omnia membra efflatur sanies late pollente ueneno; ipse latet penitus congesto corpore mersus, nec lorica tenet distenti pectoris auctum. spumeus accenso non sic exundat aeno undarum cumulus, nec tantos carbasa Coro curuauere sinus. tumidos iam non capit artus informis globus et confuso pondere truncus. intactum uolucrum rostris epulasque daturum haud inpune feris non ausi tradere busto nondum stante modo crescens fugere cadauer.

una ponzoña más grande que el cuerpo entero y que rebasa los límites humanos se expande al potenciarse el veneno; él mismo queda oculto sumergido en lo profundo de su cuerpo inflamado, y la coraza no puede contener el crecimiento del pecho hinchado. No se derrama así en el caldero hirviente el cúmulo espumoso de agua ni las velas se hinchan en cavidades tan grandes a causa del Coro. Ya no contiene los miembros hinchados el deforme globo ni el tronco con su masa sin perfiles. Al cadáver, que no fue tocado por el pico de los buitres

${ }^{697}$ Connelly, F. (2012), 84-85. 
y que alimentaría, no sin daño a las fieras, no se atrevieron a entregarlo a la hoguera.

Esta descripción abunda no sólo en la imágenes grotescas y barrocas ya destacadas, sino también en alusiones metatextuales verdaderamente relevantes: sobre el cuerpo de Nasidio se inscriben los rasgos característicos de la escritura lucaniana, es decir un discurso aglutinante que se construye sobre sus propias acumulaciones y turbulencias discursivas en un procedimiento típico de las manifestaciones artísticas barrocas y grotescas, ${ }^{698}$ y que al mismo tiempo desborda y excede los límites establecidos por la coraza impuesta del decus augusteo. Las referencias a Virgilio y Homero son diáfanas: Lucano, evidenciando su maestría y genio poético, imprime en el ámbito corporal lo que Virgilio despliega en el plano emocional:

saeuit amor ferri et scelerata insania belli, ira super: magno ueluti cum flamma sonore uirgea suggeritur costis undantis aeni exsultantque aestu latices, furit intus aquai fumidus atque alte spumis exuberat amnis, nec iam se capit unda, uolat uapor ater ad auras.

Se inflama su amor al hierro, su criminal locura de guerra, Y sobre todo su ira: como cuando la llama de unas grandes ramas crepita con grandes restallidos por los costados de un caldero hirviente y el líquido se desborda por el calor, se enfurecen las aguas y humeante se desborda el torrente de espuma, y no contiene su hervor, vuela el vapor oscuro por los aires.

Luego, redoblando la apuesta, evoca inversamente nada menos que el proemio de Ilíada:

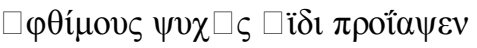

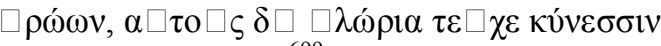

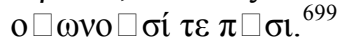

[Cólera que] arrojó al hades almas valerosas de héroes, y los hizo presa de los perros $\mathrm{y}$ las aves.

\footnotetext{
${ }^{698}$ Deleuze, G. (2005), 13-14.

${ }^{699}$ HOM., Il. I, 4-5.
} 
En Pharsalia la muerte se inscribe en el cuerpo de los soldados de maneras únicas y novedosas y los caídos, a diferencia de los héroes homéricos, ni siquiera serán presa de los perros o pasto de las aves.

\section{KÉRE Y THÁNATOS}

Los antiguos recurrían a dos figuras para representar los diferentes aspectos de la muerte: Kére y Thánatos. Thánatos representa no el terrible poder de destrucción de la muerte sino más bien un estado distinto, una nueva condición existencial. Por otro lado, la execrable Kere (Il. XVIII, 535 y ss.) es una potencia terrorífica y grotesca que se abalanza sobre los hombres para engullirlos en una noche primigenia. ${ }^{700}$ Tenemos, por un lado, la idealización de la vida heroica y personificación de la muerte bella encarnados en Thánatos; y por otro, el proceso de transformación del ser vivo en cadáver y del cadáver en repulsiva carroña que pertenece a la esfera de poder de la grotesca Kere. $^{701}$

Thánatos es la figura preponderante en Eneida. Incluso las muertes más tradicionales y cruentas presentan los rasgos característicos de la sensibilidad virgiliana, mientras que Lucano exacerba su canto a Kere de maneras más radicales aún que la de Séneca. Cuando un elemento perteneciente a otra esfera de representación aparece en los textos, las operaciones discursivas inmediatamente reacomodan el discurso a las condiciones enunciativas de cada autor. La muerte más horrorosa narrada por Virgilio se da, probablemente, en el libro VIII, cuando se describe el "tormento de Mezencio":

mortua quin etiam iungebat corpora uiuis componens manibusque manus atque oribus ora, tormenti genus, et sanie taboque fluentis complexu in misero longa sic morte necabat.

(A. VIII, 485-489)

Incluso ataba los cuerpos muertos a los vivos Uniendo las manos con las manos y las bocas con las bocas, a modo de tortura, y así en un desgraciado abrazo con la corrupción y el pus del cadáver mataba con una larga muerte.

\footnotetext{
${ }^{700}$ Vernant, J-P. (2001), 130-131: "Miremos ahora hacia el lado de los hijos de la Noche, hacia la tenebrosa $N y x$, que parece oponerse por completo a la brillante Afrodita, a la resplandeciente Afrodita. Entre esa progenitura siniestra, Kere, esa muerte con nombre femenino, tiene especialmente reservado un puesto. Noche es, junto a Érebo, el poder salido inmediatamente de Khaós, el Abismo primordial, cuando todavía no existía en el mundo nada más que un inmenso agujero oscuro, una abertura sin fondo, sin dirección. Khaós, Abismo, se imbrica con Khaíno. Khásko, abrirse, estar abierto, bostezar."

${ }^{701}$ Vernant, J-P. (2001), 129-130.
} 
Sin embargo los elementos que refieren al proceso de descomposición son sólo dos y muy precisos -sanie taboque- y además el hecho está referido por una diosa que describe la crueldad del despreciador de los dioses (contemptor diuum), ${ }^{702}$ Mezencio, quien pese a todo cabalgará al encuentro de una muerte valerosa. Es clara la ausencia del proceso mismo de descomposición en la representación virgiliana y la falta de desestastibilización y problematización de las fronteras escatológicas. ${ }^{703}$ Comparémoslo con este pasaje paradigmático de la inscripción de la muerte en el cuerpo de un soldado republicano:

sed tristior illo
mors erat ante oculos, miserique in crure Sabelli
seps stetit exiguus; quem flexo dente tenacem
auolsitque manu piloque adfixit harenis.
parua modo serpens, sed qua non ulla cruentae
tantum mortis habet. nam plagae proxima circum
fugit rupta cutis pallentiaque ossa retexit;
iamque sinu laxo nudum sine corpore uolnus.
membra natant sanie, surae fluxere, sine ullo
tegmine poples erat, femorum quoque musculus omnis
liquitur, et nigra destillant inguina tabe.
dissiluit stringens uterum membrana, fluuntque
uiscera; nec, quantus toto de corpore debet,
effluit in terras, saeuum sed membra uenenum
decoquit, in minimum mors contrahit omnia uirus.
quidquid homo est, aperit pestis natura profana:
uincula neruorum et laterum textura cauumque
pectus et abstrusum fibris uitalibus omne
morte patet. manant umeri fortesque lacerti,
colla caputque fluunt: calido non ocius Austro
nix resoluta cadit nec solem cera sequetur.
parua loquor, corpus sanie stillasse perustum:
hoc et flamma potest; sed quis rogus abstulit ossa?
haec quoque discedunt, putrisque secuta medullas
nulla manere sinunt rapidi uestigia fati.
Cinyphias inter pestes tibi palma nocendi est:
eripiunt omnes animam, tu sola cadauer.

(LUC. IX, 762-788)

Pero una muerte más terrible que aquella se presentaba ante sus ojos, una diminuta serpiente Spes se clavó en la pierna del desdichado Sabello; al cual, clavado tenaz con diente curvo se lo arrancó con la mano y lo atravesó con su lanza en la arena. Serpiente pequeña en tamaño, pero ninguna posee más poder de matar cruentamente. En efecto, la piel cercana a la llaga se retrajo desgarrada y mostró los pálidos huesos;

\footnotetext{
${ }^{702}$ VERG. $A$. VII, 648.

${ }^{703}$ Conelly, F. (2012), 13: "A grotesque history focuses on the 'impure' boundaries: where intermixing and negotiating contest the normative center and pull it into flux. Like an anamorphic perspective, a history of the grotesque cuts crossways through the traditional structures of art-historical narratives: periodicity, stylistic influence, and iconology. The grotesque cannot be characterized as a style, but it is an interrogation of style, a means to call its precepts and boundaries into question."
} 
y extendida la cavidad, ya es una herida desnuda sin cuerpo.

Sus miembros nadan en pus, las pantorrillas se derritieron, sus rodillas

quedan sin piel, todos los músculos de las piernas se licuan

y sus ingles destilan una oscura putrefacción.

Se disolvió la membrana que contiene el estómago, y fluyeron

sus vísceras; y no cayó en la tierra, como debe caer

de todo cuerpo, sino que el cruel veneno fermentó sus miembros.

La muerte lo concentró todo en un mínimo pus.

Lo que es el hombre, lo expone la naturaleza profana de esta peste:

las ataduras de los nervios y la textura de los pulmones y el pecho

hueco y lo más recóndito de las fibras vitales se abre

con la muerte. Se licuan los hombros y los fuertes brazos

fluye la cabeza y el cuello: no más rápida cae la nieve

derretida por el cálido Austro, ni se derrite la cera al sol,

poco digo, el cuerpo fue consumido disuelto gota a gota por la putrefacción,

esto también lo puede el fuego; pero ¿qué hoguera se roba los huesos?

También estos desaparecen, seguidos por las médulas podridas,

no permiten que quede ningún vestigio de esta rápida muerte.

Entre las pestes cinífeas tú te llevas la palma del matar:

todas arrancan el alma, tú sola el cadáver.

Lo que en Virgilio es una referencia y una mención dentro de un marco de crueldad extrema, en Lucano se vuelve un expresionismo macabro que se regodea en el detalle grotesco y en la descripción hiperbólica.

sed maiora parant Libycae spectacula pestes. inpressit dentes haemorrhois aspera Tullo, magnanimo iuneni miratorique Catonis. utque solet pariter totis se fundere signis Corycii pressura croci, sic omnia membra emisere simul rutilum pro sanguine uirus. sanguis erant lacrimae; quaecumque foramina nouit umor, ab his largus manat cruor; ora redundant et patulae nares; sudor rubet; omnia plenis membra fluunt uenis; totum est pro uolnere corpus.

Pero espectáculos mayores preparan las pestes de Libia. Hundió sus dientes en Tulo una áspera Hemorroo, joven magnánimo admirador de Catón.

Como suele fundirse la esencia del azafrán de Córico al mismo tiempo en todas las estatuas, así todos sus miembros exudaron al mismo tiempo roja ponzoña en vez de sangre.

Sangre eran sus lágrimas; por cualquier conducto que conocen los fluidos, de estos mana abundante la sangre; rebalsa la boca y las fosas nasales dilatadas; el sudor es rojo; todos sus miembros sangran a venas abiertas; todo el cuerpo es herida. 


\section{RECAPITULACIÓN Y CONCLUSIONES PARCIALES}

Virgilio inscribe en el cuerpo de sus personajes un tipo de muerte mucho más cercana a la figura de Thánatos, mientras que Séneca y Lucano, por su parte, estetizan incluso los rasgos más repulsivos y grotescos de la execrable Kere de modo tal que quizás haya que esperar casi 18 siglos para volver a encontrar semejante apropiación artística del proceso de putrefacción en "Una Carroña" de Charles Baudelaire. ${ }^{704}$ Cada autor, entonces, trabaja con un aspecto particular y definido de la muerte y esto se traduce en muy precisas formas de inscripción en los cuerpos. El regodeo de Séneca y Lucano en describir hiperbólica y minuciosamente el sufrimiento corporal despliega una estética del espanto expresionista: el dolor y la muerte desbordan los límites y la forma del cuerpo y de la escritura misma. Se produce un inexorable proceso de descorporización tanto diegética como textual a través del cual la violencia se inscribe no sólo en el cuerpo sino también en la propia lengua poética.

La profunda crisis de valores que experimenta la sociedad romana entre los siglos I a.C. y I d.C. se manifiesta, entre otras cosas, en las implicaciones ideológicas del hecho estético. La distancia que separa a Virgilio de Lucano en los distintos modos de representación y de escritura de la muerte, en las diferentes maneras en que la muerte y el sufrimiento se inscriben en los cuerpos y también en los efectos producidos sobre ellos es una manifestación específica y particular de la compleja metamorfosis que sufre la Weltanschauung romana en su transición desde la República al Imperio.

\footnotetext{
704 Baudelaire, Charles, Les Fleurs du mal, 'XXIX - Une Charogne': "Les jambes en l'air, comme une femme lubrique,/ Brûlante et suant les poisons,/ Ouvrait d'une façon nonchalante et cynique/ Son ventre plein d'exhalaisons./ [...] Et le ciel regardait la carcasse superbe/ Comme une fleur s'épanouir./ La puanteur était si forte, que sur l'herbe/ Vous crûtes vous évanouir./ Les mouches bourdonnaient sur ce ventre putride,/ D'où sortaient de noirs bataillons/ De larves, qui coulaient comme un épais liquide/ Le long de ces vivants haillons." (vv. 5-8 \& 13-20).
} 


\section{CONCLUSIONES FINALES}

Séneca nos muestra en sus tragedias cómo los personajes pueden construirse racionalmente a sí mismos a través de las técnicas de subjetivación propias del sapiens y recomendadas al proficiens y cómo, a través de las técnicas de sí y las tecnologías del yo, logran un uso instrumental de estos y consiguen aplicar una virtud específica, la constantia, al control y utilización de las pasiones, paradigmas de la inconsistencia y la inconstancia. La ratio desbocada de los personajes se apropia de la dicción estoica y de los medios e instrumentos propios de la doctrina, tales como las estrategias de autocontrol y auto-admonición para aplicarlos a fines claramente anti-estoicos. Séneca ahonda e inquiere en la perturbadora y paradójica posibilidad de una firme construcción estoica de un individuo criminal e incluso de un tirano, quien es capaz de hacer un uso consciente y racionalizado de la doctrina y de aplicar las herramientas y conceptos centrales de ésta para sus fines irracionales y criminales. Lucano, por su parte, subvierte de manera radical los paradigmas épicos y los elementos constitutivos y fundantes del vir Romanus. Virtus y pietas se convierten en significantes anamórficos pues sus significados se ven subvertidos y multiplicados en furiosos remedos de lo que antaño fueron: los grotescos despliegues de valentía y fuerza por parte de los personajes operan dentro de la representación como agentes de dispersión del significante y de corrosión y disolución de los elementos constituyentes del signo, difuminando la relación significante/significado y permitiendo la coexistencia polémica de varios significados para estos signos eminentes cuya resolución requiere de la intervención violenta del lector.

El mecanismo de representación por el cual el signo es sometido a este proceso de confutación de sus significados primigenios y disolución interna se da a través del horror inherente al espectáculo, que desestabiliza los paradigmas de representación clásicos y augusteos. El horror de la representación, que se apoya en formae grotescas, agrega significación y actúa sobre el signo al replegar el significante sobre sí mismo y generar así la disolución de los límites y las relaciones internas a través de recursos

expresivos barrocos y expresionistas: el proceso de anamorfización del significante coloca al lector en una posición en la cual debe comprometerse ideológicamente - esta operación es particularmente radical en Pharsalia- con las operaciones poéticas y resolver el conflicto textual, intratextual y sígnico a través de una intervención de 
lectura efectiva. De este modo, el lector de Pharsalia deviene necesariamente un lector Caesarianus que genera la ruina de los significados posibles y de las interpretaciones ideológicas y operativas que desestima, asimilable, en el plano de la recepción, a las figuras de Atreo o César, personajes activos y agentes de las turbulencias cósmicas que desestabilizan el universo eminentemente estoico en el que habitan. Si el lector intentase, en una operación de lectura también profundamente ideológica, retrasar ese movimiento hermenéutico de privilegiar cierto significado y elegir cierta perspectiva de interpretación de estos significantes polivalentes y anamórficos, puede entonces ser asimilado a la barroca figura del héroe estoico deviniendo un lector Catonianus, sujeto pasivo cuya heroicidad se basa en la patientia y en el perseverar en la vía elegida. Las radicales operaciones de Lucano ponen al lector en un territorio semiótico inestable y disoluto y éste debe resolver esta situación a través de intervenciones de lectura eminentemente ideológicas.

La tragedia de Séneca es el resultado de un puntilloso proceso de inversión y desestabilización de los conceptos y estrategias desplegados en sus trabajos filosóficos a través de las operaciones y los procedimientos poéticos analizados. Siguiendo la cronología relativa de John Fitch (1981) es posible detectar un claro crescendo en la importancia y la efectividad poética de estos procedimientos particulares, desde las tragedias tempranas hasta el último Thyestes. La conciencia estética y comunicativa de personajes como Edipo, Fedra o Clitemnestra es bastante limitada y poco operativa; Troades indaga y explora las posibilidades subversivas del teatro del horror a través de un efectivo despliegue de representaciones dentro de la representación. Sin embargo, son los personajes de Atreo y Medea los que ofrecen el salto cualitativo y cuantitativo en la aplicación de estos procedimientos específicos, tanto en lo que respecta a las estrategias de construcción de su propia subjetividad y su autoafirmación existencial en tanto criminales-artistas, así como también en la profunda concepción espectacular de sus venganzas, resultando entonces figuras asimilables y análogas a la del propio Séneca como tragediógrafo. Debemos destacar que, aunque Lucano lleve al extremo las posibilidades dramáticas y la concepción y ejecución espectacular de los actos inherentes a la doctrina estoica dentro de los límites del género épico y también en lo que respecta al uso específico de los procedimientos y estrategias de representación dramática, no logra superar, en este aspecto específico, a su maestro y fuente de inspiración poética. Esto, creemos, no invalida nuestra hipótesis inicial sino al contrario, probablemente la sustente y refuerce, pues no es tarea menor elevar el género épico, 
eminentemente narrativo, hasta las alturas espectaculares del teatro trágico. Habla a las claras del genio revolucionario y transgresor de Lucano y de su innegable capacidad para derribar y transgredir las formae intrínsecas a los esquemas tradicionales y establecidos de la épica.

El espectáculo del horror hunde sus raíces en la noción estoica del exemplar y en la profunda concepción espectacular de las acciones. La figura ejemplar estoica por excelencia para los romanos, Catón, y el despliegue eminentemente espectacular de sus actos resulta invertido y subvertido por la profunda conciencia estética y teatral demostrada en los actos criminales y fratricidas que personajes como Atreo, Medea, Vulteyo o Esceva realizan en las tragedias y en Pharsalia, cuya ejecución y realización cuestiona, problematiza y subvierte los valores morales, éticos y estéticos romanos, cuyos significados primigenios eran la base fundante de la concepción del vir Romanus.

En cuanto a la representación poética de la historia y sus profundas implicancias ideológicas y literarias, ya hemos destacado cómo la ausencia total de alusiones históricas y sociopolíticas comprobables en la tragedia de Séneca puede interpretarse como una operación poéticamente afirmativa: creemos que Séneca erradica toda alusión histórica de su poesía para enfocar la totalidad del despliegue trágico sobre las acciones furiosas de sus personajes y en los procesos de subversión y desestabilización de los paradigmas estéticos, poéticos y filosóficos que lleva a cabo en su obra trágica. La representación eminentemente poética de la historia que lleva a cabo Lucano, por su parte, está íntimamente ligada a los conocimientos enciclopédicos del lector. Nadie, en efecto, podría creer que la representación de César en Pharsalia VII cumpliendo tareas propias de un simple auxiliar durante la batalla, alcanzando proyectiles y armas a los legionarios, posea pretensiones de realismo o rigurosidad histórica, así como tampoco es plausible considerar que las veteranas legiones de César se desplegasen en el campo de batalla de manera menos que impecable (como, por otra parte, lo demuestra el resultado histórico del combate): la representación lucaniana busca inscribirse en el plano simbólico y poético, no en el histórico, y no existe, creemos, voluntad alguna por parte del autor de proponer una versión revisionista o alternativa de los acontecimientos, pues, como vimos, las discrepancias y divergencias con las versiones aceptadas de los hechos son flagrantes y presuponen un lector cognoscendus con las capacidades enciclopédicas suficientes para detectar, significar e interpretar estas divergencias literarias como lo que son, representaciones poéticas cuya intencionalidad es agregar significado y efectividad a la representación. 